Florida International University

FIU Digital Commons

FIU Electronic Theses and Dissertations

University Graduate School

6-18-2015

\title{
Mathematics Teaching Experiences of Elementary Preservice Teachers with High and Low Mathematics Anxiety during Student Teaching: A Multiple Case Study
}

Leslie Nisbet

2263064, lnisb001@fiu.edu

DOI: $10.25148 /$ etd.FIDC000106

Follow this and additional works at: https:// digitalcommons.fiu.edu/etd

Part of the Curriculum and Instruction Commons, Elementary Education and Teaching Commons, and the Science and Mathematics Education Commons

\section{Recommended Citation}

Nisbet, Leslie, "Mathematics Teaching Experiences of Elementary Preservice Teachers with High and Low Mathematics Anxiety during Student Teaching: A Multiple Case Study" (2015). FIU Electronic Theses and Dissertations. 2193.

https://digitalcommons.fiu.edu/etd/2193 


\section{FLORIDA INTERNATIONAL UNIVERSITY}

Miami, Florida

\section{MATHEMATICS TEACHING EXPERIENCES OF ELEMENTARY PRESERVICE}

TEACHERS WITH HIGH AND LOW MATHEMATICS ANXIETY DURING

STUDENT TEACHING: A MULTIPLE CASE STUDY

A dissertation submitted in partial fulfillment of the

requirements for the degree of

DOCTOR OF PHILOSOPHY

in

\section{CURRICULUM AND INSTRUCTION}

by

Leslie Deanna Nisbet

2015 


\section{To: Dean Delia Garcia}

College of Education

This dissertation, written by Leslie Nisbet, and entitled Mathematics Teaching Experiences of Elementary Preservice Teachers with High and Low Mathematics Anxiety during Student Teaching: A Multiple Case Study, having been approved with respect to style and intellectual content, is referred to you for your judgment.

We have read this dissertation and recommend that it be approved.

\section{Laura H. Dinehart}

Thomas G. Reio

Tonette S. Rocco

Maria L. Fernandez, Major Professor

Date of Defense: June 18, 2015

The dissertation of Leslie Nisbet is approved.

$\begin{array}{r}\begin{array}{r}\text { Dean Delia Garcia } \\ \text { College of Education }\end{array} \\ \hline \begin{array}{c}\text { Dean Lakshmi N. Reddi } \\ \text { University Graduate School }\end{array}\end{array}$

Florida International University, 2015 


\section{DEDICATION}

I dedicate this dissertation to all my family and close friends. Without their support throughout this process, the completion of this dissertation would not have been possible. Specifically, I dedicate this to my children; know that you can achieve anything you put your mind to. 


\section{ACKNOWLEDGMENTS}

I would like to thank the members of my committee for their dedication, support, and valuable feedback throughout this process. Dr. Thomas Reio, Dr. Laura Dinehart, and Dr. Tonette Rocco each strengthened my work with their specific areas of expertise. My major professor, Dr. Maria L. Fernandez, has been a steady source of support from the beginning of my course work throughout the end of my dissertation, and continues to be a valuable mentor. I would also like to thank Dr. Cohen for her help in the data collection of this dissertation.

I would also like to thank my family and friends who all gave their support to make this happen. I would like to thank my friends for their patience and guidance. Worthy of particular mention are Claudine, Roxanne, Marissa, Esther, Visho, and Marisa. I would also like to acknowledge my sisters, Gina, Cherie and Chandra who have been there to support me throughout this process. A special thank you goes to my mother, Deanna, who has always been there for me and believed in me even when I doubted myself. Most importantly, I would like to thank my husband, Robert, and son, Andrew, who have always supported me even when it meant sacrificing precious time. Thank you all. 


\begin{abstract}
OF THE DISSERTATION
MATHEMATICS TEACHING EXPERIENCES OF ELEMENTARY PRESERVICE TEACHERS WITH HIGH AND LOW MATHEMATICS ANXIETY DURING STUDENT TEACHING: A MULTIPLE CASE STUDY
\end{abstract}

by

Leslie Nisbet

Florida International University, 2015

Miami, Florida

Professor Maria L. Fernandez, Major Professor

This study investigated the teaching experiences of six elementary preservice teachers (EPTs), three with high mathematics anxiety and three with low mathematics anxiety, during their student teaching semester. The EPTs were selected from an initial pool of 121 EPTs who took the Abbreviated Mathematics Anxiety Scale. The cases were compared in a cross case analysis to highlight mathematics teaching experiences among EPTs. Data sources included EPT and researcher journal entries, interview transcripts, pre-lesson surveys, field notes, lesson plans, and artifacts of observed lessons. Data were coded using Shulman's content knowledge, Graeber's mathematics pedagogical content knowledge, and mathematics anxiety characteristics.

Findings revealed both similarities and differences across EPTs as related to four major categories: (a) planning and resources used, (b) role of the cooperating teacher, (c) content knowledge, and (d) pedagogical content knowledge. All EPTs used mostly direct instruction and relied on the course textbook and their respective cooperating teacher as their primary resources for planning. Additionally, across participants, the cooperating 
teacher influenced EPTs' perceptions of students and teaching. Also, EPTs with high mathematics anxiety were weaker with respect to content knowledge and pedagogical content knowledge. Findings suggest a need to re-design methods courses to address improving the pedagogical content knowledge of EPTs with mathematics anxiety. Findings also suggest a need to develop content specific mathematics courses for EPTs to improve their content knowledge. Future studies could include a longitudinal study to follow highly anxious EPTs who take content specific elementary mathematics courses to observe their content knowledge and mathematics anxiety. 


\section{TABLE OF CONTENTS}

CHAPTER

PAGE

I. INTRODUCTION

Background of the Study............................... 1

Problem Statement...................................... 5

Purpose of the Study....................................... 6

Research Questions...................................... 7

Theoretical Perspectives.................................. 7

Significance of the Study.................................. 12

Assumptions of the Study ................................ 14

Delimitations of the Study............................... 15

Definition of Key Terms................................ 16

Organization of the Study.............................. 17

II. LITERATURE REVIEW .................................. 19

Mathematics Anxiety and Its Connection to Test Anxiety.... 19

Defining Mathematics Anxiety......................... 22

The Development of Mathematics Anxiety................. 24

The Cyclical Nature of Mathematics Anxiety............... 28

Instruments Used to Test for Mathematics Anxiety........... 30

Elementary Teachers and Mathematics Anxiety............ 35

Preservice Teacher Education Courses and Mathematics

Anxiety............................................ 42

Teacher Efficacy and Mathematics Anxiety................. 49

Chapter Summary.................................. 52

III. RESEARCH METHODS .............................. 54

Purpose of the Study.................................... 54

Research Questions.................................... 55

Research Design: Multiple Case Study..................... 55

Researcher's Role....................................... 57

Research Site....................................... 63

Research Participants................................... 64

Data Collection......................................... 66

Data Analysis...................................... 73

Integrity Measures.................................... 77

Pilot Study....................................... 80

Chapter Summary................................... 81

IV. FINDINGS: CASES OF HIGH MATHEMATICS ANXIETY... 82

Introduction...................................... 82

The Case of Nancy: High Mathematics Anxiety-Moderate Content-Weak Pedagogy ............................ 83 
The Case of Ally: High Mathematics Anxiety-Moderate

Content-Weak Pedagogy ............................... 112

The Case of Belinda: High Mathematics Anxiety-Weak

Content- Aspects of Strong Pedagogy........................ $\quad 150$

Chapter Summary .......................................... 179

V. FINDINGS: CASES OF LOW MATHEMATICS ANXIETY .... 180

Introduction............................................... 180

The Case of Val: Low Mathematics Anxiety-Strong

Content-Strong Pedagogy................................. 181

The Case of Gigi: Low Mathematics Anxiety-Strong

Content-Strong Pedagogy................................ 220

The Case of Yoli: Low Mathematics Anxiety-Strong

Content-Weak Pedagogy....................................... $\quad 270$

Chapter Summary ..................................... 317

VI. DISCUSSIONS, RECOMMENDATIONS, AND

CONCLUSIONS.............................................. 318

Summary of the Study .................................. 318

Discussion of the Findings................................... 319

Implications for Practice................................ 334

Recommendations for Future Research...................... 341

Limitations of the Study ................................. 342

Conclusions............................................. 343

REFERENCES ......................................... 344

APPENDICES........................................... 349

VITA ..................................................... 383 


\section{LIST OF FIGURES}

FIGURE

PAGE

1. Data analysis process for individual case study analysis..................................... 76

2. Data analysis process for cross-case study analysis ............................................77

3. Unifix cubes used in Nancy's fourth observed lesson ........................................... 110

4. Unifix cubes used in Nancy's fifth observed lesson...........................................110

5 Picture of Individual Clocks Used by Students in Ally's first observed lesson ...........148

5 Picture of Individual Clocks Used by Students in Ally's first observed lesson ...........148

6. Picture of class clock broken up into quarters used in Ally's first observed lesson ...148

7. Fraction poster used in Belinda's first observed lesson .......................................176

8. Pipe cleaners used in Belinda's second observed lesson .......................................176

9. Fake Coins used in Belinda's third and fourth observed lessons..............................177

10. Pictures of coins hung on student volunteers during Belinda's third observed

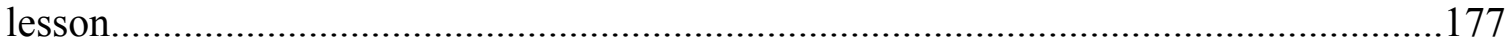

11. Geometric shapes used in Val's first observed lesson .........................................218

12. Fake coins and literature books used to teach money in Val's second observed .....218

13. Picture of coins being displayed on the overhead projector used in Val's third and fourth

14. Poster used to display dollar bills during Val's fifth observed lesson. .219 


\section{CHAPTER I}

\section{INTRODUCTION}

\section{Background of the Study}

Mathematics anxiety has been widely researched for several decades with multiple studies investigating its causes and revealing the phenomenon is complex and multi-dimensional (Bursal \& Paznokas, 2006; Harper \& Dane, 1998; Jackson \& Leffingwell, 1999). Mathematics anxiety has been defined as "the general lack of comfort that someone might experience when required to perform mathematically" (Wood, 1988, p. 11). Early studies focused on understanding the emotional impact of mathematics anxiety on those experiencing the phenomenon. Individuals who experience mathematics anxiety are often heard making negative statements related to the subject, as well as their own performance (Bekdemir, 2010). Examples of these statements include "I can't do math!", “If I could do math, I would study engineering", "I wasn’t born with the math gene" (Tobias, 1993). These types of statements not only provide evidence of the negative attitude individuals experiencing mathematics anxiety feel toward mathematics, but also of a larger issue. This larger issue is that individuals with mathematics anxiety may allow the phenomenon to hinder the career choices that they make in their lives (Hembree, 1990; Tobias, 1993).

Mathematics anxiety has been found to be associated with strong, intense emotions (Bibby, 2002). According to Trujillo and Hadfield (1999), mathematics anxiety can evoke physical manifestations of emotions in individuals including panic, tension, fear, helplessness, shame, distress, inability to cope, sweaty palms, nervous stomach, difficulty breathing, and loss of ability to concentrate. All of these emotions can prevent 
a student from learning and internalizing new material. When a student encounters such emotions, it often results in a low level of self-esteem and self-confidence related to doing mathematics (Trujillo \& Hadfield, 1999). For example, students who experience physical manifestations of emotions such as difficulty breathing or a nervous stomach may no longer be able to focus on solving mathematics problems and instead may focus only on their physical ailment.

Tobias (1993) described mathematics anxiety as a feeling of helplessness and tension when a person is presented with a situation where the person has to manipulate numbers and shapes. Individuals with mathematics anxiety can often remember the exact moment when the anxiety presented itself (Tobias, 1993; Trujillo \& Hadfield, 1999). For example, students who are asked to solve a problem in front of a class may freeze and forget how to manipulate simple mathematics tasks which they are otherwise very capable of performing (Tobias, 1993). These individuals take these negative experiences with them throughout their subsequent mathematics experiences resulting in poor performance in mathematics, which limit personal choices (Bibby, 2002; Richardson \& Suinn, 1972; Tobias, 1993).

Initially, mathematics anxiety was thought of as more prevalent in women than in men (Betz, 1978). However, more recent studies show that mathematics anxiety exists in both women and men, although not equally; more women are still reported to have mathematics anxiety (Brady \& Bowd, 2005; Widmer \& Chavez, 2001). Richardson and Suinn (1972) found mathematics anxiety not only impacts individuals in academic settings, but also in a wide variety of ordinary life situations as the phenomenon involves feelings of tension that interfere with basic manipulation of numbers and everyday 
problem solving. Further, mathematics anxiety exists in students at all stages of schooling ranging from elementary school to the university level (Tobias, 1993). Research has also suggested that mathematics anxiety appears significantly more often in elementary preservice teachers (EPTs) than other college students (Bursal \& Paznokas, 2006; Harper \& Daane, 1998). In particular, elementary education majors have the highest levels of mathematics anxiety as compared to their peers in other majors at the university level (Bursal \& Paznokas, 2006; Harper \& Daane, 1998; Vinson, 2001). This is concerning as EPTs are responsible for the development of future generations of mathematics students and mathematics anxiety may affect their teaching of the subject.

Other studies related to mathematics anxiety investigated the origin of the phenomenon in EPTs. Some studies have found that mathematics anxiety for individuals has its roots in the elementary classroom because of negative experiences at this level (Jackson \& Leffingwell, 1999; Trujillo \& Hadfield, 1999). Many EPTs with mathematics anxiety report negative experiences with past teachers (Harper \& Daane, 1998; Trujillo \& Hadfield, 1999; Widmer \& Chavez, 2001). In their study on mathematics anxiety, Widmer and Chavez (2001) collected data on 236 elementary school teachers and explained that participants linked attitudes toward mathematics to the attitudes and behaviors of their former teachers. Trice and Ogden (1987) also found that teachers with high mathematics anxiety avoided teaching mathematics when possible.

Brady and Bowd (2005) concluded in their study on EPTs enrolled in a teacher education program that the anxiety associated with teaching mathematics can be described as a cyclical phenomenon. Brady and Bowd (2005) administered the Math Anxiety Rating Scale (MARS) to determine the participants' level of mathematics 
anxiety. They created and administered this survey to examine participants' level of mathematics anxiety and attitude toward mathematics. Based on results from these two surveys, Brady and Bowd (2005) concluded that the higher level of self-reported mathematics anxiety correlated to less confidence with respect to teaching mathematics. Their participants described a perception that their mathematics education at the elementary and secondary levels had not prepared them to teach mathematics confidently. This lack of confidence has the potential to be repeated and transmitted to their future students (Brady \& Bowd, 2005). Mathematics anxiety may have a negative effect on how teachers teach the subject, and additionally, may cause some teachers to avoid teaching mathematics when an alternative is presented, as found by Trice and Ogden (1987).

Research that provides insights on the teaching of mathematics by EPTs with different levels of mathematics anxiety is lacking. Many previous studies have investigated causes of mathematics anxiety in preservice teachers through quantitative methods (Bursal \& Paznokas, 2006; Gresham, 2007; Jackson \& Leffingwell, 1999; Malinsky, Ross, Pannells, \& McJunkin, 2006). A number of studies have used mixed method analysis where there was mostly quantitative methodology with interviews to explain mathematics anxiety in EPTs (Brady \& Bowd. 2005; Daane, 2001; Daane, Giesen, \& Sloan, 2002; Harper \& Daane, 1998; Swars, Daane, \& Giesen, 2006; Widmer, \& Chavez, 2001). However, only a limited number of studies have attempted to use qualitative methods to understand mathematics anxiety in EPTs and these were done through interviews or self-reporting by the EPTs (Trujillo \& Hadfield, 1999; Unglaub, 1995). There is a lack of research that provides a deep understanding of student teachers 
with mathematics anxiety including observing the ways that EPTs with high and low levels of mathematics anxiety teach mathematics during their student teaching experience where theory is connected to practice in an EPTs educational training.

In order to fill this knowledge gap, this study was undertaken to develop a deep understanding of the experiences of EPTs with high and low levels of mathematics anxiety during student teaching through multiple observations of their teaching of mathematics. Given that previous studies relied on self-reporting of participants, these observations were pivotal in developing the understanding of similarities and differences of EPTs with high and low levels of mathematics anxiety. In order to gain an in-depth understanding of the experiences of the participants, this study used a multiple case study approach. In particular this study emphasized observing evidence of content knowledge, pedagogical content knowledge and mathematics anxiety of EPTs with both high and low mathematics anxiety. Further, EPTs with both high and low levels of mathematics anxiety were compared in order to better understand the similarities and differences between both groups of EPTs.

\section{Problem Statement}

Elementary school teachers have to teach all subjects, including mathematics, whether or not they experience mathematics anxiety. Mathematics anxiety could be a potential problem for EPTs as it could influence the way they draw on and develop mathematics content knowledge and pedagogical content knowledge (PCK) during their student teaching, two important knowledge types that are essential for effective teaching. EPTs with weak content knowledge and PCK can negatively affect the learning of their elementary students (Brady \& Bowd, 2005), or even more seriously, these EPTs could 
pass on mathematics anxiety to their students (Wood, 1988; Trujillo \& Hadfield, 1999).

As such, it was important to increase our understanding of how EPTs who experience mathematics anxiety plan and enact mathematics lessons through engagement and interaction with elementary school students during their teacher education programs. The development of a deeper understanding of the role mathematics anxiety plays among EPTs during student teaching can equip mathematics educators with necessary knowledge to help the EPTs as they prepare to teach.

Most research investigating mathematics anxiety has investigated either elementary school teachers in practice or EPTs during coursework, but very few studies have investigated EPTs at the student teaching phase of their training In particular, a gap in the literature exists with respect to observing EPTs as they teach mathematics lessons specifically during student teaching, a point where theory is linked to practice.

\section{Purpose of the Study}

The purpose of this study was to gain an understanding of the mathematics anxiety that EPTs experienced during student teaching and how this anxiety manifested itself in their performance in the classroom. This multiple case study investigation sought to describe the mathematics teaching of EPTs with high and low levels of mathematics anxiety during their student teaching experience. The case studies provide insight into the role of mathematics anxiety in the teaching of mathematics during student teaching, and also provide insight into how EPTs develop and enact lessons during student teaching. Additionally, the case studies reveal how EPTs who had high mathematics anxiety reflected on their teaching in contrast to EPTs who had low mathematics anxiety. Of particular importance was understanding EPTs use and 
development of content knowledge and PCK as they planned, enacted, and reflected on mathematics lessons. The case studies provide rich descriptions of the teaching of mathematics by EPTs with high and low levels of mathematics anxiety.

\section{Research Questions}

The broad research question that guided this study was: What are the mathematics teaching experiences of elementary preservice teachers identified as having high and low levels of mathematics anxiety during student teaching?

A Subsidiary Question was:

- What similarities or differences exist, if any, between elementary preservice teachers with high and low levels of mathematics anxiety in drawing on and developing content knowledge and pedagogical content knowledge during planning, enacting, and reflecting on mathematics lessons during their semester of student teaching?

\section{Theoretical Perspectives}

To deeply understand experiences related to the teaching of mathematics during student teaching by EPTs identified as having high and low levels of mathematics anxiety, the constructs of mathematics anxiety, content knowledge (CK), and pedagogical content knowledge (PCK) were used as lenses of analysis throughout this multiple case study investigation. Mathematics anxiety was used as a theoretical construct through which the EPT's behaviors and their attitudes related to their teaching of mathematics, including planning, teaching and reflecting on their lessons, were observed. Widmer and Chavez (2001) defined mathematics anxiety as a form of uneasiness or apprehension regarding mathematics. 
Many researchers have related mathematics anxiety to test anxiety; suggesting that mathematics anxiety may be similar to test anxiety (Brush, 1981, Hembree, 1990, Dew, Galassi \& Galassi 1983). Hembree (1990) suggested that mathematics anxiety is similar to test anxiety, in that both relate to general anxiety, both affect performance in similar ways, both respond to same types of treatment modes, and both types of anxiety are relieved when performance improves. Building on test anxiety theories, Tobias (1985) reviewed two interpretations of test anxiety, the deficit model and the interference model. The deficit model hypothesizes that anxious students do not underperform on tests because they have anxiety, but rather due to poor study habits and test taking skills. The second model, the interference model, assumes that test anxiety affects a students' ability to recall knowledge that was learned prior to taking a test. Tobias (1985) hypothesized that these two models of test anxiety were complementary rather than mutually exclusive. Tobias (1985) further explained that students who have high test anxiety focus on both the task that they are anxious about and their own personal concerns about negative self-perceptions; however, those who are less anxious may spend more time and give more attention to completing the specific task since they do not spend time focused on being anxious or worry about their negative self-perceptions.

Given that the examination of content knowledge and PCK was an important aspect of this study, Shulman's (1986) ideas on subject matter content knowledge and PCK and Graeber's (1999) ideas on PCK were used to guide this study. Shulman's (1986) work encompassed content knowledge, PCK, and curricular knowledge. This study focused on his ideas related to content knowledge and PCK. Shulman (1986) described content knowledge as the "amount and organization of knowledge per se in the 
mind of the teacher" (p.9). Shulman (1986) argues that content knowledge in a subject area goes beyond the knowledge of facts or concepts in that domain; it goes further to the understanding of the structures in the subject matter. A teacher must understand the syntax or rules of a particular subject area, and must also explain why these are worth knowing, and how they relate to other areas within the subject area. An example of content knowledge in mathematics would be that a teacher knows how to divide fractions (the rule), and additionally understands why division of fractions is possible and how it is related to subtraction and multiplication of fractions. Shulman (1986) explained further

the teacher need not only understand that something is so; the teacher must further understand why it is so, on what grounds its warrant can be asserted, and under what circumstances our belief in its justification can be weakened and even denied. (p. 9)

Shulman (1986) went on to further express that teachers need to know why certain topics are central to a discipline and other topics can be peripheral.

In addition to content knowledge, Shulman underscored the importance of teachers' PCK. Shulman (1986) stated that PCK "goes beyond knowledge of matter per se to the dimension of subject matter knowledge for teaching" (Shulman, 1986, p. 9). This includes knowing the topics specific to a content area and knowing the most useful strategies to represent these topics to students. Teachers must understand that many representations can be used to teach specific topics, and they must have a repertoire of strategies originating from both research and wisdom in practice to provide explanations to their students. Also important in PCK according to Shulman (1986) is the understanding of what makes learning concepts easy or difficult, and the conceptions, preconceptions and even misconception that are associated with content. 
Graeber's (1999) work drew on Shulman's (1986) PCK but is more specific to the subject of mathematics. Graeber (1999) expanded on Shulman's (1986) ideas and proposed five "big ideas" as attributes that mathematics teachers should possess to have PCK in mathematics. Graeber's (1999) ideas include: (a) 'understanding students' current understanding is important" (p. 192), (b) "students knowing in one way do not necessarily know in other(s)" (p. 195), (c) "intuitive knowledge is both an asset and a liability" (p. 198), (d) "certain instructional characteristics appear to promote retention" (p.200), and (e) "alternative representations and the recognition and analysis of alternative methods are important" (p. 202). These ideas are discussed in more detail in the following paragraphs.

Graeber's (1999) first big idea is “understanding students' current understanding is important" (p. 192). This means that teachers have the ability to assess where their students are in terms of developing a particular idea. The teacher is charged with knowing about the research involved in developing mathematics topics. An example of this would be to identify the different types of addition and subtraction problems (join, separate, part-part whole, compare), and to identify the stages in understanding place value. Graeber (1999) suggests that a teacher should be able to identify and elicit students' understanding through the knowledge of mathematics topics and should plan lessons that can move students through the stages of these mathematical ideas.

Graber's (1999) second big idea, "students knowing in one way do not necessarily know in the other(s)" (p. 195), refers to the idea that teachers need to have the ability to recognize that a student might be able to solve a problem algorithmically, but is not able to explain why the algorithm works or the conceptual knowledge underlining the 
algorithm. For example, a student might know how to perform multiplication of fractions, but this student might not have a clear understanding of fractions or of multiplication. Graeber (1999) suggests that preservice teachers must recognize that students understanding a topic in one way does not imply that they understand the same topic in another way. Preservice teachers are charged with equipping their future students with several forms of knowledge of mathematical topics.

Graeber's (1999) third big idea, "intuitive knowledge is both an asset and a liability" (p. 198), refers to the ability of a teacher to be able to have knowledge of misconceptions and preconceptions of students associated with a particular topic in order to address them accordingly. As preservice teachers design lessons they must be cognizant of the fact that intuitive knowledge can lead to misconceptions. Graeber (1999) discusses that intuitive knowledge might be helpful in problem solving, but that knowledge is not always correct. An example to illustrate this idea would be that of basic multiplication of decimals. Multiplication is often understood as repeated addition (2 X 3 where two can be added three times); however, when working with decimals, an answer cannot be derived by adding a number half a time $(2 \mathrm{X} 0.5$ - the answer cannot be obtained by adding two half times). In the classroom it is important for preservice teachers to be skeptical of intuitive knowledge. Teachers should help students challenge ideas and seek alternative ways of understanding.

"Certain instructional characteristics appear to promote retention" (Graeber, 1999, p. 200) is the fourth big idea. Graeber (1999) argues that teachers must have knowledge of strategies that will promote student retention in learning mathematical topics. Graeber (1999) claims that students who are encouraged to reflect on their learning experiences 
throughout the development of a concept tend to retain new ideas more effectively. Mathematics teachers should plan mathematics tasks that will help students remember topics. Often this can be accomplished through tasks that involve reflection on ideas through writing and speaking about these ideas. Students should be encouraged to explain their ideas, and justify their answers. Graeber (1999) suggests that a classroom environment where teachers talk less and listen to their students' ideas more often promote a deeper understanding of concepts.

Graeber's (1999) last big idea is "alternative representations and the recognition and analysis of alternative methods are important" (p. 202). This big idea suggests that students may use different approaches (models, strategies, methods) to understand mathematical topics. This suggests that teachers need to provide alternative paths to understanding for their students so that no student is left without some understanding of mathematical ideas. Graeber (1999) advocates for the use of various models and strategies when planning to teach a mathematical topic. Graeber's (1999) "big ideas" were used in this study to examine documents (lesson plans), observe the teaching of lessons (field notes and video recordings), and analyze interviews with EPTs who had both high and low levels of mathematics anxiety.

\section{Significance of the Study}

Through a multiple case study approach, this investigation provided rich descriptions of the mathematics teaching experiences during student teaching of EPTs identified as having high and low levels of mathematics anxiety. It was important to understand the similarities and differences amongst EPTs with high and low mathematics anxiety related to their content knowledge and pedagogical content knowledge as they 
participated in their student teaching experience in order to understand the extent and ways that mathematics anxiety was manifested in the teaching of mathematics in novice teachers. The results of this study helped to fill a gap in the research literature and can help mathematics educators, EPTs, cooperating teachers, and university supervisors of student teachers understand ways mathematics anxiety manifests itself in novice elementary school teachers' teaching of mathematics. Findings from this study provide insights on ways to help lessen the mathematics anxiety of preservice teachers in teacher education programs before and during student teaching and recommendations for teacher education programs to better prepare EPTs, particularly those with high mathematics anxiety, for teaching mathematics.

Additionally, mathematics educators, and EPTs themselves, may be able to use the case studies to help EPTs understand ways to manage their mathematics anxiety in practice. This study presents case studies that reveal the content knowledge, PCK, and mathematics anxiety displayed by EPTs with high and low levels of mathematics anxiety during student teaching. Mathematics educators, who identify EPTs with similar qualities as the participants of this study, as well as EPTs themselves, may benefit from understanding and reflecting on the experiences that these participants encountered. This study may help mathematics educators better understand how to work with and help students who share similar qualities as the participants of this study. Additionally, this study may also provide insight to cooperating teachers and university supervisors who mentor EPTs with high and low levels of mathematics anxiety during student teaching. 


\section{Assumptions of the Study}

The first assumption that was made was that EPTs possessing different levels of mathematics anxiety were enrolled in the elementary teacher education program at a southeastern university, the site of this study. Research across varied universities has revealed that students enrolled in elementary teacher education programs have different levels of mathematics anxiety and these students possess some of the highest levels of mathematics anxiety in comparison to their peers enrolled in other university programs (Bursal \&Paznokas, 2006; Harper \&Daane, 1998; Vinson, 2001). A second assumption that was made was that EPTs with high and low levels of mathematics anxiety can be identified through the use of the Abbreviated Mathematics Anxiety Scale (AMAS) (Hopko, Mahadevan, Bare, \& Hunt, 2003). The AMAS has been found to be reliable and valid in relation to measuring individuals' levels of mathematics anxiety (Hopko et al., 2003). Participants were expected to respond honestly to the AMAS items given that participation was voluntary, responses were identifiable only by students' university numerical identification, and anonymity and confidentiality were preserved. Through the use of the AMAS during a pilot study at the site of the present investigation, a range of levels of mathematics anxiety from low to high levels were identified among a previous group of elementary school student teachers at the start of their student teaching semester. The same range of AMAS scores was expected and was found with the participants of this study.

A third assumption that was made was that the EPTs selected for the case studies behaved and responded honestly within their student teaching contexts and put forth their best effort in teaching mathematics. Student teachers typically attempt to teach to the best 
of their abilities because they care about their students and want them to learn. The participants in this multiple case study were volunteers who were able to withdraw from the study at any time and with no ramifications; thus, it was assumed that they were authentic in their participation in the study and their student teaching activities. A fourth assumption was that student teaching provided a more authentic context than other program field experiences for examining the manifestation of mathematics anxiety in EPTs' teaching of mathematics. Although the EPTs may have engaged in teaching mathematics during experiences prior to their student teaching, their student teaching experience was daily, full-time, extended over a semester and, in turn, was expected to be more closely aligned with their future experiences as novice teachers in their own classrooms than other teaching experiences. A fifth assumption made was that mathematics content knowledge and PCK are important for EPTs to possess to enact quality mathematics lessons with elementary students. Based on completion of the education course work required for EPTs program, it was assumed that they had sufficient content knowledge and pedagogical content knowledge to teach elementary school students.

\section{Delimitations of the Study}

This study had a few delimitations based on the research population. Primarily, this study included a very specific group of EPTs during their student teaching experience; EPTs from a southern, urban, state university with a large Hispanic population. EPTs at other stages of their education were not included in this study; only those at the student teaching level were included. This study also excluded other EPTs at other universities around the country, especially those in more rural areas, and those that 
did not have a predominant Hispanic population. The use of this population for this study yielded the collection of in-depth and descriptive case studies of EPTs in a southern, urban, state university.

\section{Definition of Key Terms}

This section defines key terms that were used throughout the dissertation in alphabetical order.

\section{Content Knowledge}

Content knowledge "refers to the amount and organization of [their mathematics] knowledge per se in the mind of the teacher" (Shulman, 1986, p. 9).

\section{Elementary Preservice Teacher (EPT)}

In this study, elementary preservice teacher (EPT) refers to the university student in an undergraduate elementary education teacher preparation program studying to teach mathematics as well as other subjects at the elementary level.

\section{Mathematics Anxiety}

For the purpose of this study, mathematics anxiety refers to "the general lack of comfort that someone might experience when required to perform mathematically" (Wood, 1988, p. 11). Mathematics anxiety were measured in participants by using the Abbreviated Math Anxiety Scale (AMAS) (Hopko, et al., 2003).

\section{Pedagogical Content Knowledge (PCK)}

In this study, Graeber's (1999) pedagogical content knowledge in mathematics was used. It includes all the mathematics pedagogical knowledge that a preservice teacher should possess. Graeber (1999) includes in this mathematical content knowledge five big ideas: (a) Understanding students' current understanding, (b) Students knowing 
in one way do not necessarily know in the other(s), (c) Intuitive knowledge is both an asset and a liability, (d) Certain instructional characteristics appear to promote retention, and (e) Alternative representations and the recognition and analysis of alternative methods are important.

\section{Preservice Teachers}

The use of preservice teachers in this study refers to college level students who are enrolled in an education program, and are completing credits toward a Bachelor's degree in Education.

\section{Student}

The use of the word student in this study will refer to individuals in grades K-20 who are not preservice teachers.

\section{Organization of the Study}

This chapter presented the background of the problem with reference to mathematics anxiety. The problem statement, purpose of the study, and the research questions which informed this study were also included. Pedagogical content knowledge (PCK) in mathematics as defined by Graeber (1999), content knowledge as defined by Shulman (1986), and mathematics anxiety were presented as the theoretical constructs which were used in the analysis of this study. Additionally, key terms were defined as a reference to be used throughout the context of this study. The significance of the study, as well as the assumptions and delimitations of the study were also included. Chapter 2 presents a review of literature on the definition of mathematics anxiety, its causes, possible instruments used to measure mathematics anxiety, research on student teachers' teaching, and EPTs' PCK in mathematics which provided a context for the study. 
Chapter 3 highlights the multiple case study research design that was used. Chapter 4 presents the detailed cases of the three participants with high mathematics anxiety, and Chapter 5 presents the detailed cases of the three participants with low mathematics anxiety. Finally, Chapter 6 includes a discussion of similarities and differences of those case studies, as well as presents recommendations and areas for future research. 


\section{CHAPTER II}

\section{LITERATURE REVIEW}

This chapter begins with a discussion of the connection that mathematics anxiety has to test anxiety. A section then follows that highlights the various definitions of mathematics anxiety in the literature that culminates with a discussion of the definition of mathematics anxiety that guided this study. Then, research studies related to the development of mathematics anxiety are presented followed by a discussion of research studies investigating the cyclical nature of mathematics anxiety. Next, several instruments used to measure mathematics anxiety are presented along with a discussion as to the rationale for the one selected for this study. A review of research studies involving EPTs and mathematics anxiety is presented followed by a discussion of studies involving preservice teacher education courses and mathematics anxiety. Lastly, research studies involving teacher efficacy and mathematics anxiety are discussed. The chapter concludes with a summary of the literature reviewed.

\section{Mathematics Anxiety and Its Connection to Test Anxiety}

According to Stober and Pekrun (2004), test anxiety is mentioned in the literature as early as 1914. However, scientific investigations on test anxiety did not begin until 1952 with Mandler and Sarason's (1952) study. Findings from this study established that anxiety present in testing was an important variable in the performance on the test (Mandler \& Sarason, 1952). Later studies built on this earlier work established two models of test anxiety. Tobias (1985) reviewed the differences between two interpretations as to why high-anxious students perform poorly on tests. He reviewed the deficit model and the interference model used to explain test anxiety. The deficit model 
assumes that high anxious students do poorly on tests because of their lack of study-skills and their poor habits in test-taking skills. This model also assumes that high-anxious individuals do poorly because they are aware that they prepared poorly for the test, and during the test, they are aware that they are doing poorly. The second model that Tobias (1985) reviewed was the interference model which assumes that high anxious individuals do poorly on tests that are important to their future (high stakes tests). It is hypothesized that these high anxious individuals divide their attention between the task of the test and negative self-preoccupations; their attention is not focused on only the test, and anxiety interferes with the ability to retrieve prior knowledge. After reviewing both models Tobias (1985) concluded that the two models are complementary; they do not occur mutually exclusively. Tobias (1985) hypothesized that test anxiety leads to a decrease in performance by causing a reduction in the cognitive capacity available to the high anxious individual and that study skills and test taking skills promote learning and test performance by reducing the cognitive capacity required of the high anxious individual. Several research studies have investigated the connection between mathematics anxiety and test anxiety. One early study by Dew, Galassi, and Galassi (1983) investigated the relationship of mathematics anxiety to test anxiety. The subjects of this study were 769 college students enrolled at the same university who were predominantly female, first and second year undergraduates. The participants were asked to complete three measurement tools to assess their mathematics anxiety, including the Mathematics Anxiety Rating Scale (MARS), The Mathematics Anxiety Scale (MAS), and the Anxiety Toward Mathematics Scale (ATMS). The participants were also asked to complete the Test Anxiety Inventory (TAI). Results from the correlations between the three 
mathematics anxiety instruments showed they were moderately related to each other. However, interestingly, although the results of this study revealed a correlation between each of the mathematics anxiety measures and the test anxiety measures, the relationship was not as strong as the correlation between each of the mathematics anxiety measures. This suggests that although mathematics anxiety is related to test anxiety, mathematics anxiety may have aspects that are unique to mathematics anxiety. It is still important to note that in their study, Dew et al. (1983) provided evidence that mathematics anxiety and test anxiety are related and suggested that mathematics anxiety is a subject specific of test anxiety.

In a later study, Hembree (1990) conducted a meta-analysis of 151 studies related to mathematics anxiety to describe the construct of mathematics anxiety as fully as possible based on the available research. Results of the meta-analysis revealed some of the common features between mathematics anxiety and test anxiety. Mathematics anxiety and test anxiety both relate to general anxiety. For both mathematics anxiety and test anxiety, the differences found in anxiety level with regard to student ability, gender and ethnicity were similar. Both forms of anxiety affect performance in a similar fashion. The most effective treatment modes for both mathematics anxiety and test anxiety were behavioral methods such as systematic desensitization, and cognitive-behavioral methods, particularly including cognitive modifications emphasizing confidence building. Further, the least effective mode of treatment found for both constructs was the cognitive method such as group counseling to relieve expressed concerns. Lastly, improved performance relates to the relief of both constructs (Hembree, 1990). 


\section{Defining Mathematics Anxiety}

The subject of mathematics is highly emotional; people come to know mathematics through emotions (Bibby, 2002). Mathematics anxiety is a complex phenomenon that has been defined in several ways. Mathematics anxiety has been described by Trujillo and Hadfield (1999) as a feeling of discomfort that is evident when mathematical tasks threaten an individual's self-esteem. According to Trujillo and Hadfield (1999), mathematics anxiety can evoke emotions in individuals including panic, tension, fear, helplessness, shame, distress, inability to cope, sweaty palms, nervous stomach, difficulty breathing, and loss of ability to concentrate. All of these emotions can prevent a student from learning and internalizing new material. When a student encounters such emotions, it often results in a low level of self-esteem and selfconfidence related to doing mathematics (Trujillo \& Hadfield, 1999). Mathematics anxiety is referred to as "the general lack of comfort that someone might experience when required to perform mathematically" (Wood, 1988, p. 11). Tobias (1993) defines mathematics anxiety as a feeling of tension, helplessness, and mental disorganization one has when he/she is required to manipulate numbers and shapes.

Widmer and Chavez (2001) defined mathematics anxiety as a form of uneasiness or apprehension regarding mathematics. Their study which was conducted on 230 elementary school teachers ( 25 men and 203 women, apparently 2 participants did not disclose their gender) sought to investigate the relationship between mathematics anxiety and four characteristics including sex, career choice, type of mathematics training, and recency of that training (Widmer \& Chavez, 2001). A thirty-six item Likert scale was

developed for the purpose of their study. The researchers also conducted interviews that 
led to the examination of four themes: feelings about mathematics both as a student and as a teacher, relationships between attitude toward mathematics and career choice, sexrole stereotyping in relation to mathematics, and suggestions for preventing and alleviating mathematics anxiety in students. The researchers concluded that there was a significant relationship between mathematics anxiety and evidence of inhibited career goals in mathematics. Additionally, the researchers concluded that fewer teachers who identify their mathematics education as having stressed understanding will show greater mathematics anxiety than those who identify their mathematics education as having stressed computation. In this particular study, no significant relationship was found between sex and mathematics anxiety (Widmer \& Chavez, 2001).

The present multiple case study drew on the definitions of mathematics anxiety proposed by Wood (1988), Widmer and Chavez (2001), and Trujillo and Hadfield (1999). According to Widmer and Chavez (2001), mathematics anxiety is a form of uneasiness or apprehension toward mathematics. Wood's (1988) definition includes a discomfort toward mathematics when expected to perform mathematically. Because EPTs in the present study were performing mathematically during the enactment of lessons, this definition was valuable. Trujillo and Hadfield (1999) use adjectives which describe observable behaviors including panic, tension, fear, helplessness, shame, distress, inability to cope, sweaty palms, nervous stomach, difficulty breathing, and loss of ability to concentrate. In relation to the EPTs in the present dissertation, these definitions were used to describe uneasiness and apprehension regarding the content knowledge and the PCK associated with teaching mathematics. Widmer and Chavez's (2001) conclusion that teachers whose mathematics education stressed understanding 
show less mathematics anxiety than teachers whose mathematics education stressed computation was important to understand how the participants of this case study learned mathematics as well as how they enacted mathematics lessons. This multiple case study explored EPTs' teaching of mathematics and observed those EPTs who stressed understanding versus computation as part of their pedagogical content knowledge.

\section{The Development of Mathematics Anxiety}

The origin of mathematics anxiety is as unique and diverse as the individuals who experience this type of anxiety (Uusimaki \& Nason, 2004). Trujillo and Hadfield (1999) assert that the origins and beliefs about mathematics anxiety can be classified into three categories: (a) environmental, (b) intellectual, and (c) personality factors. Environmental factors include negative classroom experiences, parental pressure, insensitive teachers, and mathematics that are taught in a more traditional, rigid way, as a set of rules. Intellectual factors include students' attitudes and lack of perseverance, lack of confidence, self-doubt, and perceiving that mathematics is useless. Personality factors include extreme shyness, lack of self-esteem about the ability in the subject area, and for females, viewing mathematics as a more male dominated field (Trujillo \& Hadfield, 1999).

Brady and Bowd (2005) concluded that the phenomenon of mathematics anxiety manifests itself in specific situations. Their study was conducted on 238 education students (176 women and 62 men) near the end of their preparation for teaching, and mathematics anxiety was found to be manifested in relation to prior experiences in the elementary and high school settings (Brady \& Bowd, 2005). The instruments used to 
collect data included a survey questionnaire consisting of two parts. The first part was constructed to elicit participants'

(a) highest level of formal mathematics education; (b) past experiences with mathematics education at the elementary and secondary school levels; (c) perceptions concerning the utility of mathematics; (d) number of years since they had enrolled in a formal mathematics course; (e) level of confidence in teaching in general during their practicum; (f) level of confidence in teaching mathematics. (p. 40)

The second part of the survey consisted of the Mathematics Anxiety Rating Scale (MARS). Brady and Bowd (2005) used both quantitative and qualitative techniques to analyze their data. Quantitatively, the researchers calculated a number of Pearson correlation coefficients to determine the relationship between the years of formal mathematics education and the total MARS score; between attitudes toward mathematics and the total MARS score; and between past experiences in mathematics instruction and the total MARS score. Qualitatively, Brady and Bowd (2005) transcribed and coded the open-response items. The themes that emerged included the following:

previous experiences with mathematics instruction at a variety of educational levels, their impressions of the teaching techniques they had been exposed to in previous mathematics education, the anxiety they experienced in teaching mathematics during their practicum and their attitudes towards mathematics as a subject. (Brady \& Bowd, p.40)

Brady and Bowd (2005) concluded that a relationship exists between respondents' mathematics anxiety score and the apprehension they experienced when faced with teaching mathematics during their practicum.

Malinsky, Ross, Pannells, and McJunkin (2006) conducted a study on mathematics anxiety and college students; 481 students participated (392 women, 88 men, and one not reported by gender). Two-hundred seventy-nine of the participants 
were preservice elementary school majors. These preservice elementary school majors were subdivided into 134 early childhood majors, 45 middle level language arts/social studies majors, 36 middle level math/science majors, 56 early childhood interns; 12 middle level language arts/social studies interns; and 13 middle level math/science interns. There were also college students with non-science majors taking physical science labs (a required course). After taking the 24-item Revised Mathematics Anxiety Rating Scale (R-MARS or MARS-R), the students were asked to respond true or false to 12 mathematics myths. The scores on the MARS-R indicated that the middle level math/science majors and the middle level math/science interns had the lowest mathematics anxiety compared to the other groups of students. Those who were noneducation majors had less anxiety than all other education majors except for the middle level math/science majors and interns. Based on their qualitative analysis, Malinsky et al. (2006) claimed that mathematics anxiety is a phenomenon which affects many people and is very common among college and university students. They suggested that mathematics anxiety has its roots in teaching and teachers, with teachers often contributing to the poor performance of their students in mathematics. Poor performance is often a result of the teachers' attitudes toward the subject (Malinsky et al., 2006).

In another study, Jackson and Leffingwell (1999) conducted research to investigate instructor behaviors and determine when mathematics anxiety first occurred in the students that were studied. Jackson and Leffingwell (1999) carried out their research on 157 college seniors in an elementary mathematics methods course over three different semesters. The subjects responded to the written prompt: "Describe your worst or most challenging mathematics classroom experience from kindergarten through 
college" (Jackson \& Leffingwell, 1999 p. 583). The responses were characterized into three clusters: elementary level (especially grades 3 to 4 - a total of 16\%), high school level (especially grades 9-11 - a total of 26\%) and college level (especially freshman year - a total of $27 \%$ ). Although some students reported mathematics anxiety at other grade levels, and $7 \%$ of students had only positive experiences in mathematics, these three clusters describe where the students experienced the most mathematics anxiety. The instructional behaviors that caused mathematics anxiety in the students were classified as either being covert or overt. Instructors who displayed either covert or overt behaviors interfered with the students' ability to concentrate in mathematics classes (Jackson \& Leffingwell, 1999).

It was discovered that many negative feelings toward mathematics are a result of teacher actions at the elementary, middle, and high school levels. Students are aware of their teachers' happiness, interest and enthusiasm for teaching mathematics (Jackson \& Leffingwell, 1999). Also, these students could detect when their teachers were not happy and did not enjoy being in the classroom. Negative experiences have a profound impact on students and can last as long as twenty or more years (Jackson \& Leffingwell, 1999). If teachers are made aware of how their actions impact students, then they will be able to include new methods in their lesson plans to enhance their students' learning, and develop a positive environment where students enjoy mathematics (Jackson \& Leffingwell, 1999).

In a study conducted by Uusimaki and Nason (2004) findings indicated that the mathematics anxiety of EPTs often originated in elementary school and were caused by experiences with a teacher at that level. The researchers studied 18 EPTs in their third 
year of university in Australia. The 18 participants (17 woman and 1 man) came from a total cohort of 300 third-year EPTs. Of the 300 preservice teachers, 45 identified themselves as having mathematics anxiety and 18 volunteered to participate in the study. A semi-structured interview consisting of four questions was developed and administered to the 18 participants. The four interview questions were as follows: "1. When did you learn to dislike mathematics? 2. Why did you learn to dislike mathematics? 3. What causes your math anxiety? 4. What mathematical concepts cause your math anxiety?" (Uusimaki \& Nason, 2004, p. 371). The interviews were analyzed and emerging themes were identified.

The analysis of the Uusimaki \& Nason (2004) study revealed that $66 \%$ of the participants perceived that their negative beliefs and anxiety toward mathematics emerged in elementary school. Of the other participants, $22 \%$ believed their mathematics anxiety and negative beliefs began in high school, and $11 \%$ identified college as the time when their negative belief and anxiety toward mathematics developed. The researchers indicated that their results were in contrast to the belief that mathematics anxiety begins in secondary school. Based on their study, Uusimaki and Nason (2004) claimed that teachers' attitudes toward mathematics influence either a learned helplessness toward the subject, or promote positive, worthwhile experiences; thus, either positive or negative attitudes are passed on to students by their teachers.

\section{The Cyclical Nature of Mathematics Anxiety}

Brady and Bowd (2005) concluded in their research that the anxiety associated with teaching mathematics can be described as a cyclical phenomenon. A cyclical 
phenomenon is usually used to describe an occurrence in nature that happens over and over again during a period of years. With regards to mathematics anxiety, it can refer to a teacher (adult) passing the anxiety to a student (child) who then grows up and passes it on to another student (child). Mathematics anxiety is caused by negative experiences with formal mathematics instruction, and can be passed on through various negative interactions with future children that the adult comes in contact with in a mathematical setting (Brady \& Bowd, 2005). The perceptions of the 238 EPTs surveyed in Brady and Bowd's (2005) study included the belief that their mathematics education from K-20 had not fully prepared them to teach the subject. These participants described a perception that their mathematics education (K-20) had not prepared them to teach the mathematics confidently. This lack of confidence has the potential to be revealed when teaching their future students.

Another interesting finding by Brady and Bowd (2005) was the strong negative correlation $(r=-.28, p<.01)$ between the level of mathematics content classes taken and the level of mathematics anxiety as reveled in the MARS scores of the participants. Only $11.8 \%$ of the participants in their study had taken mathematics content classes past the first year of college; thus, most were apprehensive when faced with the prospect of teaching the subject. EPTs that had stronger backgrounds in mathematics content had less mathematics anxiety. Another significant finding of the Brady and Bowd (2005) study was the strong correlation $(r=.52, p<.01)$ between the MARS score and mathematics being the least liked subject in elementary and high school. Those participants who scored highly on the MARS reported that mathematics was their least liked subject in elementary and high school. The present study contributes to the 
literature how EPTs with high and low levels of mathematics anxiety reacted to the teaching of mathematics and how the dislike of mathematics and the lack of confidence in mathematics associated with high mathematics anxiety by Brady and Bowd (2005) were evidenced in the EPTs' teaching of mathematics.

\section{Instruments Used to Test for Mathematics Anxiety}

There have been various tests developed to indicate the level of mathematics anxiety in individuals. This section highlights three of these instruments and concludes with an explanation as to why the instrument for this study was selected. Table 1 summarizes the three most prominent instruments in the literature used to measure mathematics anxiety.

Table 1

Instruments used to test for Mathematics Anxiety and Related Attitudes in Mathematics

\begin{tabular}{|c|c|c|l|}
\hline $\begin{array}{c}\text { Instrument } \\
\text { used to } \\
\begin{array}{c}\text { Measure } \\
\text { Mathematics } \\
\text { Anxiety }\end{array}\end{array}$ & Author(s) & $\begin{array}{c}\text { Year of } \\
\text { Publication }\end{array}$ & \multicolumn{1}{c|}{ Description } \\
\hline $\begin{array}{c}\text { Math Anxiety } \\
\text { Rating Scale } \\
\text { (MARS) }\end{array}$ & $\begin{array}{c}\text { Suinn, R., } \\
\text { Edie, C., } \\
\text { Nicoletti, J., } \\
\text { \& Spinelli, P }\end{array}$ & 1972 & $\begin{array}{l}\text { It consists of 98 Likert format items designed to } \\
\text { measure mathematics anxiety; it has been tested for its } \\
\text { reliability. }\end{array}$ \\
\hline $\begin{array}{c}\text { Mathematics } \\
\text { Anxiety Rating } \\
\text { Scale (MARS-R) }\end{array}$ & $\begin{array}{c}\text { Alexander \& } \\
\text { Martray }\end{array}$ & 1989 & $\begin{array}{l}\text { This is 25 item scale derived from the original MARS. } \\
\text { Alexander \& Martray (1989) claimed that the original } \\
\text { test was too long of an instrument, and it was time } \\
\text { consuming to administer and score. }\end{array}$ \\
\hline $\begin{array}{c}\text { Abbreviated } \\
\text { Math Anxiety } \\
\text { Scale (AMAS) }\end{array}$ & $\begin{array}{c}\text { Hopko, } \\
\text { Mahadevan, } \\
\text { Bare \&unt }\end{array}$ & 2003 & $\begin{array}{l}\text { It is a new, more concise version of the MARS-R. The } \\
\text { newly 9-item rating scale was tested for factor } \\
\text { structure, internal consistency, and test-retest } \\
\text { reliability. The researchers concluded that the AMAS } \\
\text { is a superior measure of mathematics anxiety than the } \\
\text { MARS-R. }\end{array}$ \\
\hline
\end{tabular}

One of the most popular instruments developed was the Math Anxiety Rating Scale (MARS) (Suinn et al., 1972). Later a more popular version of the MARS instrument, the Revised Mathematics Anxiety Rating Scale (MARS-R), was developed 
by Alexander and Martray (1989). The MARS consists of 98 Likert format items designed to measure mathematics anxiety. A total score is calculated based on a 1 (low anxiety) to 5 (high anxiety) Likert scale for each item with the MARS score ranging from a total possible score of 98 to a 490 (Suinn et al., 1972). On the MARS, Richardson and Suinn (1972) reported a test, re-test reliability coefficient of .97.

The MARS-R was later developed by Alexander and Martray (1989) because they claimed that the MARS was too long as an instrument, and it was too time consuming to administer and to score. The MARS-R is a 25 item scale that was derived from the original MARS. The MARS-R has a coefficient alpha of .98 and correlates with the MARS at a level of .97 (Plake \& Parker, 1982). Several studies have commonly used the MARS to test mathematics anxiety as a pre-test and post-test (Brady \& Bowd, 2005; Daane, Giesen \& Sloan, 2002; Gresham, 2007; Harper \& Daane, 1998; Swars, Daane, \& Giesen 2006; Vinson, 2001). Several researchers have used the MARS-R as a more concise instrument to measure mathematics anxiety in their research (Bursal \& Paznokas, 2006; Malinsky et al., 2006).

These types of instruments help individuals and researchers to identify levels of mathematics anxiety so that measures can be taken to either study the anxiety further, or examine ways of helping students to overcome this type of anxiety. A study which relied on the results of the MARS was the Brady and Bowd (2005) study conducted with 238 education students (176 woman and 62 men) near the end of their training or preparation for teaching. All the students were enrolled in a compulsory mathematics course at a small Canadian University. The mean age of the participants was 26.03 years. Criterion sampling was used to select participants; participation was voluntary. The women scored 
higher than the men with a mean MARS score of $206.47(S D=69.02)$ compared to the men's mean score of $183(S D=56.76)$. A t-test was conducted to show that this difference was significant $(t=2.406, p<.05)$. In this study, the findings revealed that the women had higher mathematics anxiety than the men.

Malinsky et al. (2006) used the MARS-R in a study similar to that of Brady and Bowd (2005) and both found that women showed higher levels of mathematics anxiety even though different instruments to test mathematics anxiety were used in both studies. Malinsky et al. (2006) also used the scores that the preservice elementary teachers obtained on this more modified MARS-R test to test six hypotheses. The hypotheses formulated by the researchers included the following:

(a) there is a significant difference in math anxiety scores based on gender as reflected on the MARS-R, (b) there is a correlation between the age of students and the anxiety scores achieved on the MARS-R; older students are more likely to express higher levels of anxiety than younger students, (c) there is a significant difference between the anxiety scores of students majoring in mid-level math/science and students majoring in mid-level language arts/social studies as reflected on the MARS-R, (d) there is a significant difference between the anxiety scores of preservice interns majoring in mid-level math/science and interns majoring in mid-level language arts/social studies as reflected on the MARS-R, (e) there is less anxiety presented on the MARS-R by interns as opposed to other levels of education, (f) there will be no significance for the statements presented as math myths. (Malinsky et al., 2006 pp. 275-276)

It can be assumed that the other levels of education discussed in hypothesis (e) refer to education students at levels other than the teaching internship level.

The independent variable of the Malinsky et al. (2006) study included the scores of the participants on the MARS-R test. There were several dependent variables based on each of the different hypotheses tested. The researchers used an analysis of variance (ANOVA) of mean scores for the MARS-R. The results of the ANOVA were used to 
test each of the hypotheses listed. The findings of the study concluded that there was a significant difference between the students of different age groups. However, it was not a significant linear trend and the oldest students did not show the highest levels of mathematics anxiety based on their MARS-R scores (Malinsky et al., 2006). The researchers also found that a significant difference between the anxiety scores of middle school teachers majoring in math/science and those majoring in language arts/social studies. A significant difference was also found between anxiety scores of interns (seniors) majoring in language arts/social studies and those interns majoring in math/ science (Malinsky et al., 2006). The researchers of this study claimed that the results should be viewed as more suggestive than definitive. The data suggested that some education students experience mathematics anxiety. However, there are some limitations in the study. It was pointed out by the authors that there may have been a limitation due to the fact that the population of the study included only a small number of minority participants and a limited number of interns who chose to participate.

The Abbreviated Math Anxiety Scale (AMAS) was developed by Hopko et al. (2003) as a new, more concise version of the MARS-R. They tested the psychometric properties of the scale to ensure its validity and reliability as well as the generalizability to the larger population. The researchers designed this particular study to develop an abbreviated mathematics anxiety scale using a large sample (1,239 undergraduate students - 729 women and 510 men) to represent the population. The newly developed scale was a 9-item AMAS (see Appendix A) that was tested for its factor structure, internal consistency, test-retest reliability, and convergent/divergent validity. Internal consistency $(\alpha=.90)$ and test-retest reliability $(r=.85)$ of the AMAS were strong. 
Convergent validity $(r=.85)$ was present when comparing the AMAS with the MARS-R, and confirmatory factor analysis that was conducted on the replication sample provided strong support for the 9-item AMAS.

Confirmatory factor analyses on a third (replication) sample provided strong support for

the 9-item abbreviated measure with the attainment of excellent goodness-of-fit values using multiple indexes. As such, these data support the notion that the abbreviated measure may be an externally valid, more parsimonious, and superior measure of math anxiety as compared with the original instrument. (Hopko et al., 2003.p. 181)

The AMAS can be used in similar ways to the MARS and MARS-R. The AMAS measure is a good instrument to use in early detection of mathematics anxiety (Hopko et al., 2003). The AMAS could be used to identify the extent mathematics anxiety manifests itself in individuals. Additionally, researchers could use the AMAS as an instrument to select participants for investigations and as pre and post measures for assessing the success of treatments of mathematics anxiety. This present study used the AMAS to select participants based on the highest and lowest overall AMAS scores to determine high and low mathematics anxiety in participants.

After reviewing these instruments, the AMAS was chosen to measure mathematics anxiety in EPTs for this study (see Appendix A). This instrument is a shorter more concise version of the both the MARS and the MARS-R and can measure mathematics anxiety consistently and reliably. The researchers who developed the AMAS even argue that it is a more superior measure of mathematics anxiety than the MARS-R (Hopko et al., 2003). Most importantly, the AMAS required less time from the participants since it only consists of 9 items. 


\section{Elementary Teachers and Mathematics Anxiety}

Research suggests that teachers who display mathematics anxiety avoid mathematics as much as possible (Trice \& Ogden, 1987). In their study on first-year elementary school teachers, Trice and Ogden (1987) visited 40 first-year second- through fifth- grade teachers in four different school districts once a week for three weeks. These teachers were asked to submit their lesson plans for analysis and were given a number of assessments including the MARS-R. Three visits to the teachers' classrooms were conducted by graduate assistants enrolled in a course on student teacher supervision. The observers noted the topic of instruction and rated the teachers on five, 5-point scales including content knowledge, student involvement, discipline, lesson organization, and use of audiovisuals. Neither the observers nor the first-year teachers knew that the focus of the study was on mathematics. The first-year teachers were divided into quartiles based on their MARS-R scores. Trice and Ogden (1987) found that teachers who were most anxious scheduled less time for teaching mathematics than those in the two least anxious quartiles. Additionally, those teachers in the quartile with the highest mathematics anxiety were observed to be 10-15 lessons behind similar teachers in other anxiety groups. A debriefing interview was also conducted with the participants and those with the highest mathematics anxiety indicated that there was at least a mild dislike for teaching mathematics (Trice \& Ogden, 1987).

Teachers who are mathematically anxious often use more teacher-directed methods of teaching than their peers who are less mathematically anxious (Bush, 1989). Bush (1989) conducted a study on 31 fourth, fifth and sixth grade teachers and their students in six different elementary schools. Both the teachers and the students were 
tested for mathematics anxiety. The teachers were tested with the MARS and the students were tested using an adolescent version of the MARS. These instruments were administered twice throughout the school year, once in October and then again in May to determine if there was a decrease in mathematics anxiety by the students and the teachers. The teachers were asked to audio-record three typical mathematics lessons in October, January, and March. The investigator called the schools on the same day and asked all teachers to audio-record their mathematics lesson for that day. Audio-recorded lessons were coded using a Lesson Coded Form developed by the investigator with the focus on measuring time and frequency of selected teaching behaviors and classroom discourse (Bush, 1989). Teachers' mathematics anxiety scores positively correlated $(p<$ $.05)$ with time devoted to whole class instruction and negatively correlated $(p<.05)$ with the number of questions asked by students during the lessons. Teachers with high mathematics anxiety spent more time on whole class instruction and their students asked less questions in class (Bush, 1989). With regards to teaching methods, Bush (1989) found that teachers with high mathematics anxiety were more traditional in their teaching, meaning that they devoted more time to seatwork and whole class instruction and devoted less time to checking homework, playing games, problem solving, small group instruction, and individualized instruction. Finally, Bush (1989) found that the teachers who had high mathematics anxiety taught fewer mathematical concepts and more mathematical skills.

In their study of 18 EPTs in their third year of university in Australia who selfidentified as having mathematics anxiety and volunteered to participate, Uusimaki and Nason (2004) identified and categorized themes arising from the interview data according 
to three aims of their study: (a) the causes underlying the negative beliefs and anxieties of mathematics; (b) situations causing these beliefs; and (c) the types of mathematics causing the negative beliefs and anxieties. Through their analysis, the researchers found that situations causing the most anxiety for the EPTs included when the participants were asked to communicate about their mathematical knowledge (48\%) and in the teaching of mathematics during practicum situations (33\%). Finally, the mathematical topics that caused the most anxiety in these participants included algebra and patterns (33\%), space (31\%), and number and operations, especially division (21\%). Based on their findings, Uusimaki and Nason (2004) indicated that preservice teachers needed to be provided with learning environments where they can freely communicate and explore mathematics, relearn basic concepts, and apply this relearned knowledge to real-life situations. The EPTs in Uusimaki and Nason's (2004) study were self-identified, and no instrument was used to measure their mathematics anxiety, which would have made the results of this study stronger. The results suggested that mathematics anxiety begins in elementary school and topics that cause mathematics anxiety for the EPTs included algebra and patterns, space, and number and operations which are all covered in elementary school. Additionally, the researchers found that the EPTs reported feeling most mathematically anxious when asked to communicate about mathematics and when teaching mathematics in their practicum. The study by Uusimaki and Nason (2004) informed the present investigation. The present multiple case study investigated the occurrence of mathematics anxiety during student teaching as observed by the researcher rather than just through self-reported data. EPTs were observed teaching mathematics in elementary school classrooms. 
Unglaub (1995) conducted a qualitative study in Australia looking at the mathematics anxiety of 12 EPTs during their internship (professional) year. Six participants had high mathematics anxiety, and six participants had low mathematics anxiety. To select participants, Unglaub (1995) surveyed 155 preservice teachers using the MARS to determine their level of mathematics anxiety. The six participants who exhibited high levels of mathematics anxiety were all female preservice teachers, and the six participants who exhibited low levels of mathematics anxiety included five females and one male. Three in-depth interviews were collected during the first semester of the Professional Year (The Professional Year includes two semesters with student teaching experiences and seminars conducted interchangeably). The first interview was an introductory interview which solicited information on the participants in light of their level of mathematics anxiety. The second interview questioned the participants about their present experiences with mathematics anxiety and their feelings about teaching in an elementary school setting. The final interview took place after five weeks of student teaching and asked participants to reflect on their experience since the onset of their Professional Year in relation to mathematics anxiety and teaching mathematics. Along with the interviews the researcher also coded and analyzed into categories a student teaching journal in which participants wrote about their experiences with teaching and about observations of their cooperating teacher teaching lessons. At the end of the semester, the researcher met with all participants as a group and administered a survey asking them about their feelings toward their future encounters with the teaching of mathematics. 
Unglaub (1995) analyzed the data and created five categories and several subareas. The five categories were: (a) statements that define or indicate high or low mathematics anxiety, (b) statements that indicate possible causes of high or low mathematics anxiety, (c) coping with mathematics anxiety, (d) mathematics anxiety and teaching mathematics, and (e) retrospective and projections for future. The researcher entered the research assuming that participants with high mathematics anxiety would have trouble in their role as teachers of mathematics, but she did not find this to be the case with these participants since those with high mathematics anxiety claimed to seek more help. Through the analysis of the data, Unglaub (1995) determined that mathematics anxiety was not as serious a problem as had been anticipated for those EPTs who were teaching mathematics. However, there was no theoretical framework used for this analysis. Emerging themes were identified from the analysis of the interviews and self-reporting journals. This was a limitation of Unglaub's (1995) study because students may believe that lessons are taught well, but an independent observer might see otherwise. The researcher also determined that participants with high mathematics anxiety demonstrated some advantages over participants with low mathematics anxiety when dealing with students with high levels of mathematics anxiety. A conjecture made by the researcher was that participants with high mathematics anxiety could more effectively deal with students with high mathematics anxiety because they have experienced the phenomenon of mathematics anxiety.

Unglaub's (1995) study was conducted using only interviews and self-reporting documents. The present dissertation added another layer of data collection (i.e., observation of mathematics teaching and related artifacts used by EPTs during student 
teaching) to determine how mathematics anxiety affected EPTs during student teaching. Additionally, the present investigation used Shulman's ideas related to subject content knowledge and Graeber's theoretical framework on PCK related specifically to mathematics to analyze the collected data. Also, it has been over 15 years since Unglaub's (1995) study was conducted, and new reform standards for mathematics teaching and learning are now in place. Through observations of EPTs' actual teaching experiences during student teaching, analyzing documents (lesson plans), analyzing artifacts, and conducting interviews, this study investigated differences between preservice teachers with high and low levels of mathematics anxiety, and examined the effects that mathematics anxiety has on EPTs teaching at the student teaching level.

Trujillo and Hadfield (1999) conducted a study to trace the roots of mathematics anxiety in EPTs through in-depth interviews. Fifty students from an elementary mathematics methods class were given the R-MARS. The six participants who scored the highest on the mathematics anxiety test were invited to complete in-depth interviews to explore their individual experiences related to mathematics anxiety. One individual did not wish to participate in the interviews, so only five in-depth interviews were conducted. The five subjects were women ranging in ages from 21 to 40 . After analysis of the interviews, the researchers found several themes that led to mathematics anxiety in the participants of their study. The themes included a view of mathematics, self-concept in mathematics, elementary school experiences, secondary school experiences, college experiences, examples of good mathematics teachers, examples of bad mathematics teachers, family influence, mathematics test anxiety, and plans for teaching children mathematics. 
The results of the study by Trujillo and Hadfield (1999) were categorized into five general areas including, (a) self-perception of mathematics; (b) school experiences related to mathematics; (c) family influences on mathematics attitude; (d) mathematics test anxiety; and (e) future plans for teaching mathematics. All five participants in the study had several negative experiences in their past with mathematics in school. None of them received much support in mathematics at home, and all of them suffered from severe mathematics anxiety (Trujillo \& Hadfield, 1999). All of the participants declared that they would offer a more positive experience for the students in their own classrooms when they become elementary school teachers (Trujillo \& Hadfield, 1999). The present study adds to this work by conducting observations of the experiences that EPTs with high and low levels of mathematics anxiety offer their elementary students in their classrooms.

Trujillo and Hadfield (1999) offered some suggestions to help students who suffer from mathematics anxiety such as offering mathematics anxiety reduction clinics, providing mathematics methods courses and professional development opportunities that would help reduce mathematics anxiety by teaching the development and the delivery of cutting edge lessons for students, and not requiring elementary teachers who have mathematics anxiety to teach mathematics. Trujillo and Hadfield (1999) proposed that these teachers should teach content in areas where they show confidence and expertise. Trujillo and Hadfield (1999) also offered some possible causes of mathematics anxiety which included bad experiences with mathematics and with their teachers of the subject, a lack of support with mathematics from their family, and having mathematics test anxiety. This research provided valuable information which can ultimately lead to the 
improvement of mathematics programs for EPTs. The participants in the Trujillo and Hadfield (1999) study discussed that they plan to implement future mathematics lessons differently than they experienced them, and they planned to use manipulatives and use more progressive methods to teach the subject. Although this was reported by the participants, this was not observed by the researchers. The participants of the Trujillo and Hadfield (1999) study may have good intentions, but they may not be successful. The present multiple case study took these ideas proposed by Trujillo and Hadfield (1999) another step further and the researcher observed EPTs during enactment of lessons.

\section{Preservice Teacher Education Courses and Mathematics Anxiety}

EPTs in teacher education programs at the university level may experience mathematics anxiety. As newly educated teachers, EPTs could subconsciously pass mathematics anxiety on to their future students as research indicates that mathematics anxiety is a cyclical phenomenon and it can be passed on from teacher to student (Wood, 1988; Trujillo \& Hadfield, 1999). Teacher education programs should be designed to offer assistance to EPTs who have mathematics anxiety to help them overcome it. According to Uusimaki and Nason (2004), focusing on the causes of negative beliefs and mathematics anxiety that are held by preservice teachers was vital to help improve their teaching skills and the mathematical learning of their students (Uusimaki \& Nason, 2004). They suggested that teacher educators can help to guide this process by identifying the origins of the negative beliefs, situations that cause anxiety, and the specific types of mathematics that cause the anxiety. This can help preservice teachers to 
examine the nature of their beliefs and change those beliefs to a more positive outlook (Uusimaki \& Nason, 2004).

Many teacher education programs at the tertiary level are now more focused on teaching mathematics using more student-centered methods with a strong focus on problem solving as advocated by the Principles and Standards for School Mathematics (PSSM) (NCTM, 2000). The curriculum in present teacher education programs in the current state are also guided by the state standards and the Core Curriculum State Standards for Mathematics (2011) which emphasize the use of problem solving and critical thinking to teach mathematics concepts. This could be a problem since Harper and Daane (1998) found problem solving to be an overwhelming cause of mathematics anxiety among EPTs. NCTM (2000) supports a conceptual, reform-oriented approach to teaching mathematics through problem solving and critical thinking as opposed to a purely procedural method of teaching mathematics. The NCTM (2000) standards demanded a change in curriculum standards to focus heavily on constructivist principles. Those EPTs with mathematics anxiety find these new methods of teaching (such as using problem solving) uncomfortable since they may have been exposed to a more teacher directed method of teaching as students (Harper \& Daane, 1998). These methods involving problem solving and critical thinking posed a new way of thinking about mathematical concepts.

Harper and Daane (1998) researched the causes and reduction of mathematics anxiety in EPTs; the study had two purposes. The researchers wanted to determine factors that originally contributed to mathematics anxiety in the subject as well as examine the effects of a mathematics methods course that focused on the use of 
manipulatives to see if the course influenced the mathematics anxiety of the preservice teachers. The participants of this study consisted of 53 preservice elementary teachers who were enrolled in an undergraduate methods course at a mid-sized, southeastern university. The students were enrolled in a methods course that consisted of 10 class sessions, each 3 hours long. The students were also enrolled in 28 full days of fieldwork experience over the course of a semester. The data collection for this study was conducted using three instruments administered to all participants as well as semistructured interviews with 11 of the 53 participants. The three instruments used included, Mathematics Anxiety Rating Scale (MARS), Factors Influencing Mathematical Anxiety (FIMA), and Methods Course Reflection (MCR). The MARS is a 98-item test that was used as a pre-test and post-test. The FIMA is a 26-item checklist developed by the researchers of the study, and the MCR is a 7-item test also designed by the researchers (Harper \& Daane, 1998).

At the end of the course eleven students were selected for the interviews. These students displayed the greatest differences on the MARS pre-test and post-test scores (6 students increased on their scores while 5 decreased). The students were asked to discuss the influence of the methods course on their mathematics anxiety, and the data was analyzed using the grounded theory approach. Harper and Daane (1998) found that mathematics anxiety was still evident in EPTs. The cause of this anxiety often began in elementary schools. Oftentimes, elementary school teachers influenced the development of mathematics anxiety. This indicates a potential cycle. The researchers also concluded that the course made a difference in decreasing the anxiety level of the preservice teachers (Harper \& Daane, 1998). The authors proposed that a good mathematics 
methods course "emphasizes working together, using manipulatives, writing about mathematics, and having extensive fieldwork experiences" (Harper \& Daane, 1998 p. 36). One of the factors in Harper and Daane's (1998) study that had an overwhelming effect on the mathematics anxiety of the participants was problem solving and word problems. This type of research could indicated how methods courses could be structured to help students become better mathematics teachers. A change in the curriculum of mathematics methods courses could better prepare EPTs to teach mathematics, and could decrease the transfer of mathematics anxiety from future teachers to future students. This type of research also informed observations that were made when EPTs left the methods course and begin student teaching. This preset study considered how the EPTs put learned mathematics methods into practice.

Gresham (2007) conducted a study to investigate the changes of mathematics anxiety levels in students enrolled in six sections of a mathematics methods course for preservice teachers. This mixed-methods study was conducted over four years during the fall and spring semesters. The participants included 246 junior-year preservice teachers enrolled in early childhood and elementary education programs. The participants were mostly women (237 out of 246). Data collection included both quantitative and qualitative methods. The MARS was the instrument used to measure mathematics anxiety. The MARS was used as a pre-test on the first day of the methods course and again as a post-test at the end of the course. The qualitative aspect of the study included informal observations of pre-service teachers during the methods course taught for the semester, questionnaire-guided narrative interviews, informal discussions, and informal interviews that were either initiated by the pre-service teacher during or after class or by the professor (the researcher in this study)" (Gresham, 2007, p. $185)$. 
Field notes and audio recordings of interviews and discussions yielded the emergence of themes such as reduction of mathematics anxiety through the use of manipulatives, the personality of the professor along with an inviting environment created by the professor, and the use of journal writing to express feelings and concerns. One of the most unanimous findings was that the EPTs claimed that their mathematics anxiety could have been prevented in elementary school (Gresham, 2007). Those EPTs who reported an increase in mathematics anxiety after the methods course attributed it to stress and lack of understanding when it came to working with manipulatives because they had never used them before (Gresham, 2007). The pretest MARS scores were subtracted from the posttest MARS scores for each participant. A positive answer indicated that an EPT's mathematics anxiety increased during the methods course, and a negative answer indicated that an EPT's mathematics anxiety decreased during the mathematics methods course. Overall, EPT's mathematics anxiety was reduced significantly such that he mathematics methods course helped to reduce EPT's mathematics anxiety (Gresham, 2007).

Vinson (2001) also compared mathematics anxiety of EPTs using a mathematics methods class as a treatment measure to study mathematics anxiety of students. The participants of the study included 87 EPTs enrolled in a mathematics methods class at a university in the United States. These participants were given the MARS as a pretest at the beginning of the methods course and then given the MARS as a posttest at the end of the semester. The students were given the test during the first week of class and were allowed to take it home to complete it. The post-test was done during the last week of class where the students were again allowed to take the MARS home to complete. The 
pre-test score was subtracted from the post-test score for each student. Those with a negative difference showed that mathematics anxiety was decreased at the end of the class and those with a positive difference showed that mathematics anxiety had increased. Informal observations, informal discussions, and informal interviews were also conducted during the study. These were performed by the researcher who was also the teacher of the class. The course focused heavily on the use of manipulatives to make mathematics concepts more concrete and also focused on Bruners's framework of developing conceptual knowledge prior to procedural knowledge. The mathematics methods course was used as a treatment for mathematics anxiety in these students. Overall, mathematics anxiety was significantly reduced after the methods course after comparing their pretest and post-test scores $(p<.05)$. Some students who reported an increase in mathematics anxiety were interviewed and also commented that it was the first time that they used manipulatives (Vinson, 2001). They claimed to be struggling to relearn mathematics at the same time that they were learning to use manipulatives (Vinson, 2001). However, in a majority of participants, using manipulatives reduced mathematics anxiety, and in interviews students reported that they understood the mathematics more clearly (Vinson, 2001). Research should focus on following these EPTs, who were identified as having mathematics anxiety, into student teaching to see what aspects of the mathematics methods course they use in their teaching. For the present study, it was also interesting to observe the use of manipulatives by EPTs; of particular interest was the effective use of manipulatives, and whether the use of manipulatives in lessons taught during student teaching caused more or less mathematics anxiety in EPTs. 
Bursal and Paznokas (2006) examined 65 EPTs (juniors and seniors) enrolled in three methods courses as a part of an undergraduate teacher education program. In their study, the participants were given a mathematics anxiety survey known as the Revised Mathematics Anxiety Survey (R-MANX) to measure their level of mathematics anxiety. The participants were also given the Mathematics Teaching Efficacy Beliefs Instrument (MTEBI), a Likert scale instrument with subscales related to efficacy and mathematics teaching. The researchers discovered that EPTs with high levels of mathematics anxiety also showed a lack of confidence to teach mathematics and science. On the MTEBI, items 1 (Can teach math effectively) and 4 (Know procedures to effectively teach math concepts) addressed the elementary preservice teacher's confidence to teach mathematics effectively. Only about half of the EPTs with high mathematics anxiety agreed with these statements ( $48 \%$ for Item 1 and $52 \%$ for Item 4 ) as compared with $95 \%$ of the EPTs with low mathematics anxiety (Bursal \& Paznokas, 2006). This means that EPTs with high mathematics anxiety believed that they would not be able to teach mathematics effectively. The conclusions of this study state that nearly half the teachers who indicated higher levels of mathematics anxiety than their colleagues also reported that they were less confident in their ability to teach mathematics and science. This suggests that teacher education programs should design methods courses that would help EPTs reduce their mathematics anxiety levels and increase their efficacy in teaching mathematics and science. This quantitative study examined EPTs' confidence in mathematics and science teaching, but no observations were conducted to observe the EPTs while teaching. Qualitative data such as observations and interviews could add another layer of valuable information. 


\section{Teacher Efficacy and Mathematics Anxiety}

Positive teachers can be linked to better performance in mathematics. In her study on perceptions of mathematics teaching effectiveness with EPTs who have differing levels of mathematics teacher efficacy, Swars (2005) found that "past experiences with mathematics were associated with level of mathematics teacher efficacy and influential upon perceptions of mathematics teaching effectiveness among the preservice teachers" (Swars, 2005 p. 144). The study was conducted to research students' perceptions of their effectiveness in teaching mathematics. These preservice teachers had differing levels of mathematics teacher efficacy (some of the participants believed that they could teach mathematics very well while others believed that it would provide a challenge for them). The study consisted of only four participants, EPTs who had just completed an undergraduate, mathematics method, 3-semester hour course. During the last week of classes all the students in this particular course completed the MTEBI. This instrument uses a Likert scale and has subscales built into it. The MTEBI has been tested and the reliability analysis produced an alpha coefficient of .88 for the Personal Mathematics Teaching Efficacy subscale and an alpha coefficient of .75 for the Mathematics Teaching Outcome Expectancy subscale (Swars, 2005). The participants who were finally selected were the two students who scored the highest on the MTEBI and the two who scored the lowest.

The researcher developed an interview protocol to use with the participants which consisted of five questions. The researcher tried to prove content validity by emphasizing that three experts in the mathematics field reviewed the interview protocol and offered suggestions and improvements. This was a form of triangulation in terms of the 
interview tool that was used. All four students were interviewed within one week of their completion of the mathematics methods course. The interviews were audio taped and lasted approximately 45 minutes each.

Grounded theory was used to analyze the interviews which were first analyzed individually and then collectively. The data was coded several times to build a framework for the themes of the interviews. Initially, open coding was used and the data was broken down by asking simple questions. After comparison, the data was grouped and given a label or category using an axial coding process, and finally selective coding processes were used to create a framework for themes. Three themes emerged from the data: (1) past experiences with mathematics; (2) influences upon perception of mathematics teaching effectiveness; and (3) mathematics instructional strategies.

Both the preservice teachers who scored lowest on the MTEBI had bad experiences with mathematics in the past. On the other hand, the two teachers who scored the highest had different experiences. One indicated that mathematics was one of her better subjects while the other indicated a struggle with the subject in school. Swars (2005) explained that this preservice teacher viewed her struggles with the subject to be an asset for her to effectively teach her future students as she can understand their struggles. All four of the students who were interviewed felt confident in their abilities to teach mathematics, but the two who scored the lowest felt that it would require more time and effort in comparison to other subject areas. All students interviewed believed that the most important teaching strategy that needed to be used to teach mathematics effectively was to provide students with authentic mathematics activities. With reference to the use of manipulatives, all preservice teachers reported that it was an important tool, but the 
two students who scored the lowest felt that it might be difficult to accomplish in their classrooms.

In a related study to the one previously discussed, Swars et al. (2006) linked mathematics teacher efficacy to mathematics anxiety. This is an important connection because students who displayed mathematics anxiety were required to take mathematics methods courses in their education programs, but they may not be prepared within themselves to try new methodologies which could benefit their future students. Even after taking such courses, these teachers with high mathematics might revert to teaching mathematics the way they were taught. Teacher efficacy is a term derived from Bandura's (1977) conceptualization of self-efficacy. The construct of self-efficacy is broken into two dimensions including self-efficacy expectations and outcome expectations. Teacher self-efficacy is the belief in one's own abilities to teach a subject well. Teaching outcome efficacy deals with the belief that a teacher can teach a subject to students regardless of any external factors such as home environment or family background (Swars et al., 2006).

The 28 participants (26 women and 2 men) completed two surveys during the last week of classes for the semester. The surveys were the MARS, and the MTEBI (Swars et al., 2006). There was a qualitative part to this study as well. The two EPTs who had the highest degree of mathematics anxiety and the two students who had the lowest degree of mathematics anxiety were interviewed using semi-structured interviews within one week of completing their mathematics methods courses.

The analysis of the relationship between mathematics anxiety and mathematics teacher efficacy was conducted using the Pearson product-moment correlation. The 
results of the Pearson product-moment correlation showed that there was a moderate negative relationship between mathematics anxiety and mathematics teacher efficacy (Swars et al., 2006). Swars et al. (2006) revealed in their study that students who had low levels of mathematics anxiety in general felt highly effective. The researchers concluded that mathematics anxiety has a negative relationship on a preservice teacher's belief in his or her ability to be an effective mathematics teacher. On the other hand, there was no relationship between mathematics anxiety and a teachers' belief that effective teaching can bring about student learning. The four EPTs who were interviewed in the study embraced teaching practices that used manipulatives. All four EPTs believed that they could teach mathematics effectively regardless of their level of mathematics anxiety. This Swars et al. (2006) study prompted additional research. The present study observed mathematics anxious preservice teachers during their teaching experiences to examine if EPTs with mathematics anxiety were comfortable with the use of manipulatives.

\section{Chapter Summary}

This chapter presented a discussion of the various perspectives of the definition of mathematics anxiety and several instruments used to measure mathematics anxiety were examined along with the respective rationales for the definition and instrument selected for this study. Next, after a review of the literature related to the development of mathematics anxiety as well as studies investigating the cyclical nature of mathematics anxiety, it is was concluded that identification of mathematics anxiety in EPTs while in teacher education programs is essential to prevent the phenomenon from being passed onto future generations. Furthermore, examination of research studies involving EPTs and mathematics anxiety, preservice teacher education courses and mathematics anxiety, 
and teacher efficacy and mathematics anxiety revealed the need to investigate mathematics anxiety of EPTs during the student teaching experience.

No study reviewed investigated the mathematics anxiety of EPTs while engaged in student teaching. While qualitative methods were used in other studies, no study that was reviewed included observation of EPTs while enacting lessons as a data source. This multiple case study helped to fill this knowledge gap by analyzing observations of EPTs as they enact lessons during student teaching through the use of qualitative methods. 


\section{CHAPTER III}

\section{RESEARCH METHODS}

\section{Purpose of the Study}

The purpose of this multiple case study investigation was to explore the mathematics teaching experiences of EPTs who were identified as having high and low levels of mathematics anxiety during student teaching. These EPTs' teaching of mathematics were analyzed with respect to their use of mathematics content knowledge and PCK and their manifestation of mathematics anxiety. Individual case studies of the EPTs with both high and low levels of mathematics anxiety were developed. These individual case studies provide rich descriptions of mathematics teaching experiences during student teaching of EPTs with high and low levels of mathematics anxiety. Through these case studies, similarities and differences in the teaching experiences of mathematics of EPTs with high and low levels of mathematics anxiety were evidenced. Knowledge developed through this investigation may be used to inform experiences for lessening the mathematics anxiety of future EPTs during their teacher education programs. The case studies may also be drawn on by mathematics educators, cooperating teachers and university supervisors, as well as read by EPTs themselves, to understand the manifestation of mathematics anxiety related to teaching mathematics among student teachers and, in turn, consider ways to alleviate their own mathematics anxiety, as needed. 


\section{Research Questions}

The broad research question that guided this study was: What are the mathematics teaching experiences of elementary preservice teachers identified as having high and low levels of mathematics anxiety during student teaching?

A Subsidiary Question was:

- What similarities or differences exist, if any, between elementary preservice teachers with high and low levels of mathematics anxiety in drawing on and developing content knowledge and pedagogical content knowledge during planning, enacting, and reflecting on mathematics lessons during their semester of student teaching?

\section{Research Design: Multiple Case Study}

This multiple case study developed individual case studies of EPTs with high and low levels of mathematics anxiety during their student teaching experience with respect to their teaching of mathematics. Creswell (2007) defines case study as a

qualitative approach in which the investigator explores a bounded system (a case) or multiple bounded systems (cases) over time, through detailed, in-depth data collection involving multiple sources of information (e.g., observations, interviews, audiovisual material, and documents and reports), and reports a case description and case-based themes (p. 73.)

The research questions for this study were designed to investigate cases of EPTs with different levels (high and low) of mathematics anxiety enrolled in an elementary education program at an urban southeastern state university in the United States who were completing their student teaching experience. Flyvbjerg (2011) identifies four characteristics of case study methodology including the following: a focus on the boundaries used to identify the case study, the intensive nature of case study, 
developmental factors stressed by case study, and relation to the environment or context. This multiple case study investigation addressed the first characteristic through the criteria of EPTs with the highest and lowest levels mathematics anxiety from a cohort of EPTs enrolled in student teaching during the 2013 spring semester. The boundary of the cases was defined as a particular cohort of EPTs at an urban southeastern state university in the United States from which participants were selected. This multiple case study investigation was intensive in nature. It contains rich detail, and included several data sources which were used to allow for completeness and variance (Flyvbjerg, 2011). The in-depth nature of these case studies included the use of data from interviews, observations, and review of documents and artifacts. Thirdly, this multiple case study investigation examined the developmental factors of the identified EPTs of a particular cohort at the specific stage of their student teaching experience. The EPTs at other stages of the elementary education program were not included in this study. Finally, this multiple case study inquiry focused on the context of elementary school classrooms in a southeastern public school system where EPTs were completing their student teaching.

The type of case study method used in this investigation was a multiple case study. In this type of case study design, the researcher examines one issue and uses multiple case studies to illustrate the issue (Creswell, 2007). Yin (2003) suggests the use of logic of replication where the investigator replicates the same procedures for each case in a multiple case study. This logic of replication was used when collecting data for each of the cases of EPTs with high and low levels of mathematics anxiety. The same procedures were used to collect data for each case. 
As a research method, a multiple case study was used to conduct this research as this investigation sought an in-depth understanding of mathematics anxiety as experienced by EPTs during student teaching. The researcher was the primary instrument used to collect and analyze data and the end product was a rich, descriptive interpretation (Merriam, 2002a) of the experiences of EPTs with high and low levels of mathematics anxiety. The researcher acted as the sole observer of the EPTs selected as participants during the semester.

Through understanding of the experiences of EPTs with high and low levels of mathematics anxiety in this multiple case study, mathematics educators can better prepare EPTs with high and low levels of mathematics anxiety for teaching mathematics during student teaching. Additionally, the knowledge gleaned through these case studies can support improved mentoring of EPTs during student teaching, as well as provide support for novice teachers in the profession. Through this in-depth understanding of how mathematics anxiety may affect EPTs' teaching of mathematics, mathematics educators can design or implement strategies to help EPTs reduce and cope with mathematics anxiety. By having a more in-depth understanding of mathematics anxiety through these case studies, EPTs can also benefit by being aware of how this type of anxiety affects their teaching; and take measures, if necessary, to create changes in their behavior.

\section{Researcher's Role}

Qualitative research stems from topics that interest researchers (Merriam, 2002a). In this multiple case study the researcher acted as the primary observer. In order to lessen the impact of researcher bias, Peshkin (1988) recommends that researchers should actively seek out their subjectivity (sources of potential bias) throughout the research 
process in order to provide a more objective view of the results of the research. Peshkin (1989) suggests that the researcher's subjectivity "is like a garment that cannot be removed. It is insistently present in both the research and nonresearch aspects of our life" (p.17). Peshkin (1989) suggests seeking out the subjective I's throughout the research. To do this, I monitored myself and my feelings as they arose during data collection (Peshkin, 1989). Peshkin (1989) suggests the use of note cards and a researcher's diary (journal) to document both positive and negative feelings. I used both forms of documentation. As Peshkin (1989) suggests this practice helped to tame subjectivity in the researcher. My subjectivity audit revealed a few subjective I's to be revealed including the Pedagogical Coach I and the Nurturing I.

The following section provides an autobiography that attempts to identify potential biases or prejudices on mathematics anxiety through the experiences that I have encountered throughout my career thus far.

\section{Researcher's Autobiography}

I have always had a passion for mathematics, for not only the subject itself, but for the understanding of it. I knew from an early age that my calling was to the teaching profession, and I knew I would have to teach the subject that I love, mathematics. Very early in my teacher preparation I noticed that a large number of people do not have my love and understanding for mathematics. I never truly understood why.

Presently, I have had 14 years of teaching experience including at the elementary and middle school levels ( 4 years), at the junior college level (4 years) and the university level (6 years). I hold a Bachelor's degree in Mathematics and English Education and a Master's degree in Educational Leadership. As an elementary and middle school teacher, 
I taught mathematics to students in grades 5, 6 and 8. Concurrently, I taught Intermediate Algebra and Mathematics of Finance to junior college students in an evening program. I have been teaching mathematics methods courses to EPTs at the junior college and university levels for the past 12 years in both Belize and the United States. Most of these experiences have been with undergraduate students. I am currently a doctoral student and I have been interested in the topic of mathematics anxiety since prior to beginning my doctoral program. I am hoping to continue investigating it further to understand this phenomenon, and to be able to help future students who will struggle with mathematics anxiety. The reasons for my interest in mathematics anxiety are numerous. I never personally experienced mathematics anxiety, but I knew others who struggled with the subject through their academic careers during various periods of my life.

Growing up I have always enjoyed mathematics. I never had negative experiences with mathematics teachers, and I can recall two outstanding mathematics teachers, one taught me during sixth, seventh and eighth grade, and the other taught me in my junior and senior years of high school. As a child, I used mathematics as a motivator. I remember always beginning with mathematics homework since it was so easy for me to accomplish. I never experienced mathematics anxiety during elementary, middle, nor high school.

The closest experiences to me with mathematics anxiety were encountered within my family. My sisters never liked the subject and would openly proclaim their feelings. As a younger sibling, I would watch them spend hours on mathematics homework and speak negatively about the subject. I even recall my eldest sister coming home from college one semester and boasting of the fact that she had gotten out of taking the only 
mathematics course required for her program. How she managed to avoid taking the subject still puzzles me. However, when I decided to major in mathematics at the junior college level and subsequently at the undergraduate level, I received full support from my family. After completing my undergraduate degree, my mother told me that she did not know how I succeeded. She revealed being fearful and anxious when I told her that I wanted to study mathematics since no one in our family liked the subject, or had been very successful with it. I truly believe that if she had told me this at the beginning of my undergraduate degree, I would have doubted myself and I would not have been successful.

In my experience as a teacher, I have encountered students of all ages who exhibit mathematics anxiety. These students include fifth, sixth, seventh and eighth graders, preservice teachers, and in-service teachers. I have been intrigued and concerned by the phenomenon of mathematics anxiety as I have seen how this phenomenon has caused concerns for preservice teachers, in-service teachers and other students. More recently, I began to question if mathematics anxiety would affect a teacher's ability to teach mathematics effectively.

Because of the nature of mathematics anxiety, it is my personal belief that this phenomenon would negatively affect teachers working in the elementary school setting. When I was an elementary school teacher, I witnessed teachers rearrange their class schedules to avoid teaching mathematics. I taught at a K-8 school that was Catholicoriented, so the school would attend mass once a month on Wednesday mornings. Because mass lasted over an hour, the scheduling would be interrupted, and the time for all classes in the day would either be cut short, or one subject would be eliminated in 
order for other classes to proceed as scheduled. It was during this time that I witnessed teachers eliminating mathematics from their class schedule. Additionally, a part of my job was to substitute for teachers who were absent during my "free periods." Often the principal assigned me to the mathematics classes of absent teachers. During these substitute roles, I reviewed the lesson plans of the teachers. Through these informal observations, I noticed that some teachers would use only traditional methods to teach the subject including seatwork with worksheets and direct instruction. I observed that other teachers would plan creative lessons using manipulatives and incorporating studentcentered and hands-on methods. During informal conversations, I heard teachers express their dislike for the subject, and often these were the same teachers who used more traditional methods to convey the content of their lessons.

I also noticed students who had more traditional teachers for mathematics complained about the way their teacher taught mathematics, and some students even observed that their teacher just did not like the subject. This was evident in the way that they described their teachers. They explained that the teachers who did not like mathematics did not take an interest in it, and did not really answer their questions, but in other subjects, these same teachers were excited and interesting.

Prior to and during the data collection and analysis of this study, I taught a methods course designed for EPTs. I observed that many EPTs exhibited signs of a high level of mathematics anxiety. In my experience, these EPTs had a difficult time adopting new methods. Rather than try the methods I introduced, which were generally different from their own experience, they regressed and relied on the same methods that may have initially caused their mathematics anxiety. Through one of the components of the course, 
the EPTs were asked to develop lesson plans aligned with reform standards using a student-centered, hands-on approach to teaching mathematics recommended by both national organizations such as the National Council of Teachers of Mathematics (NCTM) and the local state. I observed that the lessons created by EPTs displaying mathematics anxiety were teacher-centered in nature. I was interested in investigating more thoroughly this observed phenomenon since I have never experienced mathematics anxiety, and I wanted to understand the experiences of preservice teachers who have mathematics anxiety. More specifically, I was interested in investigating the student teaching experience of preservice teachers who exhibited high and low mathematics anxiety, including their planning process, their interactions with students, and their use of resources in the classroom.

Because of all these experiences, I have always assumed that it would be better to have one teacher teach certain subjects beginning in elementary school as is done at the middle and high school levels. I believe this would alleviate some of the pressure of teaching mathematics by those teachers who do not like the subject and who might not do a good job teaching our students. I undertook this study believing that teachers who dislike or have a fear of mathematics will not be as effective at teaching the subject as those who enjoy and clearly understand mathematics. This might not be the case, and my experiences may be unique. I know that it was not possible to completely separate myself from my previous experiences, but I was fully aware of these experiences as I entered this investigation and used note cards to track my feelings, kept a research journal, and by uncovered my Subjective I's as I conduct this research (Peshkin, 1989). 
Also, I focused on the experiences of my participants as the primary source of information, and remained aware of my subjectivity as I collected and analyzed data.

\section{Research Site}

All EPTs who participated in this study were enrolled in an urban southeastern state university in the United States. The participants of this study were assigned to student teach in various urban public elementary schools across a large school district. The population of this school district consists of a majority of students of Hispanic descent. The demographics are broken down as follows: 68.4\% Hispanics, 22.3\% Black Non-Hispanic, 7.5\% White Non-Hispanic, and 1.8\% Other.

The participants in this study were EPTs enrolled in an elementary education major who had taken all the coursework required for their major, and were in their final semester in which they completed their student teaching experience. These EPTs were required to take three mathematics related courses for their education major. The three courses were comprised of two content courses offered to all students at the university (e.g., college algebra, finite mathematics, etc.) and one elementary mathematics methods course. The mathematics methods course focused on the content to be taught at the elementary level and the methodology used to teach this content. These courses were required in fulfillment of their elementary education degree. The two mathematics courses were completed during their lower division coursework and the elementary methods course was completed at any time as part of EPT's upper division course work prior to student teaching. The EPTs at this university were acquiring a bachelor's degree in elementary education. Students enrolled in this education major were mostly women, with a majority of them being Hispanic. 


\section{Research Participants}

The participants of this study included six (6) EPTs during their student teaching semester. These six participants were chosen from an initial 121 EPTs who completed the Abbreviated Math Anxiety Scale (AMAS) at a student teaching orientation to assess their level of mathematics anxiety at the beginning of their student teaching semester. The AMAS was developed by Hopko et al. (2003) as a new more concise version of the Mathematics Anxiety Rating Scale - Revised (MARS-R). Hopko et al. (2003) tested the psychometric properties of the scale to test validity and reliability as well as the generalizability to the larger population. The AMAS, a 9-item scale (see Appendix A), was tested for its factor structure, internal consistency $(\alpha=.90)$, test-retest reliability $(r=$ $.85)$, and convergent/divergent validity between the MARS-R and the AMAS $(r=.85)$.

"A two-factor solution was identified that accounted for $70 \%$ of the variance" (Hopko et al., 2003 p. 180). This AMAS measure was a good way to help assess individuals who struggle with mathematics anxiety (Hopko et al., 2003).

Creswell (2007) recommended no more than four or five cases in a collective (multiple) case study in order for the data collection to be in-depth. However, this case study used six participants to have an equal number of participants with high and low levels of mathematics anxiety. Criterion purposeful sampling was used to acquire the six participants for this study based on their AMAS scores. Six participants were recruited to ensure that there were at least four or five participants who completed the study; however, all six participants completed the study.

Prior to the start of the student teaching semester, the researcher gained permission from the Office of Field Experiences to administer the AMAS to elementary 
education majors during their student teaching orientation. During the student teaching orientation the researcher explained the purpose of the study, described the requirements for participation, answered clarifying questions, and gained consent before administering the AMAS. The only identifying information on the AMAS was the unique ID number for each student. The AMAS was collected and analyzed, and the participants with highest and lowest mathematics scores were contacted.

The participants were contacted by gaining access to their email address using their unique ID number. With the help of the Office of Field Experiences, students were solicited to participate in the study. Initially, the three participants with the highest mathematics anxiety scores and the three participants with the lowest mathematics anxiety scores were invited to participate as case study participants. However, not all of the initial six participants agreed to participate. As a result, two lists of participants were created, one list of participants with the highest anxiety ranked in descending order, and one list of participant with the lowest anxiety ranked in ascending order. The researcher contacted participants based on list. For those participants whose scores were the same, they were randomly placed using their unique ID on the list in the order of their score. The researcher recruited participants though email and initial visits to their school placements. After contacting a total of 18 participants six participants (three participants with high mathematics anxiety, and three participants with low mathematics anxiety agreed to participate. The other 13 participants had various reasons for not participating in the study. Student teachers were not able to participate in the research for a variety of reasons including, (a) they were not teaching mathematics, (b) their cooperating teacher did not want them to participate in the study, and (c) the student teacher was not willing 
to participate. The six participants who agreed to participate were informed about the expectations of the study and were told that they were selected based on their level of mathematics anxiety. The participants were informed of the 7 interviews that they would complete, and they were also informed of the 5 lesson observations that would be videotaped. The participants were informed about the pre-interview surveys, and told that the researcher would be looking at lesson plans, artifacts, and their journal entries. All six participants agreed to this criteria. They understood that they would not have to complete additional work beyond the requirements of their student teaching placement. All participants were enrolled in their semester of student teaching and had successfully completed the course requirements in their elementary education program.

\section{Data Collection}

Several types of data collection was used in this study. Because this investigation involved case study methodology, data collection was in-depth and thorough. Detailed, in-depth data collection involving multiple sources of information (Creswell, 2007) was used to gain a rich understanding of the participants. Audiotaped interviews, pre-lesson surveys, lesson observations with field notes and video-recordings, post observation interviews, document review, artifact examination, and a research journal were used in the data collection (See Appendix E for a data tracking table). Creswell (2007) advocates for the use of multiple data sources to gain rich detail.

In a multiple case study it is important to replicate the procedures for each case (Yin, 2003). The interviews of this multiple case study were conducted with each participant in the same order, and were conducted at the same general time of the semester. The observations made by the researcher were also conducted in the same 
order with each participant. The researcher documented any decisions made during the data collection process through a detailed explanation of those decisions in the research journal. Yin (2003) also suggests that the investigator in a case study research design must be an independent investigator who can make intelligent decisions when collecting data. Any decisions made contrary to the plan of data collection were documented with justification provided.

\section{Administration of the AMAS}

With the permission of the Office of Field Experiences, during the Spring 2013, the researcher administered the nine-item AMAS to EPTs enrolled in student teaching that semester. See Appendix A for question on the AMAS. Taking the AMAS was voluntary and the participants were able to refuse participation without penalties. A total of 121 EPTs took the AMAS.

\section{Audiotaped Interviews}

The researcher conducted a total of seven audiotaped interviews with each participant (See Appendix B). All interviews followed a semi-structured design, and allowed for probing and follow-up questions. The researcher acted as the interviewer in this study. The main questions were broad and addressed the research questions outlined for this study. These main questions did not impose the interviewer's judgments in the questions (Rubin \& Rubin, 2005). An example of a main question includes "What is involved in your planning process for a mathematics lesson?” In addition to main questions, follow-up questions were included in all interviews. Rubin and Rubin (2005) advocate for the use of probe and follow up questions to elicit responses from interviewees that are rich in detail, depth, and nuance. Continuation, elaboration, and 
clarification probes were planned for and were used in the interview process (Rubin \& Rubin, 2005). An initial student teaching interview, five post observation interviews, and a final student teaching interview were conducted with each participant. These interviews will be discussed in following sections.

The researcher solicited some assistance of a professional transcriptionist to transcribe some of the interviews, while the researcher transcribed some of the interviews. The interviews were transcribed verbatim. The researcher carefully listened to the recorded interviews and simultaneously read the transcripts done by the transcriptionist to make sure the transcripts were accurate (Rubin \& Rubin, 2005). Any corrections were made at this point, prior to data analysis.

\section{Initial Student Teaching Interview}

An initial student teaching interview was conducted toward the beginning of the student teaching semester. This interview lasted approximately one hour. The purpose of the initial student teaching interview was to gain knowledge of the EPTs' past experiences with mathematics content and mathematics anxiety. The questions asked were general and allowed for follow up questions and probing questions. An example of a question asked in the initial student teaching interview was, "What was your first bad experience/good experience with mathematics?" The participants were encouraged to speak freely and give details in their answers.

\section{Pre-Lesson Survey}

An open-ended, four question survey was developed to gather information from the participants prior to teaching each of the five observed lessons (see Appendix C). This pre-lesson survey was distributed to the participants before the start of their lesson. 
The participants completed the survey in a few minutes and returned it to the researcher before beginning the observed lesson. The answers to the pre-lesson survey were discussed in the post observation interview. The purpose of this pre-lesson survey was to acquire information about the participants' feelings before teaching the lesson, about their general preparation for the lesson, about the resources that were used to plan the lesson, and about any general apprehensions that the participants had before teaching the lesson. This pre-lesson survey informed the researcher about the experiences of EPTs during their planning of mathematics lessons and before beginning to teach the observed lesson.

\section{Lesson Observations}

Lesson observations were conducted while the EPTs were teaching mathematics lessons. They occurred five times during the course of the semester. The researcher took descriptive field notes and video-recorded each of the lessons. The researcher also looked for visible signs of mathematics during the lesson observations. See Appendix D for a list of the signs of mathematics anxiety that were observed during the lessons. An interview was conducted after each lesson observation. The researcher planned convenient times with the EPTs as well as with their cooperating teachers to plan the lesson observation visits required for data collection. On some occasions two lesson observations were conducted on subsequent days to capture continuity in lesson planning, implementation, reflection and modification to meet student learning needs. Initially this method was planned for all participants, but scheduling conflicts arose for most participants.

The observed lessons were video-recorded so that the researcher could refer back to the videos when reviewing observation notes, and add any additional observations. 
During these observed lessons, the researcher took field notes that focused on content knowledge, PCK, and mathematics anxiety. The field observation notes were taken in 10 minute time segments. The notebook of the researcher was set up in two columns. The smaller column on the left side of the notebook was used to record the time that the notes were being taken, and the larger column on the right side of the notebook had the actual observation notes. The researcher noted the time at every 10 minutes in the lesson and posted the time on the left hand side of the notes.

\section{Post-Observation Interviews}

Five post-observation interviews were conducted for each observation immediately after the observed mathematics lesson to gain a better understanding of the experience of the EPTs during that particular observed lesson, as well as their reflections on the lesson and their plans for future lessons. The questions for the post-observation interviews consisted of questions about the enacting of the observed lesson and planning for the lesson. It also included reflection questions and follow-up questions. Rubin and Rubin (2005) suggest using follow-up questions in later interviews to help clarify meaning, provide examples, or examine the limits of generalizability. The purpose of the postobservation interviews was to acquire an in-depth understanding of the elementary preservice teacher's mathematics anxiety over time, to clarify any questions that arose in observations, to inquire about the feelings of the participant during the planning and enactment of a lesson, and to get additional information on important statements made in previous interviews. 


\section{Documents}

Documents were collected and analyzed to triangulate with other data sources for the development of richer understandings about the EPTs experiences during their teaching of mathematics. These documents included the available lesson plans of the five lessons observed and copies of the student teacher's Professional Development Journal used to capture references participants made related to teaching mathematics and mathematics anxiety. The university required a total of eight detailed lesson plans (one per week) in the content areas of reading, language arts, mathematics, or a content area specific to a particular program. The student teachers were allowed to choose the subject area in which they created these lesson plans (consequently, a detailed mathematics lesson plan was not available for every student teacher). After the eight detailed lesson plans, the remaining lesson plans that the EPTs created followed the format used by the cooperating teacher. The lesson plans and journal entries provided another layer of understanding of the experiences that student teachers with high and low mathematics anxiety encountered during student teaching.

\section{Artifacts}

Artifacts produced or used for the observed lessons by the EPTs were examined as another type of data collection. These artifacts consisted of manipulatives, posters, literature books, and other artifacts used during the lessons observed. These artifacts added another layer of understanding about the EPTs' experience with the teaching of mathematics. During interviews, the researcher asked about the creation of the artifacts and how they were used in the teaching of the lesson. The researcher also asked about the EPTs' feelings associated with the use of the artifacts. 


\section{Research Journal}

A research journal was used to collect additional data. As the researcher, I used a research journal to record additional observations, reflections after interviews, and decisions made as I collected, analyzed, and interpreted the data. I also included correspondence and communications with participants and their cooperating teachers in this research journal. Bogdan and Bilken (2007) advocate the use of research journals as an additional source of data.

\section{Final Student Teaching Interview}

The final student teaching interview was conducted toward the end of the semester after all five of the lesson observations had occurred. The last interview consisted of questions to gather an overall understanding of the student teaching experience with respect to teaching mathematics for the EPTs with high and low levels of mathematics anxiety. During this final interview the EPTs were asked about their overall experience with teaching of mathematics during student teaching and changes in their feelings toward mathematics content and the pedagogy associated with teaching mathematics. They were also asked general questions relating to their planning process, the feelings that they had during that planning process, the enactment of lessons, and feeling that they had during the enactment of lessons. EPTs were also asked about the relationship that developed during the semester with their cooperating teacher, and the influence that their cooperating teacher had on the development of their lessons.

\section{Data Management}

After the data was collected, the interviews were transcribed by both the researcher and a professional transcriptionist. The researcher reviewed all transcriptions 
to ensure accuracy by listening to the audio files while simultaneously reading the transcripts. A folder was created electronically for each participant, and all the data for the participant was stored in that folder. The transcripts were also printed and the paper copies were kept locked in a file cabinet in the home of the researcher. The pre-lesson surveys were scanned and saved electronically, and were added to each participant's folder. Copies of lesson plans were stored electronically, as well as excerpts of the participant's journal that were useful in the investigation. Finally, pictures of any additional artifacts that were used during the observed lessons were also stored in the participants' electronic files. The field observation notes which were hand written in notebooks were kept locked in a file cabinet in the home of the researcher. All data was stored according to the university's IRB Data Management/ Security Guidelines. The electronic data were password protected and kept on two separate hard drives which were also locked in a file cabinet in the researcher's home office. The researcher was the only person to have access to that cabinet. The data will be kept for five years after data collection after which it will be destroyed.

\section{Data Analysis}

Data analysis of qualitative data was challenging (Creswell, 2007) and required organization and careful attention to detail. Data analysis in qualitative studies such as a multiple case study "consists of examining, categorizing, tabulating, testing, or otherwise recombining both quantitative and qualitative evidence to address the initial propositions of a study" (Yin, 2003 p. 109). Yin (2003) identifies three strategies that can be used in data analysis for a multiple case study including relying on theoretical propositions, setting up a framework based on rival explanations, and developing case study 
descriptions. This multiple case study used the first of these strategies to first analyze the data collected throughout the investigation: relying on theoretical propositions. The theories of Shulman's (1986) content knowledge and Graeber's (1999) PCK in mathematics, and the construct of mathematics anxiety were used to analyze the data including interview transcripts, field notes on lesson observations, pre-lesson surveys, documents and artifacts, on the EPTs with high and low mathematics anxiety. These constructs informed the initial codes that were used to code the data.

The initial step in the data analysis phase was to transcribe the recordings of the interviews. These were transcribed verbatim and organized into computer files. The transcripts were printed. The researcher read the transcripts of data, field notes, and artifacts several times in their entirety to get an overall sense of the data (Creswell, 2007). During this initial reading, the researcher wrote memos (ideas, key concepts) in the margins of the transcripts, field notes and artifacts as they occurred to the researcher (Creswell, 2007). After the transcribing phase, the researcher reviewed the videos of each of the observed lesson for each participant. This was done to enrich the field observation notes. Missing information was added to the notes and clarifications were made to the notes for better understanding. Next, the researcher organized all the data. Creswell (2007) offers suggestions to begin the data analysis process. Data analysis requires the researcher to prepare and organize the data for analysis. The observation field notes were in a notebook and tabs were created for easy access to notes on each observed lesson. The transcripts, lesson plans, and research journals kept by the participants were organized in a large three-ring binder by participant. The researcher used an initial seven codes to begin coding: mathematics anxiety, content knowledge, 
understanding students' current understanding is important, students knowing in one way do not necessarily know in other(s), intuitive knowledge is both an asset and a liability, certain instructional characteristics appear to promote retention, and alternative representations and the recognition and analysis of alternative methods are important. The researcher used five different color highlighters to represent each of the last five codes related to content knowledge, and used MA to represent mathematics anxiety and CK to represent content knowledge when coding. All transcripts, pre-lesson surveys, field observation notes, lesson plans, and journal entries were coded using the seven predetermined codes. However, other repeated ideas emerged that needed to be coded. New codes including personal experiences with mathematics, student teaching setting, planning for lessons, relationship with cooperating teacher, cooperating teacher, and future with mathematics and teaching were created and all the data was coded a second time with the new codes. After the coding process, tables were created for multifaceted codes in order to get a better understanding of the overall case. The tables created included a table highlighting the five lessons and planning times for each lesson, a table to show the overall content knowledge over the five observed lessons and a table to highlight the pedagogical content knowledge for each observed lesson. These tables can be found in the Appendix section (Appendix F - K). Finally, each case was written and organized into section based on the coding process. Figure 1 below highlights the process used to analyze each individual case study. 


\section{Data Analysis: Individual Case Study}

\begin{tabular}{|c|c|c|c|c|c|}
\hline $\begin{array}{l}\text { Multiple } \\
\text { Data } \\
\text { Sources }\end{array}$ & $\begin{array}{c}\text { Identified } \\
\text { Codes }\end{array}$ & & & $\begin{array}{l}\text { Created } \\
\text { Tables }\end{array}$ & $\begin{array}{c}\text { Wrote Case } \\
\text { Study }\end{array}$ \\
\hline $\begin{array}{l}\text { Reviewed } \\
\text { video of } \\
\text { lessons to } \\
\text { enrich } \\
\text { field notes } \\
\text { - Organized } \\
\text { data to } \\
\text { code }\end{array}$ & $\begin{array}{l}\text { - Based on } \\
\text { Theoretical } \\
\text { Perspective }\end{array}$ & $\begin{array}{l}\text { - Interviews } \\
\text { - Field Notes } \\
\text { - Student } \\
\text { Journals } \\
\text { - Documents }\end{array}$ & $\begin{array}{l}\text { Repeated } \\
\text { ideas } \\
\text { different } \\
\text { from } \\
\text { theoretical } \\
\text { perspective }\end{array}$ & $\begin{array}{l}\text { - Created only } \\
\text { for } \\
\text { multifaceted } \\
\text { codes }\end{array}$ & $\begin{array}{l}\text { - Personal } \\
\text { - Experiences } \\
\text { - } \text { Context } \\
\text { - Relationship } \\
\text { - Planning } \\
\text { - Math Anxiety } \\
\text { - Content Knowledge } \\
\text { - Pedagogical } \\
\text { - } \text { Content Knowledge } \\
\text { - Future }\end{array}$ \\
\hline
\end{tabular}

Figure 1. Data analysis process for individual case study analysis.

The next major step in the data analysis was to conduct a cross-case analysis. The cases were coded for similarities and differences using all codes, both the codes from the theoretical perspectives as well as the additional codes that emerged. The researcher then created tables that highlighted the content knowledge and pedagogical content knowledge of all cases. The researcher identified similarities and differences across participants with high mathematics anxiety and participants with low mathematics anxiety. The finding of this analysis were written up using five major headings: planning and resources used, the role of cooperating teachers, mathematics anxiety during student teaching, content knowledge, and pedagogical content knowledge. Figure 2 below shows the process for 
data-analysis across case studies.

\section{Data Analysis: Cross-Case Study}

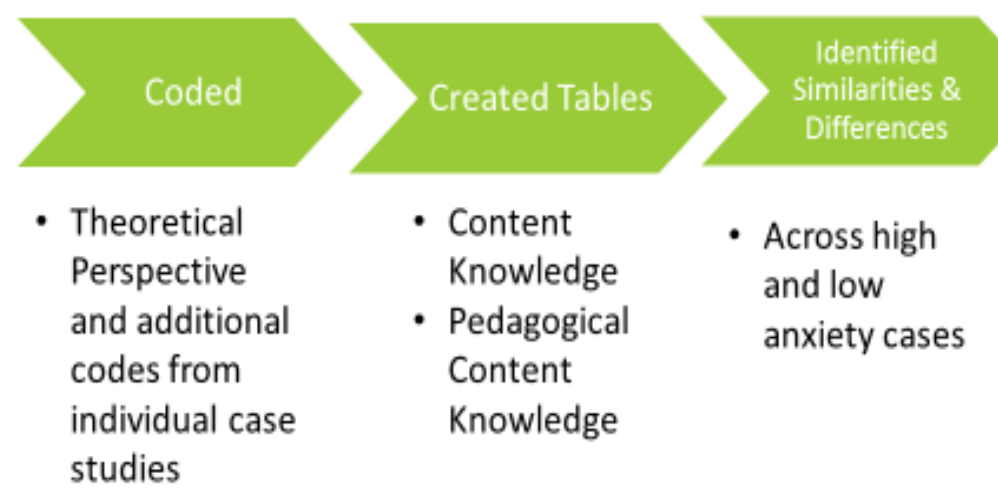

studies identified

Similarities \&

Difierences

Across high and low anxiety cases
Wrote Findings

- Planning and Resources Used

- The Role of Cooperating Teachers

- Mathematics Anxiety During Student Teaching

- Content Knowledge

- Pedagogical Content Knowledge

Figure 2. Data analysis process for cross-case study analysis.

\section{Integrity Measures}

Guba (1981) suggests addressing trustworthiness of a qualitative research by addressing credibility, transferability, dependability, and conformability. The following section will describe how trustworthiness was addressed in this present study.

\section{Credibility}

To address credibility Guba (1981) suggests prolonged engagement at a research site. The researcher spent several hours in the classrooms of the participants throughout the student teaching semester to ensure that she was not a threat. The researcher conducted five observations and kept a research journal during the visits to the research site. Collection of referential adequacy materials are also recommended (Guba, 1981). The researcher of this present study videotaped the lessons of students and assessed them later to flesh out the field observation notes. Finally, to help establish credibility, 
member checking was done during the study on raw data. The participants were asked to read and validated the transcripts of their interviews to determine whether the written words were the words that they intended to say. The participants were given copies of the transcripts of audio recordings of the interviews and video recordings of their lessons. No participant gave any suggestions for change to any of the transcriptions.

To ensure the honesty of participants, they were reminded that they did not have to participate in the study, they were reminded of confidentiality, and they were reminded that they could refuse to answer any question that was asked. The researcher also developed a rapport and trust with the participants. This helped to ensure that participants gave honest answers.

Finally, peer review was conducted to address credibility. Conducting peer review encompasses consulting with colleagues about the methodology and the analysis of the data. This helps to ensure that the findings emerging out of the analysis are consistent (Merriam, 2002b). The members on the dissertation committee were asked to review the methodology, data collection, and data analysis procedures. Also, a fellow mathematics education doctoral candidate conducting a dissertation on a similar theoretical framework was asked to code a random sample of the transcripts and field notes to see if the analysis they produced was comparable to the analysis conducted by the researcher. The samples of transcripts and field notes were coded similarly with about $75 \%$ of the coding matching both the researcher and the doctoral candidate.

\section{Transferability}

To address transferability, the researcher of this study selected participants with high mathematics anxiety and low mathematics anxiety based on the scores of the 
AMAS. The final participants were representative of EPTs with high and low mathematics anxiety from the original sample. Guba (1981) suggests that during the study the researcher collect thick descriptive data, and after the study, the researcher create thick descriptions. The researcher is this present study collected thick descriptive data and then created a thick description in the cases that were written.

\section{Dependability}

To address dependability in a qualitative study, Guba (1981) suggests the use of overlap methods as a form of triangulation. In triangulation, the researcher uses multiple data sources to provide collaborative evidence (Creswell, 2007; Merriam, 2002b). Evidence of several data sources including the interviews, lesson observations, artifacts, documents and research journal collected were analyzed to develop case studies with rich descriptions of the experiences of EPTs with high and low levels of mathematics anxiety. Across cases, comparison tables were created of themes that emerged for each case and those tables along with the case studies, and original data were used during data analysis.

An audit trail was also conducted to address dependability. The researcher kept a research journal that outlined the decision process at all steps of data collection and analysis which helped in the justification of all decisions. This research journal also included researcher notes taken throughout all steps of the research process. It included notes on communications with the participants and their student teaching cooperating teachers beyond the videotaped post-lesson interviews. This journal provided a resource for the researcher when discussing the findings. 


\section{Conformability}

To address conformability, Guba (1981) advocates the practice of reflexivity. The researcher kept a research journal during the collection of data and during data analysis to keep track of her beliefs and assumptions in order for the researcher to remain as objective as possible.

\section{Ethical Issues}

An ethical issue associated with this study included maintaining confidentiality. To maintain confidentiality, pseudonyms were used for all participants. The researcher choose pseudonyms that were used throughout the study. The participants' real names were kept confidential. All the observations and copies of documents were kept in a secure cabinet in the researcher's home. Two copies of all digital recordings and transcripts were stored on two separate password protected hard drives in the secure cabinet of the researcher's home. All data will be kept for 5 years following data collection after which all data will be destroyed.

\section{Pilot Study}

A pilot study was conducted the semester before the actual study to determine if EPTs had different levels of mathematics anxiety. During the pilot study, the researcher gained permission from the Office of Field Experiences and attended the student teaching orientation. The researcher explained the study, gained permission from the EPTs and administered the AMAS to a population of EPTs similar to that of this investigation. The researcher then analyzed and scored the AMAS and found that there were indeed vast differences in the levels of mathematics anxiety of EPTs before student teaching. The researcher then contacted two EPTs, one with high mathematics anxiety and one with low 
mathematics anxiety and asked them to participate in an interview. The researcher piloted the initial student teaching interview with the participants. After analysis of the interview, the researcher concluded that the interview questions produced worthwhile discussion of experiences with mathematics content and mathematics anxiety. The questions used in the pilot study were then used in this study. The data collected from the pilot study was not used in this investigation.

\section{Chapter Summary}

This chapter presented a multiple case study as the research method of choice for this study. Also presented in this chapter was the researcher's role which included a brief autobiography of the researcher. The sampling strategy and data collection methods were detailed and the data management and method of analysis were explained. Quality measures along with ethical issues were discussed. 


\section{CHAPTER IV}

\section{FINDINGS: CASES OF HIGH MATHEMATICS ANXIETY}

\section{Introduction}

This chapter presents the cases of the three participants with high mathematics anxiety of this multiple case study. The case of Nancy is presented first because her case is most representative of a student with high mathematics anxiety. Next, the case of Ally is presented followed by Belinda's case. Ally's case is unique in that Ally ended up having less mathematics anxiety than her cooperating teacher. Belinda's case is most unique, and after her student teaching experience she now would prefer to teach mathematics although she has high mathematics anxiety. Each case follows the same format. They all begin with an introduction, followed by a section describing the participants' student teaching placement, a section describing the participants' mathematics anxiety during student teaching, a section highlighting content knowledge of the participant, a section discussing the pedagogical content knowledge of the participant, and finally a section discussing the ideas of the participants' future with mathematics and teaching.

All cases are set during the spring semester of the school year where students encounter standardized testing. Ally's students who were in third grade were preparing to take the State Comprehensive Assessment Test (SCAT) which is a standardized test given to all students in the state who are in a given grade level. Belinda's students who were in second grade were preparing to take the Stanford Achievement Test (SAT), a standardized test administered by school districts across the United States. These 
standardized test caused some pressure on cooperating teachers, EPTs during student teaching, and students in the preparation process.

\section{The Case of Nancy: High Mathematics Anxiety-Moderate Content-Weak Pedagogy}

Nancy is a Hispanic female from a southeastern state. She completed her student teaching experience as a university senior at a large, southern, urban university. She described mathematics anxiety as "how badly somebody gets nervous when conveying mathematical problems or explaining problems to other people." Nancy explained during her first interview that her biggest anxiety comes when having to explain anything in mathematics to other people. Her score on the AMAS supported that she has high mathematics anxiety. When Nancy was asked how she felt about the AMAS she replied, "I felt a little embarrassed to admit that I do get anxious with math." Based on classrooms observations and interviews, Nancy's content knowledge was limited. With respect to pedagogical content knowledge, Nancy showed some weakness.

Nancy's overall GPA was 3.52 prior to completing her student teaching. Her mathematics content GPA was 2.00, which is based on three mathematics courses. These courses included Intermediate Algebra, Statistical Methods, and Mathematics for Liberal Arts I. Nancy's pedagogical content knowledge GPA was 3.33, which is based on one mathematics course. This course was Teaching Elementary Mathematics Methods.

\section{Nancy’s Personal Experiences with Mathematics}

Nancy indicated that she has always had trouble with mathematics; she commented that mathematics has always caused her problems, "I really have always had a problem with math; I've never been a fan [of mathematics]. From very young, very young, it was always a problem." She did not feel as anxious when she had to solve 
mathematics problems alone, but her anxiety was greatly manifested when she had to convey her solutions to others. Nancy also explained that she sometimes "run blank" on mathematics tests even if she felt that she was prepared for it. Nancy did not think that her family really influenced her thoughts about mathematics anxiety. Her little sister had an opposite experience with mathematics.

My sister is very good at math. When I see her, I mean it's just incredible, you know? Because it never comes that easy to me, so I guess her in a positive way, it's like people can actually be not so scared like how I am about math.

Her little sister would actually help her with mathematics at times. On the other hand, Nancy described her mother as being scared of mathematics and she said that her mom was not fond of the subject.

Nancy described her first negative experience with mathematics in fourth grade when she encountered the concept of fractions and said that she has always had trouble with that content area. She even remembers the teacher who she recently encountered and the first thing that fourth grade teacher asked her was, "Hey Nancy, how is the math going?" She was shocked that even the teacher remembered her struggles after several years had passed. Nancy regarded her fourth grade teacher as her worst mathematics teacher. When Nancy was asked to describe her fourth grade teacher she explained, "She didn't have patience. No patience. She'd bang on that board, "Nancy, do you get it!" and I would be like, "No I don't." I mean I loved her, but it was just...for math, she didn't have the patience." Nancy explained that this particular teacher focused on lecturing, having students practice, and then giving tests to assess students. When asked what she disliked most about this fourth grade teacher, Nancy explained, "I'd say the lack of patience. Especially early on, you should be patient with students I'd say. I mean I don't 
remember her telling me, "You're struggling, but you'll do fine, come after school." No, no." Nancy added that this teacher never had students work in groups or use manipulatives. She described her experience of classroom instruction in mathematics as "a lot of demonstrating". In general she does not remember mathematics being taught to her using a "hands-on" approach, and she expressed that she thought this approach might have helped her to better understand the content. Nancy remembered that she never voluntarily participated in mathematics class; she would never raise her hand. The few times that she had to participate was when she was asked an answer and she would have no answer; she remembered this to be very embarrassing, even though the teacher would try to explain it again she would usually not understand.

Nancy did have one positive experience with mathematics in high school with Advanced Topics during her sophomore year. She liked the teacher and described her as being patient.

I guess she's one of the teachers that encouraged me to become a teacher because she was very devoted to what she did. And me not being able to produce the way that she expected for me to do was a little bit I guess, sad on my part, like I felt sad, "Gosh, I'm not showing her what I'm capable of and I wish I was." So for sure, she was my junior teacher, in high school. She was very all over the place. If students didn't understand, she'd go back. If it meant to stick on the same problem for an hour, she would stick with the same problem until everyone got the problem. She was very patient.

Nancy explained further that this teacher created an atmosphere where she wasn't afraid to raise her hand in class to ask for help. She felt too embarrassed to ask for help with other mathematics teachers. 
Nancy's mathematics methods course required for her education major at the university provided her with some positive experiences. Specifically, she explained that the course helped her understand fractions,

I mean some of the things I did understand like the fractions and how you were able to give like a rough estimate of how, if it was a little bit more than half, or less than half, I mean I guess that was a good experience.

However, she struggled in other mathematics courses required at the university level.

\section{Context of the Student Teaching Placement}

Nancy's student teaching placement assignment was in a Kindergarten, selfcontained classroom of 20 students with a balanced number of boys and girls. This class did have a special needs student, but he was a part of the regular mathematics class. Nancy thinks that her most valuable quality as a teacher this semester is that she is patient, the quality she described was lacking in her worst mathematics teacher. "I'm the most patient: if somebody has a problem, ok, let's go back, do it again, do we get it now. I think I'd say I'm the most understanding, the most patient." She believes that a good foundation in mathematics is the most important for students, and she said she would be willing to take extra time to help students if necessary.

She described her ideas about teaching mathematics at the beginning of the student teaching semester,

I've seen that manipulatives, using manipulatives a lot helps because not every student will understand by just looking at a problem on the board or in listening to the teacher explain. You know, they have to have all types of, many types of ways to explain an aspect about math. I think I'll use a lot of manipulatives in my class. I will trigger all of their learning styles, and communicate with the kids, yes.

She also mentioned that she would use manipulatives during her student teaching, 
I've seen that manipulatives, using manipulatives a lot helps because not every student will understand by just looking at a problem on the board or in listening to the teacher explain. You know, they have to have all types of, many types of ways to explain an aspect about math. I think I'll use a lot of manipulatives in my class.

Nancy explained that she was not struggling with the content of her Kindergarten, "I'm not struggling that much because I'm not working with fractions because that's really what I've always feared. So teaching kinder isn't that bad, it's not so I have been looking, I've been very happy teaching it [Kindergarten]." Nancy did not believe that she would experience much mathematics anxiety with the Kindergarten curriculum.

However, when Nancy was asked about teaching mathematics to an upper level elementary class, she exclaimed,

I think I would cry! I think I'd cry. Oh my gosh, because it's that bad! I think my evenings will be reviewing a lot of the things we'll be doing the day before. I mean obviously it's something that you need to do but I'll be doing it a lot more.

Nancy did not think she would be able to overcome her mathematics anxiety, "I mean I think math anxiety is something that unfortunately I won't be able to overcome." When asked what might have helped her overcome her mathematics anxiety, Nancy could not think of anything, "I mean like I said like with me, it goes back to elementary school, and you get me? It's not something that just happened fairly recent so I wouldn't know." She expressed that she wanted to help her students with mathematics anxiety at an early stage by fostering good communication with them,

I think the best way of helping my students would be to develop that communication. You know, giving them the image or making them feel that around me, they can ask, they can be themselves, they can ask questions; they don't need to be embarrassed, they're not going to feel...I guess it's not the correct word but I guess dumb, by asking questions. Which is a fear that everyone has, even in university level. 
Overall, Nancy did experience some mathematics anxiety during student teaching, but she indicated that teaching mathematics to Kindergarten as opposed to a higher grade level was fairly easy. At the end of the student teaching semester she expressed the following:

This semester it was very easy. I wasn't as anxious because of the level of difficulty I would say since I was teaching a Kindergarten class it wasn't as bad so the flow of each lesson was always consistent. I had little to no interruptions unless we were using manipulatives where it can get a little out of hand with the little ones.

However, Nancy still maintained that the harder the mathematics content, the more anxious she would have become. She reiterated, "I would've died in a fourth or fifth grade classroom." She explained at the end of student teaching that if she ever had to teach in a higher grade level that she would need to practice the content,

I will have to give it my all; practice everything that I know. Probably look into my lessons a lot more, so that I'm actually prepared for whatever question my students may ask; whether it be, I don't know, something about fractions-- which is something that I completely am scared of-- or, I don't know, something really basic. But whatever I do, whatever I plan, I want to make sure that I've looked through it enough so I'm prepared. I would definitely take longer to plan.

By the end of her student teaching experience Nancy stated that her mathematics anxiety decreased for the following reasons, "I got the experience on how to convey a lesson in math; and because I've learned from my mistakes and from the tips that I've gotten from my cooperating teacher." Nancy still wants to be a teacher,

Oh my God I love it. I don't think-- I think I'm so blessed; because I don't think many people have that, that they truly enjoy and love what they do, their job. And I feel that I do; like I'm love with what I do.

Nancy maintained throughout the experience that she would prefer to teach any other subject over mathematics. 


\section{Nancy's Relationship with her Cooperating Teacher (CT)}

Nancy conveyed that she and her cooperating teacher had good communication. In the beginning of the semester, Nancy observed her cooperating teacher as she carried out lessons. Nancy never feared asking her cooperating teacher for help. In fact, Nancy relied on her cooperating teacher to help her plan every lesson. In general, Nancy's cooperating teacher offered suggestions which Nancy found helpful. Nancy even indicated that she would sometimes ask her cooperating teacher for help during a lesson.

For the fourth observed lesson, Nancy used songs to help the students skip count; these songs were first introduced by the cooperating teacher. Nancy mentioned that her cooperating teacher liked to incorporate other subject areas into mathematics as well. For her last two observed lessons, Nancy relied exclusively on her cooperating teacher's suggestions on how to teach the lessons. For observed lesson four she explained,

No, I didn't use the book since I wasn't familiar with it, so I only spoke with her $[\mathrm{CT}]$ and, you know, she gave me pointers on what to do and, one of her suggestions was to go ahead and actually use manipulatives, which is what I used and then we talked about only using two colors, to prevent any misunderstanding.

After Nancy's fifth observed lesson she said, "I made suggestions, and she went ahead of course you know, and let me know if I was wrong or maybe what I should fix or what I should keep." Nancy mentioned in her final interview that her cooperating teacher was always there for her and because of that she didn't feel the need to seek additional resources to help her plan. She relied on her cooperating teacher's suggestions, which she stated helped her the most during student teaching. Nancy reflected on a valuable lesson that her cooperating teacher taught her which was to incorporate writing in 
mathematics by creating an important sentence from what was learned to have the students copy from the board to make it more challenging:

My cooperating teacher taught me; which was try to incorporate writing in math, where the kids would have to through discussions explain: Oh okay what does a solid shape have, what does a 3D shape have, or is it heavy? And then through the discussions get-- like they got an important sentence from it; and then just write it on the board. I guess since going-- like it boils down to if it's really basic let's try to take it up a notch let's say.

Although Nancy found her cooperating teacher helpful, and she was always nice, we did not have any conversations about teaching in general, or even more specifically Nancy. She was always busy when I observed.

\section{Planning for Teaching Lessons}

Nancy did not take a lot of time to plan mathematics lessons during her student teaching semester. When asked how long she took to plan for the five lessons that were observed her responses ranged from 20 minutes to 30 minutes. She explained that she usually planned the day before by looking at the textbook and speaking to her cooperating teacher. After her first observed lesson, Nancy described her planning, "I felt prepared. Yesterday I made sure to look through the teacher edition and through the questions, the engage questions, to more or less you know be a little more prepared than I should have as opposed to not looking at the book at all." When asked if she planned for different examples that she used with the students, Nancy indicated that she usually improvised and created examples as needed during the lesson. When I asked her how she planned using the lessons in the text book she explained, "I just looked through it, I didn't practice." 
Nancy used mainly two resources to help her plan for the lessons during her student teaching semester which included the Teacher's Edition of the textbook and the advice from her cooperating teacher. In her fourth and fifth observed lesson Nancy only relied on the advice of her cooperating teacher for planning. She didn't use any additional resources to help her plan her lessons. She did not find additional tasks or activities during planning to help her teach lessons.

\section{Nancy's Mathematics Anxiety throughout the Semester}

Nancy was aware of her mathematics anxiety and knew that she showed signs of

it. She described those signs as follows:

How do I show it...I mean, when I'm with the kids, I think I show it by I don't know, I'd say just moving around or would tell them, "give me a second" and shift through papers seeing if somehow I get what I'm doing, or just working the problem. I don't think I know exactly when I can say, "oh my gosh, you're nervous." I just know that it happens. I feel my face get warm when I'm in front of the kids, like oh god, I'm probably blushing cause I don't get it.

Nancy did blush at times during some of the lessons observed. When she was aware of it, she tried to calm herself down by taking the time needed to figure out the problem and by saying to herself, "You know what, ok, you got it. You could explain to the kids how you can do it." Nancy showed anxiety during her teaching and reported to being anxious before her last two observed lessons during the semester.

Before her lessons, in the pre-lesson surveys, Nancy indicated that she was comfortable with the content of her lessons rating her comfort at a $5 / 5$ on all lessons except her fourth lesson where she indicated a rating of a $4 / 5$ with a 5 indicating that she was very comfortable and a 1 indicating that she was not comfortable. She also felt very comfortable with teaching the lessons she had planned indicating the same results of a 
rating of 5/5 on all lessons except her fourth lessons where she indicated a rating of a $4 / 5$. When asked about her feelings getting ready to teach the lessons in the pre-lesson surveys, Nancy described confidence in the first two lessons using phrases such as, "I feel prepared to convey the lesson" and "I feel excited to teach the students". However, she indicated that she felt nervous for all subsequent lessons.

Nancy felt confident about the first observed lesson because she felt that the content was easy since she only had to discuss morning and afternoon. She indicated that she would be very anxious if the content was more challenging,

I think it would make me a little more anxious to begin to explain to them if I ever do touch upon it, the different increments in the time, how long a 5 minute is as opposed to a 20 minute [increment]. I think there I would be a little bit more anxious to explain to them.

That lesson lasted a total of 20 minutes; she was speaking fast, and did not allow the students to have any discussions.

The second observed lesson covered the topic of more time and less time. Nancy felt comfortable with the content and excited to teach the lesson before it began. During the lesson Nancy spoke quickly and again she was not willing to have discussions with the students. She stopped them from expressing their ideas at times. When she was interviewed after the lesson, Nancy indicated that she was comfortable with the content of the lesson, but was unsure of how she would convey the lesson,

I was comfortable with the overall objective of the lesson, but I wasn't so comfortable as to how I was going to convey that to them, so that they were able to understand as in like giving them examples that were easy enough for them to understand and easy enough for them to actually go ahead and give me examples of their own. 
She contradicted herself by also mentioning that she was really comfortable with the examples since those were her own examples. She did not prepare them ahead of time, but instead improvised in creating the examples for the lesson.

For her third observed lesson, Nancy continued the topic of more time and less time so she felt comfortable before the lesson. During the lesson, she showed anxiety when a student took longer to do a task than was expected. It was obvious that she was anxious and did not know what to do. She nervously laughed and tried to explain why the outcome was different than she had expected. She describes being most anxious during the lesson at this time:

I didn't know how we are going to react or, actually one of the things that happened is, I had one of the little girls write her name, the other one tie her shoes and, the little girl tying her shoes was able to finish quickly than the little girl writing her name. I didn't expect that. I was a little nervous. I would've wanted to like do it in a different way but it just happened. I told the little girl who tied her shoes that, maybe she was racing or, maybe she was just trying to do it a little quicker than usual since we were trying to compare what would take longer and what would take less time.

Nancy' face was also flushed after this happened.

Nancy reported being anxious before the fourth observed lesson. She was nervous about whether the students would have enough examples to understand the topic. During the lesson she blushed when she discussed some of the examples with the students, and they made errors in their responses. After the lesson, Nancy reported being anxious about using the new practice book since it was different from the text that she was used to. She was also anxious during the lesson when she had to explain using the number line,

Because the kids weren't getting how to use the number line so they wouldn't understand that in order to ask about what number comes before one, that they 
had to move to the left side of the number line and then, if they wanted to know what comes after one, they had to move to the right so, I guess I was like a little bit nervous about explaining that to them but eventually, some would have gotten it, although I didn't hear all of them respond.

Nancy moved through the examples quickly and stuttered when asking some of the questions.

Before the last observed lesson, Nancy reported feeling very nervous about teaching this lesson. During the lesson, Nancy began to speak really fast when the students were having trouble with some examples; her face turned red, and she giggled nervously. When she was asked about these feelings in the interview after the lesson, she explained, "I was a little nervous. Not because of the concept, but more because I was a little scared of how the kids would work in groups." Nancy had never tried to have the students work in groups for mathematics before. Nancy reiterated that she was not anxious about the content during her lessons because it was easy, but she was more anxious about conveying the content to the students.

\section{Nancy's Content Knowledge}

Nancy stated the importance of mathematics, "math revolves everything, I mean from budgeting yourself when you're going to do your groceries or little things in my situation, whenever I grade papers and average out grades and things like that." She indicated that it is vital that she teach mathematics to her students, but she is anxious about the content. She believes that she has mathematics anxiety because she had a weak background in the subject,

I didn't have a concrete beginning, like in terms of my elementary school years, I'd say that's a big part as to why I feel like that. I think you need to have like a very strong, I guess you could say background or step in math and then eventually work your way up. That's how I see it. 
With this being said, it was observed that Nancy experienced multiple challenges in her teaching of the content to the kindergarten class. At times her presentation of the content could create possible misconceptions for her students. Examples of these observations will be presented.

During the teaching of the first observed lesson, Nancy introduced students to the concept of times of the day, which included morning and afternoon, as well as before and after events. To begin the new topic Nancy told the students, "Today we are going to learn about before and after. Who can tell me an example of something we do before and something we do immediately after?" She did not use any point of reference to explain what these two words meant. She immediately asked for an example without any type of discussion about the new topic being introduced. One student was able to provide her with an example of completing their journal before and then going to lunch after. She replied, "Good." Nancy did not provide a point of reference to explain the context of 'before' and 'after'. In order for something to occur before there already needs to be something occurring. Similarly, for 'after' to be explained it needs to be referenced to an occurrence that already in the past. Nancy did not discuss this; instead she agreed and then went on to the picture examples in the text. This showed her lack of understanding the need for a point of reference when explaining 'before' and 'after'.

Later in the lesson, Nancy discussed events that occur in the morning and afternoon. Some of the examples that were discussed could have happened at either time of day which indicated her lack of understanding with respect to the content she was teaching. An example of this occurred when one student said that they go to the park in 
the afternoon. While it is possible for them to go to the park in the afternoon during school days, there is also a possibility of going to the park during the morning on weekends. This second possibility was never discussed, and Nancy even used that example as a final sentence for them to write in their books, "In the afternoon, we go to the park." This further demonstrates her lack of understanding with respect to the content she was teaching.

The second observed lesson dealt with the topic of 'more' and 'less' time. Nancy introduced the lesson by saying, "Today we will talk about things that take more time and things that take less time." Similar to the first lesson, Nancy did not provide any context about more and less needing a point of reference. She began with asking which would take 'more' or 'less' time, driving to school or brushing your teeth. One student answered that driving to school would take more time and brushing your teeth would take less time, but it was not clear if the two events were being compared to each other. Next, she divided the class and told them that they should pretend one half of the class was reading a book and the other was writing their name. She asked which activity would take more time, and one student answered reading a book would take more time. She immediately asked what would take less time than reading a book and another student answered writing her name. She said 'yes' then asked for any other example of something that would take less time than reading a book and one student answered coloring a book. She told them to think about that example and said that "Coloring a book would take more or less the same time as reading a book." There was no further discussion; she moved on to the examples given in the text. At the end of the lesson she asked the students to provide her with an example of something that would take more 
time and one student answered, "Driving to Georgia will take more time." She wrote this on the board to have them copy it. She then asked for an example of something that would take less time, and one student said, "Walking to my back yard will take less time." Again she wrote this on the board to have the students copy. There are no points of reference in the sentences. This demonstrated Nancy's limited understanding of the differences between explaining the concept of 'more' or 'less' time.

In the third observed lesson Nancy continued the topic of 'more time' or 'less time'. She tried a new approach of having students act out scenarios for them to determine which scenario would actually take more time and which would take less time. Nancy divided the class in two and had one half write their name and the other half find a specific page in their textbook. After they were finished she switched the activities for the students. Both times the students concluded that writing their name would take longer than finding a specific page. The next scenario did not go as Nancy planned. She asked two students to come to the front of the classroom and had one student tie her shoe and another student write her name. The two students finished at the same time and Nancy giggled nervously. She asked the girl who tied her shoe if she was racing, or if she was doing it a little more quickly than normal. She told the class that was not supposed to happen; she said, "In reality it would take longer to tie your shoe. Do you get what I am saying?" Nancy did not discuss the reason the students finished at the same time; and even though it did occur she told them that it was wrong. This showed a lack of full understanding of the content.

After that occurred, Nancy stopped acting out scenarios with the class and instead continued to go over the examples in the textbook. The students were arguing about one 
of the examples; there were two pictures, one picture showed a girl sweeping the floor, and the other picture showed a girl washing dishes. One student argued that washing dishes would take less time. Nancy told them that this was hard, and they needed to think about it. She explained the girl would only need to sweep the kitchen floor, and not the whole house, but it would take longer to wash all the dishes well. She told them to put an $\mathrm{X}$ next to sweeping the floor because it would take 'less time'. It was clear that the students needed more discussion of the scenarios presented for them to agree, but Nancy did not have any real discussions. After the lesson, Nancy reported that she wanted the students to act out more of the examples from the textbook, but she did not have the resources necessary to have the students act them out.

During her fourth observed lesson, Nancy used a number line to show the students the numbers that came before and after a specific number. She asked the students to look at the number line and tell her what number comes before the number 3 , the students answered chorally and some said "2", but a majority said "4". She did not address this she only said " 2 ", and asked the students to write the number 2 in their books. She moved away from the number line and asked the students what number comes before the number 4 and some said " 3 ", but the majority shouted " 5 ". She walked back to the number line and said, "Guys, when something happens before you move to the left." Nancy went on to explain that when asked for a number that comes after you move to the right, but most of the students still shouted out wrong answers. She moved away from the number line and continued to ask for numbers that came before and after other numbers. She asked for three more examples of that idea. Some students were 
answering correctly, but others were obviously guessing. Nancy did not clarify the students' understanding and did not explain the content using any other method.

Nancy wanted students to master skip counting by $2 \mathrm{~s}, 5 \mathrm{~s}$ and $10 \mathrm{~s}$ for her last observed lesson. Nancy showed strong knowledge of the content and could clearly skip count. However, Nancy used Unifix cubes to have students make groups of $2 \mathrm{~s}, 5 \mathrm{~s}$, and $10 \mathrm{~s}$, and then had the students work in groups to count the cubes. The students were able to create the cubes and they were able to skip count; however, some of the students were unable to see the value in skip counting when she asked them, "Why do we skip count?" Nancy chose to skip the counting by ones section, and she did not allow students to compare counting by ones to skip counting. This may have helped students to see why skip counting is faster than counting by ones.

\section{Nancy's Pedagogical Content Knowledge}

This section presents examples describing Nancy's actions and ideas pertaining to Graeber's (1999) five big ideas on pedagogical content knowledge that preservice teachers should possess. With respect to Graeber's big ideas, Nancy somewhat demonstrated the ability to assess students' understanding. She demonstrated some ability to implement lessons that provided alternative representations of concepts. However, Nancy did not demonstrate the ability to implement lessons that provide opportunities for students to demonstrate both conceptual and procedural knowledge, nor did she create lessons that considered students' intuitive understanding of concepts. Nancy was also lacking in the ability to implement lessons that promoted student retention of ideas. Overall, Nancy showed some evidence of pedagogical content knowledge. This section will outline examples describing Nancy's actions and ideas 
pertaining to Graeber's (1999) five big ideas on pedagogical content knowledge that preservice teachers should possess.

Understanding Students' Understanding is Important. According to Graeber (1999), assessment of student understanding and reasoning is crucial. Nancy knew this was important and showed some evidence of analyzing student understanding. Nancy measured the success of her lessons by analyzing the students' understanding of the concept. She said, "I saw what the kids did, their response to whatever I asked, so I based it [success] on the fact that most of them were cooperating and were giving me their input." Nancy explained how she checked for understanding during lessons, "I would definitely look in there and obviously I would see if they actually did understand. I looked around to make sure they were actually doing the work and that they were doing it correctly of course if time permits I would actually go ahead and look at their books." While this may have been a way to check for understanding, it might have been misleading because during the observed lessons Nancy usually completed the activities in the textbook with the students and she told them what to circle or write.

During her second observed lesson, Nancy stated, "The kids were able to give me feedback to let me know that they actually did understand what I taught." She contradicted herself by immediately saying, “I felt a little nervous because I wasn't sure if they were quite understanding what I meant as in what would take more time or less time. So I guess I was a little nervous in that sense, but overall, it was... I think it went well." She was teaching the topic of more time and less time and she explained that because it was a vague topic she did not know if the students were going to understand it. However, she did feel that the students understood the concept because of their feedback, 
"They were able to understand it (loud nervous laugh). They were able to get it you know. Based on their feedback, I would think I wouldn't need to reteach them the lesson." She described the feedback as their verbal responses, and everything they wrote in their books. Nancy allowed choral answering to her questions in this lesson as well as in other lessons. She did ask individual students to answer questions, but when students answered incorrectly she did not explain why the answer was incorrect, nor did she have discussions; Nancy continued asking different students for the answer until the correct answer was given.

During the observed lessons, Nancy asked students to give examples to illustrate the concept, but when students made errors, she did not have a class discussion, but instead told students that she would come back to them, or ask another student for an example until a student gave an acceptable answer to illustrate the content. For the fourth observed lesson Nancy asked students for examples of things that were equal, and the students were able to tell her. However, when she used the number line, the students did not seem to understand the concept and Nancy had trouble explaining how to use it since it was the first time she had ever used the number line. Nancy was aware that some students did not understand, but she did not explain the concept in a new way to help them understand it. Nancy explained that she did not know how to help them understand the number line, and when she was asked what she could have done differently she explained that she could have found worksheets with individual number lines or the students to look at. The number line was located on the top of a white board on one side of the classroom and she explained that she was not sure if all the students were looking at her as she was pointing to it. 
In the same lesson, Nancy used Unifix cubes to help students understand the idea of equal parts. She explained that she checked for student understanding by observing how the students manipulated the Unifix cubes,

When the students were giving me their examples and, when I was seeing them work with the little connecting cubes, they were able, when they weren't sure they had the correct amount on both sides, I saw they were able, they counted each of the cubes, so I understood that, ok, they grasped the concept if you have the equal amount on both sides, you need to have the same amount.

Nancy did not have students explain their thinking to check for their understanding.

Nancy never called student up to the front of the class to explain their ideas, and she allowed choral answering as a means for checking for understanding. At times she also accepted the correct answer of one student as an indication that the whole class understood the concept or would be able to answer the question. In the last observed lesson, Nancy asked if the students noticed patterns on a hundred chart when counting by $5 \mathrm{~s}$ or $10 \mathrm{~s}$. When I asked her if the students were able to discover the patterns, she replied, "Yeah. One of them was able to tell me. She said that the numbers 5 were 0 for counting by $5 \mathrm{~s}$." She did not ask for patterns when counting by 10 s or $2 \mathrm{~s}$ because she said "Cause I didn't want to make it too complicated." She accepted the one answer given by one student as an indication that all of them noticed that pattern.

Nancy did not allow students to work independently during any of the lessons observed, all the work was done together, and she prompted them on the correct answers they were to fill in their workbooks. The work that was done would not indicate a true assessment of their understanding.

\section{Students Knowing in One Way Do Not Necessarily Know in the Other(s).}

Evidence of conceptual understanding was scarce in both the observations and interviews 
conducted with Nancy; however, Nancy did have procedural understanding. During the observed lesson interviews Nancy alluded to the possibility of having the students explore their ideas, but her lessons were all teacher-led and she conducted the assessment from the textbook together with the students. During her first lesson, Nancy directed questions to the students to answer what would come before or what would come after. She asked students for examples from their lives, but she did not allow students to discover anything on their own. All her questions dealt with having students identify before and after events as opposed to having students draw or sort pictures to make sense of the content. She did not give students an opportunity to consider the idea of before and after before going into the examples of the books. Students were not allowed to construct their own learning. She did not promote discussions that allow students to discover their ideas. She stopped any discussions after she acquired the answer that she was looking for. Additionally, Nancy did not provide counter examples for students to consider. When asked about changes she could possibly make to improve the lesson, Nancy commented that she could create another assignment for the students that would allow them to draw, "Instead of telling me 'I do this in the morning', probably having them draw a picture and write a sentence with it."

Nancy covered the topic of more time and less time in the second observed lesson. For this lesson, Nancy gave the students an example that was not in the text to have them think about the answer. She asked students to pretend that one side of the class was reading a book and the other side of the class was writing their name, and asked the students which side would take longer to complete their task. She did not have the students discover this idea, but instead they only imagined what was happening. She 
could have created the scenario for the students to act out so that they could visualize the content. At the end she wrote sentences on the board to illustrate what takes more time and what takes less time; however, she could have had the students create their own sentences even though they may not know how to spell all the words properly. They could begin to develop their own ideas. Nancy relied on the textbook as well to give the students examples to discuss; she did not have the students create their own examples of things that would take more time and things that would take less time.

Nancy did have students act out some scenarios for things that take more time and things that take less time in the third observed lesson which was a continuation of the second observed lesson. However, some of those scenarios did not turn out the way she planned, for example the little girl who tied her shoe took less time than the little girl who wrote her name. Nancy did not have the students discuss the reasons why one was slower than expected; instead, she tried to explain to them that it was just not supposed to happen that way. During the observed lesson interview, Nancy discussed that she would have liked the students to act out more of the examples in the textbook, but she did not have the resources to do so. Nancy went over the examples with the students; she did not allow them to do any on their own or have discussions when the students disagreed with her answers. Again, Nancy did not have the students discover the content.

Nancy allowed the students to use Unifix cubes for the fourth observed lesson, and she gave the students the freedom to show equal parts using the cubes. The students were able to give her multiple examples that show equal numbers of cubes. Nancy explained in her observed lesson interview that upon reflection she would have used a scale to help the students understand the content of more or less and equal; she thought 
that the scale might have helped those who did not understand. After the Unifix cube activity, Nancy immediately started to work on the examples from the textbook along with the students. After agreeing as a class what the answers would be, the students wrote the answers in their textbook. For the last part of the lesson, Nancy used the number line and pointed to numbers that came before and after, but the students were not allowed to manipulate any number lines or to discover the amounts. Her explanation of this idea caused some confusion for the students.

In the final observed lesson, Nancy used the Unifix cubes to help students understand skip counting. She showed the students how to connect the cubes to form a group of two and then then had them count by twos to get the total amount. In groups Nancy asked the students to make groups of fives first, and then groups of tens and then had them skip count by fives and tens. She never allowed them to count by ones and then skip count to discover the benefit of skip counting. She even skipped the activity in the text that had the student count by ones.

Overall, Nancy never assessed student knowledge to see if they had conceptual understanding. Her assessments only indicated that the students were able to follow along and complete the lessons exactly the way she told. She never allowed the students to work on their own in order to check their understanding.

Intuitive Understanding is Both an Asset and a Liability. Nancy showed weakness in assessing students' preconceptions and misconceptions. During the observed lessons, Nancy did not examine students' previous knowledge nor did she discuss possible misconceptions. For every observed lesson, Nancy relied on the examples provided by the textbook to help students understand the content; the textbook 
used pictures to help students visualize the content. At times it was observed that the pictures provided could have been interpreted differently. Nancy did not discuss the pictures in details to help the students understand the scenario. For the most part, when a student misinterpreted a picture, she simply corrected the student and moved on.

Generally, she did not allow the students to discuss the examples in detail.

An example of a possible misconception created for the students occurred in the first observed lesson. To end the lesson, Nancy asked students to write a sentence about going to the park in the afternoon. This signaled an example of things that students do in the afternoon, and may lead the students to believe that they could only go to the park in the afternoon, or whenever they go to the park it has to be that specific time of day, "afternoon", even if it is "morning". Nancy was often vague in her discussion, and this vagueness could cause misconceptions for young children.

In the second observed lesson, the textbook showed an example of building a snowman or creating a snow angel. Nancy expected the students to know which would take more time or which would take less time. One student pointed out that she had never seen snow so they did not know, but Nancy just continued by telling them to imagine if they had to make a snow man with lots of snow that would take more time than creating a snow angel. Maybe some students did not know what a snow angel was, so they could not visualize it. Nancy could have connected this to building a sand castle at the beach or a sand angel, and explained what both activities entailed. Nancy did not do enough discussion to assess students' intuitive understanding. She also did not allow students to work on their own to truly assess student understanding. 


\section{Certain Characteristics of Instruction Appear to Promote Retention. Nancy}

showed weakness in creating classroom discussions and promoting instructional strategies that promote retention. Nancy's observed lessons consisted of direct instruction. She did try to use some strategies that would promote retention, but the strategies were very teacher directed. For example, Nancy did allow students to write a sentence about what they learned for the first three observed lessons, but Nancy created these sentences, wrote them on the board, and had the students copy what was written. When Nancy was asked why she had student write sentences at the end of the lesson, she said, "I really believe in incorporating two content areas in one, so Language Arts, of course." The writing was not used to help students promote retention in the mathematics content. The students could have created their own sentences or could have been allowed to draw their ideas if writing sentences on their own would have been an issue for these Kindergarten students.

During the third observed lesson, Nancy used the strategy of having students act out scenarios to determine what would take more time and what would take less time. She had them act out very few scenarios, and she did not have a discussion when the outcome of the acting did not turn out as she expected. Using more discussion in her teaching might have helped with student retention.

Nancy tried to incorporate group work as a strategy during her last observed lesson. She allowed students to create groups of fives and tens using Unifix cubes. The students were supposed to work together to create their groups of cubes; however, they did not really work together. Instead, most of them created their groups of cubes by themselves since there were enough Unifix cubes provided to be able to do so. Having 
less Unifix cubes might have prevented students working alone. Cooperative learning can promote retention, but Nancy's group work did not allow students to discuss the content, nor the ideas being presented.

Nancy tried to connect the mathematical content to real life by asking students to come up with examples of the content before using the examples in the text. She also came up with her own examples of real life situations for the content that she presented. Although Nancy used this strategy to help promote retention in her students, she did not write these examples down or take into account that only the students who were auditory learners would benefit from saying these examples. For example, in her lesson on morning and afternoon, the students were asked to give examples of things that happen in the morning and things that happen in the afternoon. Nancy repeated the examples as the students gave them to her, but she never listed them on the board, nor did she create a chart for the students to visualize these examples. Nancy rarely wrote anything on the board except for the page number of the lesson in the textbook, and the sentences that she wanted students to copy.

Nancy used songs to help the students review skip counting in her last observed lesson. These songs helped the students to count by twos, fives, and tens. The students sang along with the songs, and they seemed to enjoy them. These songs were not new to the students, but Nancy used them to help promote retention of skip counting. Nancy described this lesson as her favorite because she saw how students remembered content through the use of songs. She mentioned that she would use songs throughout her future teaching experiences. 
Overall, the strategies that Nancy incorporated during the observed lessons were teacher-directed and did not facilitate the students gaining knowledge on their own. Although Nancy tried various strategies, she conveyed them in a way that was teacherdirected.

\section{Providing Alternative Representations and Recognizing and Analyzing}

Methods are Important. Nancy showed some evidence of providing alternative representations for her students. She did use some manipulatives during the observed lessons. She used the hundred chart, Unifix cubes, the number line, and pictures in the textbook. In the beginning of the first observed lesson, Nancy conducted a review to help students determine what comes before a number and after a number. She used the hundred chart to point to numbers so that students could tell her what numbers come before and after other numbers. The students answered chorally when she asked the questions. They did not have their own number chart, but instead all of them had to look at Nancy as she pointed out the numbers using a meter stick. Similarly, during the fourth observed lesson, Nancy worked on the concept of what came before a number and after a number, but she used the number line. The number line was located on the top of a white board in the classroom, and the numbers were not large. It might have been difficult for some students to see it. The students seemed confused during this part of this fourth observed lesson, even though they did well on this concept in the first observed lesson. Nancy explained that it was the first time they had used the number line in this particular concept. The lesson might have been more successful if each student had their own number line, or if the number line was lower and the students were able to manipulate it. Nancy used a pointer to point to the numbers as she discussed them. 
For the last two observed lessons, Nancy used Unifix cubes to introduce the topic (see the pictures below), and the students seemed to grasp the idea. However, after the introductory activity for both of these lessons, Nancy collected the Unifix cubes and the students were not allowed to work with them for the duration of the lessons. Giving the Unifix cubes to students for them to represent the ideas in the textbook could have helped in the success of the lessons.

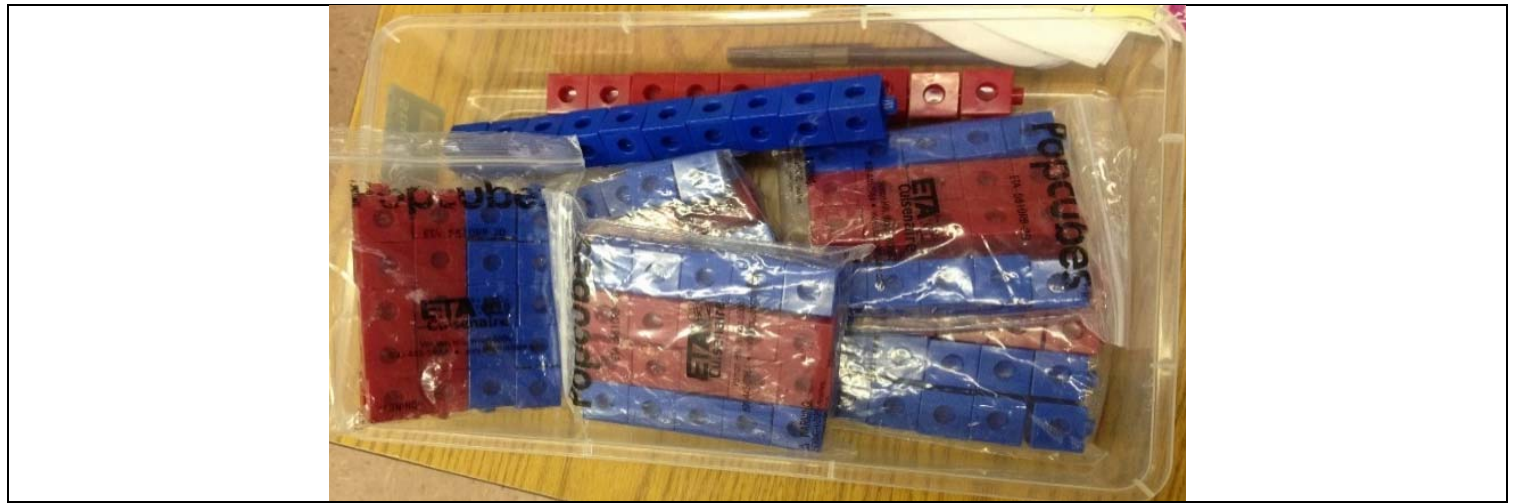

Figure 3. Unifix cubes used in Nancy's fourth observed lesson.

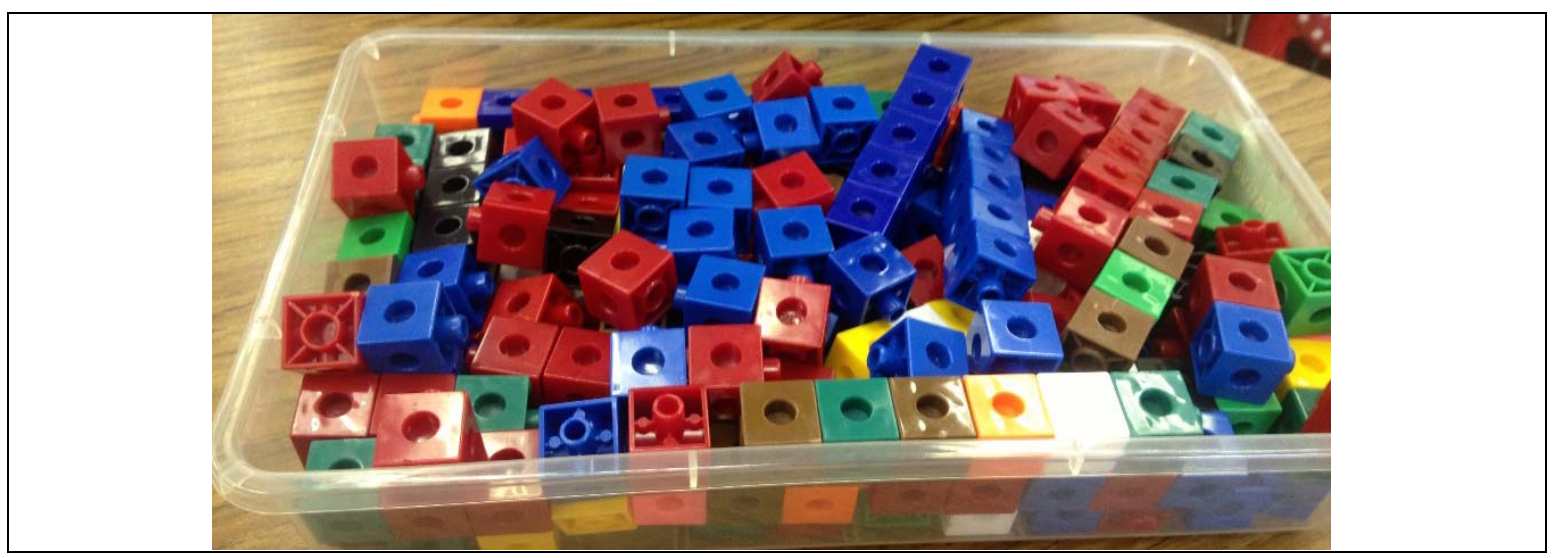

Figure 4. Unifix cubes used in Nancy's fifth observed lesson.

Pictures were used to represent the mathematical ideas in all the observed lessons.

The textbook used many pictures for the students. Nancy used all the pages in the textbook for the assigned lessons, so she used many pictures as representations.

However, Nancy never created her own visuals, nor did she have students draw their own 
pictures to represent their ideas. These additional visuals may have contributed to the overall success of the students.

During the observed lessons, Nancy did not analyze alternative solutions to problems. She checked for understanding by asking students to answer questions, but she did not go over how they arrived at the wrong answers. Nancy focused on the problems posed in the student textbook. She did not use additional resources to create contextual problems for her students. No evidence was observed on having students analyze alternative solutions to problems, or having students examine different ideas to mathematical experiences. She was not observed to analyze alternative solutions, nor did she examine different ideas to similar mathematical experiences.

\section{Future with Mathematics and Teaching}

Nancy described her biggest challenge of the semester to be incorporating group work into her teaching. She explained, “I wasn't used to using small groups, and I still need to somehow get the hang of incorporating that into my lesson and actually managing the kids meanwhile they are doing their work in small groups." Her least favorite thing about teaching mathematics this semester was using the manipulatives with the students because she said,

They can get a little out of hand. At this age it's all games, it's fun and play. They still need to learn that when we have manipulatives we're not playing, we're actually learning to do a certain concept, or try to understand a little bit.

Nancy indicated that she had trouble with giving them instructions and her management with the students during the use of the manipulatives.

When asked if she was looking forward to teaching mathematics in the future, Nancy stated that she is looking forward to teaching period. Nancy explained that if she 
secured a job teaching in a departmentalized school she would prefer not to teach mathematics. She believes reading is easier to teach than mathematics.

I'd prefer not to teach math. I mean, reading always came easy. Reading and language arts. Math is something that I had to work for. So I'd say reading in a heartbeat; reading is my main choice.

Overall, Nancy was surprised that she enjoyed teaching mathematics during student teaching, "I really enjoyed it. I really enjoyed it. I'm surprised that I enjoyed it. I'm surprised that I actually tried to- tried many things. I got out of my comfort zone every now and then; and I didn't think I was going to be able to. So it's very rewarding I would say." In conclusion, Nancy showed some weakness in the knowledge of good strategies for teaching mathematics, and also showed weakness in knowledge of the content

\section{The Case of Ally: High Mathematics Anxiety-Moderate Content-Weak Pedagogy}

Ally is a Hispanic female from a southeastern state. She completed her student teaching experience as a university senior at a large, southern, urban university. She described mathematics anxiety as

A panic that the person goes into when they either know they have to take some type of math test or just do math in general. They go into and get nervous and it can either...they might know the information but just get nervous or just might have a hard time in math, period.

Ally explained during her first interview that she has some anxiety toward mathematics, "It's [mathematics] not my favorite subject, but it's not my worst so I think sometimes depending on what we're going over in math then that's what takes that anxiety." Her score on the AMAS supported that she has high mathematics anxiety. When Ally was asked how she felt about the AMAS she replied that she felt fine taking it. Based on classrooms observations and interviews, Ally's content knowledge was average. With 
respect to pedagogical content knowledge, Ally showed some evidence of knowledge, but some areas were lacking.

Ally's overall GPA was 3.42 prior to completing her student teaching. Her content GPA was 3.00, which is based on three mathematics courses. These courses included Intermediate Algebra, College Algebra, and Mathematics for Liberal Arts I. She also completed and passed remedial classes, Developmental Arithmetic and Basic Algebra. However, these courses were not credit bearing and did not factor into her GPA. Ally's pedagogical content knowledge GPA was 3.33, which is based on one mathematics course. This course was Teaching Elementary Mathematics Methods.

\section{Ally's Personal Experiences with Mathematics}

Ally indicated that she struggled with mathematics at times but the subject has not always been the worst for her, "I would say, it's not my favorite subject, but it's not my worst so I think sometimes depending on what we're going over in math then that's what makes that anxiety." She stated that she liked mathematics until she was faced with Algebra,

I liked it, I mean math just gets hard when it goes into like algebra and stuff like that. But once you understand the concept then it's easy but you just have to get that. When you start seeing formulas with letters in it, you feel like letters don't belong in math, but once you figure that out and figure out how it works then it's ok.

Ally remembers being influenced positively in mathematics by friends

There were always these kids that were older than me and they used to help me with my homework. And now, coincidentally, they're all teachers. All four of them, and there's one that's really good at math. But every time I had a question in math, like when I first looked at it, like it was: ok, there's no way, this is wrong, I can't solve this. I would go to him and he would explain it to me, like everything would be clear so it showed me that there's just a trick to it, it's just a strategy and once you figure out that strategy, you'll be fine so you don't have to 
panic every time you see this long question and all these letters that don't belong in math.

Ally stated that none of her family members had any influence on her ideas about mathematics although her eldest brother succeeded in the subject and became an accountant.

Ally did not have any memories of early experiences with mathematics. She described her experience with taking the General Knowledge (GK) examination required for her education major as a negative experience with mathematics,

I can consider a bad experience when I had to take, my GK and then I couldn't remember what formula went with what specific thing that I had to figure out. I mean, I was able to figure out eventually but you know, you're already anxious, nervous because you're taking a test and then you're trying to figure out, "Oh my gosh, what formula is it?" I felt worried because the GK, I passed it all the first time except the math; I had to retake the math. But once I actually knew what I was being tested on and I went back and I took it and I drilled it, you know, I drilled myself going over and over and doing practice tests and you know, doing the same type of questions because I remembered it then I was fine the second time around. Like I passed it. The same thing with the professional, when I had math problems, I actually did pass it and everyone says that was the hardest test so as long as I study it and figure out what I'm looking for, then it was fine but there's so many different things and I hadn't had a math class since high school.

Ally explained that she did not have many memories of mathematics in elementary or high school and she did not remember the course that she took at Miami Dade College, but she did have to study hard in order to pass that course,

When I got my associate's at Miami Dade, I don't even remember what math it was but that one, you know it had a lot of letters in it and stuff but once I studied. I actually studied for it and figured out what I had to do, I was able to make that.

Again, Ally described her negative feelings toward algebra.

Ally could not recall any teachers in elementary school teaching mathematics, and she only remembered one teacher from high school. She explained that this teacher 
was not her favorite nor her least favorite, but he was the only one that she could

remember. She described his teaching,

I can remember that he would go over, you know, things a lot. When we had homework, he would go back and go over the problems and stuff like that so it would clarify a lot of doubts people would have or trouble people had while people were doing the homework. And that was algebra. There was a lot of visuals like he would work the problems out and he would call upon students and we would go work them out, and you know, see how he did it and we would have the chance to do it as well, work it out. And he would do a lot of reviewing, that I remember.

The teaching Ally described for Algebra was teacher-led instruction.

Ally did have an enjoyable experience with Geometry, "I enjoyed my math classes, but like I said, depending on what we were going over, that determine the outcome of that. Like geometry was fun." She also stated that she was the most confident about Geometry, and she liked that area of mathematics.

Ally did not remember much from the mathematics methods class required for her education major at the university, but she did remember the manipulatives, and she described how she used some of those manipulatives to teach a lesson during student teaching,

That [manipulative] was good. Yea that's another thing. Actually we used the shapes, patterns, the shape patterns and they [students] used the pattern blocks to create new shapes and stuff like that and they were able to trace that onto their paper and they really enjoyed that. And those are manipulatives that were introduced to us in that [methods] class as well.

Ally also remembered using technology, but explained that she was not able to use that knowledge in her student teaching placement,

I mean I remember the teacher going over gizmos and activities you can do online but I don't think this school has really taken that in yet and so it's more enjoyable for them to have a more hands on activity. I mean in that [methods] class, we also 
did go over hands on activities and things that we can take the lesson and make it more enjoyable for the students so I'll definitely take that in.

Ally planned to make use of the hands-on techniques that she acquired during that methods class.

\section{Context of the Student Teaching Placement}

Ally's student teaching placement assignment was in a third grade, self-contained classroom of 18 students with a balanced number of boys and girls. This class did have having students who came from low socioeconomic backgrounds, and others who had tough family issues. In the beginning of the semester Ally thought that she was doing a good job as a mathematics teacher, and described positive experiences,

I think I'll be a good math teacher. I mean so far my lessons and as I teach, the kids do seem to understand and take in what I'm teaching so I feel as long as the kids are actually learning and you see progress and knowledge gained then we're doing a good job. I mean I try to make activities that they can, that can benefit them. I mean hopefully I can teach them and do a good job at it.

Unfortunately, during her student teaching semester Ally was only able to create one new lesson on her own for the students. She described that lesson,

It was on classifying triangles based on their sides. I had an activity on the smart board for them, and we created the triangles with straws and construction paper, and they had to label the triangle according to which one had no equal sides, two equal sides and the equilateral, and they had to label them all. We actually got straws and we measured the straws to be all one length and we knew that was an equilateral and they put in construction paper and they created that triangle. For the scalene, they did the same thing: we cut the length of the straws to be different and have no equal sides. And for the isosceles, we did the two equal. They really enjoyed that.

Ally went on to further explain the lesson,

We did angles, triangles, classifying the triangles by their length. I did activities that they can actually create the triangles, not just reading, going on the page, looking at your page or whatever and name the triangle. No, I wanted to give 
them a hands on experience that could benefit them and be a good learning experience.

Another lesson on telling time was created by both Ally and her cooperating teacher, "I actually had another math lesson, but it was more like with just clocks and we had the clocks to manipulate and stuff like that. And we created little clocks that moved."

After the first week of her student teaching experience, Ally's cooperating teacher began to review for the SCAT (State Comprehensive Assessment Test). For the most part, Ally taught mathematics lessons that were designed to be a review and practice for the students. She felt comfortable with that type of teaching, and she indicated she had no anxiety teaching for review. "So far, I haven't [had anxiety]. I mean we've been doing angles and shapes, and now we're going to get into measuring." Ally indicated that she enjoyed teaching Geometry because she also enjoyed learning Geometry. The only anxiety Ally felt during her student teaching experience was when students had difficulty understanding the concept,

The parts that made me nervous was when a kid seemed very confused, and I was like Oh my gosh, how am I going to get this out of him? He's fine, or he's going to be ok, you know, it's not that hard but they really just close in on themselves and then you just want to take them out of there. So those times made me nervous because you know it really isn't that hard, you're over thinking it or whatever the case might be. To ensure that they do understand. I will sit there and break it down until they do understand it.

Ally stated that she feared students would not understand her teaching of the subject in the same way she did not understand certain topics,

Now that I'm teaching it, I always ask at the end, 'Did anyone not understand that? Did anyone not understand what I just went over? Did anyone understand what I'm saying?' Especially now that I'm teaching the students, I think it's very important to come across clear and have them understand either your point or the concept, and I don't want it to be something I'm not explaining well because it's something I struggled with so I do try to practice it a lot before I come in and feel 
comfortable with the objective of the lesson or whatever I'm teaching myself before I go on to teach it to them.

Ally believed that she was comfortable with most of the content being taught at the third grade level. Ally did not feel comfortable with fractions before her student teaching placement, but during her first week when her cooperating teacher taught fractions, she was surprised that she could help the students. She attributed this success during the first week to with the fact that third grade was a lower level and the fraction concepts were not difficult.

I think the fact that it's a low grade; it's third grade so it's not that bad because when I first got here, I wasn't teaching it but I would go around and help the kids. They were into fractions I think, and fractions aren't my favorite but it wasn't that bad because it was at an easier level.

She did express some anxiety toward teaching fractions during the review, but her cooperating teacher decided to review fractions toward the end of the review, closer to the SCAT because the students had trouble with some of the topics.

We're [the cooperating teacher and Ally] leaving like the fractions that they seem to struggle on their interims and their scoring wasn't too good, so we're leaving that closer to SCAT so I think that's when it's going to get a little more challenging for me to explain to them or you know give them any pointers to help them out.

Ally indicated that overall it would have been more challenging to create new

lessons for the students instead of only conducting review lessons every day,

I think creating the lessons would be more challenging because this is just stuff that are simple and you just reviewing to ensure that the kids... and it's just that, a review; you don't really go into that. If you see them struggle, then you know, spend a little more time on that but if they're fine then you keep going. And these students seem to be doing fine so far.

Although it would have been more challenging, Ally believed that it would have also been more fun for both her students and herself. 
Yea because you know, you have to come up with different lessons to reach every student and to keep them engaged in your lesson. So you have to make sure it's something fun, something educational, you know, that's really going to educate them on the content. But I think it would be...it would've been more fun to do so also.

Overall, Ally enjoyed teaching mathematics,

Overall, I feel comfortable with it [mathematics], I wish I would have had more time to actually come up with math lessons and actually more activities that the students can enjoy and learn from opposed to review, but I feel okay with it; good. Yes. The first week that I was here was the time that I actually made a lesson according to the book that they were still on.

Ally enjoyed teaching mathematics during student teaching, and it was the first subject that she took over as a student teacher because ironically, Ally's cooperating teacher had more mathematics anxiety that she did.

That was the first subject I decided to take over. Well my teacher actually had math anxiety in the beginning. Before she used to only teach reading and other subjects, and now is when they stuck her on math and she was having math anxiety because she said it's not her best subject; she says she's not good at it. Yea because I didn't feel that drastically about it.

She thought that mathematics was very important to teach her students because they would need it in their daily lives as they grew up,

I feel just like every other subject that we're trying to teach in the classroom, math is important because we are trying to teach these kids to count and to know their math because they're going to grow up just like everyone else and they're going to need that in their daily lives now.

However, Ally maintained that the content of third grade mathematics was not difficult, but if she had a higher grade level she might have encountered more mathematics anxiety. She explained that if she ever had to teach in a "for higher grades I'm a little afraid." 
By the end of the student teaching semester, Ally remarked that her mathematics

anxiety had decreased because she gained experience. When asked if she still wanted to become a teacher, she declared than she did.

Yes, I really did enjoy it. I really do. When you see those kids and how they learn, you can find at least some passion in it and at least want to do it for them and see that they really do need your help because they don't have a lot of support in their homes and stuff like that. At least they can look up to you and know 'she'll help me or she does care', or you know, [they] have somebody to go to.

\section{Ally's Relationship with her Cooperating Teacher (CT)}

Ally and her cooperating teacher had a unique way of co-teaching during the mathematics lessons that were observed during her student teaching experience. Ally's CT co-taught with her during the observed lessons, and Ally explained that that practice was common-place throughout the semester of student teaching. When asked how she felt about the teacher co-teaching with her, Ally explained,

I think that was good because a lot of times you might leave things out and you just have that other person there to back you up, and the same thing you know when she used to leave stuff out or I feel like one student is still looking at her like, 'Huh? What's going on?' You know, I could reword it a different way just to clarify for the student.

On another occasion Ally reiterated these sentiments,

Sometimes you know I am missing something to say or sometimes she is missing and you know then I add on to it even when I wasn't taking over, when I was just observing she told me 'feel free to speak whenever' you want to explain so much that sometimes you miss out on things and we're both there we see different things that different kids are missing so then we can add on to each other and then make sure that each child's learning need is being met.

Ally also explained that there were times when she taught a lesson by herself, but she said it was absolutely fine for her teacher to interrupt her. Ally enjoyed working with her cooperating teacher. 
Ally was also happy to be able to help her CT who feared mathematics more that she did.

I enjoyed being able to just help the students and actually the teacher also because it's not her favorite subject, so I know that she liked that aspect that I was able to take over math.

After the third observed lesson, Ally's cooperating teacher indicated that she has mathematics anxiety, and explained that she had been teaching for 11 years, but this is the first year that she has had to teach mathematics. Ally's CT went on to further explain that she found out that she would not be departmentalized two weeks into the new school year, so she was not prepared to teach mathematics. Ally's CT also mentioned that she has been using manipulatives and other creative ways to teach mathematics because she thinks these strategies help students learn and she, herself, learned better through the use of these strategies. Ally's CT indicated that she has been very frustrated teaching the concepts associated with time to her students, but she explained that Ally has helped her to reach some of the students.

Ally explained that she worked well with her cooperating teacher to plan most of the lessons during the semester, but she created the lesson that was previously described on triangles alone.

\section{Planning for Teaching Lessons}

Ally did not allocate a lot of time to planning mathematics lessons during her student teaching semester. When asked how long she took to plan for the five lessons that were observed, her responses averaged between 20 minutes to an hour. She took less time to plan lessons as the semester came to an end. Ally stated that her first observed lesson took her between 40 minutes to an hour to plan for, but the last two lessons only 
took her between 20 minutes to 30 minutes to plan for. Ally explained that she usually

looked over the content in the workbooks that were being used and then she tried to find a video on Brain Pop or an interactive Smart Board lesson on the Smart Exchange that coincided with the topic. Ally explained that she always tried to have the students engaged,

I always try to find an activity; they really like Brain Pop so that's always good to start the motivation, to get them engaged on the topic and sometimes I researched for a fun activity or something like that, something hands on so it's not just lecture. I find that they really learn through interaction, and they enjoy it which makes them want to learn more.

For most of the lessons, Ally found Smart Board lessons on the Smart Exchange to help her teach the lesson,

I looked in the books to see what contents we were going to cover next and then, I looked on the smart board to find an interactive lesson that would go along, cause once they see that on the board they all want to go up there. This is why I use the Popsicle sticks so they get chosen at random and, the same kids are not being picked on. I just put the lesson according to what we are going over in the Smart Board Exchange. Those are lessons that are already prepared and I do go through them between 2nd, 3rd, 4th and 5th grade (I mean 2nd, 3rd and 4th) and then I go through them and, make sure it is something that's on their level and they are capable of doing.

Ally prepared by reviewing the practice pages in the workbooks and discussing

ideas with her cooperating teacher. Ally shared the content and the resources that she would use to teach that content with the cooperating teacher before teaching her lessons. By the end of the semester the students were on a time crunch to review for the SCAT and Ally taught the content set by the crunch time schedule. Since the students were finished using the textbook, Ally and her CT selected lessons from the practice workbooks that covered the specific topic on the crunch time schedule for students to work on. There was no answer key to the problems in the textbooks mentioned, so Ally 
would have to work all the problems out ahead of time to obtain answers. She did not always work out all the problems, and sometimes she did not know the correct answer. She explained that this practice caused her some anxiety, and she cited a lack of time for her reason for doing this. However, by the last two lessons, Ally mentioned that she worked out all the problems so that she knew exactly what to expect in her lesson, and she would not be caught off guard.

Ally used three resources to help her plan for the lessons during her student teaching semester which included the workbooks used by the students, the advice from her cooperating teacher, and resources from the internet, specifically the Smart Board Exchange, and Brain Pop. In her fourth and fifth observed lesson Nancy only relied on the advice of her cooperating teacher for planning. She didn't use any additional resources to help her find additional tasks or activities for her students. Of the three resources Ally turned to, she found the internet the most helpful at improving her teaching, "The Internet because you know, you could always find different activities for the students." She also explained that her CT was a "big help."

Ally did not feel that she was able to plan meaningful lessons during the crunch time review, she did believe in the benefit of careful planning,

Sometimes it's worth it, you know, taking the time to plan your lessons and you might stay up at night a little longer to create these lessons but you're creating something more meaningful for them which helps, allows them to learn better.

Ally thought that a teacher should use resources other than the textbook to plan lessons,

I believe in looking for other resources, fun activities, motivational things to get them engaged and you know, eager to learn not just like ok, open the book and turn to this. Which is you know, the reviews are not that fun and I do try to add a video or get them up off their seats and stuff like that. 
Ally believed at times that using both workbooks got repetitive at times, so she selected problems from each for students to work on.

We go pretty much...if numbers 1,2 and 3 is $1+3=4$, you know they're all simple addition. We'll do 1 and maybe we'll do 4 and we just move onto the next one; we're not going to do number 1,2,3 and 4 when it's just the same thing, different numbers.

Ally liked the textbook used by the students; however, she was not able to use it for very long since only three chapters were taught during her student teaching experience, and most of those chapters were taught by her CT.

\section{Ally's Mathematics Anxiety throughout the Semester}

Ally believed that she only showed signs of mathematics anxiety sometimes, especially when she took mathematics tests where she was unsure of the content being covered,

I think sometimes [I have mathematics anxiety], but a majority of the times when it's math tests, but not if I've been studying for something and I already know that that's what I'm going to look forward to or have on the test then I'll be fine, but it's having a test and you don't know what it's on. And it has to do with math, and then it's a problem.

Ally was aware of mathematics anxiety and knew that she showed signs of it especially

during mathematics testing. She described mathematics testing as follows:

Well my stomach hurts sometimes, but I think it's just more being nervous and then you know, I don't think, you should go into a test thinking negatively. You know, I think that you should always go in with a clear mind, positive, you know, this will be ok, because I feel like if you're going in negatively, you're nervous and you're just going to do bad because that's what you're thinking you're going to do. So I think you know, when I'm not nervous and not as anxious, I'm like ok I have a chance at this; I studied and I'll be alright.

Ally's anxiety was apparent during some of the observed lessons when she was

put on the spot, and did not know the solution to a problem. Ally explained, 
Sometimes when I don't go over the answers before going over it with them and then I have to do it quickly, and then you know, you make silly mistakes, you're like, "Ok, why am I not getting the answer?" It makes you a little nervous because you don't want to give them the wrong answer.

Other times, the Smart Board lessons that she chose had sections that she did not expect and she was anxious when caught off guard.

Before her lessons, on the pre-lesson surveys, Ally indicated that she was comfortable with the content of her lessons rating her comfort at a $5 / 5$ on all lessons except her first lesson where she indicated a rating of a $4 / 5$ with a 5 indicating that she was very comfortable and a 1 indicating that she was not comfortable. She also felt very comfortable with teaching the lesson she had planned indicating a rating of 5/5 on all lessons. When asked about her feelings getting ready to teach a lesson in the pre-lesson surveys, Ally described increased confidence over the five lessons that she taught. In the first lesson she showed some concern using the phrase, "I hope the students grasp the concept". Before her second observed lesson, she described her feelings toward teaching as "readiness" and for the third, fourth and fifth lessons, she described her feelings as "calm".

Overall, Ally felt confident about the first observed lesson, but at times this came across as overly confident. She did report that she encountered anxiety when students appeared to be confused about the content that she was reviewing, "Sometimes when a student was confused I was kind of worried like you know is it me, am I not explaining it correctly? I just wanted to ensure that they understood."

Ally cared about ensuring student understanding. Ally also encountered some anxiety when students asked difficult questions that she felt unprepared to answer, 
Sometimes I feel like they ask questions and I'm not sure I am answering it to the fullest extent, am I really clarifying it for them? So it's not necessarily that I don't feel totally comfortable with it [the lesson], it's just sometimes they ask so many questions that it makes me think twice about what I am saying.

Ally also expressed anxiety when the students did not understand the topic; Ally encountered anxiety when she needed to find new ways to explain the content to her students,

I felt anxious when we repeatedly were telling them a quarter after 1 is $1: 15$, a quarter after 2 is $2: 15$, and then we asked them what the quarter after the next hour was and they were lost. You know when you tell them how many minutes are in a quarter and you know how many minutes are in between each number in the clock and all they have to do is count and they were not getting that. It's just like well how else do you teach them?

During the first observed lesson, when Ally taught only the hour hand on the clock, she experienced the least anxiety because the students were able to understand that part of the content very easily.

Ally felt confident about the second lesson observation, but again she seemed overconfident. She did not have much anxiety during that lesson,

I felt comfortable with the content and I reviewed the lesson before and how I was going to teach it and the book, the lessons that were in the book to follow along and just back up the presentations on the smart board.

The only anxiety she felt was encountered during the Smart Board Lesson when she asked students to match definitions to vocabulary words. The student who was at the board mixed up the meanings for "square" and "rectangle". One student caught the error, but Ally did not make the student change his answer. Ally purposefully left the answers wrong so that they could check the answers as a class on the Smart Board. Ally explained, 
I wouldn't really say [I was] anxious, but I wanted to see towards the end on the part that one student had it wrong and then I knew it was wrong, but I left them to see if they, and you know one student almost caught it at the end, well he did catch it at the end, and then we checked it they were able to see what mistake they made.

Ally also felt confident about her third observed lesson,

I was calm about it. I felt that I was at ease and felt that they were going to be successful in being that it was a review. It's not something new, and, I would say, it's a pretty easy topic.

However, Ally felt anxious when students showed signs of not understanding the topic because it was supposed to be a review. "I felt like some of them were stuck but, I think it is more being afraid to say the wrong thing or they just needed a refresher to remind them." She also felt anxious during one part of the Smart Board lesson that she projected. The lesson was on perimeter, and one slide showed the total perimeter of several shapes, and the students had to figure out the length of each side. She was anxious, but she was still more confident than her $\mathrm{CT}$ that the students would be able to figure out the lengths of the sides. Ally explained that in the end she felt that it worked out fine. Ally felt that the lesson on perimeter was relatively easy and she was least anxious about having students measure the sides, add the measurements, and come up with a total perimeter. Ally did not have any anxiety during her fourth observed lesson. She explained that she was not anxious at all because the students were simply reviewing for SCAT, I just liked it because I thought it's easy and, it is an easy review, and these are all things that they have to review before the SCAT. So, all these lessons that have been observed are pretty much reviews, you know, it's not a lesson that has been put together, for the first time, to teach them the content. So, I like it because, you know, I think it is simple work and, they can just review and go on to the next.

Ally felt that she might have been more anxious about teaching new content to the students. 
Ally described having some anxiety during the last observed lesson. Overall, she felt calm but she got anxious during the review of the homework. She had students work out their answers to homework problems on the white board. One student got a subtraction problem that involved rounding incorrect. The student solved the subtraction problem and then rounded the answer, but the answer could only be obtained by rounding the numbers before subtracting. Ally noticed that most of the students solved the problem by rounding the answer. This method was appropriate for some problems but not for others, and this confused Ally. She checked with her CT and then she showed the students how to round the numbers before adding and subtracting them. Ally explained that she was most anxious during this part of the lesson,

The part where we were already reviewing the homework when they had to round before they added [and subtracted] the problems to get the difference because, there is one that I worked out, for example, and I did not get the answer so I was like, oh, you have to round before you add it but then, in others, there are some that you can add and then round, you know, your product and then you'll still be fine. But, the fact is that, it doesn't always work like that, that's why you have to round before.

When asked if the instructions were stated in the book, Ally said that the instructions were not clear,

I don't think in the book; it just says, estimate this and pretty much, they would have to figure it out. Your option is not there [in the answers] so you're doing something wrong to figure it out and, that's why, even myself, when I was working it out, you know, it just said estimate it, based on the number they were giving you, I just saw the answer, I went ahead, and I just added the numbers and then try to round the final answer and then I saw the answer wasn't there, I went back and I said ok and, when I saw the answer was there when I rounded before, then I would say...yeah.

Ally explained that the book did not come with an answer key so she had to work out problems to figure out answers as well, and when the answer that she first obtained was 
not one of the multiple choice answers, she became anxious until she figured it out. Ally felt least anxious about the simple multiplication that the students were required to solve in the beginning of the lesson.

\section{Ally's Content Knowledge}

Ally stated the importance of mathematics,

I think we need math everyday so it's important because we need to know how to count, we need to know to calculate things, every day when we're paying for things, it's important. When we're telling the time, I think for a lot of things, I mean we don't sit there and think but we're using math all day, pretty much. Because sometimes we need things, we need to figure out how many we need and if we didn't know math, we couldn't figure that out.

She believed mathematics was vital and important to teach her students. Ally felt comfortable with the content being taught at the third grade level. Ally stated that she would review the content and after doing so she would be able to teach it. She felt comfortable with the content at this grade level, but she thought that she might be more anxious with the content at a higher grade level. For example, Ally reported that she struggled with fractions at time, but because the fractions in third grade are more introductory she didn't have trouble with it,

I mean I think the fact that it's a low grade, it's third grade so it's not that bad because when I first got here, I wasn't teaching it but I would go around and you know, help the kids. They were into fractions I think, and fractions aren't my favorite but it wasn't that bad because it was at an easier level.

Ally was comfortable with the content, and it was observed that she did not experience challenges in her teaching of the content to the third grade class. Examples of these observations follow.

During the teaching of the first observed lesson, Ally reviewed telling time to the quarter hour, the half hour, the whole hour, and the minutes that corresponded with these 
times. This lesson was a review lesson, but prior to the lesson, Ally explained that the students still struggled with the content. Ally's CT also explained that the students had been struggling with this concept for two weeks, but they seemed to be finally understanding the content now. The students took a test at the end of this lesson, so Ally and her CT reviewed the content with the students. Ally did not show any signs of weakness with the content during this first observed lesson, but she did not explain all the content either. Ally's CT kept interrupting Ally to explain the content for the students, so Ally was not given the full opportunity to explain all the problems to the students. Ally's content was strong on the problems that she did review with the students. She asked students to say times in various ways, for example, 10:15 could also be said as a quarter past ten. Ally also used the large class clock to model for the students, ways to find solutions to problems such as, 'If I started reading at 3:00 pm and I stopped 1 hour and 55 minutes later, what time is it when I stop?' Ally and her cooperating teacher felt that the students understood the content and were ready to take their test, but after grading the papers Ally commented that some students made careless mistakes,

I think a lot of them stress over it and they made careless mistakes because when we review and go over it and are on top of them, they get the right answer and we turn around and leave them alone and they work on it and they make careless mistakes.

The second observed lesson dealt with the topic of classifying shapes and identifying their sides. Again, this lesson reviewed content that the students previously learned. Ally was confident with the content and thought that the students had sufficient knowledge of the content as well, "It seemed like they [the students] had a lot of knowledge on it [content]." Ally knew the characteristics of polygons and reviewed 
these characteristics with students throughout the lesson. She also used vocabulary associated with geometry quite often. She reminded students of the difference between polygons and non-polygons, line of symmetry, and diagonal lines, and she allowed students to work on their own and learn from their mistakes. One student mixed up the characteristics of a square and a rectangle, and she allowed the students to catch the error before she explained the right characteristics. Ally explained that for this particular lesson she was not able to cover as much content as she had planned because of the early release schedule on Wednesdays,

The fact that it was Wednesday and we didn't have much time to go over [content] because at the end they were to create a pattern using their pattern shapes and they had an example, and I thought they were really going to enjoy that.

Ally wanted to provide students with the opportunity to create shapes with pattern blocks.

For the third observed lesson, Ally covered the topic of perimeter and measuring sides of shapes to calculate the perimeter of the shape. Ally displayed strong knowledge of the content. She explained why she thought the content was easy,

To me, perimeter is pretty easy. Sometimes they don't give you the measurements of the sides but, based on the perimeter total that they are giving you and the shape, you can figure out [the measures of the sides], for example, the triangle, an equilateral triangle, they give you a perimeter of $21(7 \times 3)$. A triangle has three sides so that means they all go to seven. All they have to do is either add or multiply, whichever is easier for them. So I figured once they grasped that concept, it was going to be easy for them.

Ally asked students to measure their desks and their books to find the perimeter of the objects. Although some of the students did not get the same measurements for the same objects, Ally did not review the reasons that this could have occurred. She simply measured the objects and told them what the perimeter was supposed to be. Ally made 
one error by mixing the words congruent and parallel when she was reviewing the measurement of the sides of a rectangle. The bottom of the rectangle measured $6 \mathrm{~cm}$ so she asked the students what the top measurement would be. One student correctly answered $6 \mathrm{~cm}$ and she told him that he was right because the lines were parallel. Although the lines of the rectangle were in fact parallel, in this instance the $6 \mathrm{~cm}$ could only be obtained for the top measurement because the lines were congruent. At times Ally stressed the importance of using the units after each measurement because students were having trouble remembering the importance of the units. She explained,

The reason I did that [stress units], is because when we were first on this topic, a lot of the test's errors were careless mistakes; they had the answers correct, but they had it on the wrong units.

Ally knew the importance of this idea; however, there were several times during this lesson where she did not say the units when discussing the measurements. There were also times when she did not write the units after the measurements of certain sides. She was not consistent in always using the appropriate unit.

When the students found the measurement of the sides and the perimeter of a triangle, Ally would always ask students what type of triangle they were measuring; this was a good way to activate prior knowledge and connect different topics in mathematics. For this lesson, Ally also stated that she skipped problems in order to practice more of the problems that students needed for their review of the SCAT. She explained,

Sometimes I select them [problems], sometimes if it is something going in too much depth and they don't really need that, we skip that. We just do what's important, what they really need to hit to be successful.

The last set of problems for the students focused on giving the total perimeter and having students figure out acceptable measures for the sides. This required that the student be 
knowledgeable of the properties of the shapes. Ally's CT was apprehensive about doing these types of problems with the students because she was not sure that the students would be able to be successful, but Ally was confident that the students could do it. Ally explained,

The exercise had the shape and, then under that, once we moved it over, it gave us a total perimeter. At first they looked at it wondering how it would be added to find the perimeter, but I told them it was fine. It is giving us the perimeter so all we have to do is figure out the sides, just like the example I just used. The triangular was equilateral so all we had to do is find/give the measure of one side, multiply that by three and make sure that it totaled up to the triangle. We also had the right tangle which was pretty much the same thing for the top side and both left and right side. All they had to do is find that, do it twice on the sides, twice on top and then add it all up. I would say the trapezoid was the trickiest one and, he was able to see the sides were the same. All he had to do was make one number larger than the other; being that it is something you can see visually that the bottom part of the trapezoid was longer.

She continued to explain,

I was calm and I felt that I would try to push them if I felt they needed a little nudge or they felt a little lost, cause like I said this was just a refresher, but I didn't feel as if they didn't know what was going on or anything like that. I felt good about it.

When Ally was asked how she would improve this third observed lesson to ensure that students understood the content more clearly, she explained that she would have given students more items to measure, "I would have given them [the student] more things to measure, so that way they could have that extra practice, like pencils, things that they use, that they can just measure."

During her fourth observed lesson, Ally reviewed how to read pictographs using the key as a guide. Ally displayed strong knowledge of the content for this observed lesson. She described why she believed the content was easy, 
Well, I think it is pretty simple. It is just a graph. It shows you the picture. It gives you the key. All you have to do is count or find the difference, depending on the question that it is asking you. It gives you the pictograph and, it tells you use this pictograph for the following questions. So, it is all there for you.

The students did a lot of independent seat work for this lesson because the students were practicing for the SCAT. Although the students worked independently, Ally with the assistance of her CT corrected the problems together as a class and explained problems that students had difficulty on. Ally and the CT helped students to figure out the key because some of them were having a difficult time figuring out half of the objects. For example if the key has one book representing four, half a book would represent two, but some students didn't grasp that,

I think they were confused a little bit like when they used half of a picture and they figured ok if that whole picture equals four, it kind of threw them off but, once we cleared that up and refreshed their memory, I think they were ok.

Ally further explained how she tried to help the students who were struggling with this idea,

First thing when you see your chart [key], count, put your number on your right hand side. Most of the time when they have something wrong, it is because they haven't followed that step so I tell them, you know, go back, do what you got to do first so you can figure out the answer or if they do that and, they are still wrong, I say look at that again, check over your work.

Ally had some difficulty explaining the concept of 'at least' to the students. Ally tried to explain the term 'at least' but she said look at the graph, "Which two subjects were at least more than 35 students." The students did not understand. The CT told them that the minimum can be 35 and she draws $35<$ _to show that 35 is the smallest amount. However, not all the students understood that. The students were still having difficulty but Ally and the cooperating teacher said it has to be 35 or more. Ally used the example 
of grades to help one group of students understand, she told them "When you get your grades, you want to get at least a 90 to get an A. If you get an 80, what happens?" The students seemed to understand that analogy but she did not share that with the rest of the class.

During the last observed lesson, Ally reviewed using the strategies of either multiplication, repeated addition, or tree diagrams to solve combinations. Ally was confident in the content of this lesson and she believed that the students understood as well,

I think they did well, some of them just over think things, sometimes especially for the combinations, if you work it out a way and you see your answer is not there [in the multiple choice options] then, you have to find another way. You are obviously doing something wrong but, I think they were successful.

Ally thought the content was very straightforward and she explained, "It is simple, just multiplying, just simple multiplication. It doesn't go in depth or anything like that; it was pretty simple." The students were successful in all their answers, but some students appeared to just be multiplying numbers. As Ally introduced tree diagrams, she orally reviewed what the book explained, and some students did not understand. However, after Ally drew a tree diagram on the board the students seemed to understand the content more clearly.

Overall, Ally displayed good knowledge of the content. Ally's good grasp of the content might have been linked to the fact that all the lessons observed were review lessons for the SCAT. Ally only presented one new lesson to the students during her student teaching semester and that lesson was not observed. 


\section{Ally’s Pedagogical Content Knowledge}

With respect to Graeber's big ideas, Ally demonstrated the ability to assess students' understanding. She demonstrated some ability to implement lessons that promoted student retention of ideas and implemented some lessons that provided alternative representations of concepts. However, Ally did not demonstrate the ability to implement lessons that provide opportunities for students to demonstrate both conceptual and procedural knowledge, nor did she create lessons that considered students' intuitive understanding of concepts. Overall, Ally showed some evidence of pedagogical content knowledge. This section outlines examples describing Ally's actions and ideas pertaining to Graeber's (1999) five big ideas on pedagogical content knowledge that preservice teachers should possess.

Understanding Students' Understanding is Important. Graeber's first big idea focuses on the importance of understanding and supporting students' reasoning. She argues that it is important for preservice teachers to have knowledge of students' thinking practices (1999). Preservice teachers should be aware that assessing students' thinking during instruction of a lesson can change the direction of that instruction. "Classroom instruction must involve ongoing assessment of students' understanding of concepts" Graeber, 1999 p. 193). Student understanding was of some importance to Ally.

Ally believed that it was important for her students to understand her teaching. In fact, she most feared that her students would not understand her. Constantly, throughout the observed lessons, Ally asked questions such as, "Did everyone understand that? Did anyone not understand what I am saying? Did anyone not understand what I just went over? Does anyone have any questions?" Ally believed that by asking these types of 
questions at least one student might report not understanding as opposed to having all students just sitting quietly, not wanting to indicate their lack of understanding. Ally's lessons were based on reviewing topics for the SCAT, so she constantly checked students work and called students up to the board to assess their understanding.

Ally made it a point to always walk around the classroom. She explained that she wanted to ensure that her students were understanding and would even take the time to explain things to individual students, "I always walk around, I ask them you know, 'Did you understand that?', if they don't then I go over it with them, I take the time." During all the observed lessons, Ally also walked around to check the students' work as they completed worksheets for review.

At the end of her second observed lesson, Ally concluded that all her students understood the content. She used the practice worksheets to assess understanding, she explained,

At the end of each review that we were doing on the book, they had a little practice which I allowed them to do that on their own and then I went over the answers with them and as I walked around and the cooperating teacher walked around we didn't find any mistakes, and you know the ones that they did [silly mistakes], well that was the purpose of this to review the silly mistakes that they make.

Ally also used quizzes as a form of assessment to check for student understanding. She explained that she gave quizzes at the end of some smart board presentations, at the end of some lessons, and at the end of the week. Ally explained that after grading most quizzes either she or her CT would review any errors with the students. She tried to provide immediate feedback. 
Ally enjoyed when students had a lot of questions about the lesson because she felt that showed student interest and curiosity,

I always like that the students ask questions and that they are always curious and if they are confused about something, I try to get it clear. I like that they are engaged in the review or lesson.

Ally enjoyed going over work to clarify any misunderstandings. During her fourth observed lesson, Ally explained the steps she took to ensure that students understood how to use a key in pictographs,

First, I check to see if they did what the teacher told them. For example, first thing when you see your chart, count, put your number on your right hand side. Most of the time when they have something wrong, it is because they haven't followed that step so I tell them, go back, do what you got to do first so you can figure out the answer or if they do that and, they are still wrong, I say look at that again, check over your work.

Ally encouraged students to check for their own understanding by reviewing their work.

\section{Students Knowing in One Way Do Not Necessarily Know in the Other(s).}

This big idea focuses on understanding both conceptual and procedural mathematical knowledge. Graeber (1999) writes "Not only must preservice teachers be aware of student's thinking, but they must be skillful in distinguishing what the students understand as opposed to what students can do" (p. 195). Preservice teachers must understand that students know in different ways; those who are able to perform procedures may have poor conceptual knowledge of the topics associated with those procedures. Preservice teachers must also know that obtaining the right answer does not always imply that a student has conceptual knowledge of a particular topic. Preservice teachers must select assessment that measures both types of understanding in their students. 
Evidence of conceptual understanding was scarce in both the lesson observations and the interviews conducted with Ally. Ally discussed a lesson that she created in the beginning of the semester that allowed students to create triangles from straws measured to different lengths. The triangles contained different angles and sides to help students understand the topic in a more conceptual way instead of just memorizing vocabulary about types of triangles. The products (student work) of that activity hung in the classroom, but unfortunately, this activity was not observed. During the observed lessons, Ally and her CT were focused on review and did not plan lessons that allowed students to create their understanding of the topic. Ally and her CT had some difficulty with the topic of time. Ally explained that she tried to act as a guide for the students, by having them complete worksheets and then reviewing the answers. However, during the first observed lesson, Ally modeled finding elapsed time for the students, and then had them try it. The modeling was done in a procedural manner. During the second observed lesson, Ally worked with pattern blocks to help students describe polygons. Ally explained that she wanted students to create new shapes using the pattern blocks but she ran out of time. This might have helped students conceptualize new shapes, but unfortunately they were not able to do so. Ally explained, "We wanted students to create new shapes from pattern block shapes, but there was not enough time in the lesson.”

During the last observed lesson, students were figuring out combinations. Ally presented multiple ways to solve for combinations and had the students practice using the various strategies. At the end of the lesson, the students were allowed to choose which method they wanted to use to solve problems involving combinations. Ally explained how she believed the students made their selection of the strategies, "I think depending 
on how the question was asked in the book, that's what decided how they worked it out." Instead of presenting the various strategies to the students, Ally could have possibly allowed them to discover the various strategies to solve computations on their own before practicing them.

Overall, Ally’s observed lessons lacked conceptual knowledge. Although the lessons were geared as a review, some strategies could have been used to help promote conceptual understanding as well as procedural understanding.

Intuitive Understanding is Both an Asset and a Liability. Intuition plays a role in thinking about mathematics problems and connecting mathematical ideas, but that same intuition can lead to common misconceptions in mathematics. Graeber (1999) explains "Intuition plays a key role in problem solving or in construction of a proof, where students must take first steps based on what they feel are similarities to other problems, a visual model of the problem, or the start of a string of logic that will lead to the desired conclusion“"(p. 198). Graeber (1999) points out that preservice teachers need the knowledge to assess students' preconceptions and understanding to determine if misconceptions are evident and then use strategies to help student reorganize their thinking. Graeber (1999) goes on to explain that preservice teachers need to "help students develop the 'habit of mind' of challenging the 'obvious' and seeking alternative ways of confirming what seems "certain"' (p.199).

Ally's observed lessons were all based on topics that the students had already learned. The lessons were all review lessons. Ally did access prior knowledge, but there was not much evidence of students' reorganizing their thinking to clarify misconceptions. Ally did describe that she noticed her students making careless mistakes, 
For example there's a question on elapsed time and a girl missed the answer by a minute so the answer was supposed to be $2 \mathrm{hrs}$. and $45 \mathrm{~min}$ and she put $2 \mathrm{hrs}$. and 44 min, so that just showed me that it was a careless mistake; she didn't really count the minutes and even if she did she didn't take the time to count it again and make sure her answer was correct.

Ally did mention misconceptions of students, and she was able to identify the difficulty that students had with time. She alluded to the possibility of misconceptions in the following example,

The hour, they find the easiest. So you know you tell them an hour is from 2 to 3 . But once they have to get into the minutes you know precisely like when 45 minutes go by or 43 [minutes], that is not even counting by $5 \mathrm{~s}$ or anything like that.

Ally described these errors as her most anxious time of the lesson. However, Ally did not try new strategies to correct these errors; instead, she used procedures to show students how to arrive at the correct answers.

During the fourth observed lesson, Ally described a misconception that students had in figuring out the total amounts from a pictograph. The key showed a picture of a person that would be equal to five students. The students were given questions based on the key to figure out totals. Ally described their errors, "Just counting it [the key], the fact that one picture doesn't equal one student, per se, it would equal....one of those little pictures could equal five students. Just careless mistakes." Ally attributed the errors to careless mistakes and not possible misconceptions of the students. She gave them procedures to help them organize the information so that they could correctly obtain the right totals.

Finally, during the last observed lesson, when reviewing the homework, Ally and the students all made the same error of rounding the answer after adding and subtracting 
instead of rounding before adding or subtracting, as explained in the Content section.

This was a misconception that was never clarified. Ally told students that the answer they obtained by rounding at the end was not a multiple choice option, so they needed to try to do it the other way. She said,

The book; it just says, estimate this and pretty much, they [students] would have to figure it out. Your option is not there so you're doing something wrong to figure it out and, that's why, even myself, when I was working it out, you know, it just said estimate it, based on the number they were giving you, I just saw the answer, I went ahead, and I just added the numbers and then try to round the final answer and then I saw the answer wasn't there, I went back and I said ok and, when I saw the answer was there when I rounded before, then I would say...yeah...

Ally never clarified why the students were to round before adding or subtracting nor did she clarify the difference between finding the answer both ways. This was a clear misconception that was not resolved. Ally simply told the students to solve the problem "the other way".

Certain Characteristics of Instruction Appear to Promote Retention. Graeber (1999) explains that preservice teachers must be aware of and use strategies that promote retention of ideas in students. These classroom strategies include creating meaningful contexts for students to reflect on. Graeber points out that it is also important for preservice teachers to understand that "writing or speaking about or in other ways reflecting on knowledge and change in knowledge is considered by many an important strategy in learning" (p. 201). Preservice teachers should learn how to create classroom discussions in mathematics where students can explain their thinking and justify their answers to meaningful problems. These types of strategies move away from having the teacher "tell" the student how to solve problems. 
During the observed lessons, Ally used direct instruction as her main strategy of

teaching. Ally liked direct instruction and believed it was successful,

I definitely found the direct instruction to be successful and just the fact to take the different approaches for them going up to the board or them doing it from the work and stuff like that; always changing it up so that they don't know what to expect and they're always just there, ready to work.

She did use other strategies that would promote retention, but most of the strategies were teacher-led. Ally did a lot drill exercises with the students during the observed lessons.

She explained how she used drilling as a way to help students learn the concept of Time,

We've broken it down we've done one day it would just be minute another day it would just be hour, you know we've broke down the days and you know we gave worksheets on it, we gave extra work to send home as homework for practice. Now we are actually having them every time they do an assignment during class they have to write down the time they start, the time they end and so we are trying to you know just give them as much practice as they need.

Ally said for those that were still struggling with the concept she pulled them aside and drilled them individually,

There is one student that was really struggling with the quarter hour and I pulled him to the side and I just drilled it like repeated it you know continuously repeated what a quarter was and after that I would let five minutes go by and I would ask him so what's a quarter after and he is getting the hang of it but I think it's just he needs practice like big time practice you know just going over and reviewing it just memorizing that.

Ally believed that the students "barely met" her expectations for learning time, even after drilling them.

Ally encouraged students to participate by having them share their work on the Smart Board, and interact using interactive Smart Board lessons, or Brain Pop videos. Ally used these interactive lessons and videos to capture students' attention and to involve the students because she remarked the review was monotonous, "I try to push 
those videos in and or try to get them to interact with the board and have some type of movement, kinesthetic." Ally called students up to the board by using Popsicle sticks with their names on them to ensure that all students got a chance to approach the board. She then discussed any student work and asked the other students in the class if they understood the work shared by their peers. This type of work on the Smart Board was done during the second, third, and fifth observed lessons. An example of a Brain Pop video was a video on repeated addition to solve combinations used during the final observed lesson.

During the third observed lesson, Ally allowed students to measure objects such as their textbook and their desks, Ally explained that she wanted her students to have practice with measuring and experience measuring as opposed to always be given the measurements. She wanted her students to make the actual measurements and add them up themselves to get the perimeter of objects. Ally also used a Smart Board lesson that allowed the students to use a large ruler to measure objects embedded in the Smart Board lesson. She explained,

I like the interactions in the lessons, so I like the fact that they are able to go [up to the board], I thought that the smart board lesson was really cool, that they actually had a ruler on there that they can manipulate and could measure the objects that were presented in the lesson. It was life sized to those objects, as opposed to, like if I had given them regular ruler we were using for their paper.

Ally decided to have the students exclusively do individual work for the fourth lesson because she wanted the students to practice individual work. Ally modeled for the students and then had them follow her modelling by doing individual work. Ally had students work individually for all the lessons, but she used individual work exclusively for this lesson. Ally explained that she used small groups at times in the semester when 
they introduced new topics, but they chose not to use group work at this time in the semester because it is a whole group review. Ally said,

Yes group work we do; not at this time cause of the fact that this is all stuff that we've gone over, so it's just pretty much review as whole group but, prior when they were just introduced we had group work.

She explained that she enjoyed group work because, "They can help one another work together as a team and someone who's struggling more has a stronger partner they can teach each other." Although Ally did not use group work, the students were seated in group clusters for four of the five observed lessons, and Ally allowed them to talk to their neighbors if they needed help. Ally said that she wanted to try small group interaction in her future teaching.

During the final observed lesson, Ally and her CT used counting songs to help students remember skip counting by $3,4,6,7,8$, and 9 . Ally found the songs to be effective, "We like teaching them with songs and stuff like that, that really sticks in their head, and they're young so they enjoy [the songs]. They really use that as a tool to help them." During this lesson Ally also used visuals such as having students draw a tree diagram to figure out the combinations. The Brain Pop video also helped students visualize the tree diagrams. Ally described the reason she used these visuals,

We gave them visual learning, when I actually drew the tree diagram, when they saw me modeling it for them; I had them do it on their own and the video also, they got to hear auditory, as well, and stuff like that.

Ally explained that she enjoyed having students do hands on activities, but she did not get an opportunity to do so during the SCAT review,

I always like hands on activities and something that they can actually work on but, being the fact that these are all reviews, I know that's not something that will be able to be done because, well I would assume, they were done already, they 
already had hands on lessons and other types of lessons that make it more motivating and engaging for them.

Although Ally was not able to use many strategies during her student teaching, she said was open to trying new strategies that would promote retention in her future students, "I would try small groups. Any approach that I feel every time they would be learning and I'm reaching a different learner so I'm open to all of those types of learning approaches, or teaching."

\section{Providing Alternative Representations and Recognizing and Analyzing}

Methods are Important. Graeber (1999) explains the last big idea that a preservice teacher should be aware of and use in the teaching of mathematics is knowledge of different approaches to learning and alternative representations. Within this idea lay several factors including the use of manipulatives to help students make sense of the content, analyzing alternative solutions to problems, and examining different ideas to similar mathematical experiences. Ally showed some evidence of providing alternative representations.

Ally used several manipulatives during her observed lessons. She used individual student clocks, pattern blocks, and rulers although not all manipulatives were effectively used. During the first observed lesson each student had an individual clock that the child could manipulate to tell time; see Figure 5 for an example of the individual clocks used. Ally said she enjoyed having the students use their clocks,

I liked that they were able to practice and that they had a lot of practice with the clocks, moving and seeing where the hour hand was and the minute [hand]. They actually got to [move it] as opposed to just looking at a clock. 
During the lesson all of the students were required to manipulate their clocks. Ally used direct modelling to show them examples of how to use their clocks and at the end of the lesson the students had the option to use their clocks during their individual work; however not all students used their individual clocks. Ally did not allow students to develop their own understanding using the clocks. Instead she showed her students exactly how to use the clocks. Ally and the cooperating teacher also broke the class clock into quarters and colored the four quarters different colors to help students identify quarters; see Figure 6 for a picture of the class clock.

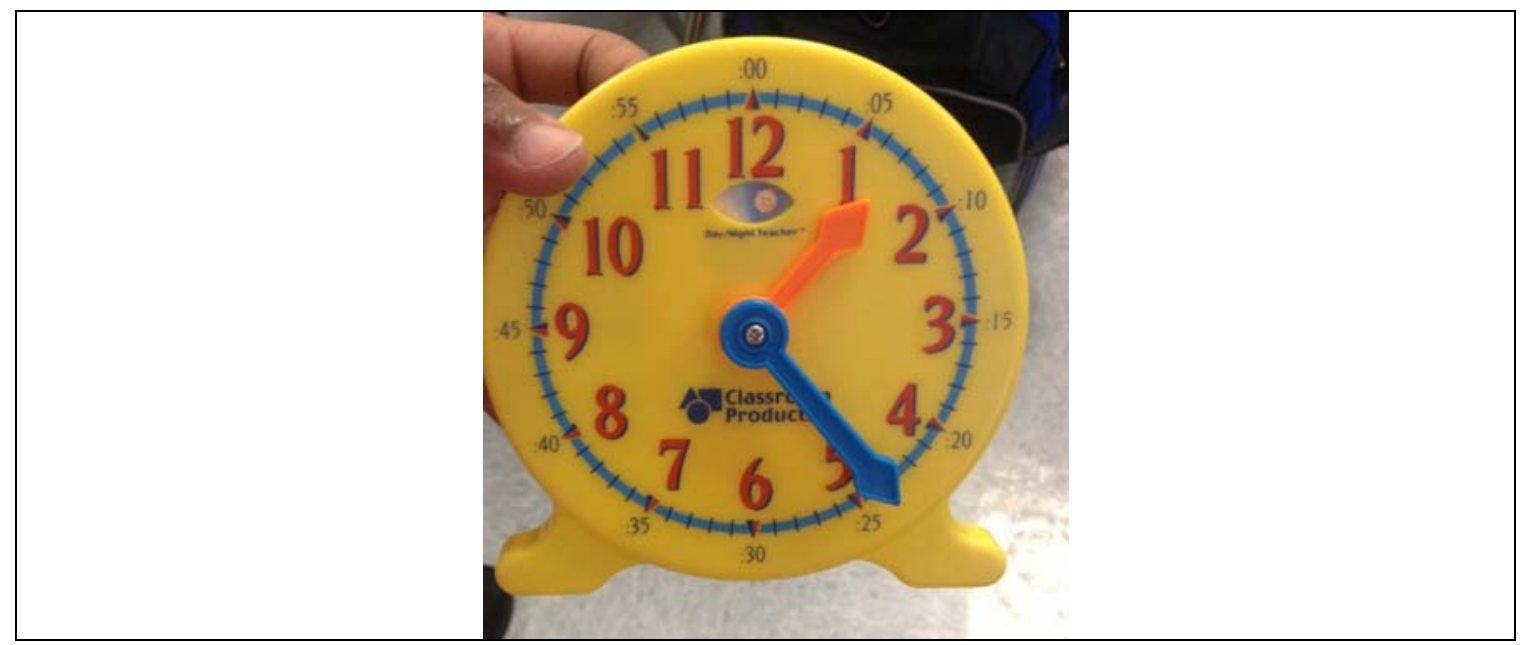

Figure 5. Picture of individual clocks used by students in Ally's first observed lesson.

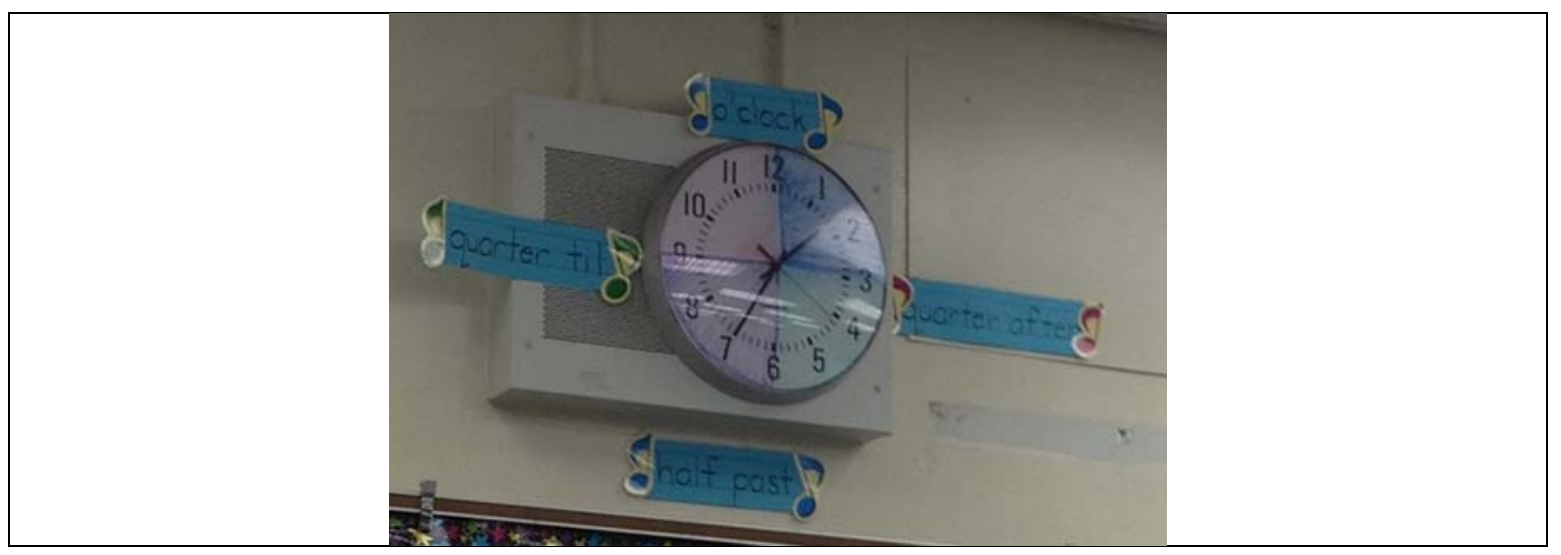

Figure 6. Picture of class clock broken up into quarters used in Ally's first observed lesson. 
For the second observed lesson Ally used pattern blocks to help students identify properties of polygons. Ally had polygons on the Smart Board that the students sorted, but the individual pattern blocks on their desks were only used for reference. The students were allowed to use the pattern blocks to help them answer questions, but the lesson was not focused on their use. Ally did not have students use the manipulatives to promote understanding.

During the third observed lesson Ally used rulers. Each student received a ruler which they used to measure objects and come up with the perimeter. The students already knew how to use rulers, and they seemed to enjoy using them. Ally never discussed the measurements that the students made, she was more focused on them being able to come up with the perimeter of the objects. Even when the perimeter of certain objects was wrong, Ally never really discussed the possibilities of making incorrect measurements with the rulers. Ally also used a Smart Board lesson with a large ruler and allowed students to use that ruler to measure shapes embedded in the Smart Board lesson. The ruler was "life-sized" and corresponded to the size of the shapes in the lesson.

Ally indicated that different methods to obtain a solution were important, but she did not analyze any methods that the students used. Ally allowed students to use multiple strategies to come up with their answers during some of the lessons. During the first observed lesson, Ally discussed different techniques to figure out the time from the start of one even to the other. During the final observed lesson on finding combinations. She accepted repeated addition, multiplication and even tree diagrams to figure out combinations, 
Let's say if they had an option of a blue pair of pants and a tan pair of pants and then, 3 different color shirts and 2 different color shoes, they can multiply each... $2 \times 3 \times 2$, whatever it is like that or, they can do the tree diagrams, which their book showed them how to do it and they can see their choices.

Ally said that some students used different strategies depending on the way the question was worded in the textbook. Ally did not analyze students' solutions and did not use any contextual problems that would promote alternative solutions.

\section{Future with Mathematics and Teaching}

Ally described the biggest challenge of the semester to be the review for SCAT because she thought it was boring and wanted to be able to create new lessons. However, Ally learned that she enjoyed math, "It can be fun, and it can be challenging, and you just have to ensure that you do reach all the different types of learners." Ally also learned a lot of content from her third grade student teaching experience that she believed could have helped her take the GK examination required for her major. Ally was looking forward to learning fractions with the students because fractions were her weakest subject, "We haven't gotten into fractions so I'm looking forward to seeing how that's going to work."

Ally indicated that she is looking forward to teaching mathematics to third grade or lower, "As the grade level gets higher it would be more of a challenge but as far as 3rd grade and down for now, I know that for sure." She believed that she will be a good teacher in the future because she is always looking for ways to perform better. If given a departmentalized school Ally would want to teach mathematics to lower grades, but she would be anxious about teaching to grades higher than third grade,

For lower grades yes, for higher grades I'm a little afraid. I would prefer the third grade and down, like I don't know. I don't think I've ever been to a fourth or fifth 
grade class, maybe fourth but not fifth. But then you know math at sixth grade, I'm sure I'd be fine, I'm sure I'd figure it out but it's just the students are at a different age level and the math does get a little more difficult so.

If Ally was in a departmentalized school she would not mind being assigned to mathematics for younger grade levels, but for higher grade levels, she would prefer to teach reading, "If it was a younger grade level, no, I wouldn't care. Math I think math can be fun."

\section{The Case of Belinda: High Mathematics Anxiety-Weak Content- Aspects of Strong Pedagogy}

Belinda is a Hispanic female who originally migrated to the United States from Cuba as a child. Belinda was enrolled in her student teaching experience as a senior at a large, southern, urban university. Belinda's experience with mathematics as a student was always challenging. As an immigrant, Belinda described her transition to the U.S. public school system as a difficult one due to language barriers. She explained that this language barrier caused her to have a difficult time with solving word problems in the subject, and explained her emotions when a grade was attached to problems that she had to solve,

I get really hot and I get sweaty and I can't do the problem; I blank out. I could do it if I'm at home relaxed if I was at my house but once I know it's for a grade or it depends on me to pass to the next grade level, I just can't do it.

Belinda's scores on the Abbreviated Mathematics Anxiety Survey revealed that she has high mathematics anxiety which she confirmed several times in her interviews. Her first statement in our first interview confirmed her self-proclaimed mathematics anxiety, “math is not my strongest subject - I get big anxiety when I see a math test. So I don't do well with math." Belinda describes mathematics anxiety as follows: "I think math 
anxiety is when you get a math problem or a math test, you can't focus because you're nervous and you get anxious to answer it so you either answer it wrong because you're nervous or you just, you can't do it at all."

Belinda's overall GPA was 3.57 prior to completing her student teaching. Her content GPA was 2.67, which is based on three mathematics courses. These courses included Intermediate Algebra, College Algebra, and Mathematics for Liberal Arts I. She also completed and passed remedial courses, College Prep Mathematics and Basic Algebra. However, these courses were not credit bearing and did not factor into her GPA. Belinda's pedagogical content knowledge GPA was 3.00, which is based on one mathematics course. This course was Teaching Elementary Mathematics Methods. It should be noted that she had dropped this course in a previous semester and received a grade of 'DR' on her transcript.

\section{Belinda's Personal Experiences with Mathematics}

Belinda described negative experiences in mathematics during middle school with long division and in high school with algebra and solving word problems. She describes her frustration toward the concepts on the SCAT, “I just didn't understand the concepts I couldn't understand it since it was SCAT, and I just couldn't pass it, I like shut-down. So I was frustrated." Belinda stated that she learned best from one-on-one experiences with teachers and described this as the most effective method to help her understand mathematics content. Belinda encountered her least favorite teacher in high school as well. She described her least favorite teacher to be an algebra teacher who focused her attention on the students who were understanding the concept, "She would pick on those [who understood] and go, "Oh you know! Show me" and then the ones that struggled 
even though she knew based on her grades, she wouldn't like pull them aside and be like, "I know you're shy but show me what you don't understand"." This particular teacher did not use cooperative learning strategies nor did she use manipulative to aid in understanding. She focused on traditional methods of teaching mathematics such as lecture and note taking.

Belinda carried this anxiousness toward mathematics all the way to her college/university classes where she describes her first good experience with the subject. Her first good experience was described during the mathematics methods course that she took as a requirement for her education degree.

Honestly, college. I had a really good math professor that made it very fun and helped me understand a little better. [she] helped me to realize things you can use to help the students to help them understand, but make it fun at the same time, to be able to learn how to solve the problems, and here I try to use it as much as possible because sometimes it's really hard and it's boring, so you have to try to use different manipulative in order for them to have fun at the same time they're learning, so I think that's really important.

Belinda even described her favorite mathematics teacher as the instructor of this mathematics methods course at the university because she enjoyed the course and the instructor opened her eyes to the use of manipulatives to aid in students' understanding of the content.

I really, really enjoyed the class and I really learned. Well you were able to use manipulatives to solve the problems, because maybe for example with fractions. I don't like fractions, but if I give my students fractions, the fraction circles they help because they're able to play with it and they're able to see how they could get the answer by using different things they could touch to solve it, not just solve it with a pencil.

Another good experience Belinda described in college was during a course which focused on probability. She enjoyed this course because she explained that the content of the 
course focused on more logic than using formulas to solve problems, and she enjoyed that aspect.

Belinda's family influenced her perception of mathematics in different ways. She explained that her father was always good at mathematics and constantly encouraged her, but her mother was not very good at the subject.

Well my father is really good with math so he was always pushing me, he would put me on the table if you need to, he'd make little flashcards for me, "you need to memorize this to understand, to learn it"; he was a positive one. My mom on the other hand, her math is not the strongest subject for her so she would just be like oh you know, more to the lenient side. But my father was always like you have to do it, no TV, why don't you understand it? And then he would try to explain it to me as much as he could because he doesn't speak English but that was my positive. He was my positive. And my mom, she wasn't as...she doesn't know she was like. "Oh try your best", but my dad would like sit with me and try to explain.

Belinda explained that her dad had language barriers as well so although he was able to explain the mathematics to her, he could not help her understand word problems.

\section{Context of the Student Teaching Placement}

Belinda's student teaching placement was in a second grade self-contained classroom of 19 students with a balanced number of boys and girls. Although Belinda feared mathematics, it was the first subject that she assumed responsibility for teaching; she began teaching mathematics during the third week of the student teaching experience. In the beginning of the semester when Belinda was asked about how she planned to teach mathematics during student teaching, she highlighted her plans to focus her efforts on becoming a mathematics teacher who would make a difference for her students and who would display qualities opposite to those teachers with whom she had negative experiences as a student. Because of her positive experiences with learning from one-onone instruction, Belinda planned on using this strategy with students who she believed to 
be having trouble understanding the content. She enjoyed and learned from teachers who used this approach with students.

I don't like teachers that teach and sit down, or teachers that know that the student is shy and they don't pick on them. What I do in this class, the students are always raising their hands in class; I pick on them but not as much as the ones that are quiet because I know they're quiet because they're scared but I don't try to put them out there - I try to help them. What do you think about this? Do you understand? What is your answer? What did you get wrong? Let's try to do it to see if we could get it right. Because if you don't focus on those students, they're never going to raise their hands; you don't know if they're understanding or not so I always try to pick on those [students]. Because the ones that raise their hands know what they're doing.

Belinda recalled being one of the shy students who refrained from raising her hand and from participating in class.

I was the one sitting all the way in the back and my hand was always down. Whenever the teacher will say, "Who doesn't understand?" I didn't understand but just because I was embarrassed, I wouldn't raise my hand.

Belinda explained further that during her student teaching she would specifically help

students who demonstrate traits of mathematics anxiety by reassuring them,

I would approach them and tell them that they're going to be ok; that they know what they're doing, because when you're nervous, you don't feel confident about what you're capable of doing so you automatically shut down. "Do you know what you're doing? We've been practicing all this time and you answer correctly." "This is just...don't think of it as a test - think of it as homework that you're doing at home, don't think it's for a grade and...", just so that they could calm down. The important thing is telling them they know what they're doing; you do this in class.

Throughout her interviews, Belinda stressed the importance of building confidence in her students because she never had confidence in her understanding of mathematics.

In the beginning of student teaching when Belinda was asked about what she feared most as a teacher of mathematics she described her concern of not being able to impart knowledge to her students. 
I'm scared that they don't understand the way I'm teaching it to them, sometimes I teach them something and I stop and I'm like, "okay, do you understand what I'm saying?" because then they're not going to be able to understand me so I try to make sure I think about it before I tell them this is the way how you do it or who could tell me another way they might be able to solve the problem that they could help me.

She was cognizant that she needs the students to explain the content in their own words to ensure their understanding. Belinda affirmed that she would use manipulatives, project images onto the Smart Board, and have the students approach the board to work out problems. She believed that even if students solve a problem the wrong way it is important to discuss the student's work to come up with the answer, "I have the students teach it to the class."

Belinda believed that she would be a successful mathematics teacher during student teaching because of her placement in a second grade class. Belinda was not concerned about the mathematics content as she described it as "baby math"; however, she would fear the content of a fifth grade classroom.

I fear the content in 5th grade for math. If they're already getting to the hard...because it's SCAT stuff; I don't see myself teaching SCAT stuff, I refuse. It's horrible. I mean if I don't have a choice; I would have to just cry every night but it's horrible. That's all you focus on, and here [in second grade] you focus on SAT. Every day we do a page of SAT in this class for math.

Her anxiety to the mathematics content of a higher grade level is evident throughout the interviews with Belinda. In the final interview Belinda stated that she was still anxious to teach mathematics to a higher grade level because she knows that mathematics would get harder and she would need to find other ways to help students understand the content.

By the end of the student teaching semester Belinda indicated that she had always been anxious about teaching mathematics but some of that anxiety had decreased. 
At first I was really nervous. I didn't know whether or not they were going to understand the way I taught, but little by little, they were able to understand and I felt more confident with the students and pretty much little by little.

Belinda cited several times that mathematics had been her favorite subject to teach during student teaching because she found the content easy to explain to someone since she had a better understanding of it now.

Overall, Belinda had some anxiety about teaching in general, but she said that that anxiety decreased over the course of the student teaching semester and she was looking forward to becoming a teacher. "I feel great [about teaching]. I noticed some improvement in my students, which made me feel that I was teaching and they were able to understand the way that I was approaching toward the content." During student teaching, Belinda was also anxious about teaching Social Studies,

I don't like the subject. I really don't like it, so for me to teach it I had to really go home and read it and see, 'Okay, how can I make this fun?' It's really boring and they get really bored, so you have to make it fun in order for them to understand what you're talking about.

She indicated that she had to learn a lot of content for Social Studies that she never knew before. She also said that reading was a little challenging to teach.

\section{Belinda's Relationship with her Cooperating Teacher (CT)}

Belinda expressed that she had a good relationship with her cooperating teacher and explained that she was the one who helped Belinda the most during the student teaching semester, “My cooperating teacher because if I didn't understand, I would go up to her and be, "Okay, how would you do this?" so I can do it the same way." Her cooperating teacher helped her plan for each lesson that was observed. Belinda stated 
that her cooperating teacher allowed her to try new strategies with the students and was very supportive of her work.

Belinda's cooperating teacher wanted to voice her opinions of Belinda. The cooperating teacher approached me after the third lesson to state how much she enjoyed that Belinda was willing to try new strategies. She stated that she learns as much from the student teachers as they learn from her. She was impressed that Belinda tried new strategies because she indicated that they were strategies that she knew but didn't use because she gets too caught up with testing. She even made it a point to show me various literature books that Belinda used during her teaching. She said, "The world is made up of many colors!" Belinda's cooperating teacher also interrupted the fifth lesson observation interview to share explain why Belinda selected not to cover certain problems during the SAT practice. She explained the reason Belinda skipped problems and opted for the cooperating teacher to do them is because of the concern that Belinda has for the students; she only wants them to understand the content. She said that Belinda is too hard on herself because sometimes the students don't even understand it when she (the cooperating teacher) explains it. Her cooperating teacher felt that sometimes teachers just have to relearn content and explained that she had to relearn rules when she began teaching.

\section{Planning for Teaching Lessons}

Belinda took her time in planning for her mathematics lessons. In general she took three hours to plan her lessons spread over a couple days; however for the practice lesson on the SAT practice booklet that was already created by the school she only took one hour and for another lesson she took as long as four hours because she had to create 
additional activities. Belinda never planned a lesson all at once. Belinda consistently used the resources of her cooperating teacher and her textbook. In addition she used the student practice book and the Encore workbook from common core for assessments. "I took the books home and then read the books and see how I am going to present the information to the students." In addition, Belinda even used resources from teachers in other grade levels.

I borrowed materials from first grade. The manipulatives that we used with the shapes, only first grade has it so I borrowed it from three different teachers. The book was a first grade book. I had to go to the teacher and borrow it. Cause we don't have...second grade does not use those manipulatives, so I had to borrow them and then I sat down with my cooperating teacher...ok what can I do to extend the lesson cause it is really short, it's really short, so I always extend it. So since she was observing me I had to do that... demonstrate, guide... so I had to work at extending it.

Belinda discovered valuable children's literature that could be used to enhance her mathematics lessons. She found literature books that related to the topics online and ordered the books to use during her student teaching experience.

For one lesson, Belinda had to plan additional activities because there was only one worksheet assigned to teach an hour long lesson.

I got with my teacher and I said, how can I expand it to make it longer and, we came up with that they could put all the different coins on the board, similar to their assessment so they can be comfortable with it and, I know now what I should've done. I should've flipped the coins on the smart board but, that is something to do different.

She used google to find the images of the coins to present to students during one lesson on teaching the value of coins.

I try to use the textbooks to see how I can incorporate some other things like, I incorporated things that we did yesterday as a practice, like the dollar sign, the decimal point, to remind them and, then I did how many quarters equal $\$ 1.00$. We did that yesterday as a refresh. I had to create a practice sheet, then I had to make 
sure all the bags had the same amount of coins and then, I had to do the smart board copy/paste and resize.

Belinda used multiple resources throughout her student teaching semester and was always prepared for the observed lessons.

\section{Belinda's Mathematics Anxiety throughout the Semester}

On the pre-lesson surveys, before her lessons, Belinda indicated that she was very comfortable with the content of her lessons, rating her comfort level at a $5 / 5$ on all lessons except her second lesson where she indicated a rating of a $4 / 5$ with a 5 indicating that she was very comfortable and a 1 indicating that she was not comfortable. She was also felt very comfortable with teaching the lesson she had planned indicating the same results with a rating of 5/5 on all lessons except her second lesson where she indicated a rating of a $4 / 5$. When asked about her feelings before the lesson in the pre-lesson surveys, Belinda described comfort and confidence to teach all the lessons using phrases such as, "I am comfortable and feel for the lesson", "I feel confident in teaching the lesson", and "I feel excited to be able to teach the lesson on coins." However, this contradicts what she told me verbally before the lessons.

Belinda indicated that she was anxious and nervous to teach four of the five lessons that were observed. Before the first lesson she mentioned to me that she was very nervous and she was sweating. During the first lesson observation interview she made contradicting statements about being both confident and nervous; she said, "I was confident about the lesson but nervous, very nervous. I was comfortable with the lesson, but nervous teaching it." She indicated that the mathematics vocabulary in that lesson caused her the most anxiety, "There are certain things that I needed to further explain." 
Belinda stated that she explained things the way she understood it, but that is not necessarily how it should have been presented to the students. During the second lesson she came up to me fanning herself, and exclaiming "I don't know why I get so nervous!" Toward the end of the same lesson, she was flustered and her cheeks were red, and at the end of the lesson she took off her jacket and asked if I was hot as well.

Before the beginning of the third observation Belinda approached her university supervisor and myself and mentioned that she was very nervous; her cooperating teacher also told us that she was nervous but assured us that Belinda would do fine. Belinda showed no obvious signs of mathematics anxiety during the fourth observation, and she revealed that she was not nervous because the content was not brand new. "I felt confident since it's not something new to them. We've been working with coins, like I said, like two weeks in a row, so they are more comfortable with them."

During the fifth observation Belinda showed signs of anxiety when she decided to skip a problem. The students were working on a packet of SAT practice and the content varied across the questions since it was a cumulative review. She was reviewing the answers with the students, but when she arrived at number 30 she decided to skip the problem. She also decided to skip number 31. She paused for a long time, her face turned red and she said "let's see". After that she repeated "skip 31" three times to the students. When she was asked about this behavior during the lesson observation interview she said,

I was comfortable teaching it, except for a few questions that I skipped because they were covered when I wasn't here and I don't know how to explain it to them, so that I put a star, then I let her [Cooperating Teacher] take over it and do it more in depth. 
She went on to further explain,

when I see it and I know, I am like ok, I know I won't be able to; I'll confuse myself as I am explaining it to them, and they are going to be confused and then it is just going to create, so I'd rather her do it as she knows exactly how to tell them and they understand. But if I tell them, they're going to be like Aww...you don't know what you're talking about, so I rather not tell them.

At another point in the interview she elaborates on this idea:

That specific question was tricky and, I wasn't sure they needed a ruler for that one because they were asking, they had a pen and, the pen was this small and then the other things was this size and, they want to know what size this was but, the answer was, the number was very low so, I was actually confused myself so I wasn't sure, ok, if this is bigger, and they are asking for the size of this, why is the answer, let's say a two, when you have a four or a six here?

These statements are evidence to the lack of confidence in the mathematics content that Belinda projected at times. (These statements also demonstrated issues with Belinda's content knowledge, which will be discussed in another section of this case study.)

Belinda's anxiety was evident in her teaching when she hesitated at times to review a question, or when she would repeat the same phrase a number of times. Belinda also made careless counting errors where she would count nickels from 5, 6, 7, 8, 9, 11 and then say that 11 nickels equaled to 50 cents. Mathematics anxiety was also evident through her perspiration and flustered face during lessons 1,2 , and 5 . Her anxiety mostly manifested itself before the lessons when she would indicate her anxiousness.

During the first four lessons observed, Belinda was also having a formal supervision conducted by either her Cooperating Teacher or her University Supervisor; she was being observed by two people during these lessons. When she was asked if that made a difference she said her nervousness might have decreased if she did not have that additional pressure. "Maybe I would be a little less nervous having my cooperating 
teacher and my supervisor both looking at me teaching, so maybe it is going to be different because I'm going to be more comfortable teaching my students. I won't be so scared and nervous." She also indicated that she planned a little extra when she was being formally supervised.

\section{Belinda's Content Knowledge}

Belinda's belief in the importance of mathematics content was apparent during her interviews; she stated “you need math because if you didn't have math, you can't solve problems and then once you graduate, you need math to solve problems in everything you do in your life." Although she believes that mathematics is important, Belinda said several times that she feared teaching the content of mathematics in higher grades, "I fear the content in 5th grade for math. If they're already getting to the hard...because it's SCAT stuff; I don't see myself teaching SCAT stuff, I refuse. It's horrible." Belinda believes that the second grade mathematics that she had been teaching was relatively easy and considered it "baby math". With this being said, it was observed that Belinda encountered a few challenges in her teaching of the content to the second grade class. At times her presentation of the content could create possible misconceptions for her students. Examples of these observations will be presented.

During the teaching of the first observed lesson, Belinda introduced students to the concept of whole, half, thirds, and fourths using various shapes. When presenting the different shapes to the students Belinda did not discuss any properties of the shapes except for their name. Belinda presented partitioned shapes on a teacher-made board. She partitioned these shapes inconsistently. The rectangle divided into half was divided with a vertical line down the middle of the shape, while the shapes partitioned into thirds 
and fourths were partitioned using horizontal lines through the rectangle. The circle representing thirds that she presented to them was not partitioned in equal parts so when she asked a student to tell her if this shape represented thirds, the student answered no. Belinda told her that it was supposed to be equal, but it was very hard to draw thirds on a circle. In partitioning the next shape, the octagon, Belinda did not draw the line through two vertices, but instead drew the line from the middle of one side to the middle of the opposite side. Also, she did not include an octagon that was partitioned into thirds when the shapes were presented to the class. This inconsistency in partitioning shapes could cause a misunderstanding for the students when introduced to other topics in mathematics such as comparing fractions.

On the practice worksheet for the same lesson on fractional parts, she did not asses the students' knowledge of thirds; there was no problem that covered this topic. After the main lesson was over, Belinda went over some problems in a practice booklet for their SAT. One of the problems required students to count by fives "What comes after 20?" When she asked for the answers to that question, one boy answered 25, so she said "Correct, let's count by 5s." Belinda held up one finger and asked the students what number comes after 20 and they answered chorally, 25. But she said no and forced them to count one by one, $21,22,23,24,25$ then she stopped and said 25 . After that she repeated the process until they got to 30 . In reality she was counting by ones and stopped at the five intervals. She went on to another question without any further explanation. Belinda did not reflect on any of these ideas when asked about things that she might change for her lesson. 
The second observed lesson dealt with learning to identify angles. She explained that angles were similar to vertices and said "an angle is when two lines connect". Belinda pointed out the vertices as the points where two lines connect and then said that "the angles are where they [lines] meet." She showed the four angles drawn inside a square, but did not indicate that they were right angles, she drew circular arcs to indicate the angle. After drawing the arcs she asked "what is the outside where they meet called?" The students answered the vertices. She said "ok", and continued to identify angles in various shapes. During the lesson she decided to distribute 3D shapes to the students for them to identify the angles. She only had students look at one face and did not discuss the other faces of the 3D shapes. It was hard for the students to identify the angle of the cone on the 3D shape, but when the cone was drawn as a 2-dimentional figure on the smart board a student was able to identify the angle that she wanted them to identify. At the end of the lesson she read a story titled 'The Greedy Triangle'. The word quadrilateral comes up in the story but she did not mentioned this word in class before. She did not review the word as a new vocabulary word. In the story the shape continued to gain more sides, but she did not connect that to the fact that the shape eventually becomes a circle.

In the third observed lesson Belinda's objective was to use different coins to represent the same value of another coin. When she discussed the values and sizes of coins she chose students to wear signs indicating the names of the coins as well as their monetary value. She chose two students who were the same height for the penny and the dime and when she asked the class if they were the same size, the class chorally answered 
that they were. She never clarified that the penny was larger in size than the dime, but that the dime was actually worth more than the penny.

During the fourth observed lesson on money Belinda used the word 'coin' several times inappropriately when she meant to say 'penny'. For example she asked, "If I have 100 coins how much do I have now?" The students gave the answer that she wanted which was one dollar, but she kept using the word coin in place of penny throughout the lesson. This mistake occurred several times. An error like this can potentially confuse some students. Even when she was asked during the interview, Belinda did not correct herself. "I want them to know that a hundred coins equal one dollar. That one dollar bill will be a hundred coins put together."

Belinda's last observed lesson was a cumulative review for the SAT. SAT practice booklets were being completed during this part of the semester. Belinda had to cover a variety of topics during the discussion of the answers to these practice problems. During this review Belinda encountered some errors in her presentation of the content to the students. Students were confused on a question on probability asking what number a spinner would least likely land on if there was a circle broken up into four parts where the part labelled ' 3 ' was the smallest part. She tried to explain the spinner would land on the others because there was "more space" or "a lot of space", but she never indicated that the part labelled ' 3 ' covers the least area; she only alludes to it being a small or little space.

Similarly, the next question dealt with the chance of obtaining a specific bead if there were 10 beads in a jar and 4 are of one color, three were of another color, two were of a third color, and one was of a fourth color. Two of the students voiced that they did 
not get the color associated with the four beads, but instead thought the right answer was the color associated with the two beads. She explained to them that this was a tricky question. She illustrated the beads on the board indicating color by different shading inside of a circle. She asked "What are my chances of getting the one single white one?" No student answered and then she asked "Can I just get it?" "No" she says because I only have one. In reality it would be the least likely to get the white one, but it would not be impossible. Then she moved on to the other and asked "What are my chances of getting one of these two? Can I get one?" At this question, the students answered no chorally and she agrees that she cannot pick any of those because there are only two and she puts an $\mathrm{X}$ through the pair of beads. She explained that when you shake a jar of beads you are likely to get four because this is the best answer. She does not explain that it is the group that contains the most beads. She proceeded to add four more beads to the group that contained three beads to make it a new group of seven, but she shaded the four new beads differently from the other three in the group. When she asked, "Now which one would we get?" One boy still replied the original group of four beads, but she said no and asked another student. When the second student indicated the group of seven she replied, "Yes this one because look how many I have." The group of seven were not shaded the same way so some students might have assumed it was two separate groups of four and three instead of a whole new group of seven. She ended that discussion by saying, "you always get the one that has the most so that is why A is the correct answer." During this same practice lesson, a subtraction problem was posed. The students were subtracting 8 from 26. She asked them if they could take away the 6 from the 8 instead of 8 from 6 . The students still answered no, but it could have possibly been 
confusing. She also reminded them of the rules for regrouping a number by saying when you take a 1 away from the two it becomes 1 and the 6 becomes 16 . She was just showing the students the procedure for subtraction, but there were still errors in the procedure that she explained.

Belinda had content errors in all her lessons. The errors described in this section could have affected students' understanding as well as their misconceptions toward mathematics. Belinda showed poor content knowledge in the topics where she made these mistakes.

\section{Belinda's Pedagogical Content Knowledge}

This section will outline examples describing Belinda's actions and ideas pertaining to Graeber's (1999) five big ideas on pedagogical content knowledge that preservice teachers should possess. With respect to Graeber's big ideas, Belinda demonstrated the ability to assess students' understanding. She demonstrated some ability to implement lessons that promote student retention of ideas as well as provide alternative representations of concepts. However, Belinda did not demonstrate the ability to implement lessons that provide opportunities for students to demonstrate both conceptual and procedural knowledge as well as create lessons that consider students' intuitive understanding of concepts.

Understanding Students' Understanding is Important. Graeber's first big idea focuses on student understanding and supporting students' reasoning. Student understanding was very important to Belinda. She constantly spoke of the importance of having her students understand the material. She commented that a good teacher is one 
who takes the time to make sure all her students understand a topic even if that requires one on one explanation.

Belinda often asked students to explain their answers to the class after working problems out on the board. She loved the interaction of having students approach the board to solve problems. She used this approach to teaching during each lesson that was observed. When the students were not working problems out at the board they worked in pairs or did worksheets. When going over classwork, Belinda also asked the students to verbally explain their thinking by using the phrase "How do you know that?" She practiced this technique during all the lessons that were observed. Belinda explained that as a student she learned best from other students, and she wanted to give her class the opportunity to learn from each other as well and that is why she would have students explain their solutions on the board,

I guess if they understand something, I will have them come up to the board and, 'Okay, show me. Show the class what you know. Be the teacher.' Because sometimes I feel like because it happened to me when I was in school. The teacher would tell us what to do and I don't understand, but then when my friend would explain it to me, I understood it better. So I think I would allow that.

Belinda described the use of pair work to enhance student understanding. During her lesson on using different coins to represent the same amount, she had the students work in pairs. She explained that they could help each other this way,

Having the students work together; they help each other. If this student doesn't understand then, this one would explain; like they help each other understand how they can use different coins to come up with the same value.

Another strategy that Belinda used to assess student understanding was her movement in the classroom. Belinda constantly circulated the classroom when students worked on 
assessment. These assessments were always in the form of worksheets or questions to answer from the text. Belinda explained that she checked students' answers as she circulated and answered any questions that arose.

Belinda also accepted choral answers to questions that checked for understanding. If students voiced that they did not understand something, Belinda would re-explain the content, but it was never observed that she changed her teaching strategies or the direction of the lesson. During the last observed lesson, when a student did not get a correct answer for an addition problem that was shown on the board, Belinda counted her fingers with the student as a strategy to help them understand.

While discussing her teaching, several times Belinda alluded to the fact that she enjoyed having students explain their thinking because it helps other students see different ways of understanding a problem and Belinda believed that some students can possibly learn better from hearing another student explain their way of understanding. When asked to work out a subtraction problem for the SAT practice a boy wrote the correct answer without using regrouping "he did it, I don't know how he found the answer; he got the correct answer so maybe the way he is doing it, they understand but, when I do it, they don't understand”. After allowing the boy to explain his work, she still made him solve the problem using the regrouping strategy to solve the problem. This demonstrated Belinda's ability to assess student understanding in multiple ways.

In the final interview when Belinda was asked what she enjoyed most about teaching mathematics during the semester she replied,

Being engaged with the students, like I told you before I like for them to come up to the board. I like to see. I like for them to teach me what they know so I can be 
able to help them understand better or give them other strategies to help them come up with the answer.

Belinda also mentioned that she learned to be flexible as a teacher during her teaching of math. She learned that sometimes she needed to extend a lesson for another day to further explain the content.

Sometimes you plan for a lesson and you might either depending on the way the students understand, you might go over your time or you might want to extend it to the next day so you can further explain so they can really understand the concept. That I learned as really important.

By the end of the experience Belinda indicated that she was confident that if a student does not understand in one way she can help them understand in another way. "I know they're going to understand and if they don't understand one way, I find another way to help them understand, even if I have to go baby steps."

\section{Students Knowing in One Way Do Not Necessarily Know in the Other(s).}

Evidence of conceptual understanding was scarce in both the observations and interviews conducted with Belinda. She alluded to different types of knowledge but never provided concrete examples that provide evidence of conceptual understanding. She indicated that as a student she found word problems to be challenging, "I struggled with the word problems more. I remember word problems and then they give you graphs and then ask you questions and you have to like put everything together. That to me was hard." She

alludes to conceptual understanding in one interview when she was reflecting on teaching fractions "I don't like fractions, but if I give my students fractions, the fraction circles they help because they're able to play with it and they're able to see how they could get the answer by using different things they could touch to solve it, not just solve it with a pencil." This type of teaching was not observed. 
Belinda did identify different types of understanding in relation to her understanding versus the students' understanding but she did not distinguish between the different types of understanding. She described situations that may have helped students with conceptual understanding in her first post-lesson interview, "I was considering having them actual shapes," She knew that students understand in different ways but when she had students explain their answers, the discussions focused more on explaining the procedures to solve a problem that the conceptual understanding of the students.

The assessments Belinda used during her lessons were informal observations and worksheets where students solved problems. Most of the problems could be solved using procedures. There were no problem-solving task posed that allowed the students to acquire conceptual understanding. Even when she created extra activities to "fill in" the hour of mathematics, she simply created extra worksheets on the same topics; she did not create extra mathematical tasks to promote contextual thinking. She said, "I would just use the examples from their worksheet from their workbook and just create one similar to that one." She indicated that she used the HOT (Higher Order Thinking) problems found throughout the chapters of the textbook, but I did not observe any discussion on those types of problems. She stated, "We did do all those [HOT Problem]; they are challenging." When asked which topic she enjoyed the least for the semester, she said she enjoyed the measurement topic the least, and when asked if she discussed nonstandard units for measurement with her students she replied that she only used a ruler and yardstick and went over examples on the assessment worksheets. Belinda used many manipulatives in hope that these would aid in understanding, but the way these 
manipulatives were used and the questions posed did not elicit the ideas that promote conceptual understanding.

Belinda was able to help students develop procedural understanding. During the lessons observed, Belinda always provided an example of the procedure she wanted the students to use before having them work on their own. When the content required procedures already been taught for instance addition and multiplication skills, she helped the students review those skills.

Intuitive Understanding is Both an Asset and a Liability. Graber's third big idea focuses on misconceptions and preconceptions important for learning. Belinda showed some evidence of understanding about students' intuition. During her second observation interview, Belinda showed some knowledge of understanding that students' prior knowledge and understanding could cause misconceptions. She discussed the difficulty that students had with understanding the difference between the vertices and angles; however she did not discuss this misunderstanding with the students. She explained,

It [the lesson] was good. I was happy because they really understood I think. But it is a little confusing cause the vertices and the angles are similar, but they have to understand that the angles are what's connected inside, so...

During the lesson, she simply tried to explain the difference. Her explanation as discussed in the Content Knowledge section might have also caused some misconceptions for students, but she had a discussion with the students about their ideas. During the observations conducted Belinda never posed mathematical tasks that created discussion about mathematical ideas. She did not demand students to challenge each other's thinking. She did ask students to explain "how they know" their answers were 
right, but those explanations did not provide alternative ways of thinking about the content. During her second observed lesson Belinda used 3-dimentional shapes to discuss the 2-dimentional property of an angle. The top of the cone was used to illustrate an angle, but no discussion of why this might or might not illustrate an angle was carried out.

During her last observed lesson, Belinda actually discussed her own misunderstanding with one of the problems that the students needed to solve on measurement. The question was asking the comparison of the size of two objects and the answer should have been two because the pen was twice the size of the other object. Belinda skipped that problem with the students and wanted her cooperating teacher to explain it to the students. This indicated that Belinda was avoiding the content she was not comfortable explaining.

Belinda says she likes to teach mathematics because she believed it was straightforward. She did not discuss possible misconceptions that might arise "I actually like teaching math because it's straightforward. It's either you know it or you don't." She continued to explain that reading is more challenging to teach because of possible misunderstandings in the reading or comprehension difficulties. She does not make any mention of these difficulties with mathematics.

Certain Characteristics of Instruction Appear to Promote Retention. Belinda showed weakness in the area of using instructional strategies to promote retention. During the lessons observed, Belinda did not use any strategies that included having students write about their ideas. She did have students explain their thinking at times, but the discussions did not promote healthy criticism of ideas. In the beginning of her fourth 
lesson Belinda did introduce a meaningful mathematics problem. She posed a scenario to the students about buying ice-cream from an ice-cream truck. The students were visibly excited. She told them that they would need $\$ 1.50$ to buy an ice-cream cone. She continued to explain that one student had lots of coins in his pocket and he would need to count out the coins to get to $\$ 1.50$. She asked if that would take a long time and the students answered that it would. She then went on to explain that another student had a dollar bill and some coins. She asked the class to determine the child would take longer to count their money in order to buy the ice-cream. The children were able to explain that the student with the dollar bill would take less time to come up with $\$ 1.50$. This mathematical task was meaningful to these children but the rest of the lesson did not focus on the length of time needed to count money, it simply focused on the different ways coins could be put together to create a new amount of money. Belinda shows awareness of the importance of using meaningful contexts, but she only used this type of problem in this lesson.

Belinda at times used real life situations to explain concepts in her teaching. In her second observed lesson, Belinda did ask students to identify objects in the classroom that had angles. In her final interview, Belinda explained that during a lesson that was not observed she brought objects from the real-world such as a can of soup and a basketball into the classroom to provide real-life examples of 3-dimentional shapes. However, Belinda never posed a contextual problem and had student work on solving that problem. The mathematical tasks were done in the form of worksheets assigned after the topic was taught. 
Belinda used literature books to highlight mathematical concepts during the lessons observed. Those books included, "The Greedy Triangle", "The Coin Counting Book". She used these books as motivation for her students to make sense of the concepts but did not engage in discussion about the ideas of the books presented. Finally, Belinda also used chocolate as an example to gain the students' interest in fractional parts. She used a Hershey chocolate bar to represent whole, half, thirds, and fourths as an introduction to the lesson. This motivated her students as you could visibly observe their excitement. She manipulated the chocolate and showed them the different parts. She did not have them discuss the parts or even tell her how she should break the chocolate up.

Overall, Belinda did have students explain their ideas but there was no class discussions observed that had students debate on topics or grapple with those ideas. Belinda is aware that classroom discussions are important but she did not pose contextual problems that cultivated rich classroom discussions. Belinda also discussed her awareness of the importance of posing contextual problems in her final interview. When she was asked what approaches to learning she enjoyed using and would use with her future classrooms, Belinda answered "I guess giving them real-life examples. Something that they can relate to, to be able to understand what the subject is."

\section{Providing Alternative Representations and Recognizing and Analyzing}

Methods are Important. Graeber's (1999) last big idea focused on using alternative representations and using alternative methods to help students understand mathematics. Belinda provided multiple representations for her students in each observed lesson. Belinda used manipulatives during four of the five lessons that were observed. Although she explained that it was sometimes difficult to use manipulatives because it led to 
behavior issues with the students, she believed the use of manipulatives was necessary. She used shapes cut into fractional parts, she used fake coins and pictures of coins to help students with ideas on money, and she used drawings on the board, pipe cleaners, and 3dimentional shapes to explain angles. Although these manipulatives were mostly used to explain ideas, her knowledge of the importance of these were evident. Also, she helped students explore their own ideas with the use of some of the manipulatives. During her interviews she emphasized the importance of using manipulatives with students, "I would use manipulatives with every lesson I teach. If I have it, I will use it. If not, I will make it up. That's what I would do."

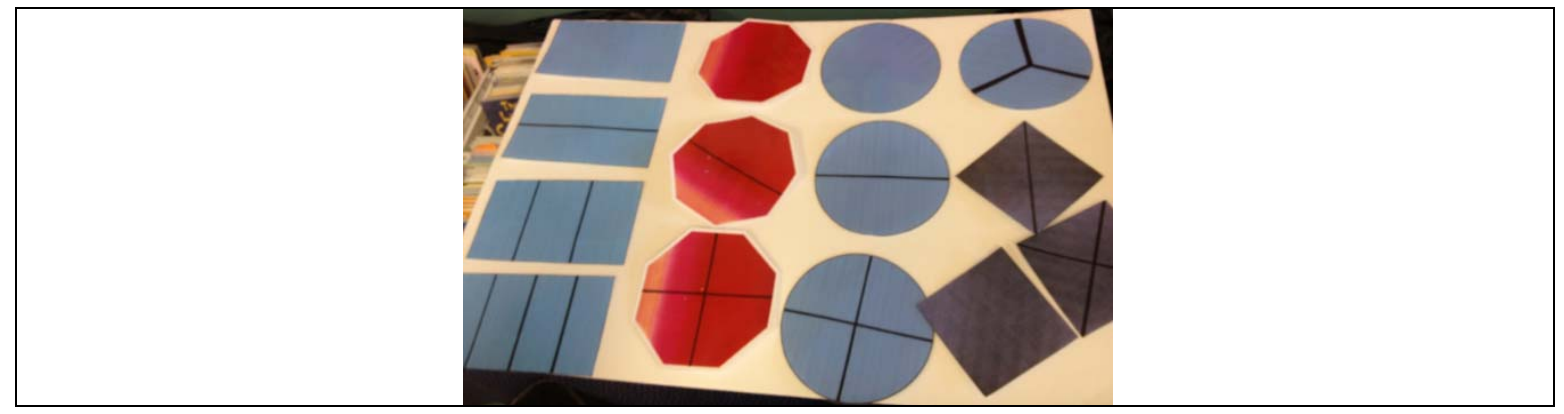

Figure 7. Fraction poster used in Belinda's first observed lesson.

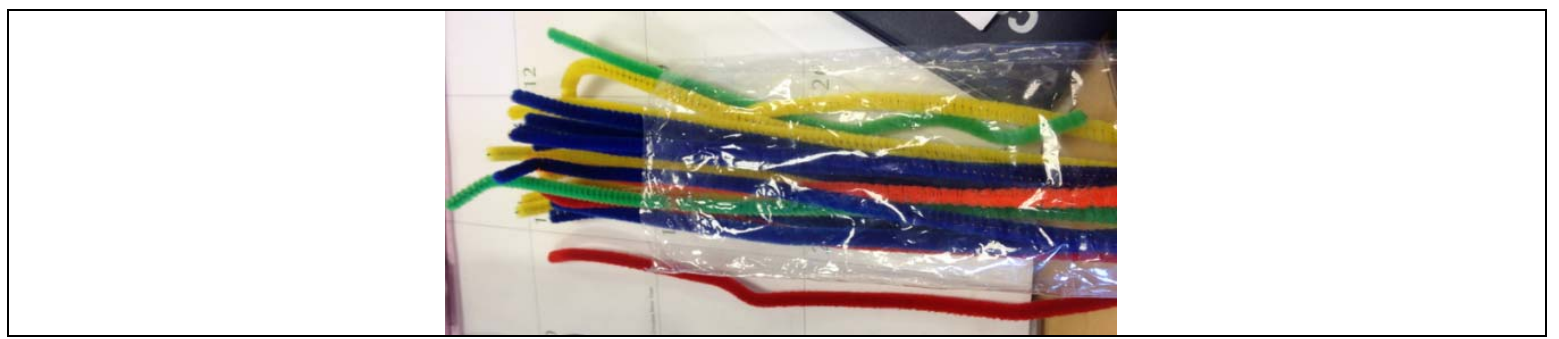

Figure 8. Pipe cleaners used in Belinda's second observed lesson. 


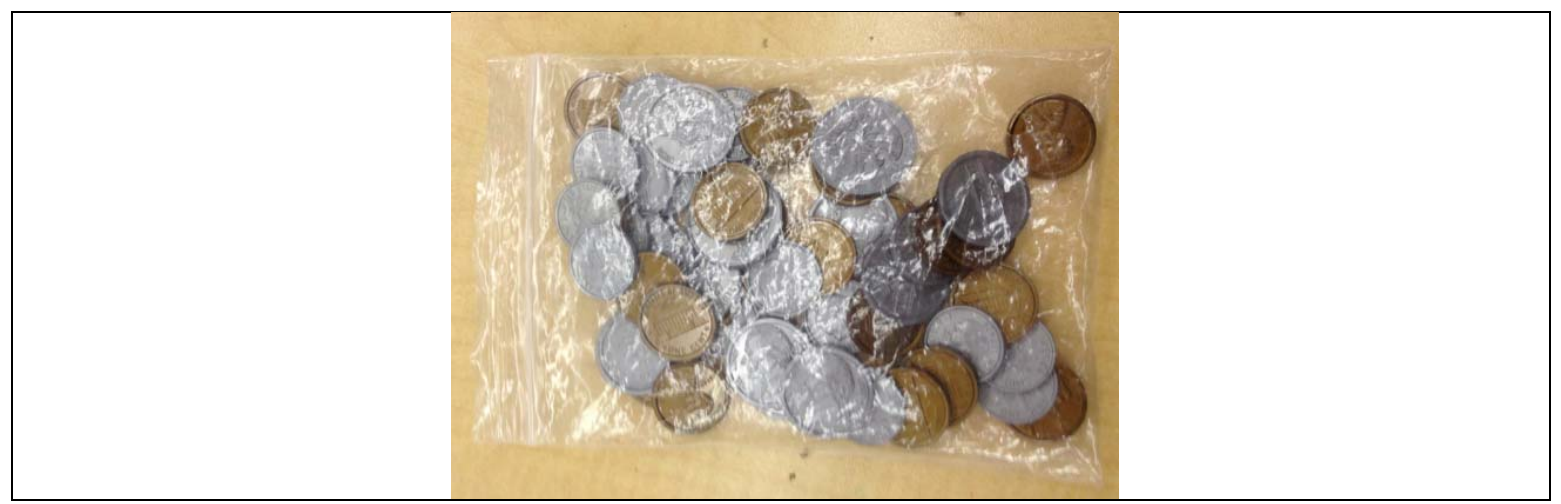

Figure 9. Fake Coins used in Belinda's third and fourth observed lessons.

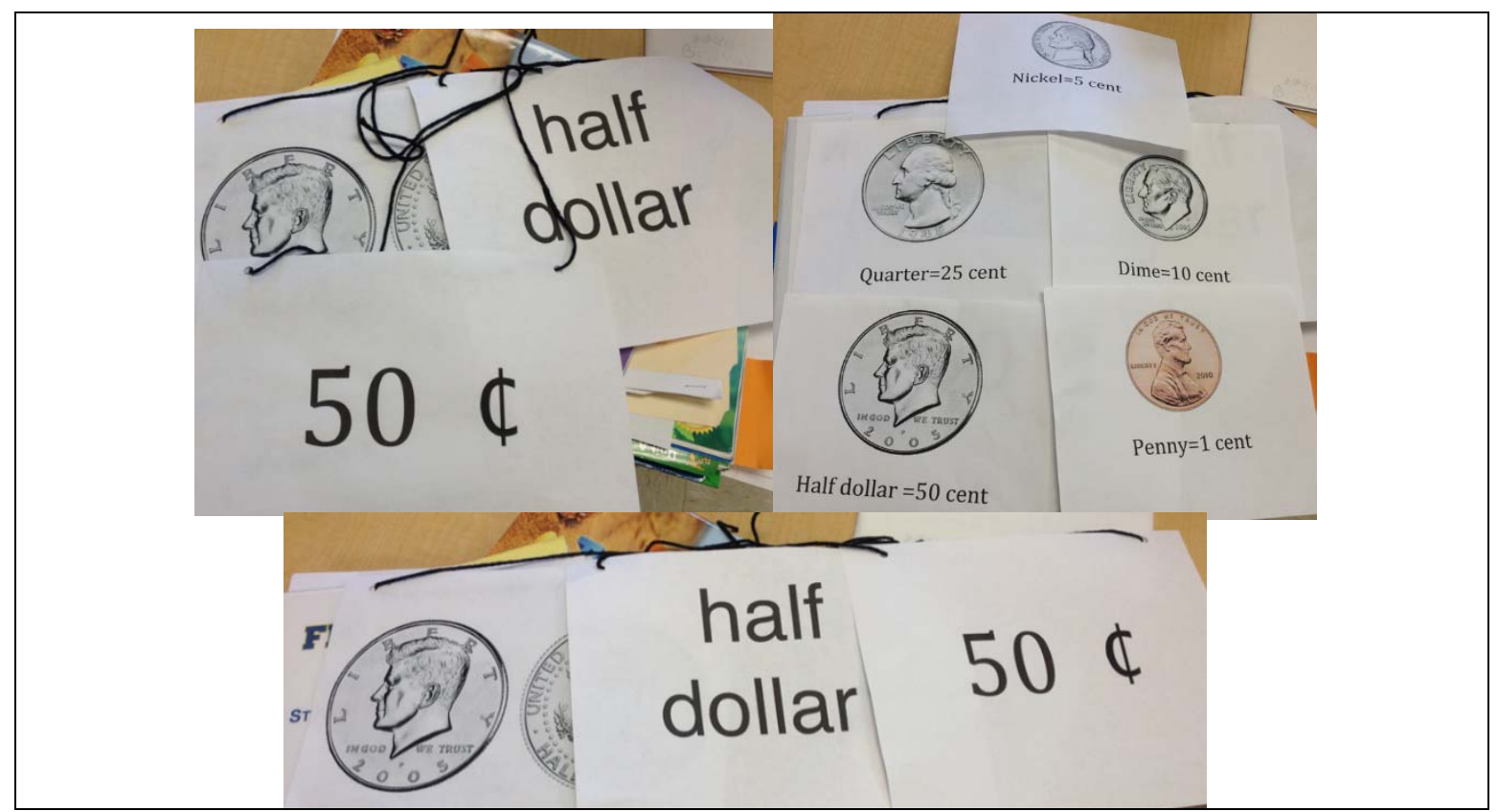

Figure 10. Pictures of coins hung on student volunteers during Belinda's third observed lesson.

During the observed lessons, Belinda did not analyze alternative solutions to problems. She did check for understanding by asking students if they arrived at correct answers or not, but she did not go over how they arrived at the wrong answers, she would have students come up to the board to explain how they arrived at the correct answers. Belinda focused on problems posed in the student textbook as well as the teacher's edition to the textbook. She did not use additional resources to create contextual problems for her students. No evidence was observed on having students analyze 
alternative solutions to problems, or having students examine different ideas to

mathematical experiences.

\section{Future with Mathematics and Teaching}

Belinda stated that she is looking forward to teaching mathematics after student teaching. During the student teaching semester it became her favorite subject to teach, and if she secured a job teaching in a departmentalized school she would prefer to teach mathematics. She believes reading is harder to teach than mathematics.

After my experience teaching the math and I was able to learn different ways to help them understand, giving them examples and doing different problems so they could understand, I feel more confident teaching them and I feel of all the subjects I've taught, it's my favorite to teach. I have more fun doing it and I will say it will become my strongest subject. I'm sure my first year I'm going to make a lot of mistakes and I've made mistakes with them too where they're like, "Oh, that's not the right answer," and I'm like, "I was just testing you to see if you knew," but you get nervous, so you start like but I'm pretty sure with time it would get better. When I first started, I hated math. I did not like teaching it. I didn't want to look at a book. Now actually it's my favorite subject to teach. I like teaching it. I feel like the students are actually learning when I'm teaching and I feel confident teaching the students because I know they're going to understand and if they don't understand one way, I find another way to help them understand, even if I have to go baby steps.

Belinda believes that mathematics is an important subject to learn, but she did not articulate any specific examples that highlight its purpose.

You need math because if you didn't have math, you can't solve problems and then once you graduate, you need math to solve problems in everything you do in your life so I think it's important to have that base from you're small.

Overall, Belinda faced a few challenges in teaching mathematics during student teaching, "Teaching a few subjects [content areas] that I had trouble myself. I kind of had to teach myself first, reminding myself before I was able to teach the students." She identified the 
topic of measurement to be an example of a difficult content area. In conclusion, Belinda showed knowledge of good strategies for teaching mathematics, but showed weakness in knowledge of the content.

\section{Chapter Summary}

This chapter presented the cases of Nancy, Ally, and Belinda who all had high levels of mathematics anxiety. The cases discussed the EPTs' student teaching placement, their experiences with mathematics in general, their experiences with mathematics anxiety during their student teaching semester, aspects of their content knowledge throughout the semester, and aspects of their pedagogical content knowledge. 


\section{CHAPTER V}

\section{FINDINGS: CASES OF LOW MATHEMATICS ANXIETY}

\section{Introduction}

This chapter presents the cases of the three participants with low mathematics anxiety of this multiple case study. Val's case is presented first, followed by Gigi's case and then Yoli's case. Val's case is most representative of student with low levels of mathematics anxiety during student teaching. Gigi's case is more unique because she taught a fifth grade class with gifted students. Yoli's case is the most unique of the three cases of low mathematics anxiety. Each case follows the same format and begins with an introduction, followed by a section on personal experiences with mathematics, a section that introduces their student teaching placement, a section describing the participants' mathematics anxiety, or lack of mathematics anxiety during student teaching, a section highlighting content knowledge of the participant, a section discussing the pedagogical content knowledge of the participant, and finally a section discussing the ideas of the participant on their future with mathematics and teaching.

The student teaching experience of all three participants occurred in the spring semester when students were preparing to take standardized exams. Val's students were preparing for the SAT and Gigi's and Yoli's students were preparing to take the SCAT. The preparation for these tests put added pressure on cooperating teachers, EPTs during their student teaching, and on the students taking the examinations. The participants in this study discussed their experiences in relation to having to help prepare their students for these standardized tests. 


\section{The Case of Val: Low Mathematics Anxiety-Strong Content-Strong Pedagogy}

Val is a Hispanic female from a southeastern state. She completed her student teaching experience as a university senior at a large, southern, urban university. She described mathematics anxiety in the following way:

Well most people will say that they don't like math because they just don't know it, they don't understand; they don't know how to do it - they are just not good at it. What I've heard people mostly say is 'I'm not good at math, I'm not good at math.

Val's AMAS scores revealed that she had low mathematics anxiety and she confirmed it by stating that she was very comfortable with mathematics and she understood the subject. She explained that she has favored mathematics to reading,

Well I've always been better at math than at reading. Reading is my down subject. I don't know, I've always felt like math is so much easier to understand. $2+2$ is always going to be 4 . As opposed to reading, there's so much, so many theoretical reasons behind everything, it's a lot and more complex to me.

Val said that she has never had mathematics anxiety. Based on classrooms observations and interviews, Val's content knowledge was very good. With respect to pedagogical content knowledge, Val showed strength.

Val's overall GPA was 3.38 prior to completing her student teaching. Her content GPA was 3.00, which is based on two mathematics courses. These courses included Mathematics for Liberal Arts I and Mathematics for Liberal Arts II. Val's pedagogical content knowledge GPA was 3.00, which is based on one mathematics course. This course was Teaching Elementary Mathematics Methods.

\section{Val's Personal Experiences with Mathematics}

Val has always enjoyed mathematics. Through elementary middle and high school she felt that the subject was challenging but not difficult. 
It got harder. It got more difficult, the topics...but it wasn't a struggle, it was just more complex, it was more things, some things that I have never used again were taught to me in some grade levels.

She says she remembers her first challenge with mathematics in $5^{\text {th }}$ grade with the concept of fractions, "The first thing that ever gave me a problem was fractions. So that was 5th grade that I learned fractions." She described this experience as more of a challenge than a bad experience with the subject. The only thing Val fears in mathematics is missing a step when solving problems. Val reported to be very procedure oriented when solving mathematics problems, "Probably messing up in a step, because that'll throw anybody off completely; you won't get to where you need to get."

Val was influenced positively in mathematics by her family. Her mother was good at mathematics and deals with numbers in the purchasing department of a company, and her older brother is very good at mathematics. She reported that her best friend struggles with the subject, but she was able to work with her for the mathematics methods class that was required for her education major.

My best friend, she's horrible at math! No, we actually took MAE 4310 together and there were things that I helped her on, but there were also things that she helped me on so we kind of balanced each other out.

Val was successful with mathematics and enjoyed the way that it was presented to her during elementary, middle and high school. Mathematics was taught to her using lecture and practice worksheets, and she described it in following way:

I would say a little of both [lecture and worksheets], but it was mostly explained, 'ok, it's done like this and you find the answer like this'. There wasn't really any means for exploring the way you can solve it or different ways. There's only one way to get to the answer, but I think that's how I learnt best because that's how I remembered it. I would say both - there was lecturing and practicing on worksheets. 
Mathematics tests were mostly multiple choice items with only a few problem solving questions, "I would say on a test of maybe 10 problems, probably the last 2 were in that format [word problems]". Val would have liked to be shown ways to solve problems, but she was fine with being shown only one way as well.

I wouldn't mind being taught one way so that I remember or that I get used to practicing that specific way, but I also wouldn't mind having options. Just because I learn it one way doesn't mean I like that one better. So it goes both ways.

Val had no real favorite or least favorite teachers during elementary, middle or high school, she felt neutral toward them and explained, "There were more teachers that were strict because everything was teaching it one specific way but I mean it didn't bother me." Val described her least favorite teacher in college who earned that title because she could not understand him. Val usually relied on the teacher to understand the content, but it was difficult to understand this teacher because of a heavy foreign accent; Val explained:

My least favorite was my freshman semester in college; he was in instructor for math, but the reason why I didn't feel comfortable in his class was because he had a really heavy accent. So I wasn't understanding what he was saying, and I'm not one to teach myself. I kept going with the class, I tried to keep up as much as I could but it got more difficult because I needed that guidance.

Val had to retake the class and ended up receiving an A as her grade with another teacher, so clearly it was not the mathematics content that was the problem.

Val could not really recall having good experiences throughout elementary, middle and high school, she just felt that mathematics was always better than reading and she always compared the two subjects. Val's first good experience with mathematics 
came during the required mathematics methods class for her education major. She

described that experience,

Well there were things that I hadn't touched upon in a long time so when we went over it in MAE 4310 and the teacher taught us different ways to approach the problem, I started recollecting memories of how to solve it, how to get to it, I even learned different ways to get to certain answers. We reviewed techniques that are going to help me not only now for my personal life but as a teacher, I know I can use those, those formats, those strategies with my students. And it's going to touch base with each of their learning styles, because not everyone knows how to get or understands how to get to the answer in one certain way. Some people are more comfortable with different strategies.

Val enjoyed her other college mathematics classes, and did not remember having any positive or negative experiences with them.

\section{Context of the Student Teaching Placement}

Val's student teaching placement assignment was in a second grade, selfcontained classroom of 13 students for her mathematics period with a balanced number of boys and girls. There were a total of 18 students in the class, but 5 students were pulled from the class for special instruction. Val had English Language Learners who were a part of the regular classroom, but these students were not present during her mathematics lessons because they were pulled out of the classroom.

In the beginning of the semester Val described her confidence in teaching mathematics, "Teaching math, I'm comfortable with it. So I would say the [mathematics methods] class at [the university] helped, we were introduced to different things. I feel like I'm prepared for it." In the beginning of the semester Val explained that she began to use manipulatives and found that she enjoyed using them, and wanted to continue using them for the remainder of the semester, 
Well we just recently started using manipulates. We used the shapes, so we had the hexagon and the trapezoid, and all those shapes and I was probably more into it than some of the kids in the class. I feel like they need the hands on because for all of them it's not just going to click like, "ooh $1+1$ is 2 ", they need to see that 1 square plus 1 square is 2 squares.

Val believed that mathematics was important and strived to teach it in a way that would help all her students understand the content.

Val created many lessons for the students during her student teaching experience, but she was able to describe one lesson in Geometry as her favorite. She explained that she came up with the idea for the lesson during her lunch break and got inspiration in an isle at the supermarket as she passed the marshmallows, "The 3D shapes with the toothpicks and marshmallows was a total last-minute thing. I was literally buying lunch at Publix and I said, "Wait a minute, we can use these," and I picked them up and took them to the counter." Val described her favorite lesson,

I like the geometry lessons, with the 3D shapes, and the shapes overall. They had the little manipulative that we used in your class too, so they were able to make different shapes with smaller ones, and create their own stuff, and there was a lesson that I did. I made 3D shapes with toothpicks and marshmallows. I told them, "Okay, today we're doing something totally different," and followed my instructions to make their shapes. I made sure to have enough supplies for everyone to have their own. We made a square, a rectangular prism, and a pyramid.

Val mentioned this lesson several times throughout the semester because she really enjoyed it and believed that the students enjoyed it as well. Although Val loved this lesson, the topic of Geometry also posed some challenges for her in remembering the vocabulary associated with shapes. Val described this challenge,

I had to remember what an edge is, and what a vertices is, cause I can just say corner, but they're not going to understand, that's not the right vocabulary to use for them, so I think it was just like going back in my knowledge and remembering 
ok I have to tell them that 'this is this, and that this is this', and remembering what terms to use in what part.

Overall, Val indicated that she loved to teach mathematics during the semester because she enjoyed the fact that she could have fun with the subject and she could use manipulatives to help them,

It's just always something different. There's always a different way for them to solve their problem or whatever there is. There's always something different that we can use. Like right now we're learning time, so they have their own little clocks, analog clocks with them.

Although she loves teaching mathematics Val did have challenges and there were areas of mathematics that she did not enjoy. She was challenged by finding creative ways to help her students, but she did not describe these challenges as difficult,

I guess the creativity of it, something different that they can remember. Not only in their daily lives, but while they take their SATs next week. Like using their manipulatives, or some type of activity that I know in their mind they can refer back to, so that they remember the process, or how they get to their answer. It's challenging in the sense that I had to think outside of the box, but it wasn't difficult to come up with the actual activity.

Val did not enjoy the crunch time that she had to do for the SAT. She explained why,

It's one huge review after the other. There's nothing specific that they're targeting. It's just everything put together in one packet. I feel like you waste a lot of time, they're doing their own practice, and then you have to go back and review with them. I mean you review regardless on a daily basis, but it's just so much information that they're in taking at one time.

Val described that there was no order to the review, "They use different resources to find problems for crunch time. We just grab from different places, things that they have targeted this year, and it goes all together in one." Although she did not enjoy the crunch time, she believed that more importantly, the students did not enjoy it either, "They know 
that they're testing, and they don't like all that different stuff, and it's confusing for them."

Val commented on the importance of mathematics for her students,

I know it's [mathematics] important before teaching it, but it's crucial for them; like for example, now that they're telling time, they had no idea that we are going to lunch at 10:45, they just know that when that big hand hits the 9, it's lunch time; but they don't know... well they didn't know, so I...it's like crucial, they need it.

She also learned the importance of meeting the needs of all her students,

Meeting their needs in the sense that I use whatever is available, not just stand in front of the room and lecture, lecture, but use what's out there; like these books [past editions of textbooks], just because they're not using this edition anymore, doesn't mean you can't keep it stored in the back of classroom, and when you get to that lesson, you can refer back to it and use things that are in there, because it's always going to be something different for them. Online, there's a ton of stuff that they can use. Manipulative, I think there's manipulative for every kind of Math lesson out there.

Val has also learned that she always needed to refresh her knowledge of the content before teaching,

I need to touch upon everything, and maybe there's things I forgot in between my 2nd grade year and now, so there's things that they have clicked like, 'Oh ok that's what that's called' and I remember ways that I've learned it, and it's easier ways to express it to them.

By the end of the semester Val felt that she had become more experienced and more

knowledgeable in teaching mathematics and more experienced overall,

I've become more professional. When I'm dealing with the students I feel they know that they can come to me. You know, if they have an issue, they are not shy. I feel like I've grown in a relationship with them already and it's easier to teach them because we're so open in the class room. 
Val knew that she would encounter students who would have different feelings

about mathematics including fear she explained how she would help those types of students,

It depends how I approach my students, how I teach them my strategies, how they feel comfortable in it. I would hope that I'm successful with them and that they are confident in themselves to succeed! Most likely, I think there are more people that are afraid of the subject than people that are not. I would probably offer them [those who fear math] several ways to go 'head on' to that problem because I don't think there's any other way but letting them explore. If they are not getting it the way I plan on teaching it then they need to seek different options.

Val's greatest fear with her future students after student teaching was that she would not be able to reach all types of learners, "I fear I won't reach out to the students that need it the most."

\section{Val's Relationship with her Cooperating Teacher (CT)}

Val conveyed that she and her cooperating teacher had a good relationship. Val appreciated the guidance that her CT provided throughout the semester, "It's a guidance that she gives me and I found it to help until now." Val pointed out that her CT even helped her discover new ways to use the textbook,

Well, the other day we did differentiated instruction during math and the book is awesome for that. I never knew for example when you're teaching them on one page, let's say there's six questions. You do one through four with the students and then five and six have a little checkmark on them which means the students do it on their own and if they get it wrong, you pull them out for differentiated instruction and she was the one that taught me that because I had no idea what those checkmarks on those numbers meant. So that's something that definitely will help because after I pulled those students out and I did the re-teach with them, they understood it better. Who would've thought those checkmarks meant that!

Val explained that her $\mathrm{CT}$ also helped her with organization skills,

I guess she $[\mathrm{CT}]$ helped organization-wise. For example when I did the lesson with the three shapes with the toothpicks and the mini marshmallows, she 
suggested that I have everything prepared in a tray first rather than having to go around and pass each toothpick out.

Val was appreciative of these kinds of tips.

Val relied on her CT's help to plan for some of her lessons. Val explained that her CT helped her come up with ideas for using manipulatives during the semester, but did not always help her plan the lesson to teach. She said her CT had a lot of manipulatives and helped her decide which ones to use for lessons, but she did not know if her CT actually used them in her own lessons because that was never discussed. Val's CT helped her find manipulatives for the first, second, and fifth observed lessons. Val explained how her CT helped her with the manipulatives, "She helped me a lot because of the manipulatives. She has them stored, so she knows where everything is. She was able to give me ideas to use for those." Val also conferenced with her CT to plan for the second and fourth observed lessons.

\section{Planning for Teaching Lessons}

Val planned all the observed mathematics lessons in a short 15 to 20 minutes.

She said that she did not take a lengthy time to plan any mathematics lessons this semester. Val explained that she usually planned for the week with the other second grade teachers since they all had to ensure that they were planning to meet the Common Core Standards. She explained this routine after her first observed lesson, "I sat with the teachers and that lesson basically comes from the encore website. So, all I did on my part was gather the shapes, and made sure that there was a brain pop video for them to see regarding the three dimensional shapes. We have to follow the common core, and the common core was what told us, that you have to do this and this." Val tried to 
incorporate technology as often as possible and used videos from Brain Pop to help the students understand the mathematical concepts since she had a Smart Board in her classroom, "I am not sure if the other teachers use them [online videos], but usually if we find something we will let them know if they want to use it that there is one available, but not all the classrooms have smart boards.

Val explained that her CT was not involved during the planning with the other teachers, but she did share the lessons that were planned and she discussed the manipulatives that she could use for each lesson. Val mentioned that she tried to incorporate a manipulative in her planning of every lesson, and her CT helped her identify manipulatives to use. Val described how her CT helped her decide on the shapes that were used for her first lesson, "Yes she [CT] was involved. Not exactly while I was planning with the other teachers, but when I transferred that information to her letting her know what would be taught this week, we came up with the idea of looking for the shapes. We have the huge math resource box that has everything you can think of in there. All kinds of manipulatives and we agreed that using those shapes would be a good idea."

Val planned her second and third observed lessons with her CT, "I would tell her my ideas, she would tell me her ideas, and we would agree on what I should do." She often found assessments for her lessons from other resources such as other textbooks such as the Math Advantage Practice, or older editions of the textbook. She explained why she used other resources as assessments, "So basically whatever they are learning are in these books, but with different problems, different orders, so it's the same thing. I feel as it's a good assessment, and it matches the lessons that they do now." She 
explained that her CT helped her to find assessments as well as manipulatives for these lessons, "I planned with my cooperating teacher and she helped me bring out the manipulatives and she helped me find the assessment that I did at the end, she helped me find that in a separate book." She also used the re-teach pages, from the actual teacher edition online to assess the students.

Val used the textbook to help her plan her lessons, and she explained that she used the teacher edition to get ideas during her planning. She also used online resources to help her develop quizzes. She explained on resource that she found to help her develop a quiz on money, "I found a website that allows you to create your own quiz, and you choose what you want on the quiz; so let's say for the money, I was able to choose if I wanted $\$ 20$, \$5, what coins I wanted, how many coins I wanted in each problem." She mentioned that she enjoyed researching additional resources to use to help her plan her lesson.

Val has used and plans to use techniques that she learned from her mathematics methods class, MAE 4310 taken as a requirement for her major. She planned to continue to use those techniques, "It goes back to the different strategies, and we used a lot of manipulates in MAE 4310 for everything! And maybe that's good and it's why I like it so much now, because it's something I'm familiar with.”

\section{Val's Mathematics Anxiety throughout the Semester}

Overall, Val was confident with mathematics throughout her childhood; she always liked the subject and indicated having no anxiety at all. When asked if she felt any anxiety when teaching mathematics she responded, 
I don't think so. I always found it as fun; it's exciting, even though like I said it's always kind of uniform, because you know, it's always going to be the same thing, you always get to the same answer, but it's still always a different lesson. There's always going to be something new for them to learn, or a new different way for them to get to it.

Val's anxiety came with reading, she described teaching reading to be stressful, "I guess with reading. It's not really like an anxiety. I guess you can call it anxiety, like, stressful. Because it's what most of the kids have more of a problem with and they don't get it." She has anxiety with reading because she believes that it is more difficult to teach based on student understanding. Val described her reasons:

Most of the time that I was here before we started crunch time for reading, they were reading a story from the reading book and then it was the story being read every day in a different way. The first day we would read it to them. The second day it would be played from the tape player. Then on Wednesdays it would be played like in a short movie, like a video clip on the smart board. We would have it read to them every day differently and then at the end of the week there would be a comprehension test and it is open book. For the most part they get it, but the same students have a problem with it, still have a problem with it.

Val's anxiety comes with not knowing how to help students understand. She felt that she did not have the skills necessary to create greater understanding in her students.

On the pre-lesson surveys, before her lessons, Val indicated that she was very comfortable with the content of her lessons rating her comfort level at a $5 / 5$ on all lessons with a 5 indicating that she was very comfortable and a 1 indicating that she was not comfortable. She was also felt very comfortable with teaching the lessons she had planned indicating the same results of a rating of $5 / 5$ on all lessons. When asked about her feelings getting ready to teach a lesson in the pre-lesson surveys, Val described comfort, confidence, and excitement to teach all the lessons using phrases such as, "I feel 
excited and ready". Val also expressed curiosity and anticipation for the students' reactions to her lessons.

During each of the observed mathematics lessons Val was asked if she felt anxious. For some lessons she felt no anxiety, and for others what she described as anxiety could be interpreted as the stress associated with a lack of preparation, and the anxiety of teaching. For the first observed lesson, Val did not practice the quiz from the Brian Pop video beforehand so she actually had to take the quiz at the same time the students were doing it. She described this as anxiety,

During the brain pop video when they asked about the vertices, my brain went blank. I didn't sit there long enough to practice on my own and say ok, vertices are these, the faces are these, so when they were answering the questions I was kind of quizzing myself at the same time. So that caused a little bit of anxiety, but I got the hang of it and it was ok after.

Val showed no signs of anxiety for the second observed lesson, and when she was asked if she felt any anxiety she confirmed this observation by saying that she had none. For the third observed lesson Val felt more frustrated than anxious because the students kept working ahead and they did not obey when she told them to stay at her pace of the lesson, "Today, to be honest, I was frustrated. They were way ahead of me and they weren't listening for quite some time." Val says the only anxiety that she felt was to finish the lesson when she thought it was not challenging enough for the students. Val was confident about the fourth observed lesson, and only showed signs of hesitation and lack of confidence in the beginning of the lesson when she asked the students to show 27 cents with their coins. Val had to count each student's amount individually because she did not know all the possibilities of make 27 cents from pennies, nickels, dimes, and quarters. 
Val transitioned from working with coins to introducing dollar bills for the students to count. Val was confident with the content, but she was apprehensive about how the students would do with this transition. She explained, "It's a lot like counting coins, so I was comfortable with it, and the last time that we did the lesson they did really good on it, so I figured they'd do good again. I was nervous I guess to see how they would react to the lesson." Val did show anxiety at the end of the lesson when she gave students the quiz that she had created for them. Two of the items on the quiz called for students to count bills as well as coins and during the lesson, Val did not go over combining both types of money. She only focused on counting bills for this lesson. Some students did not know what to do and Val went around to individual students helping them with the problem and making a note to not grade that item if she had helped them. Val showed signs of anxiety such as a sweaty forehead when she discovered her mistake. Overall, Val never showed anxiety toward mathematics content; the only evident signs of anxiety came when she was not fully prepared or made errors in preparing for teaching.

\section{Val's Content Knowledge}

Val believed that mathematics was important and described the purpose of teaching the subject, "The purpose of math is it goes with everything! Everything you do has math in it, maybe not everything that I've learned maybe applies to real life, but everything in real life has some type of math to it." Val continued to give examples of the purpose of mathematics in real life situations,

In the way I dress - I'm not going to wear one earring, I have to wear 1 and 1 , that's 2 earrings (laughs). When we drive, the street numbers, at least down here the street numbers. You know, you have to know that 1 mile is from 152nd to 
162 nd street. It's just its everywhere. Shopping, when you buy groceries or anything else, you have to know that it is more than $\$ 20$, you have to give a $\$ 20$ bill and something else to complete the amount.

Val remarked that she felt very comfortable with teaching mathematics content at the second grade level and she believed teaching at a higher grade level would not pose greater challenges. Val has always liked mathematics and has always understood the content. During her student teaching experience Val taught geometry and money which were new topics for the students. She also introduced time earlier in the semester, but she was not observed teaching that specific content. Val also discussed having to review other content areas with the students during their crunch time for SCAT practice. She provided the example of reviewing fractions with the students during the review time,

They did go into fractions. They had to, not really adding, but they had to find what $1 / 3$ is of a group, what $1 / 2$ is of a group. We have a ton of practice packets that they do on their own first, and then we go over it with them; Read the question, what are the options and then why, let's say "a" is correct, \& "b, c" is incorrect. Whenever we finish our math lesson, we go immediately into crunch time.

Val felt comfortable with the content that she reviewed with the students during their crunch time practice.

During the teaching of the first observed lesson, Val introduced 3D shapes to the second grade class. She described the lesson,

The math lesson that I just taught was about three dimensional shapes, so the students watched a brain pop video introducing the shapes to them and things that real life objects that have the same shapes and then we did an encore lesson from common core.

She felt that the lesson was a success and she thought that the content was easy. Val discussed the lesson, 
I think it went well. They were able to grasp the meaning of it. I think they still need more practice with the names of the shapes, but I was able to give them things that we see in the classroom, things that we see every day for them to be able to connect it to those shapes, so I think it went well.

Val used real-life objects to help the students understand the content more clearly. She used a door as an example of a rectangular prism and a basketball as an example of a sphere. She discussed that her students were able to compare the shapes to other objects, but she was not fully successful in defining the shapes, "I really didn't go over the definition of the shape like what makes a sphere, the video did it, but I didn't." When asked if she would help the students learn to define the shapes she responded, "Well the lesson's goal throughout the rest of the week do so, but to be honest with you it slipped my mind." Val reported that she forgot to review the definitions of the shapes with the students although she had prepared them on the board to do so, and she indicated that could have improved the lesson. Upon reflecting on the lesson, Val thought incorporating a checklist for herself might have improved the lesson, "Maybe I could make a checklist that lets me know I need to do this next." Despite forgetting content, Val indicated that she really likes Geometry and finds it easy to teach, "I think when you like something it is easier to explain it to someone else as opposed to not being able to relate to it maybe." She felt that she could explain Geometry to her students.

Val taught the second grade students about the value of coins during her second observed lesson. She described the lesson as follows, "The students were learning about pennies, nickels and dimes. Their value and the total value once they are in groups." Val felt comfortable with the content and thought that her teaching of the lesson was a success, "If I understand it good, then it's easy for them to understand it the way that I 
teach it to them, so I was comfortable in the sense that I know about it [the content]." Upon reflection, Val concluded that she could have improved upon the lesson content by discussing the faces of the coins for the students to know the difference of each coin, "I should have explained the faces of the coins, what president is on there because I didn't really touch upon that. They know that they are different, but they don't know exactly what it is." Val discussed the similarities and differences of the coins, showed the students pictures of the coins and even gave each students fake coins to aid in their understanding of the values. Val appeared to be very comfortable with the content that she presented to the students. She even created an extension that she did not plan for; students who were finished their classwork were asked to find the value of coins that she grouped on their desk. When I asked her about this strategy she explained that she just thought it was a good idea to have those who finished early work on something else.

During her third observed lesson, Val asked students to order coins from the greatest value to the least value and find the total value of the group of coins, "This week the students had gone over the value of coins and their names, so today what they did was count all, order the coins from a group from greatest to least, and then count the total value. Val was disappointed because she did not feel that the lesson was challenging enough for the students. She exclaimed, "They knew what to do!" Val felt that the content was very easy to teach and very easy for the students to understand, and the lack of a challenge in the lesson frustrated her, "I was comfortable in teaching it and as a whole, because it's a lesson that so easy, it's not difficult at all. They already got the difficult part through, but because it was so easy is what made me frustrated, because they wanted to be ahead." Val indicated that the students displayed poor behavior at 
times during the lesson because they were not challenged by the content and would have created a more challenging lesson if she knew that would happen. Val gave a quiz at the end of the lesson that she felt everyone did well on, and those who finished the quiz early were given coins to order from greatest to least.

During her fourth observed lesson, Val focused on having students calculate one total value of coins using various possibilities. Val did not feel anxious about the lesson, but she was not prepared with all the possibilities of combinations to make 71 cents so she had to figure it out along with the students during the lesson. She explained the reason her emotions were not anxiety,

I wouldn't say anxious, but I guess the fact that I had to go back and make sure that that 2 quarters $=$, well I know 2 quarters $=50$ cents, but let's say 71 cents, I don't know off the top of my head all the possible ways, so I guess it was time consuming; so it's not really anxiety, It's just having to go back and count them makes it kind of difficult.

Val appeared very confident with the content, and she was aware that the students would be coming up with different solutions and she was accepting of the various answers. If students made mistakes with the content she helped them see their errors and come up with the right answers, instead of just telling them the answer. Val knew the content very well.

For her fifth lesson, Val taught the students about dollar bills. She was apprehensive of the transition from coins to dollar bill, but she was pleasantly surprised that the students were able to understand the concept easily. Val had no trouble with the content and was very confident teaching about money.

Overall, Val knew the content and was very confident when students asked questions. She was observed to be able to answer questions without having to rely on the 
textbook. Val reported that her vocabulary in mathematics has improved after working with the mathematics content during her student teaching "I guess that familiarizing myself again with the terms that the book uses, how the children should learn it...that has helped." Val was careful to use mathematics terms and demanded that the students use proper vocabulary in mathematics as well. Val did a good job with the content during her student teaching.

\section{Val’s Pedagogical Content Knowledge}

This section will outline examples describing Val's actions and ideas pertaining to Graeber's (1999) five big ideas on pedagogical content knowledge that preservice teachers should possess. With respect to Graeber's big ideas, Val demonstrated the ability to assess students' understanding well. She implemented lessons that promoted student retention of ideas and provided alternative representations of concepts. Val also demonstrated some ability to implement lessons that provided opportunities for students to demonstrate both conceptual and procedural knowledge, and she created some opportunities in lessons that considered students' intuitive understanding of concepts. Overall, Val showed evidence of pedagogical content knowledge.

Understanding Students' Understanding is Important. Val understood the importance of assessing students' thinking and reasoning. She showed evidence of ongoing assessment in her observed lessons. Val indicated the importance of student understanding and strove to ensure that her students understood the content of the lessons that she was teaching. During her interviews, Val constantly assessed the level of student understanding and it was evident that student understanding was very important to her. She measured the success of her lessons by how well she felt the students understood the 
content. When asked about the success of her first observed lesson Val responded, "I think it went well. They were able to grasp the meaning. I think they still need more practice with the names of the shapes, but they understand it. They get it." Val used objects in the classroom to help students understand the 3-dimensional shapes, and she felt that this use of realia contributed to student understanding. When Val used the BrainPop series, she selected the harder quiz at the end of the video to assess understanding because she wanted to challenge the students, but she noticed that even the harder quiz was easy for them, so that confirmed for her that the students understood the content.

When asked about the success of her second lesson observation, again Val measured the success of the lesson based on student understanding, "I felt most of them understood it. They have seen money before so that makes a difference. It makes a greater impact because they have already seen it. They are more familiar with it.” Val valued participation from all her students and used it as a means to measure student understanding. She believed in calling on students whether they volunteered or not to check for understanding, and she constantly circulated the room to monitor student progress,

I know that they were understanding it. So I wouldn't only call on the students that had their hands up. I would call on the students whose voices I hadn't heard in a while. And that is kind of like an oral assessment for me. I know if they are getting it or they are not getting it. And I walked around the room to make sure when they were doing their practice and the assessment.

After the third observed lesson, Val concluded that student understanding was both an asset and a liability. Val observed that based on previous knowledge, the students knew what to do during the lesson and did not need her instruction to move along. Because they could predict what needed to be done, the students worked ahead in 
the workbook and did not follow along during the class discussion. This frustrated Val, and she indicated that student understanding could be a bad thing when it caused students to tune her out. Val explained,

They already knew what they have to do, and the names of the coins and the value of them, I felt like they felt that they can just go on, instead of following along with me, they already knew what was coming.

Val was anxious and wanted the lesson to end because she felt that the students were not involved, "I wanted it to be done, because they wanted it to be done, since they were so ahead." Val was glad that the students understood the content so well but she believed that the understanding was also a bad thing,

The fact that they understand it so well; I guess that it plays for good and for bad. I guess it's good and bad, you know the fact that they know what they're doing. If they're moving along, it's because they know what to do...

Val continued to explain that the student understanding was a bad thing because the students went ahead of her teaching. Upon reflection Val decided that she would have challenged the students more in the lesson,

They need more of a challenge; so that they won't go ahead. I mean, it was good in a sense that they understand it, but I don't want them to be moving further ahead because then, what am I there for?

Aside from informal observation, Val used the work in the textbook and a worksheet as an assessment.

During the fourth observed lesson, Val wanted to ensure that all students understood the content so she gave one on one instruction when necessary. I observed her working with one student several times during the third observed lesson and she explained that the student was not understanding the content at all, "While the other students were working, I kind of went back to her for one on one, because she wasn't 
understanding it at all. I don't even know how she did on her quiz." Val explained that it has been necessary to work individually with this student many times because the student is a slow learner. I have observed that the student even had trouble counting pennies, but Val constantly worked with her because she felt that it was imperative that she understood the content.

Val used practice worksheets and quizzes at the end of lessons as assessments to check for students' understanding. Val constantly walked around the classroom to monitor students' progress on both of these while the students were working. She explained how she checked for student understanding in the fourth observed lesson,

When they were working out the problems in their practice books, I went around to make sure that everyone was showing two different ways and not just going down one column showing one way. Everyone had two different ways to show the same amount, and it equaled to that amount. So it's not just that they are just throwing in quarters and pennies, they were doing it correctly.

She did notice some students making errors, but she explained that those errors were minor, "It was just a confusion between like as opposed to saying 4 dimes they would say 4 nickels, so it was just a slight confusion." Val also checked answers to quizzes as she was walking around and would immediately assess if students were doing well or if some students needed more help to understand the content. Val sometimes helped students during quizzes, but she made a note on the papers when she did this so that she did not count the answer toward the final grade of the quiz.

Val used a website to create a quiz to check for student understanding for the fifth observed lesson, but she did not review the quiz items before administering it. This caused difficulty because some questions on the quiz assessed content that Val did not go over in class. During the fifth observed lesson, Val focused on counting dollar bills and 
coins to find the total value; however some items on the quiz included counting both dollar bills and coins that had amounts larger than a dollar and the students would have to add the dollar value of the coins to the dollar bills. Val explained, "When I made that quiz, I actually found a program online that helps you make it, and then it asks you to click: how many of each coin; like the maximum amount of each coin that you would like for each problem, and I think I put 2 or something like that, but if there's half dollars and you have 2 half dollars, we didn't go into them learning coins equaling a dollar adding it to the dollar amount." Val noticed that these items would pose a problem and walked around to individually help students understand the problem. Val explained, "The ones that didn't understand it, I helped them with the first one, and then I put a note on the side of their paper that I helped them with that problem so I know not to count it towards their grade." Val thought that most of them understood the concept after she explained one of the items and so she allowed them to do the second item on their own. Val did not plan on teaching that but she said she knows that if she given an example of one of those types of items the students would have understood what to do. She reflected on the scenario and thought that she might have even left that concept for another day and taken the items out of the quiz. She said,

I would have either reviewed it with them so that they're prepared for it on the quiz, or change the quiz, so that it wouldn't have that; just so that it wouldn't have so much intake of information in one day. I would leave that for another lesson.

Overall Val believed that the students understood the content and were able to transfer their knowledge into real life, and she thought that was extremely important. She explained an instance where this scenario occurred, 
There will be times for example now that we're doing time, what I recently remember, they would look at the clock and they would argue with each other, but not in a bad way. They would argue and they would say, "No, it's 1:22." "No, it's 1:23." "No, it's 1:22." So they're taking about what they've learned that day and they're putting it to use in their lifestyle daily.

Val believed that this type of discussion was an example of true student understanding.

Students Knowing in One Way Do Not Necessarily Know in the Other(s).

Graeber (1999) argues that preservice teachers must understand that students learn in different ways. This learning should entail both conceptual and procedural understanding. Val showed some evidence of helping her students with both conceptual and procedural knowledge. During her first observed lesson, Val pointed out 3dimensional objects to students around the classroom for them to be able to connect the properties of 3-dimensional objects listed in their mathematics lesson to objects found in the real world. She explained, "I was able to give them things that we see in the classroom, things that we see every day for them to be able to connect it to those shapes." Val wanted her students to transfer the knowledge gained from mathematics lessons to real life situations,

They [students] can use it [content] in real life we have shapes everywhere so they know it's easy for them to connect it from their paper, from their lesson when they go outside, when they go home, and in the classroom.

Val felt that she learned best by making connections and she aimed to help her students do this as well,

It goes back to them being able to compare it to something. It is not just a sphere, but a sphere is also a soccer ball, a basketball, things you see every day, so I know that if I am confident in telling them ok this is just like a sphere or a rectangular prism is just like a door, then I know that it's easy for them. If it's easy for me, I feel like it will be easy for them. 
After the lesson Val reflected on how she could have improved the lesson and she believed that giving them even more opportunities to compare 3-dimensional shapes to real life would have been helpful,

Maybe I could have shown them more in thinking outside of the box, not just seeing things in the classroom, but maybe coming up with their own shapes like maybe they see at a park or home, something they have at home.

This type of conceptual understanding was highly important to Val.

When asked why she used different approaches to learning in her lessons, Val eloquently explained that she believed conceptual understanding was important,

Well I just feel that they [her students] need to go through every path before they reach their final destination which would be successful in counting the money that we counted today, so if I teach them one way how am I supposed to know that they liked that one way or they understand that one way? I think giving them different options to do it or different ways to see it helps them.

Val encouraged students to share their ideas and answers even if they had different answers from their peers. She asked students to explain their thinking and encouraged ideas even if the answers were not always right.

Val provided opportunities for students to come up with different answers, and allowed for students to work on different ways of thinking about a problem. She began the fourth observed lesson by asking her students to use their fake coins to show her 27 cents. She did not give any other instructions, but instead left the students to struggle with the problem and come up with their own way of thinking about it. She explained her reasoning for doing this, "So that they would realize that everyone would get different answers." There were many answers that the students came up with and Val accepted all the correct answers. She explained, 
When I was working the problem with them, I asked for more than two ways just in case anyone had another way, they wouldn't think that it was wrong, just so that they know it still equals the same amount.

Again, Val connected the content that she was teaching to a real-life scenario,

They got to see the different ways to show money, because let's say in the future they go to the store, and they have to pay for something that's $\$ 0.75$, and they look “I don't have 3 quarters, I don't have $\$ 0.75$ ", it's not like that, they can count different coins to make $\$ 0.75$, there's not just one way to get to $\$ 0.75$.

Although Val gave her students opportunities to show conceptual understanding, when she was asked if her students could solve problems in different ways, Val thought that would be difficult for her students because they were only in the second grade. She believed that her students relied on procedures to answer problems and mimicked herself or her cooperating teacher, "I don't think 2nd grade...I think they're still too little to try to find different ways. They stick more to the way that I would teach them, or their teacher."

Intuitive Understanding is Both an Asset and a Liability. Graeber (1999) explains that preservice teachers need to understand the role intuition plays in thinking about mathematics. Preservice teachers need to assess preconceptions and misconceptions. Val was aware of the previous knowledge that the students had and allowed that to dictate her teaching. She showed limited understanding of student misconceptions.

Val was careful when selecting problems and examples to pose to her students in order to ensure that there was a minimal amount of misunderstanding or misconceptions by the students. She thought ahead of time about the possibility of certain examples leading to misunderstanding. An example of this occurred during the second observed 
lesson interview. Val introduced money to the students and she was knew that although it was a new topic for the students in second grade, they had some ideas about money. She felt that students would still have a challenging time to understand money, but she felt that because of their previous knowledge most students would be able to accomplish the challenge quickly,

Not that money is easy because it takes time for them to understand the different values and what they look like, but it's an everyday thing and it's counting. It's not like there is an equation that they have to do.

Val made careful decisions when determining materials to use for each class. She explained that she chose not to use a poster for the second observed lesson because the poster had quarters on it and the lesson only focused on pennies, nickels and dimes. She explained why she decided to hold off on displaying the poser,

We actually have posters, but I didn't want to show it to them because we didn't go into quarters today. I will show them the poster board for different amounts. So if I show them now I will throw them off.

She was thoughtful in these decisions.

Val helped students to realize their own errors and allowed them to correct those errors, she did not simply tell them they were wrong or give them the correct answers. She explained, "If someone had a mistake, I'd ask them how they needed to alter their answer to get to the correct amount." Val was aware that her students needed to know the value of coins, how to count and add to be successful in the fourth observed lesson, and she knew that the students needed to combine all these skills to accomplish her lesson goals,

I knew that they already understood coins and their different value, they knew every coin from half dollar to pennies; they knew them all, so it was just a matter of them physically putting coins together, two different ways to show one amount. 
Val also indicated that the use of the half dollar might have posed a problem to some students because it was a coin that was not commonly circulated. Val also explained that there was no half dollar in the bag of fake money that the students practiced with, but she was confident that the students could still understand the concept of the half dollar amount,

I just basically remind them that they can use half dollars; I mean it is an issue, but it's not a big issue, because we don't use half dollars; we do use half dollars when we go out to pay at the grocery store wherever we need to buy something, but it's not something that they see as often as the other coins so... They're not as common, so it could be an issue because they're not physically seeing it or holding it all the time, but its ok.

After her fourth observed lesson, Val also reflected that there were other ways that students could make 27 cents and she did not discuss all the possibilities. She thought that this was a shortcoming of the lesson, and decided that she should have discussed all the possible ways to make 27 cents with the students to avoid misconceptions,

When I first started the lesson, I'd ask them to show me $\$ 0.27$; I would have liked to maybe come up with every single way to show $\$ 0.27$, and as they would tell me out loud I would probably show them on the board, because we didn't get to every possible way, just a couple. I mentioned that there were many, many ways to show $\$ 0.27$, but we couldn't get to all of them.

After reflecting on this she decided, "So at the end, I would probably have shown them every single way" that she could make 27 cents.

During the last observed lesson, Val introduced students to dollar bills, and she felt that the students' previous knowledge on working with coins allowed for a smooth transition to working with dollar bills, "They remember how to count coins, and that helped them to count the bills." On the quiz at the end of the lesson, Val created 
problems where the total value of the coins was greater than one dollar and that dollar would have to be added to the value of the bills; however, she did not give students any problems like this during the lesson. She assumed that they would know that 100 cents $=$ 1 dollar because she explained that idea, "I reminded them, 100 cents equals $\$ 1$ but they didn't get that." Val commented that this assumption led to problems during the assessment, “I mean I don't know why I assumed that because they already knew that 100 cents $=\$ 1$, that they would just add it, and that quiz was terrible." She knew the students would have been successful if the total coin value was below 100 cents, "I think they would have been prepared if the coins wouldn't have added another dollar to the total amount."

Overall, Val was aware of student's previous knowledge and some misconceptions that may occur in planning her lessons. Val was also reflective at the end of her lessons and thought of possible misconceptions that might have occurred during the lesson and gave some possible ways of helping students correct those misconceptions or misunderstandings.

\section{Certain Characteristics of Instruction Appear to Promote Retention. Val} included some strategies that offered students different ways of thinking about concepts to promote retention in her teaching. During her first observed lesson, Val offered students examples of objects around the classroom for students to associate with the 3-D shapes that she was presenting to them. Her second observed lesson focused on figuring out the value of coins; Val used manipulatives to have students count coins as an extension for those students who finished early. She described what she did, 
They had their manipulatives on their desk already when they turned in their assessment. I just separated coins for them to count so that they wouldn't just be sitting there doing nothing and then at the same time, they get their practice so they finished, they counted and I went back and counted with them, made sure that they counted the correct amount.

She also used this strategy as an assessment.

During her fourth observed lesson, Val allowed her students to explore different ways to create a certain value for coins. She described how she tied in the students' previous knowledge to the new content that she was presenting using the strategy of counting manipulatives, "Let's say if they had to make fifty cents, they knew to put two quarters together, but never different ways to make fifty cents. I started with a review of the different coins." Val continued the lesson by asking students to tell her different ways to create different values of coins, and she wrote those ways on the board to have students copy in their practice books. Val was aware of the practical use of teaching this lesson to her students, and although she did focus on that practical use once in the lesson, she did not always do it; making more connections to real-life could have enhanced the lesson. During the lesson she read a word problem to the class where Mathew had more coins than another child, and she asked if that meant Mathew had more money just because he had more coins. The students answered chorally, "no". Val did not have a discussion about this idea. It was evident that Val knew the importance of connections to real life, but she did not always help the students make those connections. In her reflection after the lesson she explained why she enjoyed this particular lesson,

They got to see the different ways to show [value of coins], because let's say in the future they go to the store, and they have to pay for something that's $\$ 0.75$, and they look "I don't have 3 quarters, I don't have \$0.75", it's not like that, they can count different coins to make $\$ 0.75$, there's not just one way to get to $\$ 0.75$. 
When I asked her if she discussed this idea with her students she said that she did not, and it would probably have be a good idea to do so.

Val gave the students a strategy in her last observed lesson that tied into their previous knowledge of skip counting. To have students find the total value of dollar bills, she had students write the values of the bills in a sequence and then add the sequence at the end. She explained that this strategy worked because students knew how to skip count, "They knew to skip count by $1 \mathrm{~s}, 5 \mathrm{~s}, 10 \mathrm{~s}$, or $2 \mathrm{~s}$ for the $20 \mathrm{~s}$." She had the students write down the amounts so that they would not be confused in the counting process, "They kept count of their total, up to where they were at. I told them that if they needed to keep their count, they can write on the paper; it was fine."

Val did not use cooperative learning for any of the five observed lessons, but she says that she had tried group work and thought group work could have been effective for some of the lessons after reflecting on it. After the fourth observed lesson she explained how group work could have enhanced student learning,

I think that everyone, there's about four tables in each group give or take, so maybe one person, everyone in the group could come up with a different way to show the same amount [of coins], and then they all compare their solutions, that would have been good.

She explained how she has tried group work with this class, but it was not always effective,

I don't remember exactly what it was, but I know that we have worked in groups. They don't work in groups on their own, but they'll do a couple of problems at their tables and then we'll go over it. For some lessons it works. For some lessons it doesn't. It depends.

Specifically, Val did not think group work would be effective for her third observed lesson, 
We do use group work, but I don't know how it would have turned out for today's lesson, since there wasn't many things they had to do for one problem, it was just order them and get the greatest value, so I don't know.

Val further explained that one student might end up doing all the work and she wanted all the students to be able to acquire the skills that she was teaching,

I don't know if it would have been for them or against them to do it together, because maybe one person is just going to be doing everything, and they're not really getting the most out of the lesson.

Val did not discuss strategies associated with cooperative learning. Although she did not use a lot of group work with her students during her student teaching experience, Val indicated that she would use group work in her future classroom when she is the only teacher, "I will definitely use group work for different lessons in my classroom." She justified her thinking,

Because I feel like interacting with each other, maybe they pick up something from another student that maybe they didn't catch onto when I taught it or I mean it's realistic too. For example, with money, when you deal with money, you have to deal with other people a majority of the time, so it's something that they can practice with each other.

Although she did not attempt much group work she reported trying differentiated instruction with small groups, and she managed that type of instruction without the assistance of her cooperating teacher.

Val involved the use of some word problems as a strategy to enhance student learning, but she thought that the students did not perform well with word problems because they have trouble with reading, "It's just that their reading [level] is low." Val stated that when she did present her students with problem solving, she worked along with them, "With the word problems there's more reading involved, and if they don't understand what they're reading, they're going to get the problem wrong." When Val 
was asked to reflect on the use of word problems after her fourth observed lesson, she believed word problems would have been effective for the students, "They should be able to use context clues in a word problem to know the total amount that they need to show." After reflecting on the fifth observed lesson, Val thought a strategy that incorporated word problems and group work would have enhanced the lesson,

I would say put them in groups, well at the tables they are sitting as a group, I would have a problem like the one, "who had more money, Jack or Nancy?", so I would probably give them something like that, and have them figure it out together, who had more money and by how much.

During student teaching Val didn't always get to the HOT (Higher Order Thinking) problems presented in the text because she thought they were sometimes difficult for the students, but she did attempt some and she saw that the students' problem solving skills improved. She explained,

When I first got here, a lot of times the students would tell me, 'We don't do the HOT problems', which is H-O-T, the higher order thinking problems. I'd tell them, 'Well, you're going to do the HOT problem. You're going to do it', and we've picked up on doing the HOT problems. Now they tell me, 'But the HOT problem's easy. It's easy.' They've gotten the hang of it. I mean just because it's about the higher order thinking that takes what they've learned to another level so they can see it and a lot of times it's something that they can relate to. It's something that can really happen or that they know can happen to someone or has happened to someone. A lot of times it's real.

Val explained the flow of the lessons during her student teaching. She enjoyed the teaching strategies presented in the textbook which followed an 'I do, You do, and We do' approach to learning. Val explained that this approach was mandated in the lesson plan template presented during the student teaching seminar. Val explained, I really like the way that this specific book does it because they have a practice page first that is just one big problem. It's usually they have to draw something or fill in something. Like for the clocks lessons, they have to draw in the hands to the hour, to the half hour, so that's usually the first page and then on the second 
page it's usually three pages per lesson. The second page they do one through four with me, five and six on their own which is where you pick up the differentiated instruction, and then they have a page of on your own where they do it completely on their own. So I like the way because at [the university] we've always learned I do, we do, you do, and the book follows the exact same thing. So it's a review, then I teach them, we do it together, and then it's completely on their own.

Val further explained why she believed that this method worked for the students,

They gradually get the concept of they're learning it when I do it, when we do it together, and then they have to show what they learned when they do it on their own, so they gradually pick up.

Unfortunately Val did not explain constructivist ideas of teaching by having students explore concepts and create learning. When Val was asked if she felt the students would benefit from exploring concepts, she explained, "Not with this class because the majority of the kids are ESL, so I don't think that would've been a good idea." She thought strategies that allowed students to explore their thinking would work better with and older grade level, specifically grade five and above.

\section{Providing Alternative Representations and Recognizing and Analyzing}

Methods are Important. Val used several alternative representations to promote student understanding. She used manipulatives during her observed lessons including 3-D shapes, fake coins, and posters and books with the pictures of coins and bills. During her first observed lesson, Val used clear 3-D shapes and objects found around the classroom to help students visualize the concept of her lesson. She used technology by allowing the students to watch a Brain Pop video which the students enjoyed. Val explained her love of manipulatives,

I love those. Because they get to touch them, they get to physically see for example in this specific lesson, they get to physically see what a face is, let's see in a cube, what an edge is, vertices, they get to feel it. 
Val explained that she wanted to use candy to further help the students visualize the shapes, but unfortunately she could not afford to do so,

I really wanted to buy the food for them. For example, a Hershey's kiss could represent a cone, and a tootsie roll can represent a cylinder, so I would have liked to use different manipulatives, not just the classroom, the standard math resources, but money is always an issue.

When asked why she liked the manipulatives she used for this lesson, Val explained,

Because I feel that it reaches every kind of learner, so by just showing them the video, but not have them touch the shapes, even though not all of them got to touch the shapes, they are still seeing the physicality of things. They know that it is in front of them and it is not just on the video. So the brain pop video reached out to I'd say visual learners, while the shapes reached out to kinesthetic tactile. While they are also listening to me say this looks like a cylinder and this looks like a rectangular prism. So I feel like I touched upon every type of learner.

For the second observed lesson, Val used fake coins to help students visualize the concept. Val enjoyed the fact that each student was able to work with their own set of coins.

I liked the fact that they had their manipulatives. Because they get to see it not only in the book, the front of a coin and the back of the coin. I am like look they are even on the projector, but each of them individually had their own pack of manipulatives where they can physically see what the front of a coin looks like, what the back of a coin looks like, what it says, what it has on it and the size, because the coins are based on the actual size.

Val also used books for this lesson to show examples of the coins, "Those are actually books. I didn't read it to them but I wanted to use the front of the book because it has a large coin on it for them to see it better." After this lesson, Val reiterated why she loved manipulatives,

I am a huge fan of them using manipulatives, so the fact that they had that with them is a big thing for me. I think if I didn't have coins that probably would have made me anxious. But the fact that they had that makes me comfortable because I can tell them ok, take off 5 cents. They can practice different things that maybe 
are not in the book. I can tell them take out nickels, make those into tens and have them count them. And I know that all of them are going to have 5 nickels and 3 dimes.

Val also used a projector at the beginning of the lesson to display the coins after she discussed their properties. Val did not like the location of the projector because it was in the rear of the classroom, and thought using the Smart Board would make more sense. Val did not try to find the application for the Smart Board, but after reflecting she thought that its use could have possibly enhanced her lesson,

I know the Smart Board has these applications where you can look up different... um they have like pictures, so they will have for the shapes they have all the shapes, and for the money they have all the money maybe I could do it on the smart board better.

During the third observed lesson, Val used the fake coins with the students again, and she wanted to use Think Central which provides an online version of the textbook, but she had technical difficulties,

The website, 'Think Central', has the textbook online, so I wanted to go along with it, for them to visually see me do it, as opposed to having to draw each coin on the board, but the website was having technical difficulties.

While she usually loved using manipulatives, Val believed that because the students had the manipulatives they went ahead of her and cause some disruption in the lesson,

Maybe without having the manipulatives with them that might have stopped them from playing with them and moving along. I wish I could have used Think Central, I guess that goes with the manipulative as well if they don't have them in front of them they can see me using them on the board so it kind of affects both things.

Val had expected the students to draw the coins, and she also drew coins on the board. Val was aware of and careful to draw the coins in correct proportion. She pointed out to the students several times that it was important to draw the quarter larger than the nickel, 
and the nickel and penny larger than the dime. Val also used the overhead projector to display the coins as she discussed them.

During her fourth observed lesson, Val used fake coins displayed on the overhead projector "to remind them what each coin looked like, and what its value is." Val also gave each student their own individual set of fake coins again, "I made sure that they each had, everyone had pennies, nickels, dimes, and quarters inside their baggies." During this lesson, she enjoyed using the manipulatives and she thought that they helped with student understanding. For the fifth observed lesson, Val did not have fake bills accessible for her students to use, but she used posters that displayed pictures of the bills. After reflecting on how she could improve the lesson, Val believed that having the actual dollar bills to manipulate would have helped the students.

During the course of the semester Val also described other manipulatives that she used but were not observed during her observed lessons,

We have the analog clocks for telling time. We had the wooden shapes for the geometry; they had fake money, which was to the actual size of real money, yes the coins. They had the other 3D shapes, the plastic ones and other things, there's a lot though.

Val found manipulatives to be meaningful for her students and she explained why,

For example the coins were to the exact size as real coins, so I feel like they can relate to, 'ok well I have this plastic penny; that means that this one is a penny', so it's always something that they can go back to.

Although Val used the book throughout the semester, she commented that the book is never enough and she will always look for additional resources to enhance her lessons, "It's [the textbook] never enough. The other resources will always give different examples. It's just different." 
Val was observed analyzing alternative solutions to problems during her fourth observed lesson when she asked students to show 27 cents at the beginning of the lesson. Throughout that lesson, Val asked students to provide different ways to show a total value of cents and she asked the class to verify if the solutions presented by their classmates were indeed correct. They analyzed the answers together as a class, but she never had her students analyzing answers alone. Unfortunately, was not observed examining different ideas to similar mathematical experiences.

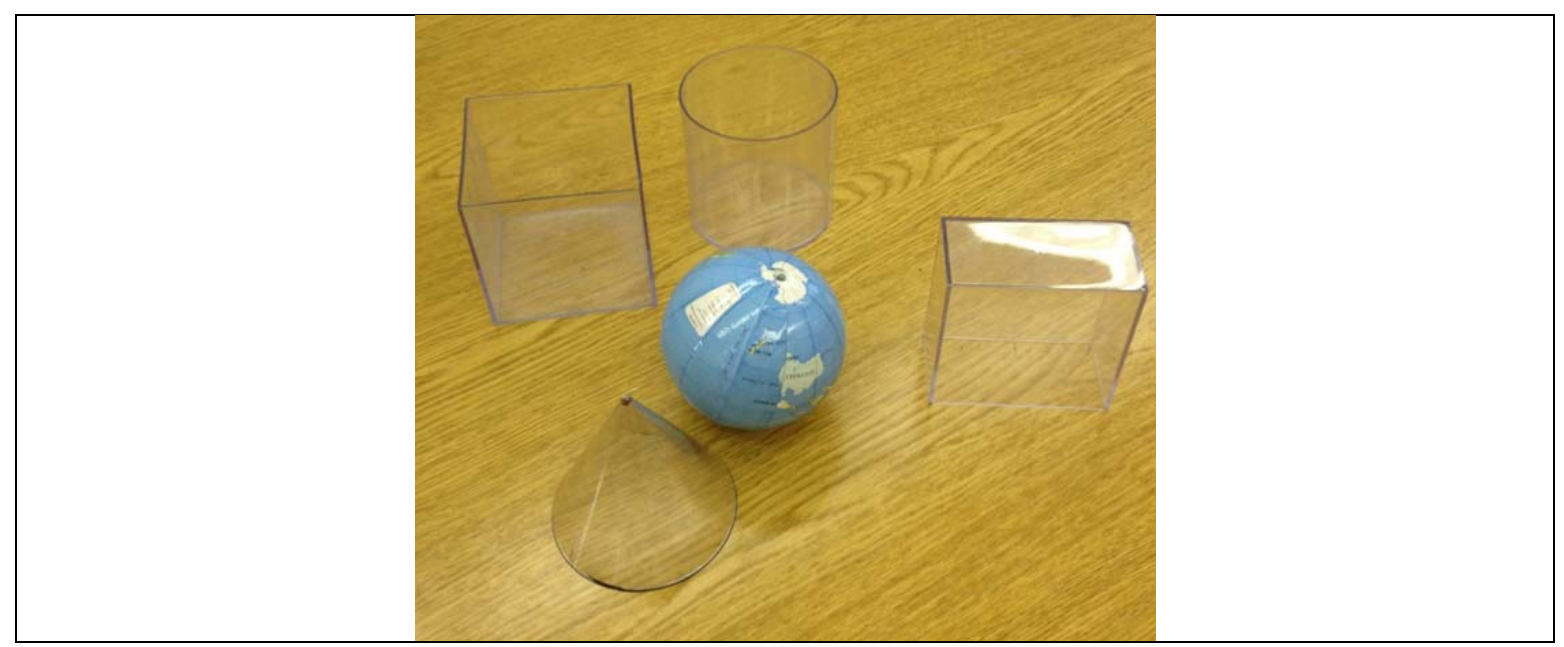

Figure 11. Geometric shapes used in Val's first observed lesson.

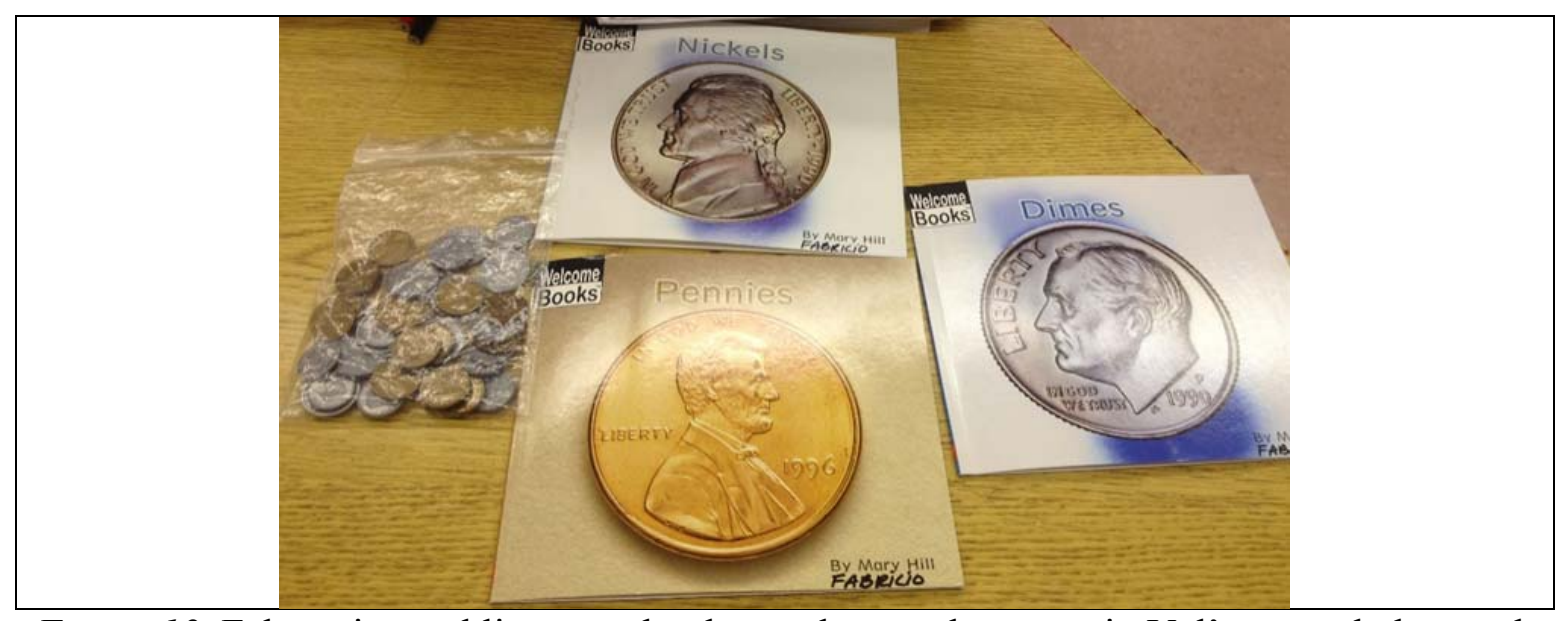

Figure 12. Fake coins and literature books used to teach money in Val's second observed lesson. 


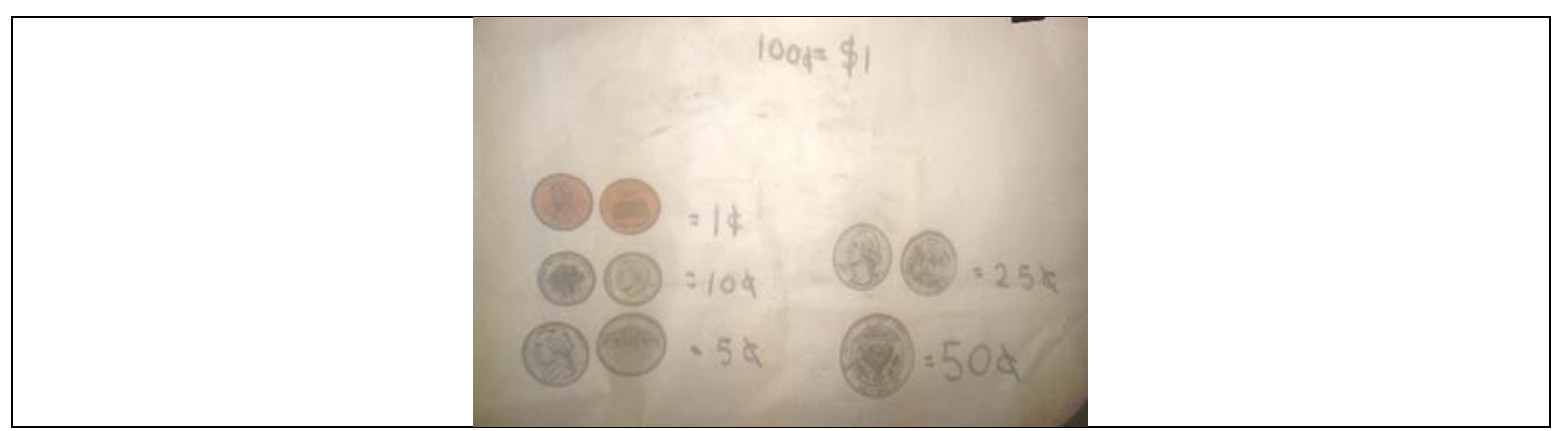

Figure 13. Picture of coins being displayed on the overhead projector used in Val's third and fourth observed lessons.

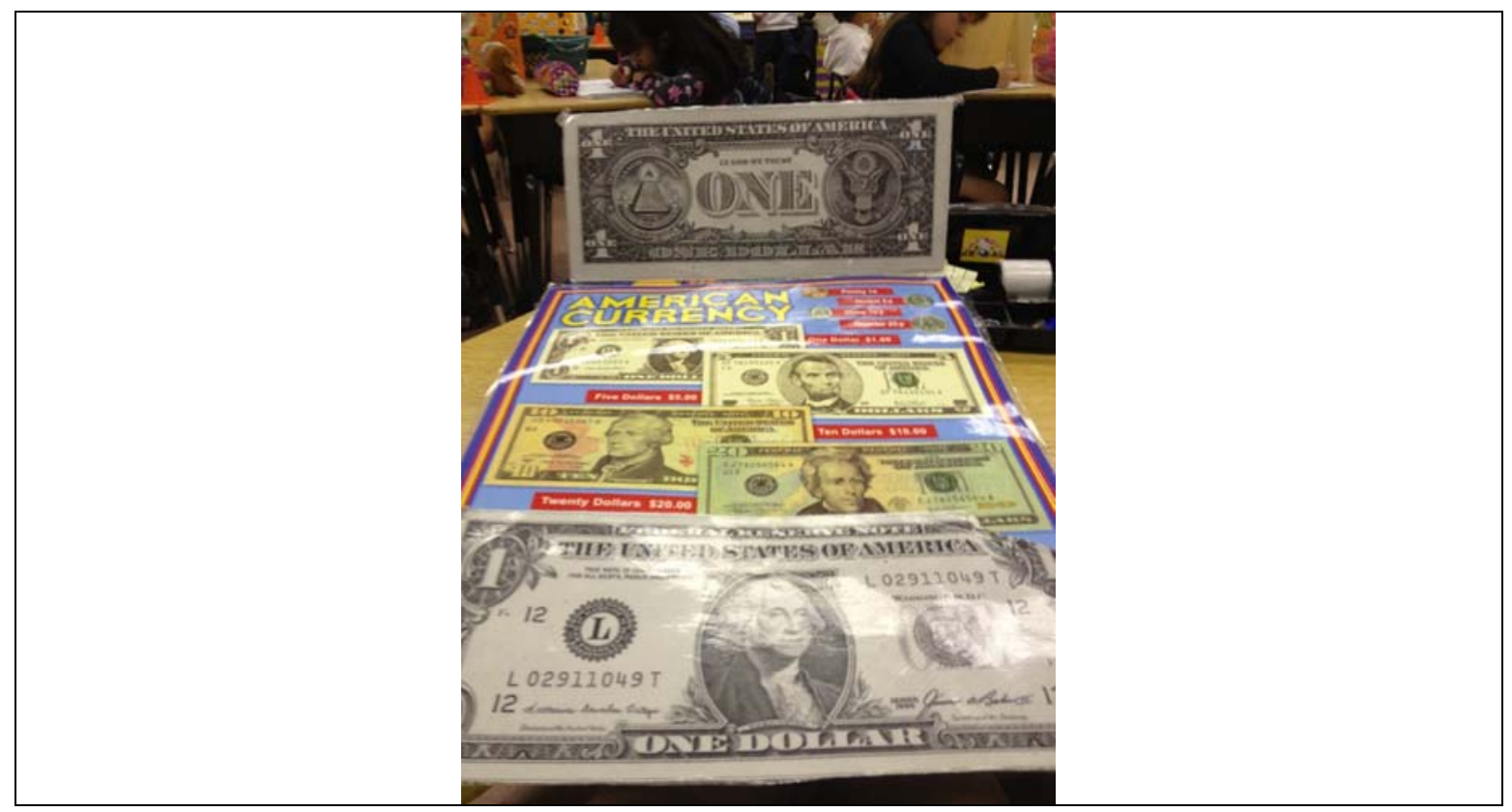

Figure 14. Poster used to display dollar bills during Val's fifth observed lesson.

\section{Future with Mathematics and Teaching}

Val enjoyed teaching mathematics more than reading during her student teaching semester. She stated,

I still like it [mathematics] a lot more than Reading because it's more relatable. I see it as $1+1$ is always going be 2 , and $2 / 2$ is always going to be 1. It's uniformed. But for reading, if someone is reading a poem "the sky is blue", you question, well what is the author feeling? He is feeling blue just because he says the sky is blue; like it's so much more complex.

Her comfort level for teaching mathematics had not increased nor had it decreased, 
I think it stayed the same because I've taught math when we've had to do hours for school. I've taught math before or when I subbed I've taught math, so I think it's not the same as someone who has never taught it and then they're just thrown in there and they have to do it. It's different. I think I've stayed about the same. I just have more to work with now, so it's better.

Val was looking forward to teaching mathematics in the future, and believed that she would be a good mathematics teacher. She explained, "This semester has given me a lot of experience and feedback from several people, so I feel I can take that positively and change or continue doing what I've done good into my future classroom." Val was confident in her abilities and anticipated good experiences in her future teaching of mathematics.

\section{The Case of Gigi: Low Mathematics Anxiety-Strong Content-Strong Pedagogy}

Gigi is a Hispanic female from a southeastern state. She completed her student teaching experience as a senior at a large, southern, urban university. She described mathematics anxiety in the following way,

I think it's basically that you do bad at math, not necessarily that you are bad, but you had a bad experience and then you just thought that that's how you are. You're just bad at math and you take it on for the rest of your life.

She believed that persons with mathematics anxiety, "probably get really stressed out even not knowing what problem they're going to be posed with, but they're already stressed out because they're thinking that they're horrible at math. They have that predisposition." Gigi's AMAS scores revealed that she had low mathematics anxiety and she confirmed that by indicating that she was very comfortable with mathematics. She described her belief about her own capabilities in mathematics during her first interview, "I feel like I know math. It's easy to me; I've always felt like I could do it; it's never really been hard." Gigi never remembered experiencing mathematics anxiety. Based on 
classrooms observations and interviews, Gigi showed strength in the area of content knowledge as well as pedagogical content knowledge. Examples of this strength will be discussed in this case study.

Gigi's overall GPA was 3.46 prior to completing her student teaching. Her content GPA was 3.33, which is based on one mathematics courses, Finite Mathematics. Gigi fulfilled her mathematics program requirement by also completing Computer Data Analysis. As this course is not a mathematics course, it is not factored into her content GPA. Gigi's pedagogical content knowledge GPA was 2.67, which is based on one mathematics course. This course was Teaching Elementary Mathematics Methods.

\section{Gigi’s Personal Experiences with Mathematics}

Gigi has always enjoyed mathematics, and felt that the knowledge came naturally, "I just always felt like I could do it, like I always felt like I was good at it; it was just natural." She enjoyed the challenge that mathematics posed and as a child she even tried to challenge herself when the work was not challenging her. An example of this occurred during fifth grade. Gigi described fifth grade as her earliest recollection of mathematics,

I know I used to do math like adding and subtracting but I just remember 5th grade. We went into division and I was a part of the tutoring group and I loved to do the division. I just kept on adding numbers and huge numbers, because I was placed in a below-grade level, even though I wasn't supposed to be there. I was in the tutoring, but I would go ahead. I guess they would let me just to keep me challenged, so I could do the big numbers. I would give myself the big numbers and just keep on going because they would give me easy ones, I would finish them and I figured out that you can just divide whatever.

She explained that she was not being challenged enough in a below-grade level class in the fifth grade and she would challenge herself. 
Gigi described how mathematics was taught in elementary school. She enjoyed using manipulatives and found her biggest challenges occurred when she was not able to use manipulatives to visualize concepts,

In the beginning, I think it was lectures but once it got to adding and stuff, you know numbers, counting, we used to count what was around us. And once we got to adding, I know we had like the manipulatives, not necessarily the little squares but we used to just have like stuff. Just maybe goldfish or whatever the teacher would have and then for multiplication, I know I was having trouble with it in 3rd grade, 2nd and 3rd grade was just lectures so I guess that's where I had trouble because I like to see it and why.

Gigi described learning her multiplication tables as her biggest challenge in elementary school, "I never learned them. Never. Not even now. I know them, but the bigger ones, I don't know them by memory, I would have to do it." Gigi explained that she would calculate the answers of two digit numbers by multiplying them in her mind,

I still have a hard time with the bigger ones. Like 12, not 11 or 10 but 12, I definitely have to think about it. Even though I didn't know the bigger ones, I knew how to do it on paper so I had like 9 times 12, I could do it quickly. I didn't have them memorized.

Recently, she has learned some strategies to easily remember some of the multiplication tables, but after years of practice she has not needed to use this strategy,

I learned one now [a strategy] as I got older for 9, with the fingers, but I mean I've never used it because I already know them. From using them so much now since I'm teaching and I tutor for math and everything, I've been learning them.

Gigi explained that in fourth grade her teacher contributed to her success in learning her multiplication tables,

In 4th grade I had a really good teacher and she really focused on that [multiplication] even though we were already supposed to know it. So once we started already knowing it and seeing it, you know, she explained it to us it's times, like in groups, seeing it in groups and she would have us do a competition. So we used to sit on both sides of the room and then she would put a problem and we had to hurry up and do it. So I think that helped us with the quickness, even 
though we didn't know it by memory, we knew how to work like big problems out.

Gigi enjoyed that teaching strategy and commented that she would, "remember that [strategy] forever!"

Gigi described two teachers from elementary school as her favorite teachers. She spoke fondly of her fourth grade teacher,

I have a favorite teacher; she's the one that did the challenging stuff in 4 th grade. She was my favorite teacher overall, just because she knew how to challenge us and she knew how to make everything a game.

Another teacher that Gigi described as a favorite teacher taught her in sixth grade,

In middle school, I had my 6th grade teacher, she was great. I was having some difficulty because you're on your own, but she loved math, she was always happy to be there and she just loved to teach us how to do stuff and it just came easy because you could feel that, that she wasn't stressed out because she was doing math. She did it because she loved it.

Gigi believed that attitude played a major role in the success of her mathematics teachers.

These teachers did not use many manipulatives; instead they provided examples and let students work on problems, and even though their teaching style was more traditional,

Gigi believed their attitude made them great teachers,

Most of the time they were lecturing; they were giving examples and letting us work through it and when you walked in you had to do a problem just to help you start thinking mathematically. But mostly they were lecturing and then they'd give us an example and have us answer it. I guess since we were older we really didn't need that next step of 'Oh, let's take out a manipulative.' Mostly it was their attitude. They were lecturing, but they knew what they were talking about and they portrayed they loved it and knew it - they weren't stressed, you know, making you feel like you shouldn't be stressed - this is fine.

Gigi believed that there was a difference in teachers in the older grades who chose to teach mathematics as opposed to teachers in elementary school who had to teach mathematics as a part of the entire curriculum, 
As you grow up, everybody's [teachers] doing it because they love it so if you're a math teacher, you're there because you want to be, it's not like in elementary you know that you could teach math. Everybody has to do it and you don't know if you like it or not.

Gigi's favorite teachers portrayed the attitude that they loved math.

Although Gigi liked mathematics in elementary school, she explained that her true

love for mathematics developed in high school. She explained,

I think in elementary, I did it [mathematics] because I had to. I liked it - I didn't have trouble with it, but I never really focused on it. It's when I got to high school when I really, really enjoyed it and really noticed that I really liked it, and I challenged myself. In senior year, I took two math classes, two AP math classes because I just wanted more; I just needed more. But it wasn't until that point that I really noticed that I really liked math.

Gigi was confident that she could do mathematics in high school and was successful most of the time. Gigi explained at times she was nervous to take tests in mathematics like in any other subject, but her confidence allowed her to persevere,

Once it [mathematics] got difficult in high school I would, like at any test, be kind of nervous, but I would try and figure it out because I already knew, I know how to figure out problems so might as well just try it.

Gigi remembered having to solve many word problems in high school, and recalled

having to be diligent when explaining solutions,

AP questions were a lot of word problems and they were very long. You had to explain every step. I took statistics, so there you definitely had to explain everything. In calculus as well, we were getting ready for those big word problems that you had to explain everything. It was just working out, so it never was multiple choice. You always had to show your work.

Gigi had a frustrating experience with mathematics in university. Gigi explained that she chose to take Finite mathematics and she was bored,

When I started [university], they had this test to put you in what kind of math you could take, and I could take whichever one but I decided, I was with a friend, let me just do something easy and I'll see how it is because I didn't know if it was 
going to be difficult, if it was going to be different. So I took finite math and it was just...it wasn't that it was bad, it was just so easy and terrible for me, because I didn't pay attention and there was no challenge, so I actually ended up getting a B which is not really what I knew. I know I can do it, but they were learning square root and stuff that I learned in middle school, and it was boring to me. I shut it out, I missed class. The first few classes I was there and I listened, but it was just so frustrating to sit there and already know, and for someone to be going over material that I already knew. There was no interest; there wasn't anything new.

The next mathematics course taken at the university did not challenge Gigi either,

And then I took my second one, I took it because I went to the advisor for education and they told me they saw that I got a B so she was like no, just take something easy, like look you already got a B on this easy one so they gave me like this excel class which had nothing to do really with math. I was just learning...to me it had nothing to do with math, like it was just learning to press a button on excel to do the math for you. Putting in the numbers and making sure if you click all of them and you press this function on here, it'll do it for you, so that wasn't math to me. It was more computer, learning how to use the system, I don't know. So it wasn't math.

She gave up on taking mathematics courses after that, "After those two I was just like, 'forget it'."

Gigi did have to take a third mathematics course at the university, the required mathematics method course for education. Gigi enjoyed that class and remembered learning how to tie children's literature into mathematics,

I actually liked it. The teacher, I think she was great. It wasn't just math - she made us find books that had to do with math so we could like open up a lesson with literature books. She had everybody bring in a list of like different books that they found and then she had us keep it so we all have the list. We had to do different lesson plans that got into each of the common core so we had to separate it and then we got to keep it. Everybody sent us theirs and we got to keep it. I think she taught us different things that were super complicated to everybody, she just went off-base, but I think it was interesting to know, like base 2s, and it was pretty weird, but I never heard that like ever, but it was interesting to see something new. You might not necessarily teach your kids or you might, they could still understand that - that's what she would tell us: they could still understand it. But I liked it. 
Gigi enjoyed that the teacher of the mathematics methods class allowed them to compose lists that would be practical to them in teaching. Gigi also enjoyed that the teacher challenged them with trying to understand base two so they could understand the struggles that students have with understanding base ten.

Gigi's family positively influenced her perceptions of mathematics. Her mother was good at the subject and helped her to learn multiplication and other concepts,

We practiced; well only when I was having trouble with multiplication. I mean my mom bought me like a board and we would practice it like that, but by numbers like 4 , and 5 , and 6 but never something bad. I never really needed that much help with math. Sometimes when I got older, I did and my mom would help me. She didn't have that anxiety either so she would help me. She was good at math, she was really good at math.

She also described cousins and a younger sister who were good at mathematics, "My cousins are good at it and my sister is amazing at it - better than me. She's younger [five years younger], and she's never had a problem with it. Never." Gigi has a younger cousin who struggles with mathematics, "I have a little cousin that thinks she's horrible at it; she thinks she's dumb, even before she starts the homework she thinks she can't [do it]. So I tutor her." In discussing her interactions with her cousin, Gigi concluded that she might have mathematics anxiety, and she explained how she has helped her cousin,

I know she feels like that, I mean no matter what she feels like that, I work with her. I'll see what she's doing on the problem and I'll tell her look, go back. Go slow, and work it out; they [her younger cousin and classmates] just want to write the answer. They [her younger cousin and classmates] don't like to show their work, I don't know why; that definitely baffles me. So I tell her show me the work and when she does, she does it slowly with me then she knows. And I tell her, I push her, 'you know this, it's easy - you know multiplication, you know decimals' because she doesn't have a problem with that, 'You know it. Just put the decimal point down' and I just push her. She does it by herself, I don't tell her the answer, and she just does it. If she's showing the work and does it by showing it, she'll be fine, but when she's hurrying, she messes up. 
Gigi felt that she has helped her and he thinks that her cousin feels that she has helped her as well,

I think she sees that because we had a period we didn't and then she asked for the tutoring. When we're tutoring, she puts that effort on her test and she does better because she remembers, 'oh she told me to work it out, work it out' and that helps her a lot.

Overall, Gigi described having more positive experiences with mathematics than negative ones and she thought these experiences would help her in future teaching.

\section{Context of the Student Teaching Placement}

Gig's student teaching placement assignment was in a fourth grade, self-contained classroom of 17 students. The class had nine girls and eight boys. This particular group of students were considered gifted for either mathematics or Language Arts. Gigi enjoyed teaching mathematics during student teaching and believed she gained confidence over the semester.

At the beginning of the semester Gigi believed that she would be a fun teacher who would use manipulatives and competition to involve her students as opposed to standing in front of the class explaining problems, and Gigi accomplished that. By the end of her student teaching experience, Gigi explained what she enjoyed the most about the experience,

My favorite thing is seeing the kids learn something new, because I already know it. So when I'm teaching them, I'm hoping that they understand how I'm teaching it. But it's just the noticing that they got it, they know it, I just feel good that I was able to explain it correctly so that they will move on and be able to hold that because it's important now.

Gigi hoped that she did not frustrate students because she believed that "if they're frustrated now then they'll be frustrated later." She wanted them to have good attitudes 
about mathematics. Gigi gave examples of numerous manipulatives and technology that she was able to use with her students,

Now that we have computers, we used videos, but I've also used, (when we did volume), we used these little cubes that filled in, so we used boxes and we filled them in showing them that volume is just not a paper, outside is what's filling in that box. You know, what makes up that object. I think that helped them.

Gigi enjoyed challenging her students the most during her student teaching

semester. She described the unit on area to be one of her favorite units,

I think my favorite one would have to be area. I like to do it. I like to do all math but that one, it's interesting because it's not there; you can't really see area. I mean you could, but it's hard for them. It's just a blank space of paper. I always like to find the area and then the multiplication I use, I like to challenge myself there. Sometimes they have big numbers: 200 times 175, and they'll have to do it, and then reviewing that because sometimes they wouldn't do that well. So reviewing the multiplication, I think that was my favorite part of the area chapter.

Gigi also enjoyed teaching about the area of irregular shapes because she liked the challenge that it posed for the students, "I like the irregular shapes. Even though they had trouble with it, it's more challenging than just a square or rectangle, in the beginning." Gigi reported that she was frustrated at times when she felt that the students were not understanding the concept, and she reported that her least favorite concept to teach was decimals. The students were learning decimals when she began teaching mathematics, and she explained that they were having difficulties ordering them and making the connections to fractions. Gigi explained that with some time and effort the students eventually gained understanding,

Decimals [was least favorite], just because it was hard for them to sometimes remember that if a fraction has a denominator of 10 or 100, that tells you the place value. But eventually they got it. Sometimes it was difficult for them and there was no other way to explain that, you know. I would bring out the 10 block and I would show them and they had it there. They needed to take some time for them to understand it but that's it. 
Overall, Gigi believed that she did a good job teaching mathematics during student teaching as evidenced by the success of her students,

None of my kids have really failed, so I think if they haven't failed then that's my result as a teacher. Not anything else. I can't tell you I'm a good teacher and then have everybody failing.

She believed student success provided evidence to prove that a teacher was successful.

\section{Gigi's Relationship with her Cooperating Teacher (CT)}

Gigi had a good relationship with her cooperating teacher. She relied on her help in planning and she used her suggestions about the use of manipulatives during the semester. Gigi often planned at school with her cooperating teacher, and explained that even if she planned lessons alone, she always shared her plans with her cooperating teacher. Gigi was open to constructive criticism that her cooperating teacher offered. Gigi explained,

If I plan at home then I bring it [plans] back and we go over it and make sure it's correct and makes sense, and that's what we want to do. And if we do it [plan] together, if we do it at school then I do it with her.

Gigi also explained that her cooperating teacher helped her to navigate the lessons in the textbook,

My cooperating teacher showed me how you write the plans out for the week, but also that you don't necessarily have to go by the book, and you really have to look at the lessons. And that some lessons, the kids won't even use for anything later on, it won't be even touched on, so if it's just an irrelevant lesson, just skip it. She's had us skip lessons before.

Reading and writing were the last subjects that Gigi took over during student teaching, and she took full advantage of observing and learning from her cooperating teacher before beginning to teach those subjects. Gigi explained, "She taught it [reading 
and writing] every day before the SCAT, she taught it for a month and a half. She would do a lot of modeling and a lot of writing prompts with them." Gigi was anxious about taking over reading and writing because even her cooperating teacher struggled with preparing the students for the SCAT writing section. Gigi shared her experience with the struggles of writing,

She's [her cooperating teacher], honestly, as lost as any of us. Because they change the rules for writing every year for the SCAT, and it's hard because the kids come in now to do this writing and they don't know anything. So they don't know punctuation, they don't know how to capitalize, so they have to start from the beginning and that has to be a subject on its own. But they haven't found like that magic trick to teach them writing. They try something every year different because they haven't found that trick for them to get a 5. It's very objective, they say you know, writing is very objective; they're going to read it and if you like it you like it. If you don't - you don't.

When Gigi finally took over reading and writing, her cooperating teacher was very supportive,

If I had any questions or problems, I would always ask her [her cooperating teacher]. And I remember we went into poetry for reading and I told her straight out, I do not know any of this stuff. I really don't know. I've never done poetry, I don't know how to analyze, and I'm really bad at that in that sense. So I told her straight out that you're going to have to help me, and she said, 'yea of course, I'm going to help you'. I sat with her before to make sure I knew what I was talking about.

Gigi depended on her cooperating teacher's insight throughout the semester, and Gigi's cooperating teacher had high praises for her at the end.

\section{Planning for Teaching Lessons}

Gigi never took more than thirty minutes to plan for a mathematics lesson. On average she took ten to twenty minutes to plan. Gigi mostly relied on the textbook (hard copy and electronic version) and the advice of her cooperating teacher to plan for her lessons. Gigi began the first step of her planning process by making sure the lessons in 
the unit were in the order she wanted to teach them in. She then reviewed the Sunshine

State Standards that went along with each lesson, and finally she reviewed each lesson

daily. She explained,

Generally, it's just going through the book and making sure that the lessons make sense in the order they are, and then if they're in the order for 5 days which is next week, then I'm going to go with those, and I like them. If they're relevant, I would just look at the sunshine state standards, what pages they're going to do for homework, what pages they're going to do for classwork.

Gigi did not always agree with the order of the lessons in the textbook and she sometimes rearranged the order in which the text book presented the lesson so that the students would understand the content more clearly,

Sometimes the book ordered stuff, in the wrong order. I remember for decimals, they started off introducing tenths place value then going into writing fractions, in the tenth, to the tenth place value, but the thousandths were all the way at the end because they went to tenth, hundredths and then they started writing simplest form, number form, and expanded form. And then they go again back to thousandths. I just thought tenths, hundredths, and thousandths first and then just go into the decimals, it would be so much easier. And they kind of already knew it - they had it on top of the board, and they've been introduced to the place values. So sometimes I just didn't get the order.

Gigi even changed the order of the chapters in the text book,

When we were doubling up [for SCAT], we didn't go [Chapter] 10 and 11 , or 12 and 13; we did 10 and 13, because we knew that for 11, you wouldn't need 10, and you know, vice versa. But you could do 13 as an isolator, so 13 didn't really have to be done at the end; it could done whenever.

Gigi explained that on a daily basis she would review the content of the textbook

and make sure that she was comfortable with the content,

Then every day in the morning, I would review; ok today's lesson is this, ok what do I need? Unless I already knew from before because it would have a note, I could tell that you needed more preparation. But, usually if I didn't, then that morning I would sit down; 'Ok, let me read through it and make sure it makes sense. Do I want to know the example?' Ok, and I had an hour and a half before 
[the mathematics period], always. So I would use that hour and a half. If I needed to go get something, I could go get something real quick.

Gigi explained that she planned for each week either with her cooperating teacher or on her own on Wednesdays or Thursdays,

Usually, we plan for the week on Wednesdays or Thursdays if Wednesday has already passed. But usually it's Wednesdays. And either we plan in that hour and a half, or we plan after school on Wednesdays when there's no meeting or I plan at home. I take it home with me and quickly I plan for the week.

Gigi mentioned that she shared her plans with her cooperating teacher.

Gigi explained that she paid close attention to planning challenging content for this class of gifted learners. Gigi was challenged in planning for her class because although the class was labelled a gifted class, not all of the students were gifted in mathematics. She had to plan for diverse learners, and she was challenged in doing so.

Gigi described her challenging experience in planning for gifted learners,

Now that I've already had time with them, I know when to they're going to have an easy time with it [content], so sometimes when it's too easy, I have to find something more challenging for them because they're going to be bored just with the regular work from the book. I think having gifted even though other teachers might think it's easy because they're smart, not all of them are gifted in math. Some of them aren't going to get it, so you have to take into account that the other ones are going to get it and they're going to get it right away. You have to find that middle ground and just like a regular class, you're going to have really low and really high and you have to accommodate for both.

Gigi went on to say,

Here in the gifted, they want challenges. They crave a challenge; they want to ask 'why?' all the time. They'll give you an example in real life like something that you never thought that you could even think of, and they have a lot of those. A lot of the time they will question you and they'll have examples that you never even thought about, so you have to be prepared for that.

Gigi explained that she allowed students who finished classwork early to read library books while other students finished the work. Gigi liked to use the strategy of allowing 
them to read when they were finished with their class work because it allowed her to help those students who were working slower with the content,

I planned enough for them to get through the lesson and then do the class work. After I tell them you can go read. So whenever I do review I have to get them back. There is no other way. Everybody works at their own pace, so I can't get them all to stop; don't read until everybody is done. Some of them are not done for a while if they don't get it. Maybe one or two, so I can't hold up the rest of the class, just go read. I let them read.

She explained that some students wanted to work ahead on lessons, but she did not allow that because it was distracting to the class when those students interrupted the lesson to ask questions about content that differed from content the whole class was working on. Gigi explained,

Sometimes there are some kids that like to work ahead. Sometimes I let them, but most of the time no because they work ahead and then they want to ask me a question on the classwork when I am teaching, so I don't like that. I don't let them [ask questions] because everybody else is going to stop and it's just a disruption.

Gigi modified her general planning model for the individual observed lessons.

She paid close attention to the information that she needed to share with the students. For example, for the second observed lesson, Gigi knew that in addition to the content of area, she wanted to review multiplication of two- and three-digit numbers, "I noticed that they were having trouble with the multiplication so I wanted to stop at one point and have someone work out the multiplication." Gigi took thirty minutes to plan for the last observed lesson because she had to think about additional resources that she wanted to use to help the students visualize tessellations; Gigi explained,

I took half hour. I wanted to find pictures that I wanted to show them because I didn't want to show them something too out there. At first, I couldn't even think about what I was going to use. 
Gigi thought it was necessary to find additional resources for this lesson because she was not satisfied with the lesson in the textbook,

I didn't like how the book was presenting it because it had only one tessellation with the triangles and, I wanted more. I thought, we have the pattern blocks, so why not use them. Just use the book to look at what tessellation means, and show them some of the real world tessellations that they see everywhere, to get them kind of used to them. The students can say, 'I've seen that at Epcot', and then have them [students] use the pattern blocks which I think is easier to visualize for them. They have a lot of trouble visualizing, without having it physically there.

Overall, Gigi was cognizant of her students' learning needs as she planned her lessons.

Gigi planned some activities for gifted students, but she often allowed students who finished mathematics work quickly to read and wait for others to catch up instead of planning more mathematics enrichment activities.

\section{Gigi's Mathematics Anxiety throughout the Semester}

Gigi was confident with mathematics content and did not have mathematics anxiety during the semester. Gigi was most confident about Geometry and she loved the Geometry content that she had to teach during student teaching, "I think I am most confident with geometry. I knew it; I just knew how to do it, so I was super confident.” Gigi had some anxiety toward algebra when working with graphs, and she reported having the most anxiety with calculus in high school. Having this anxiety toward Calculus bothered Gigi and she has reflected on why she felt this way during her student teaching experience,

I didn't have any anxiety towards elementary math. The only anxiety I've had would be in high school when I took calculus. I still have it, and I don't think teaching math right now has helped it. I've thought about why I didn't get it a lot, and I wanted to take another class to see if I could get it because I just can't believe I've gotten all the math and I get there, and it's a block. Teaching it, I've learned that maybe it's not necessarily that I didn't get it, maybe it was how the 
teacher was presenting it, but it wasn't for me. I've thought about it, and I always think about it.

Gigi was not anxious about any of the content that she had to present during student teaching, but she was anxious about teaching mathematics since she had never taught it before,

I've never taught before. In the beginning it was like, 'Wow, I don't know how to teach!' I mean you go to university and you have all these theories but have you really stood in front of anybody to teach something they don't know?

Gigi's anxiety toward teaching mathematics decreased over the semester,

I had a little bit [of anxiety] in the beginning, but it totally decreased. I think it's because I was exposed to actually being able to teach it and having someone there to just kind of guide is also helpful, so right now I'm not very anxious about teaching math at all. And I know that if you don't get something, you can ask someone or you can look it up online. We have the Internet. I've already learned math is my least worries.

On the pre-lesson surveys, before her lessons, Gigi indicated that she was very comfortable with the content of her lessons rating her comfort level at a 5/5 on all lessons with a 5 indicating that she was very comfortable and a 1 indicating that she was not comfortable. She was also very comfortable before teaching the lessons she had planned indicating the same results of a rating of $5 / 5$ on all lessons. When asked about her feelings while getting ready to teach a lesson in the pre-lesson surveys, Gigi described confidence and excitement to teach all the lessons using phrases such as, "I am confident that they [students] will enjoy the hands on activity", and "Excited to show them different tessellations. Gigi's answers focused more on the students' understanding of the content than on her own feelings.

Although Gigi appeared very confident teaching mathematics, she says that some parts of some of the observed lessons made her anxious. During her first observed 
lesson, Gigi reported being anxious when a few of the students asked her to explain why the units changed from feet when measuring the lengths of sides to feet squared when finding the area. She was a little nervous when she had to explain that,

Two of them [students] were asking me why "when you are measuring the length and the width it's just foot and then once you have the area its square foot?" That's the part [of the lesson] that made me the most nervous.

Gigi stated that she did not think the students would be interested in knowing why the units are squared, but commented that this gifted class constantly asked these types of questions. During the second observed lesson, Gigi reported being nervous when the students had difficulty visualizing the lengths of irregular shapes when they were given partial information. When the students were having difficulty, she erased the work and began to show them the lengths of the sides more slowly,

I [was anxious] in the beginning when they were getting the [measurement of the] whole side. I erased the whole thing to just start blank again, and that was when they got it when I actually identified each side for them.

Gigi was patient and took the time to reexamine the shape with the students. Gigi felt totally confident for the third and fourth observed lessons and she showed no anxiety while teaching these lessons. Gigi's only concern was the fact that for the fourth observed lesson, the students wanted to create complicated shapes, but again Gigi showed patience and helped students understand what they had to do. After the fourth observed lesson, Gigi explained,

I felt pretty confident. I never felt anxious or anything like that; it was just the fact that they were making it complicated, and I told them just use a geometric shape, whatever you want, it doesn't have to be complicated; you know they just wanted to complicate themselves, but I wasn't frustrated or anything like that. 
Gigi explained that she was not frustrated because she was very confident with the content,

I know about patterns, I know how to describe the pattern, and we've already done a whole chapter on transformations, and the different types. Before that I already knew what they were; it's simple: translation slides, rotation turns it, reflection flips it. I don't have any anxiety towards that subject. I know it.

Gigi's anxiety during student teaching was not mathematics anxiety, she was anxious about teaching and being able to convey the content to her students effectively.

Gigi understood that although she has not experienced mathematics anxiety in elementary school, some of her future students might experience this phenomenon. She said that she would try to help them by showing them a positive attitude toward mathematics, but fears that she would not be able to change all of them,

I hope they feel like I do because I'm not showing them that anxiety, but I'm sure there's going to be some [students] that's going to come in with that anxiety. I'll be there and try to help them push through that, but I don't know if I'll be able to change that if the anxiety is so deeply engraved.

Although Gigi showed minimal anxiety about mathematics she was vocal about

her anxiety toward reading and writing,

I think in writing, I'm the worst writer ever, but I changed that attitude when I got into university. But I've always thought 'I hate writing. I hate it.' I rather stay away from it, I rather not write but when I got into university, my first English course made me see that I'm not such a bad writer; I'm a good writer, I just don't like it. If I have to do it then I'll do it and I'll do it good, but I rather stay away from it.

Gigi was never able to teach writing during her student teaching semester, except for one lesson that she explained made her extremely nervous,

[I was anxious about] Writing, super anxious! I never taught it, I never took that over because after SCAT we stopped writing. But there was one time my cooperating teacher wasn't here and I had to model a writing sample, I think I suck at writing. I don't really suck, there's worse! But, I'm not great at it, and I 
don't know all those stuff, all the things that these kids know now about onomotopia and hyperbole, and if it's an adverb, and if it's a verb and a noun, whatever. All that stuff, I won't pick it out for you - I'm not like that. I'm bad at that. So I had to take it home and sit down and go through it, and ask someone else to tell me what else to highlight here because I needed to be prepared for that day. I couldn't just sit in the morning; I would get totally frustrated with that.

Gigi was also anxious about teaching reading. When she eventually took over from her cooperating teacher, the class began reading a new novel and Gigi was anxious about planning activities for the students,

In reading we started a new novel. I was anxious about it because it's reading. I know how to read and all that, I never had any trouble but how do I start a novel? What are the activities I'm going to use? I was excited, but I was a little anxious to know that it's the right activity. Not activities that are just fun, activities that are going to help them. That is meaningful for the book and for the lessons and for the lessons for life.

Gigi reported that she would still be very anxious in the future if she has to teach reading or writing,

Even though I've already done it - reading and writing, I've done it through science and through the long-short responses, I think I'm going to be super anxious. If I get 4th grade and I'm going to have to do writing, I will die, but I'll just have to ask someone else. My teacher next door, tell me how to teach writing because I don't know! I wouldn't know!

Gigi clearly displayed more anxiety toward reading than toward mathematics.

\section{Gigi's Content Knowledge}

Gigi believed mathematics was important to teach to her students and highlighted examples to support this,

I think math is important for everything and I think it's hard for kids to see it because they just see math numbers. But it makes it easier for you later one when you're doing everything: the bills, the painting, and that's when you notice this is why I did math. You need math for everything else in your life: money, how you know if you're getting the right change, how are you going to know how to pay your bills, how are you going to calculate everything? So I think it has various things that it teaches kids. 
She gave a personal example of when she needed mathematics to re-decorate her room, "When you're rearranging your new room, or when you're painting your room; how much paint you need, what square footage is the room, what bed fits in it if you're going to go buy one?" Gigi continued to explain the importance of providing students with problem-solving skills,

They [her students] need it for everything. In problem solving, there's so many different steps and you're doing it for math, but you need it for everything else to think about. There's not just one way to get to an answer; you need different steps. You can't just do one. I think it's [problem solving] teaching you how to take different steps to get to one solution.

Gigi believed that mathematics was significant to teach her students, and she tried to present content in ways that students could relate to.

During her student teaching experience, Gigi was observed teaching the Areas of regular and irregular shapes, rotation, geometric patterns, and tessellations. Gigi also worked on workbook called a 40 day countdown at the beginning of each lesson which reviewed all the content to be covered on the SCAT. The students worked on five problems each day and Gigi reviewed the answers to the problems before beginning her lessons. The content covered in the workbook consisted of various topics covered throughout the year. Each question covered a different topic so five additional topics were covered each day. The students worked on the same five topics each day for the entire week, so Gigi explained that Monday was the most challenging day because some of the content was new to the students. By Friday the students understood the topics and were able to work on the problems alone. Gigi explained that when she reviewed the answers to the questions on the forty day countdown, she sometimes felt like she was 
teaching mini-lessons in addition to the lesson she had planned. Gigi was comfortable teaching all the content from both the forty day countdown and the regular lessons because she understood the mathematics content well.

Gigi introduced the Area formula to the students during the first observed lesson. She described the lesson,

I taught them area, but they had already learned how to count the actual square units. Today I introduced the formula so that it was easier for them to find the area of bigger rectangles or bigger squares.

Gigi was very comfortable with the Area formula and she was confident in the methods she used to explain the concept to the students, "I am comfortable with area, length times width, I am comfortable with that concept and I have never had trouble with it, so I was confident in how I would teach it." Gigi clearly explained the Area formula and demonstrated its meaning using drawings of rectangles on a grid. She explained that the topic was not completely new to the students, and she believed that they would understand it quickly because they had previously seen problems involving area on the forty day countdown,

Area is length times width. I knew it and I knew they knew it because we have been slowly introducing them [the concepts of area] through the 40 day countdown which is like an SCAT Prep. They had like a Fab 5 which is just 5 problems to have them thinking and its either previous [content] areas or [content] areas that are going to be introduced so then it's easier for us to then conduct the lesson once we get there.

Although Gigi understood the content well, she showed some hesitation when a student wanted to know why the units changed from foot to square feet once the area was obtained. She described her feelings,

The whole lesson is area except for that part with the square foot and foot, what's the difference? I wasn't as comfortable cause at that moment I was like 'Whoa! 
How do I explain this?' Before [the lesson] I thought 'I already know square foot is square foot', but I hadn't really thought why.

Gigi never thought the students would want to know why the units changed and she did not have a clear explanation prepared for them. She tried to use perimeter to explain the difference between distance around a shape and the area inside the shape. She used this difference to explain why students should use feet and square feet. When she noticed that the students were not understanding the explanation, she used a garden to help them visualize the difference. She explained that she wanted a rope to enclose her garden like a fence, and the rope would need to be measured in feet. Then she explained that she needed dirt to cover the ground and that would be measured in square feet. The students seemed to understand more clearly with her explanation. Although she did not have this idea thought out ahead of time, Gigi think about the content on the spot and tried to explain the content to the students. At the end of the lesson she felt that the students understood the area formula, but might still be confused about the difference between the units and square units, "I am sure there is some that don't get it because of the whole square foot and foot, but they get the general area is length times width and they know how to do it."

Gigi's second observed lesson covered finding the area of irregular shapes. Gigi was comfortable with the content, but she thought the students were having a difficult time deriving the measurements of sides that were not clearly given from other given measurements on the shape. Overall, Gigi still thought that the lesson was successful, "I think it was successful, but I think they are having a bit of difficulty still with how to divide the shape and how to get the measurement of each side when they divide it." Gigi 
used mathematics vocabulary to explain the properties of the irregular shapes for example, parallel, rectangle, and square. The problems asked students to derive the area of irregular shapes. Most of the shapes were hexagons in an L shape, so the students had to divide the shapes into two rectangles, find the area of each rectangle, and then add the areas. The students had difficulty deriving the lengths of sides based on the lengths of other given sides. When Gigi noticed that this was the problem, she asked students to approach the board and figure out all the measures of all the sides of several shapes. After the students were successful at figuring out the measurement of the sides, she then had them figure out the area. Most of the shapes could be partitioned in more than one way and she asked students to find the area of the shape both ways.

Gigi covered rotation in her third observed lesson. She explained, "The lesson was about using what they know about degrees and $1 / 4$, I mean fractions compared to the degrees bench marks and, using it to identify clockwise and counter clockwise, as well." Gigi's goal was for the students to be able to identify clockwise and counter clockwise rotations, and the degrees associated with those rotations,

In the lesson they were supposed to identify if it was clockwise or counter clockwise and how many degrees it moved and, if there was $1 / 4$ of a turn, $1 / 2$ a turn, $3 / 4$ of a turn or full turn that it showed.

Gigi mentioned that the students had seen degrees previously as a part of the forty day countdown, so the it was not an entirely new concept for them, "With the 40 day countdown we do in the beginning, they had already seen notation before and $90^{\circ}$ and $180^{\circ}$ so that helped to introduce this, so they were already familiar with it." Gigi indicated she was very comfortable with the content and understood it very well, "I know the concept and I am comfortable with it and, I knew that they were most likely going to 
get it because they had seen it before." Gigi used the clock to help the students connect the idea of rotation with the language of clockwise and counter clockwise, and it appeared that most of the students made the connection. A few students were having difficulty differentiating between the $1 / 4$ turn and the $3 / 4$ turn, but Gigi used the manipulative and the clock to help clarify the concepts for those students. Gigi also helped the students to discover that counter clockwise meant "against the direction of the clock" so they could remember the direction of the rotation.

In addition to working on rotation, Gigi covered the topics of the forty day countdown before the start of the actual lesson. The students were unsure about one of the five questions that dealt with finding the area of a football field. The students were disagreeing on the correct answer because they were unsure of the actual measurements of a football field. At first Gigi asked the students to estimate to see if the answer made sense, but the students were still not visualizing the correct answer. Consequently, Gigi asked her cooperating teacher to look up the dimensions of a football field so that she could demonstrate how the correct answer was obtained. Gigi first converted the length and width of a football field from yards to feet and then multiplied the length and width of a football field. The multiplication was lengthy but the students followed along. After finding the answer, the students agree on the correct answer as an estimate. One student protested that this problem required previous knowledge about the size of a football field and he felt that the question was unfair; Gigi agreed with him.

Gigi's fourth observed lesson was a continuation of the previous day,

The math lesson I just taught is an addition to the one that I taught yesterday. Yesterday I introduced describing the patterns; if it's rotation or if they translated 
it or reflected it, whatever the pattern showed, or if it's large/medium/small large/medium small.

Gigi consequently asked students to create their own patterns in the fourth observed lesson, "Today it was them creating the pattern, and describing new patterns. It was kind of a short lesson on their own." Gigi felt very comfortable about creating new patterns; she explained what she knew,

I know about patterns, I know how to describe the pattern; we've already done a whole chapter on transformations, and the different types; and before that I already knew what they were; you know it's simple; translation slides, rotation turn it, reflection flip.

Gigi assessed the students' knowledge by having them create a pattern using two out of three transformations, "They had to use two. They either had to use rotation and translation, or rotation and reflection, or reflection and translation." Gigi emphasized that the pattern needed to repeat after two transformations. Gigi enjoyed the lesson and understood the content, but the students were "making the class work complicated." Gigi wanted the students to use simple objects so that they would be able to finish in an appropriate time. Gigi constantly reminded them to keep the shapes simple so that they can make their patterns. Gigi also pointed out that they should not use a square because if they do it will not show a difference in the pattern.

For her last observed lesson, Gigi taught a lesson on tessellations. Tessellations create a pattern with no overlaps or spaces using geometric shapes. Gigi explained, "The lesson today was introducing tessellations; teaching the students to identify tessellations just by looking at a shape. Can it tessellate? Can it make a tessellation on its own or with another shape?" Gigi was very comfortable with teaching the lesson and she knew the 
content. She also felt that the students would do well because the students were

introduced to tessellations previously,

The concept was pretty simple and I knew that they knew patterns and they had already seen tessellations in one of our fabulous five which is like an introduction that we used to do in the beginning of math lesson so, I knew they were really familiar with it.

Gigi introduced the lesson by showing students examples of tessellations in art, architecture, and nature. She then had students create their own tessellations by using pattern blocks. All of the shapes that she gave to the students could tessellate; however, when the students did independent work to do alone in their textbook they were given some shapes that would not be able to tessellate. This posed a problem because some of the students could not visualize the shapes and said that they were difficult to draw. Gigi described her reaction to this,

Once they got into their independent work when they were asking me, 'but, it's not really the same, or it's hard to draw it.' When you only have one shape, you would have to visualize it in your head and try to see if fits or not.

Specifically, the students were having a difficult time determining if a star can tessellate, and she did not know what to do to help them, "What am I going to do? I can't go and find an exact star like that right now!" Gigi eventually reviewed all the problems from the textbook by having students write their answers on the board. She drew the star and the students were able to see why it does not tessellate. For another problem, the students could not visualize why an octagon would tessellate. Since it was the end of the class, Gigi promised to bring in an octagon for the following class so that they could visualize the tessellation. 
Gigi explained that there were two topics that she found most challenging to teach during her student teaching experience. The two topics were decimals, and 3dimensional shapes. She explained that she was comfortable with decimals but since it was the first topic that she had to teach she was overwhelmed,

When I first started, we started a new chapter and it was decimals. I've never had trouble with decimals or anything like that, but I [wondered], 'How am I going to start with decimals?' I know it was a difficult concept for 4th grade, and I was using fractions; I was a little bit overwhelmed because I thought, 'Oh gosh! I've never taught math and this is the most difficult concept; decimals and fractions and percent's!' But, the book breaks it down for them. Then I noticed, this lesson is lesson 5 and we're on lesson 2 but we need it now so why not? Then I started learning that I could switch them [the lessons] so it could flow better; that's when I knew I can do it. It's fine.

Gigi felt rearranging lessons in the textbook made more sense and she could explain the content more effectively by doing that strategy.

Gigi also struggled to connect 3-dimentional shapes to real world applications for the students,

I couldn't see where they were going to see it. I understand that yea they're going to have to know them [the names of 3-dimensional shapes], but after that you really don't use that [knowledge] anymore. You have to know how to visualize something 3 dimensionally. But it's not going to be as simple as a shape, and I didn't know them, I didn't know the names, I had to learn them, I have to count them with the students. I had to learn with them.

Gigi did not remember the names of the 3-dimensional shapes, and she had to relearn the content before presenting it to the students, "For triangular prism, or the pyramids, I didn't know that the bottom names a pyramid, I thought it was just a pyramid! I never even thought that a pyramid could be like a triangular pyramid, or a base of a triangle, or a base of a square, a rectangle, and all that. I basically learned it with them; I learned it quick!” 
During her student teaching experience, Gigi enjoyed teaching new content to the students and although some content posed a challenge for her, she found that challenge most interesting. Gigi explained,

I've never really taught math from the beginning, just start from scratch. They really don't know anything! You go into area, for example, and they don't know anything, so you really have to teach them and go through steps so it's a new experience to be able to explain something like that and at times, I was thinking, 'Wow! I know it's easy for me to do math and I've never really been frustrated, but can I teach math? Can I teach them what length is? Or what width is? What a triangular prism is? Any concept that might not be physically there, can I word it in a way they would understand it?' I think it was a challenge, sometimes, to explain it to them, but I found that interesting.

Gigi enjoyed teaching concepts that were challenging for the students because she was able to open their minds to see things differently, "Whenever they got it, it wasn't that challenging because it's easy. I like them not to understand sometimes and then try to open their minds to see it a different way." Gigi used mathematical vocabulary with the students and often connected the content that she presented to real life situations. Gigi did a good job in showing knowledge of content during student teaching.

\section{Gigi's Pedagogical Content Knowledge}

This section will outline examples describing Gigi's actions and ideas pertaining to Graeber's (1999) five big ideas on pedagogical content knowledge that preservice teachers should possess. With respect to Graeber's big ideas, Gigi demonstrated the ability to assess students' understanding well. She implemented lessons that promoted student retention of ideas and provided alternative representations of concepts. Gigi also demonstrated the ability to implement lessons that provided opportunities for students to demonstrate both conceptual and procedural knowledge, and she created opportunities in 
lessons that considered students' intuitive understanding of concepts. Overall, Gigi showed evidence of strong pedagogical content knowledge.

Understanding Students’ Understanding is Important. Student understanding was very important to Gigi, and she referenced this idea throughout the interviews conducted during her student teaching semester. Gigi was very concerned about her students' understanding of the content of the lessons that she taught. Gigi assessed the order in which lessons were presented in the textbook and the content presented in each lesson of the textbook; she made adjustments to both the order of the lessons and the content she introduced based on the knowledge of her students' understanding as well as her own understanding of the content. During the first observed lesson, Gigi explained why she changed the content that she presented to the students,

I don't like how it [student textbook] presents rows, and then it doesn't even present columns. I had to introduce the row and the column cause that's what they know. The textbook just presents there are 4 rows and then how many are in each row, but they know it as rows and columns, so I don't like how they [textbook authors] presented it in that way.

Gigi taught the students area in the first observed lesson and she was referring to finding the area by counting the squares. Gigi explained that in her previous lesson, the students used squares to find the area, but this lesson's objective was to introduce the area formula, so the students were given larger numbers to work with; it would have been tedious to count squares for these problems. While students were working on problems, Gigi constantly moved around the classroom to check for student understanding,

From walking around I see them writing on the side. Just writing the side ones and not counting out. If they are counting it out they put the little dots and I can see it, and it's [the area] way too big. They give them big ones so that they don't waste their time counting it out. There is too much to count and you see that 
they'll write it, the width and the length. I know that they are doing it; they are not just counting it. All of them had it. That's how I observed them.

Gigi felt confident that all the students understood the area formula and she felt that was of the utmost importance.

Gigi introduced the area of irregular shapes during the second observed lesson. Again, she was very concerned about the students' understanding of the topic,

I felt they were going to have difficulty with dividing the shape and knowing the sides, the actual measurement, but I felt once they worked with it, or once they saw it over and over they would be fine.

Gigi checked for student understanding by having them work out examples on the board with her guidance, "Once we were getting to the second example I think they were getting it more; I had them come up to the board cause I knew that they would be fine getting it." After having students work problems on the board, Gigi allowed time for independent work. She circulated the room and observed the students' work; Gigi assessed that the students were successful at making regular shapes and finding the area, but they were having difficulty multiplying double digits, "Multiplying the double digits they might have trouble with, but not necessarily using the [area] formula." After this assessment, Gigi took some time to review multiplication of two digit numbers with the students. She asked students to solve some problems on the board to keep them engaged and ensure that all students are working at the same pace,

When we get to the middle [of the lesson], I feel like I lose some of them, and I have some working ahead that already [understand it]. For certain lessons, I would be fine with them working ahead, but for this one no, because there are some that are getting confused and I know that they are going to get it confused, I know that it's not as easy as $1,2,3$ so I want them to pay attention so that's why I call them up." So that they are not working ahead, so that they have to be paying attention cause if not they are not going to know when they come up. 
For the third observed lesson, Gigi introduced rotation by discussing degrees related to a quarter turn, half turn, three quarter turn, and full turn. She was very confident in student understanding for this lesson, "I think I was very successful. They did perfect. From what I've seen when I walked around, all of them had it right and they were right on task." Gigi circulated the room to check for student understanding. She explained that she enjoyed having students ask questions during the lessons because she believes that promoted student understanding,

I think that's better than just sitting there not understanding, and not even caring; at least I know that they are caring enough to ask 'why?' or 'I don't understand' or 'why does it do that?', you know, that helps them understand the concept better in their own way. I'm super comfortable with that.

Gigi liked to challenge her students' thinking.

Gigi thought her fourth observed lesson was successful, and the students understood geometric patterns. She thought that the students understood the lesson so well that they were trying to make it more complicated in order to make it challenging. She explained,

I think I was pretty successful, even though they were making it more complicated; sometimes they made it more complicated than it seems. When I asked them to make their own pattern, they were picking complicating shapes. They know how to rotate, \& how to reflect and how to translate, they were just being 'If I have to put it on the bottom of the page that needs to be there, how do I?' It was simple stuff that they were complicating. Sometimes our lessons are complicated, so I guess they are so used to that, that something as simple as that, they were trying to challenge themselves I guess, but it wasn't, it was simple.

Gigi circulated the class as the students made their own geometric patterns to assess their understanding, "I walked around and made sure that each of them had their own pattern, and that they had two transformations and that they could explain to me quickly what they had." Gigi often asked students to explain their thinking, and she asked students to 
use their prior knowledge to explain their work in their own words. Gigi asked the students,

Tell me exactly, 'I reflected it and then I translated it, or I rotated it'. Since we had already worked on it yesterday, I wanted them to show me their independent work from yesterday's lesson and use it on this one, so that I know that they know it, not that their partner knows it. I wanted them to show that they knew what we had learned yesterday.

Gigi explained that at the end of the lesson she did not go over examples of the students' geometric patterns because she noticed that everyone was able to create their own pattern successfully,

If I saw that they were having a hard time or if we had some extra time, and they were still all here (some students went to the library), then I would probably have some of them go up and show me the pattern, but with this class if I bring one up to show their pattern, they all will want to show their pattern, so it will take a long time.

After assessing student understanding during the fifth observed lesson, Gigi

determined that the students still had difficulty visualizing some tessellations. Gigi said,

I think it [the lesson] was successful, but at the same time I think they are still confused about it because of not being able to have the shapes in front of them, like the more complicated ones that have a curve or even the star. It doesn't have a curve but, if you really put it together, you won't be able to tessellate it, but they would need the shape there with them.

Gigi stated that after going over the content, she believed that the students understood the lesson, but as the students worked on problems independently, she noticed that the students were having difficulty visualizing whether or not some shapes would tessellate,

When I was teaching, I felt they knew what it was; they understood it, and they were going to be fine doing the work. When I got into the work, that's when I noticed so many questions. I noticed they're going to need to cut it out, to have it in front of them to do it."

Gigi liked to challenge the students and have them struggle with difficult problems, 
I think if it [the problem] is too easy, they really don't learn. You need to be able to see the difficult ones that you have to figure out, you really have to think about, like the two triangles that were together, you can't change them. They have to move the same way. When we went over it [class work], they said, 'Oh, it does tessellate!' They can see you can rotate or flip it, as long as it's the same shape and it's the same size.

Although she wanted her students to completely understand all the lessons the first time she explained content, she knew that was not possible, and enjoyed having to reteach content to help students understand more clearly,

At first, I was a little let down that they didn't get it, because I always want them to get it right away, but once I got to explain it again and once they get it, I think that's even more rewarding. For you to be able to change your explanation and for them to get it, and then you notice not everybody's going to get it how you say it the first time. You need to pick your words correctly.

Gigi strove to ensure student understanding in every lesson.

\section{Students Knowing in One Way Do Not Necessarily Know in the Other(s).}

Gigi had a good understanding of procedural knowledge and she displayed some instances of providing conceptual understanding. During the first observed lesson, Gigi introduced the area formula to the students. In a previous lesson, she had students count squares to determine the area of regular shapes. The students were successful with both counting squares and determining the area of a shape using the formula. However, Gigi commented that the students had difficulty understanding how units became square units after multiplying to find area when one student asked her to explain why this happened, "I felt good until that point. Where I was trying to explain the square foot is the inside not necessarily the outside that's just the length times width." As discussed in a previous section, Gigi tried to use a concrete example of a garden with string around it to determine the length and the soil inside as an example of area. Gigi tried to help students 
understand the content of Area conceptually. Upon reflection of the lesson, Gigi thought the textbook contributed to their lack of conceptual understanding,

I think I wouldn't use the book example. I would probably just come up with a couple of examples on my own, still introduce the rows and columns cause that's what they know, but I think the way the book presents it kind of confuses them.

She thought connecting area to a real world example might have helped the students fully understand the concept,

I think maybe looking up something that might explain the area in everyday life. Maybe a video, or maybe having something online that they could visually see as a day to day problem that they could use area with.

Gigi was concerned that the students understood the procedure of using the area formula, but she also wanted them to understand what area meant and why the unit changed to square units.

During the second observed lesson, Gigi addressed finding the area of irregular shapes. The students understood how to create regular shapes from irregular shapes, but Gigi noticed that the students were having a difficult time determining the length of a side given information on the length of other sides to find the area of these shapes. She knew that this was an area of weakness and said,

I am going to go over that, so that they see how to find the sides because they are not. I am going to let them do it on their own and then I am going to go over it as a class so that they see if some have made the mistake or not, and how I found that side.

Gigi used grid paper to show some examples, but she did not use the grid paper throughout the lesson. Using grid paper or having students cover the shapes with square units might have helped the students understand conceptually. Gigi used the area formula 
and had students add the areas to determine the total area; she focused more on the procedure for this lesson.

During the third observed lesson, Gigi worked on the "Investigate" section of the textbook with the students to help them understand rotation in both clockwise, and counter-clockwise directions. Gigi related the movements to a clock and used a spinner that highlighted the four quadrants of quarter turn, half turn, three quarter turn, and full turn. The spinner help the students to connect the number of degrees to the given turns. Gigi made clear connections in this lesson and used students' prior knowledge to help them conceptualize the topic.

Gigi allowed students to problem solve by giving them an open-ended task for them to work on during the fourth observed lesson. Although Gigi went over the example of a geometric pattern from the textbook, she believed that example was very easy,

I didn't like that they only had one example for us to work through together, and that it was so simple. It was fine to start with it simple, and maybe another example a little bit more complicated, so that they can see how to use more than one transformation. Then maybe they would have been more comfortable with it, when they got to the open ended one.

Gigi allowed her students to struggle with the task of creating their own geometric pattern which they had to describe. This type of activity allowed students to demonstrate their understanding of the topic and show their understanding in a creative way,

They had to do their own [geometric pattern], because it gets them to think about it. The other ones, they either already had the steps on how to do it, or they already had the patterns done for them. I like when they can do it on their own and describe them as well, so even though they were complicating it, it opened their minds for them to be creative on their own, with Math, which we don't get a lot. 
Gigi said that she often challenged her students using this type of task. This shows that Gigi was comfortable with the content and open to various possible answers.

Gigi introduced tessellations to the students for the last observed lesson. She provided real life examples of tessellations to introduce the lesson. However, she did not ask students to offer their own examples of tessellations which might have helped them conceptualize the topic. Gigi used pattern blocks to help students tessellate shapes, but all the shapes that the students worked with were able to tessellate. This posed a problem when the students were asked about shapes that were not able to tessellate in their independent work because they could not visualize the objects. Gigi reflected on this last observed lesson and came up with possible improvements to enhance student understanding,

I think I would've changed the pattern blocks because it was too easy. It was kind of getting out of hand and they all tessellated. I would've like some of them to have non-tessellations, so maybe have the partner next to you have one that doesn't so that both can see that one doesn't. For next time, I would probably use other materials, maybe myself, cut them on construction paper or something.

Gigi knew that the students needed more help with the conceptual understanding of the topic.

Intuitive Understanding is Both an Asset and a Liability. Intuition is vital in solving mathematics problems and connecting mathematics ideas. Gigi showed evidence of assessing students' preconceptions and misconceptions during her student teaching experience. During the first observed lesson Gigi addressed the Area formula with her students. She noticed that the textbook presented the idea of counting rows to the students, but did not focus on columns. From working on area in past lessons, Gigi knew that her students understood the content using the ideas of both rows and columns. She 
stated that the students became confused when they were doing independent work when the book did not highlight the columns. Gigi addressed this after she noticed it could be a possible misconception,

I think the way the book presents it confuses them a bit. Especially the first problem that they had independently. It was just the row, it didn't say rows and columns. It just says rows and then how many are inside, but then it starts adding, and they didn't know what to add. I think that that part they just get confused.

The students knew how to figure out the area of a rectangle by counting both rows and columns, and because of that preconception, they were not able to figure it out without the columns highlighted. Gigi took this opportunity to try to clarify this for the students.

Gigi identified difficulties that students encountered in the second observed lesson. Gigi noticed that the students were having difficulties inferring the measures of the sides of irregular shapes by using measures of other given sides. Some students assumed the measures of sides by simply looking at the numbers given. Gigi commented, "It's just the difficulty of that finding the actual measurement of that side. And that confuses them with the whole shape. The whole measurement of the whole shape." The students were also confused by the arrows in the textbook, and were sometimes not sure exactly where the arrows were pointing, Gigi explained, "They [students] don't know where they [arrows in the textbook] are pointing to, what side it's actually measuring. They are a little confused with the arrows." Gigi knew that because of these misconceptions about the measurements of sides, they would not be able to calculate the correct area. The students knew the area problem and how to use it, but they were not using the correct measures in the sides and that caused them have incorrect answers. Gigi addressed this by having students practice identifying all the measures 
around the irregular shapes even those that were not needed to find the area. Gigi noticed that there was another misconception causing students to calculate the incorrect area. The students were having difficulty with multiplying two-digit numbers, specifically the placement of a zero when multiplying. Gigi explained, "They [students] have to have the zero "cause a lot of them are forgetting that." Gigi took time out of the lesson to review multiplication of two-digit numbers and emphasized working with a zero as a place holder.

During the third observed lesson, the students had some difficulty with a question in their forty-day countdown given to them at the beginning of the class. Gigi spent some time clarifying this. Gigi explained the scenario,

They [students] had already seen that concept actually because it keeps on with the same concept on the same number for the whole week. So, number one is going to be the same concept as the day before. They usually do good with that but, I guess they had questions about the football field one where, they thought the answer was 800 feet. 8000 yards was too much. The 800 feet, to them, was just right but, they were not using their prior knowledge of estimating how much a football field was so that is why I decided to go with my cooperating teacher and get that information, so I can actually do it for them and see that their estimate was totally off.

Gigi wanted to ensure that the students understood the answer to the problem, so she asked her cooperating teacher to look up the exact measures of a football field to clarify any misunderstanding. Gigi explained, "I wanted to just do it right there and then, because I knew that they would have questions about it and be confused about it, and I don't like leaving them like that." Gigi did not just review the answers, she justified the meaning for the students and helped them to clarify the reason the answer made sense.

During the fourth observed lesson, Gigi had students create their own geometric patterns. She clarified some misconceptions for them. Gigi made sure to instruct the 
students not to use a square since there would be no visible difference in rotating or flipping a square in a geometric pattern. Gigi explained this, "I told them don't use a square "cause it is going to look the same, no matter what." The students were also having trouble using more than one transformation to create a pattern. After reflection, Gigi decided the next time she taught a lesson like this, that she would use her own grid to create an example of a geometric pattern using multiple transformations since the textbook only gave an example of one transformation,

I think I would have used the first example, but then probably brought up a grid on my own, using the same triangle, and done my own steps to use two transformations or three, to show them that they could do it, and that they don't necessarily have to move the triangle, rotating it around the point. They rotate it and then draw it right next to it, so it's a pattern.

Gigi had to help the students with this idea individually.

During Gigi's final observed lesson, she discussed a possible misconception that could have occurred. She provided shapes for students to make tessellations, but all the shapes that were provided could tessellate. This caused a misconception when the independent work provided examples of shapes that would not be able to tessellate and the students did not realize that there were some shapes that would fall in this category. Gigi reflected, “I should've given them something that didn't tessellate so they can see why." Gigi decided that she would bring cut-outs of shapes that do not tessellate during the next class period to clarify this possible misconception for students. In general Gigi used different approaches to clarify misunderstandings for her students.

Certain Characteristics of Instruction Appear to Promote Retention. Graeber (1999) explains that this big idea focuses on providing strategies that move away from having the teacher "tell" the student how to solve problems, but instead, provide 
strategies to help students retain knowledge. Gigi demonstrated several of these characteristics during her student teaching experience. During the first observed lesson, Gigi allowed students to solve word problems that had students create shapes given a particular area. The students had to not just solve an equation to find area, but they had to be able to determine the lengths of a shape that would yield a given area. This type of activity allowed the students to reflect on the content and use it to create shapes. Gigi explained,

I told them to do [the word problem] because it is asking them to come with shapes that have an area of 36 , three different ones, so it's getting them to brainstorm the shape cause they already know it has to be a rectangle, but they're thinking multiplication wise ok 4 times 9 ; a 4 by 9 shape. They're getting multiplication and they are getting to creatively think 'Ok, what am I going to do?' because they don't have the answer there. They came up with different shapes.

After reflection on this lesson, Gigi decided the next time taught this lesson that she would take the lesson a step further and incorporate a real life scenario to help students retain the information even better. She said,

I think maybe [I would] look up something that might explain the area in the everyday life. Maybe a video or something online that they could visually see as a day to day problem that they could use area with.

Gigi had students share their ideas by working problems on the board and she asked students to justify their answers. She thought it was important for all students to be engaged.

Gigi also liked to challenge her students to think on their own at times. During her second observed lesson, Gigi gave students problems to work on independently. The students had to figure out areas of irregular shapes knowing only the measurement of some sides. She enjoyed having the students brainstorm to figure out their answers, 
I liked when they [students] divided the shape up on their own because it's brainstorming. They really don't know the shapes. Number 3 on their independent work, they had to divide it, but they had to find the side since it wasn't given. So I like having them think about it.

After reflecting on the lesson, Gigi decided that she would like to take the content a step further by actually using a real life example such as creating a shape on the floor,

Since I know they are having trouble dividing [the shapes], if I had more time, I would have wanted to get like the measuring tape, like that painters tape, and maybe do an example here, but maybe more complicated with more ways to divide it, not just two. And have them see that this whole thing that you are telling me that it's 16 , that can't be your base here cause you are only dividing by a piece and maybe that way they will get it more than just on paper.

Gigi believed in providing students with contextual situations to promote learning. She also wanted the students to see the different strategies that could be used to find the area of one irregular shape.

During the third observed lesson, Gigi had to explain to the students the correct estimation for the length of a football field. She felt the urgency to ask her Cooperating Teacher to look up the length and width of a football field to answer the 'why question' posed by the students. She explained that this group of students constantly questioned 'Why?' and wanted an explanation. Gigi explained, "They [students] always want to know why; if they don't understand, they want to know why; 'Why does it go like this? Why does it happen like that?" Gigi's students enjoyed discussion, justification and reflection on content. Gigi felt the need to activate prior knowledge to help students solve problems. Gigi explained that estimating the area of a football field required previous knowledge on the dimensions of a football field. Gigi explained why she thought some students had difficulty with the answer to finding the area of a football field, 
There are a lot of girls in here; maybe they don't watch football, and maybe even the guys don't watch football. It won't help them, they [students who don't watch football] are not going to know how much a football field measures.

Gigi knew that her students liked a challenge, and they enjoyed trying to solve problems on their own. She allowed them to construct their ideas and during lessons.

During the last observed lesson, Gigi introduced tessellations. Gigi did not give students any shapes that were not able to tessellate to work with in the beginning of the lesson. After reflecting on the lesson, she decided that she would make changes to increase student retention. Gigi described her thoughts on changing the lesson,

Maybe cut out the ones [shapes] from the book and have them [the students] work with them as well. Then, maybe four of them [shapes] we do it [tessellate] together, and then the other four [shapes], you figure it out yourself.

Although Gigi gave the class pattern blocks to work with, she did not have students work with all the shapes discussed in the lesson. Gigi thought it would be important for the students to visualize and make connections with the actual shapes.

In general, Gigi thought it was important to have discussions in mathematics and relate the content to real life situations, "I think that sometimes kids have a hard time because it's [mathematics content] irrelevant to them, 'Why?' A lot of times when kids don't understand, they ask, 'why?'” Gigi thought it was important to always try to answer the 'Why?' questions that students pose because that makes mathematics more relevant and meaningful. Gigi values the importance of making sense of mathematics for her students,

I've always had an easy time with math, but I did have one year that I was basically, the whole year, was asking 'Why?' because I really didn't get it. I don't know if it was the teacher, if it was me, or if it was how the book was written, I don't know what it was, but I just didn't get it. So I know what they go through as well. 
She also used other strategies to promote instruction during her teaching. Gigi

strategically paired students when working on two-dimensional and three-dimensional shapes,

We had a concept before, it was on 3D building; they had to build blocks from the $2 \mathrm{D}$ that was on the paper to $3 \mathrm{D}$, and they worked in pairs, they used the same manipulative and they helped each other.

She also described how she used small groups,

We put them in groups every once in a while, and I did do small groups with them but I don't think they really need it because I go around [to each student]. But you know, it works if they really need a lot of help and the other ones are fine, you can take those, have them work independently and just quickly review the concept with the other ones. I would probably use small groups if I had you know, kids that didn't understand and I needed to review individually.

Gigi also believed in using hands on strategies to help with challenging concepts, "Whenever they're having a hard time, hands on really like gets them on the right path." Gigi cared that her students made sense of mathematics.

\section{Providing Alternative Representations and Recognizing and Analyzing}

Methods are Important. Gigi showed evidence of providing alternative representations to students repeatedly during her student teaching experience. During the first observed lesson, Gigi introduced the area formula. She used grid paper to help the students visualize the square units and allowed students to use the grid paper projected on the white board to count the rows and columns in order to find the area of rectangles. The students questioned why the unit for area was a square unit instead of the unit used for length. Gigi tried to explain to the students that the area covers a shape; however, after reflection she thought it might be better to research a better explanation for the students, "Now that I know that they are having the square foot and the foot [problem], I can 
probably look up something like that explains why for their level." Gigi understood the value of providing alternative representations for the students.

Although Gigi did not provide tangible manipulatives for the students during her second observed lesson, Gigi used the electronic version of the textbook and drew on the projected image to convert irregular shapes into regular shapes in order to use the area formula to find the area. The irregular shapes could be divided in more than one way and Gigi made sure to demonstrate all possible scenarios for the students. When the students worked on problems, she asked other students to discuss other ways to arrive at the area for the irregular shapes. Gigi explained, "They [students] could divide it [the shape] however they wanted and they'll still get the same area." She encouraged students to explore and analyze different methods.

Gigi used a spinner with four quadrants as a manipulative for the third observed lesson to help students conceptualize rotation. Each student received a spinner and was able to manipulate it to figure out the rotation of shapes by a quarter turn, half turn, threequarter turn, and full turn. Gigi also associated the number of degrees that each quadrant represented and the students were able to rotate the spinner either clockwise or counterclockwise. Gigi enjoyed using this manipulative, and indicated that her cooperating teacher provided the manipulative that she had used in the previous year. Gigi explained,

I liked using the manipulative that we had. It was actually my cooperating teacher that gave me from last year's intern; they had done it so, I used it for this lesson because it's what the book uses, and I thought it was actually a good tool. It made sense to them, and they could relate it to the clock because it looks like a clock. 
When asked what she enjoyed most about her lesson, Gigi answered her favorite part of the lesson was using the manipulative, "The manipulative because it's something they have at hand, and it's something easier for me to work with, to learn that way, I enjoy that better, teaching with that [the manipulative]." Gigi observed that the students benefitted from using the manipulative correctly, and she used it to assess the students,

They were using it how they were supposed to, especially when they were doing the work. They were able to identify [rotation] on their independent work with the model, and they were able to use the model to help them identify that; so I asked for everything clockwise, counter clockwise, which is the most important, and then the turn, like if it was a $1 / 2, a^{1} / 4, a^{3} / 4$ turn, and then the degrees as well; so I brought everything together.

Gigi also mentioned that she also introduced the lesson on the previous day with a short video on degrees that she found on Brain Pop, "I looked on Brain to have a little short video explaining degrees, and I actually played it yesterday for them as a beginning to the chapter." Gigi believed in using multiple representations to help the students understand the content.

Gigi used an orange right triangle as a manipulative for the fourth observed lesson. She used the right triangle to demonstrate the example of a geometric pattern using a transformation. The pattern that Gigi created used one transformation and one shape; however, the students' independent work asked for the use of two transformations. Gigi did not give an example of using two transformations, and after reflecting on the lesson, felt that would have been beneficial to the students,

I would have had the grid available to show more examples, because I hadn't noticed that they wanted two transformations. They [the students] didn't know what that meant, so I would probably have found a grid quickly, and projected it, and then drawn it [geometric pattern] with the triangle. 
The students were seated in groups of five this lesson and during their independent work some of them worked together. Gigi explained that she allowed students to work together when the concept was difficult, "When we have a difficult concept, I usually let them work with partners. They talk to each other, even though there's five of them; they go back and forth." Gigi allowed discussion and believed that the students benefitted from the discussion, "It [discussion] works fine, and they still ask for help, and they know that they can ask a partner for help if they really need it. They work well together." Gigi grouped students according to how well they worked together,

We already know who doesn't work well with who, so when we change the seating arrangement, we already know: we can't sit these two together, or you can't sit best friends together, because they won't even help each other, they'll just be talking. We had them seated how they work best.

Gigi promoted healthy discussions throughout the observed lessons.

Gigi covered the topic of tessellations in the last observed lesson. Gigi used many representations to facilitate learning of the content. Gigi introduced the lesson using examples of tessellations in art, nature, and architecture. Gigi explained,

I looked for them [pictures of examples of tessellations] on Google, and found patterns in art, and then I put tessellations and architecture and I looked up tessellations and nature. I saw the bee-hive, said it's perfect!

Gigi believed it was important to give students real world examples for them to be able to make more sense of the content. She thought the students would think, "I've seen it before, it's not that hard, you know, I just never really noticed that." Gigi continued the lesson by allowing students to use pattern blocks to make their own tessellations. All the pattern blocks were able to tessellate and Gigi commented that she should have provided students with examples of shapes that did not tessellate as well, 
I was thinking that all the pattern blocks would have tessellations so, I would have liked someone to not have it but, I didn't really think of it. I just wanted them to kind of see it, you know how, other shapes can tessellate. Maybe have those shapes already cut out, the ones from the book. I think they would have worked better with them already; all of them there.

She also thought that she should have had larger shapes prepared to show students as they were discussing the independent work,

I would have them [shapes] larger when we were answering the questions to show them but, I think if they had them in front of them, they wouldn't have had a problem at all to answer them.

Gigi did have the students share their work on the board by allowing them to draw the tessellations that they created,

I knew they were going to have a hard time with it, I just decided, to have them come up and, they'd draw it out so that they can see it from their peer's perspective, not necessarily a teacher just telling you this is how it is and that's it.

Gigi believed that the students learned from each other.

Gigi believed in using various representations, and used others throughout the semester in addition to the ones observed. Gigi used Brain Pop as a resource,

I used brain pop. They have really good videos there as an introduction, because they are quick videos. I also used Google. I looked up to explain the order of decimals on a number line. They [the students] had been having trouble before that with visualizing the order, so I think that having the video and having me explain that at the same time, they benefit from that.

Also, Gigi used manipulatives whenever possible because she enjoyed them, and saw their value,

I love using manipulatives. Any type of manipulative; if I can use it, I'm going to use it. If they had manipulatives for everything, then that would be great; I think that learning hands on ties into everybody. Some of the ones in here can hear it, you know audio and see it and they're done, they got it; but, some might not have that; some might need that manipulatives to actually see it visually. One little boy that I was helping, he needed to see it in order to be able to understand it. 
Gigi also described the use of other manipulatives during her student teaching experience,

I've used the blocks, the connecting cubes, I've used the pattern blocks. I've used the letter F, and I go and I print out triangles, and whatever we're going to use for rotation or reflection, or anything. I print it out and have it there so I can do it with them on the board so they can see it. Anytime I can use manipulatives, I use them. Just like with the decimals, the 10 block I used it for one lesson, but then I made a 10 block template on PowerPoint so that I can shade in and they can come up and shade it in for me.

She also mentioned that she used nets to help students understand the difference between two-dimensional and three-dimensional objects, and she used fraction circles to help students understand angles. Gigi believed that the students loved using manipulatives, "They love coming up to the board, and they love having something in front of them." Gigi also wanted to try to use different types of manipulatives, but she explained that she was not able to attempt all of the ideas she had,

Most of the manipulative are small. I used what they had, but I've always wanted to try more: like for area, to have the floor taped, or have them go measure outside and find the area of the field or something like that, actually take them outside; use math outside. Use math in the real world, in the real context. I think I would want to try that when I have my classroom.

Gigi wanted to do more hands on activities but learned that those types of lessons take more time to plan; she noticed that in order to be successful she would even have to give up any free time to plan for those lessons,

I always want to do a lot of hands on and a lot of activities, but I noticed that there is not that much time and if you really want to include something like that you would have to prepare beforehand so that you are not wasting any time. During your break you would, unfortunately, have to miss your break and prepare for whatever it is you wanted to do outside, so that when the kids got back to the class they could straight go into the activity. I would still want to do it as much as possible, and I have noticed too that you need to give the kids directions before going into the manipulatives. 
Gigi believed in being creative in teaching and discussed her plan for using other

resources in addition to the textbook,

I don't think I would turn into the teacher that will just use the book. I think because I like math so much I don't want it to be boring for kids. I don't want it to be boring. I don't want it to be irrelevant, so why are you going to go along with the math book if it is not a good material. Just find another way! The same concept the math book is teaching you can teach it a different way. It doesn't necessarily have to be that way. So I think teachers have lost that sometimes. You know they just use the book no matter what. And you know you are a teacher, be creative. You can do it. You are not straying from it you are still teaching the same concept.

Gigi believed she could use alternative representations to make mathematics interesting and relevant to students.

\section{Future with Mathematics and Teaching}

Gigi indicated that she did not encounter any real obstacles with the teaching of mathematics during her student teaching semester,

It's gone well. I haven't had a time that I was just totally lost and I didn't know the concept, or I was frustrated because I couldn't come up with something to do with them. I haven't really had any obstacle in math, in regards to math.

Gigi was looking forward to teaching mathematics in the future,

I am still looking forward to it. A little nervous to be on my own, but I think I would be fine. I think that once I have my classroom, I'll have more freedom to do more things with manipulative or with activities or anything like that. And maybe I'll have more time if I plan it ahead, but right now I came in before SCAT and we're trying to hurry up and get to it, so sometimes we don't have time to do all the activities that you want to do.

If given a choice of being in a self-contained classroom or teaching in a departmentalized situation, Gigi would prefer being in a self-contained classroom, she explained,

I like self-contained better. I have seen departmentalized, and yes you teach math twice and it is something easy for me and it could be the easiest thing, to teach math twice, but then I would miss reading. I don't know. At the same time I do like to read. I don't like the concepts sometimes, but I do like to read. I am pretty 
sure I would get kind of bored of teaching [mathematics] twice. I would be afraid of not being as enthusiastic in the afternoon as I was in the morning because I already taught. I don't want to bore the kids.

If she was in a departmentalized setting, Gigi would prefer to teach mathematics over reading,

If you are departmentalizing me, I want to be math. I would not want to be reading, I think I would be so bored and I would probably hate being a teacher. I definitely would do math and science. Or math alone, I don't care as long as it is math. I think I could interest myself more with math than with reading.

Gigi loved teaching mathematics, and she described the biggest lesson that she learned about mathematics during student teaching,

I think you have to keep it simple, you have to keep your wording simple, and you have to remember that you know, but they don't know this stuff. They don't know decimals, they don't know area; they don't know anything. You have to start from the beginning; you can't get too ahead of yourself and you have to make sure you notice the kids that aren't getting it. You can't just move on if you know, five of your kids don't get it - you need to stop, and you need to review it again and make sure that at least they get it enough to move on because they'll see it again. They need the basics, so I think it's important to know who's behind and who's not, who's getting it and who's not, and be able to sit with them, at least for a couple minutes, and go through what they don't understand.

Gigi went on to explain,

I've learned to be open; one of my students usually finds my errors (laughs). In the beginning, the first time a kid tells you that you have an error, it will bother you. It will always bother you, but then you have to know you're not perfect! Some of them know more than you know. You know something that they don't know, but they know something that you don't know. And it's going to be like that. So, I've learned to just say, 'Oh, thank you!' In the beginning, it did bother me a little bit, but I got over it.

Gigi believed that she would be a good mathematics teacher, and she showed evidence of having strong mathematical content and strong pedagogical content. 


\section{The Case of Yoli: Low Mathematics Anxiety-Strong Content-Weak Pedagogy}

Yoli is a Hispanic female from a southeastern state. She completed her student teaching experience as a senior at a large, southern, urban university. She described mathematics anxiety as follows, "When I think of anxiety it's when I think of reading, when you don't understand so you freak out and you're like 'ugh' so you get frustrated and you just don't concentrate anymore." Yoli's AMAS score revealed that she had low mathematics anxiety and she indicated that she was very comfortable with mathematics content, "I don't really struggle with it [mathematics]. Even when I don't understand something, I try and ask, and once I ask, it's clarified - I'm good." Yoli believed that she was very good at mathematics and was confident in her abilities to teach the subject. Based on classroom observations and interviews, Yoli showed strength in the content knowledge of mathematics, and she displayed some actions to demonstrate that she has pedagogical content knowledge in mathematics. Examples of these will be discussed throughout this case study.

Yoli's overall GPA was 3.42 prior to completing her student teaching. Her content GPA was 4.00, which is based on three mathematics courses. These courses included Intermediate Algebra, College Algebra, and Mathematics for Liberal Arts I. Yoli's pedagogical content knowledge GPA was 3.67, which is based on one mathematics course. This course was Teaching Elementary Mathematics Methods.

\section{Yoli's Personal Experiences with Mathematics}

Yoli has enjoyed mathematics and has become very good at it, "I like math, in general. I know that we need it to count money and all that, like your regular adding, subtracting, multiplying and dividing - that I know basics." Yoli's first memory of 
mathematics was in second grade where she described an impatient teacher, "In second grade, my math teacher used to tell me, 'You're a chicken without a head', because we wouldn't understand it [mathematics content]." Yoli described her experience with mathematics during this time as an unpleasant one,

With my second grade teacher I used to always hide under my desk during math. I would try and like untie my shoes on purpose and tie them, then untie and tie; because I just wouldn't get it. We would ask her questions and she would yell at us. I know I turned red all the time because she would yell, 'You're a chicken without a head!' I'll never forget that.

Yoli said that she didn't learn as much from her teacher as she did from her grandfather that year,

Honestly, it wasn't my teacher, it was my grandfather who taught me. I'm never going to forget 3-digit addition because I couldn't regroup; I didn't understand it and he taught it to me in Spanish. So after he taught it to me, I was able to do it because in class I wasn't getting it.

Yoli described her second grade teacher as her least favorite teacher, and described her teaching strategy,

It [mathematics content] was just on the board; if you get it, you get it - if you don't, you don't. Sink or swim in her class. It was never that extra help that we needed if we needed it or that we could go up to her and ask her for help. It was just, 'oh you didn't get it when I taught it then too bad'.

Yoli stated that she didn't provide manipulatives nor did she give extra examples if the students did not understand the content.

Yoli's experience with mathematics changed drastically in fifth grade when she began working with her teacher in the mornings,

Our 5th grade teacher pulled a small group of us for tutoring in the mornings and then we actually ended up getting ahead of the class, so we would actually be her helpers during math, and we would teach our small little group of 3. I guess falling a little behind but then once I got that extra one-on-one from her, I know that I got up to par with the rest of the class. 
Yoli's experience of helping others with mathematics gave her confidence,

Some of us were struggling; others weren't. So the ones that were and weren't, she put us together and we would work together. And then, we benefited; we got very ahead, so then she just told us that she was going to start using us more in the class while she was lecturing to help like peer tutoring and stuff like that.

Yoli enjoyed helping her classmates. She liked the teaching style of her fifth grade teacher, and she explained that the use of small groups and manipulatives were beneficial. Yoli explained, "She [fifth grade teacher] actually did a lot of small groups during math and we did get to use a lot of manipulates". Yoli even remembered an example of the manipulatives that were used, "I know it was when we were doing geometry with shapes, and she would have us create a different shape with the smaller shapes." Yoli remembered other mathematics teachers using lecture and note taking as strategies to help students learn mathematics, but her fifth grade teacher used more manipulatives, "It was mainly lecture and note taking from 2 nd to 5 th grade and in 5 th grade we used more manipulates." Yoli's fifth grade teacher was her favorite teacher for several reasons,

I would say my 5 th grade teacher [was my favorite] because she really did take the time, especially for the ones that were falling behind even the ones that were ahead, she would take the time with all of us in getting us that extra help that we needed, and she actually put the time and effort. She gave us manipulates, and whatever it took to get us to understand, she did it. She gave lots of examples. She would try and give an example, even of the ones she knew we would come across during homework that were a little more complicated, she'd give those examples in class as well, which helped us.

Yoli's experience with this fifth grade teacher helped shape her understanding of mathematics. 
Yoli became confident with mathematics and was able to do well in middle school, "I think it was just in elementary school I needed that little extra push, and once I got into middle school, I was able to do it on my own." She remembered learning more difficult concepts in middle school and thought that presently students are taught those difficult concepts earlier in elementary school,

There is a difference between elementary and middle school, you start getting to the harder concepts. I know that now I was teaching comparing fractions - I didn't learn that until 6th grade. So comparing to when I was a kid, they're doing it a lot earlier.

Yoli remembered teachers using lecture as the dominant strategy in middle school to teach mathematics, and she remembered solving many word problems.

Yoli described herself in high school as the student that others sought help from in mathematics. She even joked, "In high school I was the one that everyone copied off of." Yoli recalled working with many formulas, "In high school, there weren't a lot of word problems. It was more formulas and things like that." She also recalled taking tests that were mostly teacher-made, "In high school I remember they [tests] were always teacher made, or she wrote it on the board and you wrote it down. You did it and that was it." Yoli did well in high school and continued to help others with mathematics content.

Yoli did very well with mathematics in college except for a bad experience at her junior college when taking a mathematics course with an instructor who she had difficulty understanding,

Well, I passed all my math classes with an A, so those were all good. I think my worst experience now was probably at [junior college] where I got a professor who I couldn't understand a word that came out of his mouth, in math. It's kind of hard when you're taking math and you have to understand it, and someone's explaining and you don't understand what they're saying. He had an accent. 
Yoli shared that other classmates were just as confused as she was,

We all talked a lot, so everyone was on the same page, either they were lost during his lecture, or nobody understood, or it was just confusing because he would try and say something and we were like with those blank stares.

Yoli managed to be successful by teaching herself the content in the textbook and using other resources to help her understand the content,

I would go to the math lab at [junior college] when I wouldn't understand a concept at all, and they would help and that helped me. I'd also use the book, the explanation that was in the book. And if I could use the book then I was fine.

Yoli passed the class by being resourceful.

Yoli was positively influenced in mathematics by her family members. She recalled her mom helping her with mathematics and instilling in her the importance of the subject,

My mom always sat with me to do homework, and would tell me you need to know this; this is really important. She actually helped me with my timetables and stuff. She typed them up, she laminated them and we would go over them every day.

Yoli recalled her grandfather helping her understand mathematics by explaining it to her in Spanish, "He also helped me with timetables, he would just tell them to me in Spanish. That was the only difference." Yoli believed that having this translation of the content into her first language helped her learn the content more quickly, "Even though it was in a different language, I always did understand Spanish a lot quicker when I was younger so it was a lot easier." Yoli explained that her brother was not fond of mathematics, but he never asked her for help unlike her friends who would rely on her help, "Depending what it [mathematics content] was, if it was something simple they'd get it, but more 
complicated, they'd call me and I would explain it to them." Yoli took pride in helping others in mathematics.

\section{Context of the Student Teaching Placement}

Yoli's student teaching placement assignment was in a third grade, self-contained classroom of 15 students. The class had seven boys and eight girls. Yoli enjoyed teaching mathematics from the very beginning of the semester; and mathematics was the first subject that she took over fully from her cooperating teacher.

Although she enjoyed mathematics Yoli found it challenging in the beginning. Yoli believed that she began teaching with the most difficult concept in third grade, "I started off with one of the hardest chapters, Comparing Fractions." After completing that chapter, Yoli explained that teaching mathematics became more enjoyable and the students had an easier time understanding the content. Yoli experienced frustration during her student teaching experience when the students had difficulty understanding the content after attempting several different explanations to them,

It's frustrating when they don't understand and you taught it every way possible and you get frustrated as a teacher, and that's when you need to realize, 'I need to stop', because it's just everyone running against the same wall because we're not going anywhere. So tomorrow's another day, start off a different way, think of a different way.

Yoli believed that she was doing a good job as a student teacher and she showed genuine concern for helping her students, "So far I'm doing good. The kids are enjoying it, but I'm hoping I can get them all to that point that they need to be."

Yoli enjoyed teaching most of the content that she was required to cover in her third grade class, but her favorite content area was "Time" because the students enjoyed it and it was easy for them to understand. She explained, 
I think my favorite math lesson, or just overall the chapter was chapter 12, Time, because if there's anything that these kids got on the dime from the beginning, it was time. They were the ones that kept us on track the entire time. They would tell us when we had to go to Spanish, Art, Music, they were on top of time. And that wasn't something that we asked them to do, they did it on their own and that chapter was just-- it was really nice to be able to go through a chapter without having that constant struggle of them understanding. It was just very smooth across the board.

Yoli even enjoyed the lesson on Elapsed Time although that was somewhat challenging,

I liked going over the elapsed time with them because I saw that it is challenging for them, but they understand it even though there were times where we would have to go back and try it again so that they could understand it. Some problems from elapsed time they had to work their way backwards rather than starting from the beginning of the question to the end, but, overall, it was just a really nice chapter to teach.

Yoli described her experience with teaching Fractions completely opposite to that of teaching Time. Teaching fractions posed some difficulty for Yoli, and she described this as her least favorite content area. In particular Yoli disliked teaching Comparing Fractions,

It's fractions because the way that that lesson in the chapter is, you have to explain about four different strategies to them in order for them to know how to compare fractions. Now if you don't realize it and you don't stop at each one after you explain it and give it a name, it throws them off completely and they'll just tell you, 'Strategy one, strategy two, strategy four' and they don't know what the strategy is. But in teaching four different strategies all at once is too much. It was-- it just bombarded them with too much information all at once and when they had to do the work on their own it was like deer in headlights. They were like, 'I'm confused. I don't know what to do. I don't know how to do it.' So the part where it's on your own, we did it together. There was no on-your-own practice in that lesson.

Yoli explained that she had to take several notes, and she thought that the content was too overwhelming to be taught in one lesson,

If you see my pacing guide, there are sticky notes all across that lesson because of everything that I had to write to keep in mind when I was teaching that I had to 
say, that I had to point out. It was just so much for one lesson that one day is not enough.

Upon reflection Yoli decided that she would change the way Fractions are taught if she

had to teach this unit again,

If I had to do third grade again, I would teach it backwards. Rather than from one to seven I'd teach it from seven to one because it ends with the easier part of equivalent fractions and I do think that if you teach them what a fraction is at the beginning then you go to equivalent fractions they already know what fractions are equivalent to a half. So when you teach the benchmark of a half and a whole, they got it quicker and then you can move on from there teaching all the other strategies. The pacing guide goes from introducing fractions in chapter seven to just comparing them the first lesson in chapter eight and then it ends with equivalent fractions in chapter eight. So to me that caused more of a confusion to them rather than making it simple. I would like to try it another way, a completely different way.

Yoli would teach the content in the way that made more sense to her even if that meant reversing the order of the lessons.

During her student teaching experience Yoli described some frustration with the behaviors that her students displayed when they were called to the board and when they were put in groups to share manipulatives,

Overall they're quiet when you're teaching. They don't interrupt. They don't make a sound. The thing is when it's time for them to come up to the board and you start picking on different people they start bickering and fighting. 'But you've gone once!' 'No, but I've gone three times.' 'But you've gone more than me!' And it's like, 'You guys, really? You're worried about if you come up to the SMART Board? We use the SMART Board every day. You come up to the SMART Board every day!' It's nothing out of this world, but I'd say that the behavior in the lessons would get a little rowdy, and if they were sharing manipulatives that they didn't want to share because they don't believe that sharing is caring, and I do, but they didn't believe that. Overall their behavior's really good.

Yoli liked that her students communicated to her when they needed help and when they wanted to challenge themselves, 
They knew themselves when they were ready to do it on their own, they would ask, 'Can your ducklings swim on their own?' And when they'd start struggling, 'Your ducklings are sinking! We can't swim!' They gave me cues. When they knew that they could do it on their own, and sometimes I wouldn't want to let them go because I didn't feel that they were ready, but they were like, 'Let us do it! Let us do it! Let us.' So I'd say, 'Okay, fine, but when you start sinking you need to let me know.' They kind of cued me in and out of when they needed help, when they didn't need help, and it works with them. And it was to them a joke. 'Your ducklings are sinking!' It was okay for them.

Yoli relied on student cues to direct the flow of her lessons.

Yoli enjoyed her students communicating and participating with her. She observed that most of her students who were more active participants during mathematics were less active participants in reading, and this behavior reminded her of her own experience in elementary school,

I've noticed, especially in this class, that those that struggle with reading, their stronger area is math so they're more confident. They will participate, they will be calling out the answers, and all. And that's how I was too, I would always be participating during math, no problem, but then reading I was more quiet. No hand raising, no nothing. The ones that don't participate, don't understand, they're not really focused. I notice some of them, since they don't understand, they just kind of daze off in math class. Others just struggle with both math and reading.

She explained that she did try to get all her students to participate.

Yoli learned several lessons during her student teaching experience. She

described some of these lessons,

I've learned that for most kids, once is not enough. Sometimes you have to go back and teach it over and over and over and over. Sometimes they may not be ready to learn that kind of material at that time and you're going to have to revisit it again at some other point in the year and maybe they're ready for that kind of material then. I've learned that with math it's a lot of visuals, it's a lot of manipulatives. It's a lot of everything, especially teaching them to draw models, very important. Some don't like drawing models and they don't understand that because they're not drawing the models they're not getting the correct answer. And then the ones that do are understanding that they get the correct answer 
because they're drawing. That's one of the harder parts of getting them to try to draw models, because they're just lazy.

Yoli believed that constant review was important. She also learned patience,

Patience, patience, patience, lots of patience because you're going to have days where --- and I had those days --- where I felt I just wanted to cry because I felt that I wasn't doing my job because they weren't understanding it. I think that as a teacher if you know that they're not understanding it, you know that you can make it better and you know that you need to figure out how to make it better. As a teacher I've also learned that if once you and the students are at that frustration point, you just need to stop because there's no way that you're going to move forward anymore at that point because they know that you're frustrated, you know that they're frustrated and there's just a barrier of frustration and it's just not going to happen. You need to move on to something else or take a break or whatever it is, but I learned that you can't beat something with a bat too much because it's just going to cause more problems than getting to that solution that you need.

Yoli was aware that trying to teach something to the students over and over in the same

way did not work, and she constantly tried new ways to teach difficult content.

\section{Yoli’s Relationship with her Cooperating Teacher (CT)}

Yoli descried having a good relationship with her cooperating teacher. She

communicated well with her and even adopted her behavior modification to use with the

students. Yoli described that behavior modification plan,

I do time out, I'll say SALAME, which means 'stop and look at me', which is what I mainly use. I use the behavior mod that [her cooperating teacher] has which is their conduct grade. If I give you a silent warning that's one, verbal warning then the next one you are just moving your conduct grade. It's a daily thing so everyone tomorrow, will start at an A but as the day goes on if they start misbehaving and we keep calling on the same behavior it just gets to the point where we say go move your conduct grade, go move your conduct grade. And then that conduct grade is used at the end of the 9 weeks. It is all averaged up together to give them their conduct grade.

Yoli explained that her cooperating teacher was flexible and allowed her to plan mathematics lessons alone, but she was available for support, 
Math was the first subject I took over. Since I took over, she [Yoli's CT] said 'Do it the way you want. Just let me know if there is anything big going on, so I know, to give more time.

Yoli relied on her CT during lessons to help her and was comfortable to seek that

help when she needed it,

At first you come in with the idea, 'Okay, I know how to do this because this is how it works for me,' but no, it doesn't work for them how it worked for you. Sometimes it does, sometimes it doesn't. Sometimes I would even have to stop in the middle of a lesson and ask [my CT] for help even though I had reviewed it. I have grown because I know when I need to ask for help and what I need. I've been able to learn how my class reacts when they don't understand anything at all. So I know that I need to go back and teach it maybe in a different way or some other way but I've learned that as well.

Yoli's cooperating teacher gave her advice from her own experience with students in the

past as Yoli planned for her lessons, and she appreciated this,

If there was anything in specific that she already knew prior to me teaching, she would point it out to me and she would tell me, 'Pay attention in this part because this part always gets them and you have to explain it like this, this, this and this. You can also explain it like this' and I would take her advice.

Yoli was fortunate to observe her CT teaching mathematics in the mornings because her

CT decided to teach mathematics twice a day in order to finish the content of the

textbook before they began SCAT review. Yoli explained,

I didn't get to teach chapter 11 because what we did was we decided that since time was becoming an issue as we got closer to SCAT now we needed to have chapter 12 taught before we left to spring break. So what we did was while I was teaching chapter 10 in the afternoon she was teaching chapter 11 in the mornings, so I didn't get to teach chapter 11 , which was measurement. She did.

Yoli learned from several things about teaching measurement from observing her CT

which she discussed,

What I learned was one of the first things you need to do is introduce the students to a ruler if they've never used a ruler before and explain to them that it has two sides, inches and centimeters, and that's what we use. And show them that the 
difference between inches and centimeters, inches are further apart. Centimeters are closer together, and then just keep breaking it down from there so that when they do have to get to that point in the chapter of measuring they understand. I think something else that also I learned was that it's very hard for them to grasp the idea of a mile because they thought a mile was their driveway in front of their house. So we kind of had to explain to them and picture it. In that chapter there were certain words that threw them off, like driveway. A lot of them didn't know what a driveway was because they live in apartments, so they don't know what a driveway is due to that. So we had to go explain what a driveway was. We drew the picture on the board. We drew the driveway. We explained how fast you go on a driveway because someone did say you go 60 miles an hour on a driveway, very speedy driver there. But that's something I learned while observing her, and I also learned that the best rulers to use are if you are teaching third grade and you do get a chance to have a class that have the SCAT rulers, those are the best because it just gets them used to using those rulers before the test.

Yoli valued these lessons and said that being able to observe her CT would be valuable when she teaches measurement in the future.

Overall, Yoli described her CT as an open individual who encouraged her to try new strategies to teaching mathematics. She explained,

[My CT] was very open, and there were some times when I would ask her, 'Would you teach it this way?' and she was like, 'I've never tried it but let's give it a try and if it works it works, and if it doesn't we'll just try it the other way, and if it doesn't we'll figure out another way.' So the good thing is that she was very open to what I would try to do, and she wouldn't shut it down, which also helped me because if I saw that halfway through what I was trying to do didn't work I'd say, 'Okay, forget that. Scratch that. If you have that little delete button press it. Let's- let's try a different way.' So that helped out.

Yoli had a good experience working with her CT.

\section{Planning for Teaching Lessons}

On average, Yoli planned for thirty minutes to prepare for her mathematics

lessons. Some lessons took less time to plan for and some took a little more time with a range of twenty minutes to two hours. For some content areas Yoli took longer to plan 
because she explained that she actually worked out all the problems for the lesson

beforehand and she would also meticulously check other resources,

Sometimes is does take longer depending what the content is like previous chapters took me maybe an hour or more because I'd actually sit, work out each problem, go into it, look at the game. I'd actually sometimes I'd play the game myself to see if it's worthwhile doing it in the class or not, or finding something else to supplement.

Yoli described that she was able to use her cooperating teacher's lesson plans from previous years to plan for her lessons. Her cooperating teacher provided these lessons in an organized three-ring binder, and Yoli used those lesson plans and developed her own lessons by reviewing the county's pacing guide and she sometimes looked online for other resources,

She gives me her lessons, so what I choose to do is how I do. But normally what I do is I'll go into the pacing guide. I'll look over it, make sure that there's no problems that they are going to come across and struggle with and if there are, I need to see where it is. And I also go online to the go math in Think Central so I can display on the board. And if there is online games I'll do the online games.

Yoli used online resources to get her students involved at times.

For her first observed lesson, Yoli used the textbook, her teacher's plans, the pacing guide and Think Central which is the online component of the text book. She explained that Think Central displays the student edition of the textbook and it sometimes has games that are linked to the lesson. Yoli planned for her second observed lesson several days in advance; she described her planning process,

I actually knew what I was going to teach today from two days ago because I actually had to look ahead since we are doubling up on lessons because of SCAT crunch, so I had to double up today. I taught 10.9 and 10.10. 10.9 was the first getting them used to drawing the symmetrical shape and then 10.10 was the diagrams. So what I just did was I looked over the lesson. I tried to find a fun game, but it's a little more difficult on the smart board especially because they have to draw and it takes so much time and sometimes they don't reach so, I 
didn't do the game. There is one on Mega Math if I am not mistaken it has it, but it would just be very time consuming and it is just time that we don't have right now.

Yoli explained that she did not change her cooperating teacher's lesson plan for this lesson,

My lesson plans are already done for me, but whatever I choose to do with them is what I do. This one, all I really did was read over it. I didn't sit down and say ok this is how I am going to do this. And then I just always pick the problems when I assign it to them right there and then in the class. I don't do that ahead of time because for the most part since I have looked over it I know which ones are simple, which ones will challenge, so that is what I try to pick, the ones that will be simple and one challenging.

Yoli did not spent much time planning her second observed lesson. The only resource that she used to plan for this lesson was the lesson plan previously prepared by her cooperating teacher. She mentioned that using other resources might have helped the students, but she and her cooperating teacher were now using their planning time to tutor students to prepare them for the upcoming standardized test for third grade. During their planning time, Yoli and her cooperating teacher tutored students and drilled them on skills that they needed to pass the standardized test.

Yoli spent the most time planning for her third observed lesson. She spent a total of approximately two hours and she explained her process, and why she took more time to plan for this lesson,

I went over the section. I had sticky notes posted all over this section in the teacher's guide to remind me that whatever is on that sticky, I have to touch up on because, it is an important part for them to understand how to tell time, especially dealing with when it comes to like 11:30, that the hand is between the 11 and the 12 , and they need to know that it goes to 11 and not 12 . I went online to see if I could find any videos or songs that could, maybe, help them. Unfortunately, I didn't. I was also searching for the Salvador Dali painting of the melted clocks and that was about it. I checked destination math/mega math. They have but, I am just going to use it tomorrow as a little review of today's lesson. I was working 
on it yesterday and today so, last night when I got home from here and, today during our planning time that we have had so I think, maybe, like 2 hours between, looking up things and just making sure that I had everything done.

Yoli mentioned her plans to her cooperating teacher and her cooperating teacher suggested that she look for a video on a website that she was not familiar with, but when they looked on the website, they did not find a video that was relevant for the lesson.

Yoli reflected on ways to better plan for her lesson and she decided that she should have possibly looked up other online resources that are accessible by the school's network to help students remember the concept,

Maybe if I look up other resources for videos and songs, stuff like that, to help them remember more; had I looked in different places but, the other thing is, I was researching it here so, what I can access at home, I can't access here half the time because it is blocked by the county so, I would have to do more research here, than at home.

Yoli did not spend as much time planning for her fourth observed lesson,

This one didn't take a lot of time. It was just A.M. and P.M. so I just looked over the section, made sure there was no 'iffy' questions or anything like that and, I did go on Think Central which is how I always project the students' book on the smart board to find a game but, they didn't have a game.

The only resources that Yoli used to plan for this lesson were the Teacher's Edition of the textbook and the online resource associated with it.

Yoli did not take much time planning for her last observed lesson although her cooperating teacher warned her that the students had trouble with this lesson every year, "She told me that every year she runs into problem with this lesson and, it has been overall since she can remember." Yoli explained that she looked over the section of the textbook and used Think Central, the online resources associated with the textbook,

I looked over the chapter like I always do, every section, I used Think Central and I got them their little clocks again. I just looked over the chapter and made sure if 
there are any questions that would run into problems. It was just that and, I had looked it over, a few days before so, it didn't take long.

Yoli did not use additional resources to help her plan for this last observed lesson.

Overall Yoli mostly used the pacing guide and the teacher's edition of the textbook, and the online resource associated with the textbook to plan for her lessons.

She explained why she used Think Central so frequently,

I'd also go on Think Central, which is what I used the entire time, to project it on the board and also because it has Destination Math, Mega Math, I Tools and another one that I can't remember the name of and it was easy access throughout the entire time teaching to just click it on the board and the game would pop up and it was constant review and reinforcement for them throughout most of my lessons.

Yoli really enjoyed having Think Central as a resource during her student teaching experience.

Yoli planned most lessons on her own using the lesson plans formerly developed by her cooperating teacher, but she also accepted additional advice that her cooperating teacher gave her. Yoli also liked to plan for her lessons over multiple days because she liked to review the topics to ensure that she was comfortable with the content,

I like to go back on separate days just to make sure that I didn't miss anything in looking over, because sometimes you look over it quickly and you're like, "Oh, okay, I got it" but then you go and you teach it and you're kind of like, "Uh" and you stop. So since that happened to me once, lesson learned don't do that again, I would go back several times, make sure that I got it down pat and if I didn't I'd ask my cooperating teacher.

Yoli relied on her cooperating teacher's help when she was stuck on how to plan for lessons, "She helped out a lot because I when I would be completely stuck that I wouldn't know how to do something that was my go-to person." Yoli explained that in the beginning of the semester she used her planning period to prepare for her lessons, but as 
the standardized testing drew nearer, she and her cooperating teacher gave up their planning period to help tutor students who were falling behind. Yoli indicated that planning for lessons became challenging at the end of the semester and she would have to plan late at night or on Sundays because she tutored her own students during their planning period, and she worked afterschool to earn extra income.

\section{Yoli's Mathematics Anxiety throughout the Semester}

Yoli has always been comfortable with mathematics and never suffered mathematics anxiety, and she clearly stated that several times during her student teaching semester. At the beginning of the semester she stated, "Math has always been my strong subject, I've never experienced it [mathematics anxiety]." During another interview halfway through the semester Yoli again made it clear that she did not suffer mathematics anxiety, "Obviously, I have no anxiety to any of this, to me it's simple. I understand it and, as long as I know I understand it, and I know my content, I am confident with it."

On the pre-lesson surveys, before her lessons, Yoli indicated that she was very confident with the content of her lessons rating her comfort level at a $5 / 5$ on all lessons with a 5 indicating that she was very comfortable and a 1 indicating that she was not comfortable. She was also very comfortable before teaching the lessons she had planned indicating the same results of a rating of $5 / 5$ on all lessons. When asked about her feelings while getting ready to teach a lesson in the pre-lesson surveys, Yoli described confidence to teach all the lessons using phrases such as, "I am confident because it's easy content" and "Confident because all the previous lessons have been successful." Yoli also had confidence in the ability of the students to understand the content of the lesson that she had planned. 
During the semester Yoli never experienced mathematics anxiety, but she did have moments when she felt anxious during mathematics. For instance, after her second observed lesson, Yoli was anxious when the students seemed to not understand the content; she described,

When I saw that they were going up to the smart board to draw and they are not even drawing what's on the other side of the line...that gets me anxious, because it is right there, its projected for them. It's in their book and they are still doing it wrong.

Yoli made sure to reiterate that although she was anxious about that she had no mathematics anxiety, "I am obviously comfortable with math. I have no anxiety, no nothing." Yoli's anxiety appeared to stem more from the fact that she was not fully prepared for the mistakes that the students would make. She reported that she did not practice the problem and took only a few minutes to plan the lesson. If Yoli had prepared questions to ask students, and thought of hints to provide them, she many not have suffered anxiety.

Yoli also described being anxious when the students call out in class or make comments not pertinent to the lesson. She explained this after her third observed lesson,

What made me anxious is when they start saying silly comments. It's not an every once in a blue moon thing, it's everyday where sometimes, we have to stop the lesson, redirect them and tell them not to do that because it is distracting. Then, one says one thing, then another one, then it starts; the domino effect starts in the class. Today I didn't have to stop. Today I just went directly to their conduct grade and moved it down. They saw that. They that know once we go to their conduct grade, that's it. Some of them just stop, others don't; some of them just don't care about their conduct at this point.

This behavior was not limited to mathematics class, but at this instance it happened when she was teaching mathematics. This type of anxiety was not related to mathematics anxiety. Yoli was affected by a weakness in classroom management. 
By the end of the semester Yoli still felt her anxiety toward mathematics had not changed; she had no anxiety toward mathematics. Yoli described feeling nervous and fearful of her students not understanding the content, especially when she was teaching comparing fractions, but she didn't experience mathematics anxiety,

I've never been anxious. I think the most time that I've felt maybe nervous or at that point where I'm scared that they're not learning because I thought I wasn't doing what I was supposed to was when teaching fractions when they weren't understanding anything and I would ask [my cooperating teacher], 'You know, I think it's me.' She's like, 'It's the whole class it's the content. It's not you because you're trying and you also need to understand that as well that you're not a failure, you're just up against a hard challenge, a very big challenge.' All the other lessons and chapters and all that, totally fine. That was the one chapter that I know if I get third grade I know I can teach it now.

Although teaching fractions caused some nervousness with Yoli she came out of the experience feeling confident and ready to take on the challenge if it ever arises again.

Although she did not experience mathematics anxiety, Yoli did experience much

anxiety toward the teaching of reading. Yoli explained that she has struggled with reading and she can empathize with the students who struggle as well; she explained,

Reading has always been my weakest area, because of reading comprehension not because I can't read - I can. But it takes me an article I have to read it 3, 4 times before I finally like, 'Okay I get it.' I'm a little more hesitant because it was always my weakest subject. I know how the kids feel because when you don't understand what you're reading, you don't answer the questions and then when the teacher does call on you you're like you don't want to answer, so you do feel bad.

Yoli described struggling with the teaching of reading throughout the semester,

Reading isn't my strongest subject not even as a kid. And now, even as an adult, I need to use some of the strategies that we do teach them such as underlining or highlight or go back and number, maybe even write footnotes and stuff like that. It just gets me very, very anxious teaching them my weakest subject which is reading. I've been teaching it, it's not so bad but I still do get nervous, very nervous. And that's throughout the semester. 
Yoli described being very nervous about teaching the students the subject that she knew she struggled with. She explained that her fear and anxiety decreased somewhat, but by the end of the semester she was still not comfortable teaching reading,

Towards the end [of the semester] where I have taken [my cooperating teacher's] advice to try to incorporate more and try to get more out of one passage I feel a lot more comfortable than what I did when I first started. But I still do get nervous because I get that feeling like what if I'm not doing it right or what if I miss something and I don't go over it. So I try my best to not miss things.

It was clear that Yoli was more comfortable with teaching mathematics than reading, and it was clear that she had anxiety with reading and none toward mathematics.

\section{Yoli's Content Knowledge}

Yoli believed that mathematics is important and thought that basic mathematics skills were fundamental for success in life,

You're always going to need to know how to add and subtract, multiply and divide for the basic things in life, obviously. Others may want to venture off into something that does deal with math and they do need that good math foundation.

Overall, Yoli was comfortable with the mathematics content that she taught. Yoli never reported fearing the content and was very confident in her knowledge of the content at the third grade level.

During the teaching of her first observed lesson, Yoli conducted a review from of previous geometric topics using a worksheet from the textbook called "Show what you know". During this review, she had students work alone and went over the answers when they were finished by calling on students to say the correct answer. If the answers were correct she told the student "very good" and proceeded to the next question. Yoli did not review the topics, nor did she have students explain how they arrived at an answer. She then asked the students to complete a vocabulary exercise on their own. She walked 
around to check on their work and provided a hint to the whole class in order to elicit their previous knowledge, "We went over lines last week". Yoli then reviewed the vocabulary words by asking students to describe the different types of lines discussed in the previous week, (lines of symmetry, diagonal lines, intersecting lines, parallel lines, and perpendicular lines). She called on individual students to answer questions on the vocabulary words, and when a student was not able to answer correctly she briefly explained the meaning of the given line. She used drawings and visuals to aid in her explanations. For example when she wanted to explain the line of symmetry, she held up the workbook and asked the students if both sides of the workbook are the same when she closed it. The students chorally answered "yes" to her question and she moved on to the next one. Using the workbook was a good example; however, Yoli did not point out which part of the workbook illustrated the line of symmetry, and she did not check for understanding with all students. For the explanation of a diagonal line, Yoli simply drew the line on a 45 degree angle and told the students that diagonal lines are at an angle. This did not seem to illustrate the full meaning of a diagonal line. Although this was a review the information could have caused misconceptions for the students. In the next part of the lesson she reviewed more vocabulary words by having the students read the definitions provided. After a student read the meaning of a pattern unit, Yoli used the example from their homework to illustrate the definition. She told the students that the square, triangle, square, triangle was an example of the pattern unit. This was incorrect as the pattern unit should have only been one square, triangle combination.

Yoli continued onto the new part of the lesson by introducing the students to combining two geometric shapes to form a new shape. At first she told the students that 
she did not have pattern blocks so they would have to "think about it" to combine two triangle and visualize what new shape could be made. She continued having student visualize what new shapes could be made by drawing shapes on the board. Because the students were not actually manipulating the shapes it was difficult for them to visualize new shapes. She noted that they were not able to visualize so she decided to skip that part of the lesson, and asked the students to turn the page in the textbook. When she realized that she needed the pattern blocks for the next page as well she looked at her cooperating teacher who then told her that they did in fact have pattern blocks. Yoli passed out one set of pattern blocks to a pair of students and then had the students turn back their pages in order for them to investigate the use of two shapes to make a new shape. She worked out the problems with them step by step directing them for the remainder of the lesson except when she gave the students a few minutes to work on some problems on their own using the pattern blocks that they were given.

Yoli believed that she sufficiently explained the topic, which she thought was fairly easy, to her students. Yoli explained her thinking about the content of the first lesson,

It was combining shapes, so it was really simple. I thought it was simple. For the most part, most of them were able to understand the concept where you take the two [geometric shapes] and you put them together, what shape it gets, so it was a very simple lesson.

She felt confident in her explanation of the topic to her students because she saw that the students were engaged,

I felt good because they were interacting which helps out a lot when they interact. They are very eager and they were understanding so since they were doing that it was easy for them. You know it made me feel good and I was like oh ok...piece of mind. 
Yoli was comfortable with the content, and liked that the students were able to use the tangible shapes; she indicated that the lesson could not be done successfully using only her drawings on the smart board as a reference. She explained,

I feel comfortable with [the content]... especially with shapes because they get to have the tangible things that they get to work with, and it is easier for them to see rather than me trying to draw which is a disaster.

She reflected that she would have skipped the lesson if she did not have the shapes, "I probably would have either ended up drawing them [the shapes] or anything that dealt with having to do the actual shapes, we would have ended up skipping. So the lesson would have really been nothing." Overall, Yoli thought that content for this lesson was easier than previous lessons, "Overall, it was better than other chapters. It was easier, but it is the beginning of the chapter so we will see how the rest of it goes."

Yoli's second lesson dealt with drawing symmetrical shapes and diagrams. She considered the content for this lesson easy, "It was pretty simple, but as you saw it was still kind of hard for them to grasp the concept that they need to count each unit to get the exact way to draw their shape." The first part of the lesson focused on reviewing the homework from the previous lesson. The students were asked to draw the lines of symmetry in shapes. She reviewed that some shapes have multiple lines of symmetry and showed the students the lines of symmetry in the rectangle and the equilateral triangle. She noted that triangles have three lines of symmetry, but never explained that this only worked with equilateral triangles. During her lesson observation interview she made the same assumption about triangles and lines of symmetry, "I went over homework, I explained that a triangle doesn't have one line of symmetry it has 3." This 
displayed an error in content understanding. The next part of the lesson dealt with having students draw a shape over a line of symmetry. They were given half the shape on a grid and were asked to finish the drawing over the line of symmetry. The students were having trouble not with finishing the shape, but with drawing it exactly to scale so that it appeared exactly similar to the given shape on the other side of the line. Yoli was frustrated that the students took long to complete their drawings and believed that their carelessness was to blame for them not being able to be successful. She explained,

It was an easier lesson, and it took so long. I do wish that they would have all taken the time to just count each unit better, and taken the time to really observe how they were doing it. Not just, Oh! I am drawing the shape look here. I mean it [the lesson] was good. They got it [the concept], but not how I thought that they really would.

Yoli preferred for the students to use a counting strategy to finish the shapes and she did not focus on having students visualize the whole shape using the line of symmetry. She explained that all of them did not count even though that is what she stressed on,

Even though that was taught to them last week when we were talking about congruent shapes, to count each unit to make sure, I prefer for them to do it that way because it eliminates a lot more errors. But some don't and they just look at it and that's where the mistakes come in.

Yoli explained her understanding of symmetry which she believed to be a simple topic,

I understand symmetry, you know you fold something and if it's equal it has symmetry. Some of them still don't grasp that concept even though it is something so simple. We have tried folding, we even get their textbooks. Close it, is that symmetrical? When you open it and you fold it down the middle. Yes if I cut this in half. We even did the other day with their desks, if you cut your desks from here is it symmetrical? Yes or no? No, if I cut it right down the middle is it symmetrical? Yes.

In this description of her understanding, Yoli described using only rectangular objects to show symmetry, yet she was asking the students to visualize symmetry for objects that 
were not rectangular. When asked if she used a mirror or any other method to help students visualize symmetry she answered "no". Although the drawing gave students trouble, she still believed that the students understood the content of the lesson,

For the most part, I do feel that they know what symmetry is. After this lesson a lot of them have it down pact. The diagram part is a little more complicated because they still need to understand that they do need to count units and it needs to be precise how it is. That part is where I think I would have to go back and redo again.

During the third observed lesson, Yoli taught her third grade class time with an introduction to elapsed time. She was very comfortable with the lesson content because the students were familiar with the topic and were confident. Yoli explained why she felt confident and gave an example of how her students used time daily,

They were using the clock to tell time before, so they were the ones that were keeping us on track of time. Let's say in the morning we get in at 8:30. We do our morning routine. We start getting into whatever our lesson is, whether it be science or now for SCAT review, and some look up at the time; it's 9:05, 9:07 and they are like raising their hands, telling us "it's time for art or it's time for Spanish", so they already had the concept of time from before.

Yoli explained that they did this each day. She continued to explain why she was most comfortable with the content of her third observed lesson,

I was comfortable about teaching it [the topic] because I already knew going into it that the kids already knew the concept of time, and they understood the hour and the minute. Maybe they did not understand the hour hand and the minute hand to a ' $T$ ' but, they already had the concept of it. So I felt a lot more comfortable about this than I have about any other lesson.

Yoli's confidence was observed as she was teaching the lesson. She made connections with the content and the real world, and she engaged the students in justifying their answers to problems. Yoli had her students complete problems in from their textbook to practice, and as she was reviewing the correct answers, some students were unclear why 
the time is 2:30 when the hour hand falls between two numbers. Yoli could have explained why this occurs in more detail during her discussion, but instead she only reminded them what the correct answer should be.

Yoli's confidence in content knowledge continued into her fourth observed lesson. During the interview after this observed lesson, Yoli explained the content of her lesson in the following way,

We are teaching the kids the difference between a.m. and p.m. so that they can know to tell time. Some get it, some, at the end, kind of, oh that little light bulb went off. I am comfortable with the content; it's time, it's simple, it's not a lot of elaboration, especially with this group that they actually understand it and, I know that, so, it didn't take a lot from me either.

Yoli believed that the lesson went well,

I thought it was good. I mean, they can tell time. They're good with it. Their thing is now more being able to say morning is a.m. afternoon is p.m. and specific things and differentiate those activities that go with the time.

Yoli believed that the content of this lesson was extremely easy and she felt confident with the content, "I felt good. I mean, the ones that were pretty easy that said morning or afternoon or something like soccer that they can relate to, were easier for them to get. Oh, this is a.m., this is p.m." Yoli believed that some problems challenged the students only because they had never been exposed to the activity that the text posed as a scenario,

The ones that they had never done, like there was one, the morning flight, they kind of, even though it said morning, they were kind of stuck there on that one. Maybe they haven't done a morning flight they've never been on a plane before so they [cannot relate].

Yoli believe that her lesson went well except for the challenge of distinguishing between 12 a.m. and 12 p.m. She described why she was frustrated with this section of the content, 
What I liked least about my lesson today was probably when we got to the end. The test part question threw them off completely because they got confused with the whole 12 a.m. being there and the 12 p.m. and, they couldn't ration with the fact that, ok, at $9 \mathrm{I}$ know I am at school, at 12, I know I am at this so, that kind of, I thought they would honestly get that one. I explained that from 12 a.m., which is 12 o'clock at night, it's dark outside, to 11:59 in the morning it's a.m. and, when it's 12 p.m., which is midday when the sun is the highest in the sky till after the sun goes down, that the moon comes out at 11:59, it's p.m. and then it just keeps going.

Yoli's explanation of the concept of 12:00 p.m. and 12:00 a.m. did not clarify the ideas of the students who were confused when answering the question, 'What time are most $3^{\text {rd }}$ graders asleep?' The available answers to the questions were 7:00 p.m., 12:00 p.m., and 12:00 a.m. Many students were confused between the 12:00 a.m. and 12:00 p.m. answers. Yoli never used the terms noon, nor midnight. She did explain that a.m. times run from 12:01 a.m. to 11:59 a.m. either.

During her last observed lesson, Yoli focused more on elapsed time, which she described as "the time from when an activity starts to the time the same activity ends." Yoli faced some challenges with explaining the content during this lesson. Yoli used the elapsed time for the lunch hour as her first example. She asked the students to figure out the time between 11:35 and 12:05. When one student answered that the elapsed time was 30 minutes she told him on three occasions that he was incorrect, and only when she did it together with the class to try to prove that her answer of 35 minutes was correct, did she realize the error. Yoli did try to show elapsed time of hours and minutes to students by counting up and keeping track of the time during the counting. For example, she helped them to figure out the elapsed time between 10:05 and 12:18 by having them move their clocks by the hour first and then by five minute followed by one minute increments. However, she did this strategy orally and the students could not keep track 
of the hours and minutes they had counted. Writing it down could have possibly helped the students understand more clearly. Next she introduced skip counting on a number line to help students figure out elapsed time. Many students seemed to enjoy this strategy, and a student even exclaimed, "Oh, now we get it!" Figuring out the elapsed time between 11:50 to 2:30 gave Yoli some difficulty and she made a few mistakes. She acknowledged the mistakes and told the students that this was a tricky one since the minutes were different. She was not able to simply subtract minutes or hours. She finally explained the problem correctly. For the next problem she introduced a drawing of the clock and showed a new strategy where she skip counted on the side of the clock, and kept track of the jumps between the minutes. Finally, for another problem, Yoli explained that the students could use 'Think Addition' as another strategy. Yoli introduced several strategies in one lesson, being inconsistent with how she used them, and she only allowed students to work with one clock. Her lesson might have gone more smoothly if she allowed students to use two clocks to see the difference and allowed students more time to work on the strategies in order for them to decide which one was the easiest. It was obvious that Yoli knew the content, but her presentation of the content was scattered.

During her final interview Yoli described her experience with the content throughout the semester. She explained that 'Comparing Fractions' posed the biggest challenge for her, and unfortunately that was the first topic that she had to teach during her student teaching,

The comparing fractions in 3rd grade is just a difficult concept for them to understand. In the sense that they still don't understand what a whole means and they still don't understand what pieces to that whole are no matter how many 
times you repeat it and say it, it won't sink in to all of them. It may sink in to 1 of the 16 but the rest are kind of lost.

Yoli's used the strategy of repetition to help her explain this content, and the students might have been more receptive to the content if she had used more visuals to help explain comparing fractions. Yoli explained that her students did not understand the concept of fractions, she explained,

There are challenges of fractions in third grade. They don't understand fractions. I wish they really did. And even at this point we're almost at the SCAT, I'm grading the posttests some still don't get fractions. But at this point, we've gone over it. I think we've beat it with a stick more than we could and they just don't get it. And it's been one of the challenges this semester teaching fractions.

She reiterated that she disliked this content the most over the semester,

I really didn't enjoy teaching fractions. Those were two very long weeks of headaches and just going over and over and over and there comes a point of repeating the same thing where you end up tuning yourself out so you don't realize that you're repeating it and the kids, to them it's like you're saying something new again even though you've said it 10 times. And then my cooperating teacher is covering her ears because she's tired of hearing it too. So it's just fractions!

When she was asked if she thought her understanding of the topic of fractions improved after teaching it she thought she did and said, "I, myself, had a better grip on fractions after teaching it." Yoli eloquently explained what she learned about explaining a difficult topic to students,

Obviously as adults we know what we have to do. We know how to explain it to another adult. But, when you have to explain it to third graders you can't use the same terminology you would with an adult. You can't talk about it in such an abstract way because it is such an abstract concept to them. You need more concrete things and that's something I learned. I didn't think I would need to but it is because it's very abstract for them. For us it may not be because we understand what fractions are. We know how to use them-- we deal with them, but they don't. And since it's being introduced to them at such a young age, some are ready to understand it. Others are just like, 'What are you talking about?' And they look at you with this face and you're like, 'What do I do now? How do I 
explain' and that's kind of how I feel now. I know that it's so abstract. As a teacher I know that. When I go to teach third grade if I ever do third grade again, I need to bring it into more concrete concepts for them to understand, and the way that you explain it has to be completely different and in terminology that they are going to understand.

Yoli explained that she displayed drawings of fractions on the Smart Board to help her students compare fractions. She used an online resource called I Tools, and she allowed students to draw the fractions on their papers, but when asked about how she explained the drawings, she did not emphasize the whole numbers being compared had to be the same size in order to see the difference in the fractions. Overall, Yoli had a good knowledge of the content that she taught, but she had some difficulty breaking that content down to a level that the students would understand.

\section{Yoli’s Pedagogical Content Knowledge}

This section will outline examples describing Yoli's actions and ideas pertaining to Graeber's (1999) five big ideas on pedagogical content knowledge that preservice teachers should possess. With respect to Graeber's big ideas, Yoli demonstrated the ability to assess students' understanding some of the time. She implemented lessons that used traditional methods of teaching which at times made it difficult to promote retention of ideas. She provided some alternative representations of concepts. Yoli rarely demonstrated the ability to implement lessons that provided opportunities for students to demonstrate both conceptual and procedural knowledge, and she seldom created opportunities in lessons that considered students' intuitive understanding of concepts. Overall, Yoli showed limited evidence of pedagogical content knowledge during the observed lessons. 
Understanding Students’ Understanding is Important. Student understanding was important to Yoli, and she referenced this idea throughout the interviews conducted during her student teaching semester. When asked about student understanding after her first observed lesson, Yoli answered that she believed her students understood the lesson, It [lesson] was good. They understood it [content]. I walked around I saw them; they were doing the work and the ones that were finished quickly were playing around with them [manipulatives] and actually made other shapes.

Yoli did not ask students to justify their answers or to explain their work, she simply checked for correct answers to the problems. Yoli seemed confident in the students understanding. Unlike the first observation, Yoli was disappointed in her students' understanding of the second lesson. She blamed the students for not being focused, "I guess I would say kind of disappointed that they are not paying attention and really focusing on what they need to be doing." She reiterated her disappointment when she checked for student understanding by having students work examples on the Smart Board,

While I was teaching the lesson, I felt kind of, not uncomfortable because I know the material, but I felt kind of disappointed in a way that some of them, they would go up to the board and they weren't paying attention to how they really needed to draw their diagram or their shape, and they were just doing it however they thought it was going to be.

When one student made an error in drawing her geometric shape, Yoli encouraged her to step back and look at her work and see if it made sense,

That's why I told them [class], let her figure it out when she steps back, how she is really doing it, and then when she finally stepped back, she was like oh ok. That's not the shape at all.

Yoli encouraged students to figure things out on their own at times, and she stated that was her favorite part of the lesson, when students discover their understanding, 
What I like is when they get super engaged because they start realizing where they made their mistakes and they are like oh ok I get it I get it. That's my favorite part when that light bulb goes off.

Yoli genuinely enjoyed when students appeared to be understanding.

During the third observed lesson, Yoli felt encouraged that the students understood the content because they participated in answering questions, "I felt really good. They were all participating, super excited, and eager to answer the questions so, I just felt good." Yoli described what she perceived was student understanding in this lesson,

They understood the minutes; they understood the hours and the elapsed time, they were understanding it. They were able to do it, but elapsed time, I didn't go very in depth in this section so, I will be able to answer that even better next time.

Yoli was using traditional methods of instruction to check for understanding by having students raise their hands to answer questions posed by the textbook. However, during the interview after the third observed lesson, Yoli thought of another way that she could have used to assess student understanding,

Maybe them telling me how to write it verbally on the board, rather than having them come up, then draw the minute hand and the hour hand on the clocks. I probably would have had them tell me, so that, I can also check for understanding that way, cause they can explain it.

When assessing student understanding Yoli also commented that she chose some of the same students multiple times to share their knowledge,

I know that, for the most part, I do call a lot on Canny, Ashley, Daniela and Carolina because they are the ones who catch on to things a little bit faster, as well as Jose. The rest I call on them but, they are not as enthused to answer questions like the others are.

Yoli's assessment of general student understanding might be skewed or biased based on the students that she called upon. 
Yoli indicated several times during her interviews that her favorite part of the lesson occurred when students showed their enthusiasm for understanding the lesson. A specific example of this occurred after the fourth lesson observation,

I like when the kids get very enthusiastic about answering the questions because they know the answer and, they know how to explain it to you, especially for the ones that don't understand. That's my favorite part of the lesson.

In the same lesson, Yoli also discovered an area of weakness in her students'

understanding. She noticed during the end of the lesson that students were having difficulty understanding the difference between 12:00 a.m. and 12:00 p.m. She explained, "They got confused with the whole 12 a.m. and the 12 p.m." Yoli did not provide extra examples for the students, she just emphasized the examples in the textbook. She indicated that she was not successful in explaining the concept and knows that she will have to reteach the concept at another time,

They were successful in differentiating things that can be done in the morning and things that can be done in the afternoon. The whole 12 o'clock, that was, not successful. It was with some; some understood but the ones that didn't, I know I need to go back to those and explain it to them again.

Yoli also used the students' homework to assess student understanding. To check the homework for the day, Yoli called out the answers to the problems, and students were responsible for grading their own homework. She was confident that those who had trouble would ask for help,

I let them check their homework. All I do is come around to check that it is completed but, they have to take out their red pens and they check it and, if they have a question, they can ask at that time. Most of them do [ask for help], most of them would say, 'I didn't understand, number this. Can you explain it?' For the most part, they're really good with it. They are not that class that just sits there and says 'ok, I got them all right'. 
Although Yoli believed that students are trustworthy to check their answers, and believed that they would ask for help, this is not always a reliable way to ensure student understanding.

After the last observed lesson on elapsed time, Yoli knew that the students struggled with understanding the content of elapsed time dealing with both hours and minutes. Overall she felt good with the progress of the students, but she knew that it was necessary to revisit the topic during another lesson. Yoli explained,

I feel very good with the outcome because it was a pretty difficult lesson for them. Most of them understood the elapsed time of the exact hour but, when it got to the minutes, that is where I noticed that it started getting a little more fuzzy for them where they couldn't be able to go from let's say, 12:25 to 1:15. That part kind of threw them off. I am going to have to go back to this topic definitely again, especially with elapsed time when it is doing both hours and minutes.

Overall, Yoli believed in immediate feedback for her students. She tried to grade classwork and tests immediately in order to provide timely feedback for the students.

She believed this strategy further promoted student understanding over the semester,

I think three times I've taken home papers to grade that's been too much, but for the most part we try to get it graded here and [give] immediate feedback so that they know how they're doing. And they constantly know how they're doing.

Yoli believed it was important for students to be continuously assessed on their understanding.

\section{Students Knowing in One Way Do Not Necessarily Know in the Other(s).}

Both procedural and conceptual understanding is important to understand mathematics concpets. Yoli demonstrated procedural knowledge throughout all her observed lessons. However, Yoli was not observed providing conceptual understanding; she followed procedures in the textbook closely, and although she used manipulatives, during times of 
reflection she stated that she needed to provide more concrete opportunities to understand the mathematics. Yoli reflected on this idea after both the first and second lesson observations and she concluded that using tangible ideas would help students understand more clearly.

During her final interview Yoli alluded to the use of real-world experiences to helps students understand the topic of measurement, but she didn't provide tangible experiences for helping them visualize the distance. Yoli discussed examples and drew them on the board instead of helping students create their own understanding with real life experiences. Yoli explained,

When it came to picking what you would use for measurement like kilometer, mile or yard most of them couldn't relate to anything here because either they hadn't been exposed to it or they weren't thinking as life experience-wise, either. So we kind of had to explain to them yards think of a football field. How many of you watch football? How many of you have seen the yard? So I drew a football field on the board. I drew the yards and I explained to them how between each there's this much, and we talked about that. We explained to them a driveway, how it would be in kilometers, how miles would be from here to Orlando, that they've gone to Disney on road trips. So we had to break it down sort of like that so they could start building more of that concept.

In this explanation, Yoli was not clear on the content, but she had an idea that she needed to incorporate real world experiences to help promote student understanding of this concept.

Intuitive Understanding is Both an Asset and a Liability. Realizing students' preconceptions and misconceptions is important to promote mathematics knowledge, but Yoli showed very little evidence of assessing students' preconceptions and misconceptions during her student teaching experience. Yoli did acknowledge a misconception that the students were having during the first observed lesson. The 
students were supposed to combine polygons to create new polygons. Yoli realized that her students were having some difficulty creating a heptagon from a rhombus, a triangle and a square because they assumed that a heptagon has to look like the one pictured as an example in their textbook and on the poster on the classroom wall. The students did not understand that a heptagon could be any seven-sided figure. Yoli explained her observation,

They [the students in the class] did have trouble with combining the rhombus, the triangle and the square to make a seven sided figure because they thought that they had to make a heptagon. The way that they show in the poster in the class, but I explained to them that they didn't.

Yoli tried to clarify this misconception for the students during the lesson.

During the fourth observed lesson, the students were having difficulty distinguishing between 12:00 a.m. and 12:00 p.m. Yoli commented to the students several times during that lesson that this concept is tricky. She even explained it during the interview after this observed lesson, "When it comes to 12. That 12:00 mark is where it throws them off because they think it's always a.m. or they think it's always p.m. but, they need to know that one is tricky". During the lesson, Yoli was having some difficulty trying to clarify this concept as well. During the lesson she explained that a.m. is counted from 12:00 a.m. to 11:59 a.m. However, during one of the examples listed she reexplained and changed it saying a.m. lasts from 12 to 12 . Some students were confused and asked about this. Yoli indicated that she may have confused them and reverted her explanation to the previous explanation. When asked about what happened, Yoli explained this scenario in the following way,

Since I had already told them from 12 to $11: 59$, she already stuck with it, so when I changed it to 12 she was like, wait a minute but, you said 59 and, so I said, let's 
leave it at 59 and when, you know, it changes to 12 , you know, change it to p.m. or a.m.

Fortunately, Yoli clarified this for the students, because giving multiple explanations of a concept may confuse students and could lead to misconceptions. On another occasion in the same lesson, Yoli did use the example of sunrise and sunset to explain the concept of 6:00 a.m. and 6:00 p.m. While this example worked for the 6 o'clock hour, it further confused them with 12:00 a.m. and 12:00 p.m. concept. Yoli explained,

One of the problems was listed four different times and they had 12 a.m., 12:00 p.m., 9:30 a.m. and another time in the afternoon and I explained the sun rises in the morning at 6:00 a.m. so we know, a.m. is when the sun is rising and p.m. is when the sun is setting but that led into the discussion of $12 \mathrm{a} . \mathrm{m}$. and $12 \mathrm{p} . \mathrm{m}$. that 12:00 a.m. is dark out but, it's still a.m. and 12:00 p.m. is light out.

Yoli's example of sunrise and sunset further confused students. This lesson concluded with students still not understanding how to clearly distinguish between a.m. and p.m.

During the last observed lesson, Yoli also made a mistake that could have led to a misunderstanding or a possible misconception about time. When they discussed elapsed time, Yoli wrote " $5: 15$ " on the Smart Board to mean 5 hours and 15 minutes have passed when discussing a problem on elapsed time. The symbol ' $5: 15$ ' does not mean a total of 5 hours and 15 minutes. Yoli did not clarify this during her lesson, and some students may carry this error into future lessons on time. Overall, Yoli did not allow students to discuss possible misconceptions and she did not give them the opportunity to struggle with topics in order to clarify any misconceptions that they may have encountered.

\section{Certain Characteristics of Instruction Appear to Promote Retention. Yoli}

demonstrated some characteristics that appeared to promote retention during her student teaching experience. Yoli used the online textbook as her primary resource for 
instruction during all the lessons observed. During every lesson she projected the textbook on the Smart Board and worked through the pages with the students. Yoli had a pattern in the observed lessons of first reviewing homework with students and then introduced new vocabulary before proceeding with the mathematics content of the lesson. Yoli used a few strategies to help promote retention such as allowing students to display their work on the board, using group work and introducing real life examples in lessons; however, these strategies were not observed in every lesson. These strategies will be discussed.

In the first observed lesson, Yoli allowed students to work together in pairs with the geometric shapes that she provided for them as they worked on creating new shapes by combining more than one shape. Yoli explained that she did not usually have students work in pairs, but because there were not enough manipulatives for each student to work alone she had to allow them to work in pairs. Yoli explained,

We don't usually have them work in pairs it is normally always independent, but since we don't have enough of the manipulatives, they are seated in buddies for that reason, so that when they do use manipulatives, they are also working with someone else so they do get to have that conversation and talk and think out loud and it is not always independent seat work that they get bored.

Yoli knew that students needed to discuss ideas in mathematics, but she indicated that her class did not get the opportunity to do so on a daily basis. When asked if there was a reason she used independent work as a primary strategy in the class, Yoli explained that the students' behavior in terms of talking loudly prevented the use of too much group work. She explained, "As far as working independently it is mainly like that in the class, independently because they do get really rowdy even when they're working 
independently they start figuring things out or some finish ahead and they just start talking.”

In the second observed lesson on drawing shapes over lines of symmetry, Yoli allowed students to interact with the smart board and share their drawing with the class. Yoli did not allow students to explain their own work; instead, she explained it for them. If a student made a mistake she allowed them to redo it or she asked other students in the class to help the student. Yoli explained that she allowed students to work on the smart board to help all students visualize the work on a larger scale in addition to the work they do in the textbook. Yoli explained,

Having them [students] come up lets them interact with the smart board. It gets them accustomed to using the smart board and they know when they come up how to use it. But it also lets them see on a larger scale as well rather than just in their book.

Again during this lesson, Yoli had students working individually. No small group work was observed.

Yoli used traditional methods of teaching in her third observed lesson on telling time. Upon reflecting on the lesson she reported that she would have liked to use a game or something interactive for the students, but she did not. She explained,

I would've liked something to have been more interactive, to have more hands on. I would have done something more with that and maybe ended it with a game but, since there is only one game on mega math for the section, I chose to use it for a review for the next section that we are going into of the chapter.

She allowed students to share their work on the board, which Yoli indicated was a normal occurrence, but the students did not explain their thinking in front of the class. Yoli explained all answers. In the interview after the third observed lesson, Yoli explained that she allowed students to come up to the board for the kinesthetic learners, "I like for 
them to come up to the board so that they can move around, for those that do need to move around."

Only traditional methods of teaching were used for Yoli's fourth observed lesson on distinguishing between AM and PM. She explained that the Smart Board was not working, so she decided to verbally explain the content from the textbook while having students simultaneously work individually at their seats. She used the strategy of calling on a particular student to answer because she says it increases the speed of the lesson, "It's easier when I have them, I say their name, answer and like that, and then, moves along faster." During this lesson, the students worked alone, did not explain their answers, and stayed in their seats for the duration of the lesson.

During the last observed lesson on elapsed time, Yoli allowed students to work individually with a clock that she provided for them, and toward the end of the lesson she worked individually with small groups of students. She allowed some students to explain to her the procedures that they used to work out the problems elapsed time, but she explained a strategy that she wanted them to use in the beginning of the lesson, so most of the students followed that specific procedure. She explained that the part of her lesson that she enjoyed the least was having to explain procedures over and over,

What I liked least, is sometimes, when we have to repeat the same things over and over and over again, you kind of feel that it's not getting through to them, but you end up tuning yourself out so you don't know how many times you've said it.

Yoli explained the same procedure several times in the lesson. After the lesson, she explained the same procedure in the post-interview,

I used the strategy of subtraction or addition where there was one problem in the book that the time started at, I believe it was, 11:02 and then it went to, I think it is $3: 16$, something like that, so I told them to do the hours and once they get to the 
hour, they already know that if it is up to how many do I need to get to 16 or the other way around. They can subtract; that was one and then, the other strategy that we used was the skip counting by $5 \mathrm{~s}$ or $10 \mathrm{~s}$ and then, one of the other strategies that I used was, I call it bubble counting because, to me they're like bubbles but it's called the hopping, like the skip count but using the lines from one to the other and I had them writing it down so they can visually see it, as well.

When Yoli realized that many students did not understand the strategy, she allowed a majority of the class to work on problems alone, and she then proceeded to explain the procedure with a small group of students to the side of the classroom. She explained that she reiterated the procedure to them several times until she felt confident that they could work on their own, "I'd take my small group of however many of them it is that don't and, explain it to them again until I know that they can go on and do it themselves." At the end of the lesson she indicated that many students still did not understand the concept and she knew that she would have to revisit this particular mathematical content. When asked if she could have used other strategies to promote retention of the content, Yoli explained the following,

Maybe [if I] found more problems with both the hour and the minutes of elapsed time because they really didn't give a lot of those this time and, maybe found more problems dealing with, when it gives the hour, the elapsed time, where they have to find the end time.

Yoli believed that with more practice the students would have understood the content, "I think had they practiced more, I think they would've gotten it pretty quickly."

Upon reflecting on her lessons at the end of the semester, Yoli commented that she could have used more strategies to promote retention. Although Yoli used whole group instruction with most mathematics content during the semester, she indicated that she could use group work with easier content, and she had to use small group instruction for more difficult content. She explained, 
Depending what the assignment is and depending what the chapter-- I know that, for example, with our class time was something simple so I know that they could do it on their own really quick and if I put them in groups they could do it as well working with a buddy or whatever so that was fine. I knew that the harder ones I would have to do small groups. So chapter eight I pulled more small groups than it was whole group instruction.

Yoli explained that the students sat in pairs based on their strength in content, so when she chose to use pair work, the students worked in the groups that they were seated at. However, she did not use group work in every lesson because she thought that the students misbehaved more when given the opportunity to work in pairs. She commented that even when she didn't specifically assign small group work, students helped each other out because of the nature of the seating arrangement in the class. Although the did not assign a lot of pair work, Yoli saw the value in having students discuss their ideas and said she would like use more group work in future classes even though she did not use it often during student teaching,

With the set of students that we have if it's more than two they get way too rowdy and then they just don't do their work. So that's why I kept it at pairs. But if it was another group I would probably do more group work because I personally do like groups. Small groups I do feel that the kids work better and, at times, they understand each other more than maybe the way that I would explain it. So one gets it, the other three don't, that one explains and they're like, 'Oh, okay. Now we get it'.

Yoli explained that both she and her cooperating teaching followed the pacing guide prescribed by the district very closely. For this reason she followed the problems and ideas in the textbook very closely. She explained that she had to complete the higher order thinking (HOT) word problems with the students, but she did not always allow them to work on the problems on their own. She sometimes most often times worked the 
problems out along with the whole class. Overall, Yoli prescribed to very traditional methods of teaching mathematics during her student teaching.

\section{Providing Alternative Representations and Recognizing and Analyzing}

Methods are Important. Yoli showed some evidence of providing alternative representations to students repeatedly during her student teaching experience. During her

first observed lesson, Yoli used geometric shapes only after her cooperating teaching told her that they were available. Initially, Yoli did not plan on using the shapes, but she indicated the need after working on several problems with the students. She decided to skip certain problems after she noticed that the problems could not be understood without the use of the shapes, and after her cooperating teacher noticed that she skipped the problems she offered her the use of the geometric shapes. When asked to reflect on her use of the shapes after the lesson, she explained that the aspect of her lesson that she enjoyed the most was having students work on together with the geometric shapes. Although she mentioned that some students fought over the use of the shapes, she thought it was an overall valuable experience for the students. She explained that she did not always use manipulatives because of the students' behavior when they were given the manipulatives. She did not enjoy that aspect of the lesson,

Sometimes they [her students] get out of hand because we don't always use manipulatives. We don't do it on a daily basis so for them it's something new so it's so it's so exciting that they get a little too out of hand.

Yoli explained that if she had to repeat the lesson, she would have located the geometric shapes during the planning phase of the lesson instead of during the lesson to ensure a smooth lesson with the use of the manipulatives. 
Yoli tried to use the Smart Board during all the lessons; however, the technology was giving her trouble during her second observed lesson. She began to use this technology, but was forced to stop because it was not working properly. The textbook was projected on the Smart Board, but the students were not able to write on it. Yoli indicated that she should have checked to see that that feature was working before she began the lesson. She did not know it was working because she did not allow the students to write on the Smart Board everyday so she was unaware that it was not working. Yoli did not use any tangible manipulatives during the second observed lesson, but upon reflection she did feel that something tangible may have helped students understand the mathematics content. She explained,

I think what I would do is maybe give them something tangible where they could actually cut it in half so they can see more of the concrete rather than so abstract. Maybe give some of them different shapes. I have done lessons where they all get different shapes and they get to discuss with their partner or you know whole class. I would do something where they get to work with their partner and discuss it and then explain it to the class.

Yoli understood that the use of manipulatives would be valuable for students, but she did not plan to use them for this lesson.

During the third observed lesson, Yoli allowed the students to use individual clocks in aiding them to understand the content of telling time. She explained that she was confident that the students knew how to use the clocks because they had used them previously. She liked that all of the students were able to use their own manipulative and there was not a need to share, because Yoli commented that her students misbehaved when they were asked to share manipulatives. Although the students were equipped with individual clocks, they did not use them to solve all problems. Yoli gave her students the 
option to use them because the clocks in the book are smaller in size, but she did not require the use of the clocks. Yoli explained,

We didn't use them for every problem. I told them that they could use it. Sometimes in the book, it's so small; that's why I told them use it if you want to, if you don't, you don't have to; some I did see using it because it was easier for them to visually see it bigger than in their book where it is super tiny.

Yoli did not discuss the strategies that the students used with the manipulatives, but she allowed them to use the manipulative to aid in completing problems.

During the fourth observed lesson, Yoli distributed individual clocks to her students, but they did not use them. She used a drawing of the clock to help illustrate to her students the meaning of the word quarter in telling time. She explained,

The clock is broken into quarters and that quarters are fourths, so you know that's fractions and, that each quarter is 15 minutes so, there was one where it asked a quarter after eight so I drew the clock on the board, I drew 12, 6, 3 and 9, because those are the quarters, I had one of the students tell me what I needed to do. He told me split the clocks into fourths and then we discussed how we get to a quarter.

Yoli referenced the use of fractions and tied it into the concept of time to help students develop a deeper understanding.

During the last observed lesson, each student again received an individual clock to work with. The students were working on elapsed time and were having a hard time grasping the concept. Yoli thought if students had two clocks to look at instead of only one clock they might understand the concept better. She reflected on this and thought she might try another strategy if she had to do it differently. She explained,

If I had to do it again, what I would do differently is, when it comes to telling the elapsed time, where they need to tell both hours and minutes, I would've probably, on the smart board, projected two clocks. The clock with the starting time; the clock with the ending time so they can better see the concept because, they do only have one clock, and I would tell them to work in buddies but I know 
that's going to end up in a lot of fights in this class. So that's what I would've done differently. I would have displayed it on the board and then, gone over it in more depth.

Yoli was hesitant to have students work in pairs to share clocks so she thought projecting two clocks on the board would be a better idea.

Overall, Yoli knew the value of using multiple representations to help students understand content, but she did not often use strategies to promote multiple representations. She understood that most of her students were visual learners and some were more tangible learners, so she tried to incorporate visuals to help her students. Yoli believed that projecting the textbook onto the board each day helped her visual learners. At the end of the semester Yoli was asked if she used other manipulatives than the ones observed in the observed lessons and she listed a few, "Some additional things I used, the manipulatives of the clocks, the manipulatives for fractions, the fraction strips and the games." Yoli used some online resources to aid in representing ideas in various ways, but the online textbook was the only consistent resource used.

\section{Future with Mathematics and Teaching}

Yoli enjoyed teaching mathematics more than reading during student teaching and she commented that she will always be more excited to teach mathematics, "I get more excited about math than reading." Yoli was confident that she will do a good job teaching mathematics in the future after her experience during student teaching. She explained,

I think internship [student teaching] can either make you or break you, and it only reassured it more for me. I love teaching no matter what, no matter how tough it gets, I love it. I love working with the kids, and you learn something new about them and about yourself every single day whether it be from a simple 'I need more patience' to really getting to know kids on a different level. 
Because of her love for teaching mathematics, Yoli would prefer the opportunity to teach in an elementary school that practices departmentalization. When asked about her views on departmentalization she explained,

I am in a self-contained classroom now, and it has its advantages and it has its disadvantages. The advantage of having a self-contained class is you teach everything so if you can't get to science during science you can always find something related to science for reading or social studies, and you can use that as a reading and a science grade or a reading and a social studies grade, whatever it is, and it's always going to benefit the kids no matter what. The disadvantage to departmentalizing is you may not have a team that wants to work that way where they want to use that to benefit their reading because as we know in third grade everything is reading and reading comprehension. What sucks about selfcontained is you're always on the go. You're nonstop. So you have to plan for science, social studies, reading, language arts and math. You don't really get to focus your attention and give one area your all because if you really tried doing that it just takes so much time. So I would like departmentalized. I'm in selfcontained now. I like self-contained. I'm always on the go nonstop either way, so for me it's not a problem. But if departmentalized is where I'd get placed then that's great because then I can focus more, if I get math, more in math, which is something that I really like, and science and social studies.

Yoli stated that she would not enjoy teaching reading and if she was in a

departmentalized setting, she would not want to teach reading.

Overall, Yoli thought her semester of student teaching was a positive experience

and she learned valuable lessons,

I think what I've learned this semester is going to affect how I teach. I'm very open-minded to trying different things no matter what with teaching. I know I'm not that person that's set in one way because it's not going to work for all groups. You're going to get one group where one thing works and you're going to try it again next year and it doesn't work. It's out the window. What I have learned is that being prepared is very important, and I'm always prepared no matter what for any mishaps. But the best thing that I have learned is it's better to be over prepared than underprepared, especially for teaching.

Yoli ended her semester of student teaching with positive feelings about her future teaching of mathematics. 


\section{Chapter Summary}

This chapter presented the three cases of Val, Gigi, and Yoli, the participants with low mathematics anxiety. The cases discussed the EPTs' student teaching placement, their experiences with mathematics in general and any experiences they may have encountered with mathematics anxiety during their student teaching semester. It also

presented aspects of participants' content knowledge and pedagogical content knowledge throughout the student teaching semester. 


\section{Chapter VI}

\section{DISCUSSIONS, RECOMMENDATIONS, AND CONCLUSIONS}

This chapter presents a summary of the study, a discussion of the findings, implications for practice, recommendations for future research, limitations of the study, and conclusions.

\section{Summary of the Study}

This study includes six detailed case studies highlighting the teaching of mathematics of six participants who volunteered for this study. The participants were classified into two groups, three elementary preservice teachers with high mathematics anxiety and three elementary preservice teachers with low mathematics anxiety. The researcher observed all elementary preservice teachers teaching five mathematics lessons over the course of their student teaching. In addition to these observations, the participants were interviewed in the beginning of their student teaching semester, after each observed lesson, and at the end of their student teaching semester for a total of seven interviews per participant to better understand their experience. A brief pre-lesson survey was also given before each observed lessons to gain an understanding of the participants' feelings before the lesson. The researcher also observed artifacts used during the observed lessons, and took pictures of those artifacts for later analysis. After analysis of data, rich cases were developed for each of the six participants in this multiple case study. The case studies were then analyzed and several important similarities and differences were found between those students with high mathematics anxiety and those students with low mathematics anxiety. These findings were categorized and they will be discussed in the following section. 


\section{Discussion of the Findings}

This section discusses the findings of the research based on the research questions. The findings are presented as a comparison of the cases studies. The comparison across the case studies are presented in the following sections: (a) planning and resources used, (b) the role of cooperating teachers, (c) mathematics anxiety during student teaching, (d) content knowledge, and (e) pedagogical content knowledge.

\section{Planning and Resources Used}

All EPTs in this study showed three similarities in their planning of lessons and in the resources used to plan those lessons. All the EPTs in this study reported using the teacher edition of their textbook as the primary resource used in planning mathematics lessons. EPTs' reliance on textbooks as a primary resources in teaching mathematics has been reported in the literature (Nicol \& Crespo, 2006) All of the EPTs also reported taking the advice of their CTs to aid in their lesson planning which may have also supported their use of textbooks. Additionally, all EPTs planned mostly teacher directed lessons. This differs from Bush's (1989) finding about in-service elementary school teachers, wherein those with high mathematics anxiety showed a slight tendency toward more traditional, teacher directed lessons than those with low mathematics anxiety. Thus, with experience, elementary teachers with low mathematics anxiety may expand their teaching repertoire to include more student-centered approaches than those teachers with high mathematics anxiety.

There were several differences with regards to planning and resources used across the EPTs with high and low levels of mathematics anxiety. Firstly, the EPTs with high mathematics anxiety took more time to plan lessons than the EPTs with low mathematics 
anxiety. The EPTs with high mathematics anxiety reported taking anywhere between 20240 minutes to plan their lessons while those with low mathematics anxiety reported taking anywhere between 10-45 minutes to plan their lessons. One high anxiety EPT, Belinda, who took the most time to plan her lessons, explained that she practiced the problems in her lessons because she was not comfortable with the content, and she strove to look for additional resources to be better prepared to teach her lessons. The EPTs, who took a shorter time to plan their lessons, reported that they felt comfortable with the content they were to teach and did not feel the need to review every problem before teaching the lesson.

Another difference was found in the EPTs' use of additional resources. The EPTs with low mathematics anxiety sought out more additional resources during the planning and enacting of their lessons. Moreover, when EPTs with high mathematics anxiety used additional resources to enhance their lessons such as the Smart Board with interactive lessons and student practice workbooks, these resources were not always used effectively. Ally, for example, used lessons from the Smart Board Exchange in their entirety and did not modify them to suit the needs of her students or what she was teaching. In contrast, Gigi, an EPT with low mathematics anxiety, used similar lessons from the Smart Board Exchange, but selectively used portions of those lessons to enhance her own lessons. Basically, the EPTs with low mathematics anxiety used the same additional resources as the EPTs with high mathematics anxiety as well as a few other internet resources such as educational game websites, and they used these additional resources more effectively than EPTs with high mathematics anxiety. However, none of the EPTs in this case study did extensive research to find new resources to teach any of 
the observed mathematics lessons. This is important for cooperating teachers to note, as well as those engaged in selecting and providing professional development and oversight for the cooperating teachers, since the EPTs rely on their CTs advice and expertise to help them plan lessons.

\section{The Role of Cooperating Teachers (CTs)}

There was one similarity about cooperating teachers across all cases; the CTs of all six participants greatly influenced them during student teaching. In the present education program, the university supervisors for student teachers are typically retired principals and elementary teachers who do not have a mathematics education background. Additionally, the university supervisors were only required to see one mathematics lesson of the four total lessons that they observe for the semester. Because of the limited observation of mathematics lessons by their university supervisor, EPTs during student teaching rely heavily on their CT for help in planning mathematics lessons and feedback on those lessons.

Overall, the CTs played a major role in influencing the decisions that the EPTs made. All EPTs reported relying heavily on the advice of their CT to plan their lessons. However, not all CTs had the same type of influence during the teaching experiences of the EPTs with both high and low mathematics anxiety. All the CTs influenced their EPT differently with regards to the type of support they provided, the influence on the EPTs' mathematics anxiety, and the influence on the EPTs' attitude.

Nancy’s CT helped her plan every lesson and Nancy reported taking many suggestions offered by her CT. Nancy relied so much on her CT that she did not feel the need to research other ways to plan lessons. She stuck to the advice offered by her CT 
and thought that it was good enough. Although, Nancy's CT tried to incorporate other subjects into the mathematics curriculum, Nancy may have benefitted more if she was allowed to take more leadership in planning the lessons and encouraged to research different ways of teaching mathematics topics. Nancy indicated that her CT maintained good communication with her. However, I am unaware if her CT offered Nancy any constructive criticism.

In the case of Ally, her CT had high mathematics anxiety as well. She finished the curriculum early in the year, and by the time Ally took over teaching mathematics (which was the first subject that she fully took over) the class only reviewed for standardized testing. Ally gained a false sense of confidence because she commented that she was more confident to teach mathematics than her CT. Unfortunately, because the CT finished the curriculum quickly, Ally only planned one lesson that introduced new content. Since she did not have to plan completely new content to teach students, it is unclear how well she would be able to plan mathematics lessons that deliver new content to students.

Belinda's CT assumed the role of a cheerleader and constantly praised Belinda. She was aware of Belinda's mathematics anxiety and she encouraged Belinda and told her that she was doing better than she gave herself credit for. I understand that she wanted Belinda to feel comfortable and gain confidence, but her constant praise did not provide much constructive criticism. Belinda's CT did provide her with ideas of how to introduce difficult topics, and Belinda did appreciate the role that her CT played.

Val relied on her CT to give her advice on planning mathematics lessons throughout the semester. Her CT encouraged her to look for new ideas when teaching 
mathematics and offered her suggestions on using manipulatives in her lessons. Val's CT allowed her to plan lessons on her own and then offered her constructive criticism on making the lessons successful. There was mutual respect evident in the relationship between Val and her CT.

Gigi's cooperating teacher greatly influenced her teaching as well. Gigi discussed that her $\mathrm{CT}$ allowed her to plan lessons and then offered constructive criticism. Gigi's CT encouraged her to create challenging lessons and constantly reminded her that the gifted students need to be challenged. Gigi's CT offered good feedback on her lessons and an evident mutual respect and understanding was evident between both Gigi and her CT.

Yoli's CT greatly influenced her behavior. It was observed that Yoli discussed the students' behavior in the same negative manner as her CT. They both blamed the students' behavior for much of the lack of success of lessons. Yoli maintained a close relationship with her $\mathrm{CT}$ and it was evident that this relationship impacted Yoli in her teaching of mathematics. Yoli's CT put a lot of pressure on herself, on Yoli, and on the students to do well on standardized testing. Yoli understood the impact that the students' grades play on teachers, and she felt the pressure of standardized testing. Yoli appeared at times to even take on the personality of her CT; she followed the CT's previous lesson plans exactly, and complained about the students in a similar fashion as her CT. Because Yoli relied so much on her CT's lesson, she did not have the need to plan her own lessons, and this lack of preparedness affected her teaching of mathematics. Given the findings from this investigation, there needs to be more collaboration and common messaging pertaining to teaching mathematics between the university supervisor 
and the CT as suggested by Fernandez and Erbilgin (2009). Also, professional development for mentoring student teachers with respect to teaching mathematics should be provided to CTs and university supervisors, as needed, in order to better guide EPTs to implement recent reforms and continue learning about teaching mathematics during student teaching (Fernandez \& Erbilgin, 2009),

\section{Mathematics Anxiety during Student Teaching}

There was only one similarity across the cases of EPTs with high mathematics anxiety in contrast to EPTs with low mathematics anxiety; they all felt very confident about the content of their lessons and about teaching those lessons before the actual enactment of the lesson. Although this confidence about the lesson was reported prior to the lesson, the EPTs with high mathematics anxiety showed signs of mathematics anxiety during the enactment of the lesson and confirmed this during post-observation interviews. The EPTs' self-reported data is in line with Unglaub's (1995) finding on self-reported data that determined that having mathematics anxiety was not a serious problem for EPTs during their teaching of mathematics. However, in the present study, the lesson observations and post-lesson interviews contradict Unglaub's (1995) finding.

Overall, those EPTs with high mathematics anxiety showed a higher level of anxiety during the teaching of mathematics lessons than those EPTs with low mathematics anxiety. Brady and Bowd (2005) noted that it is important to help EPTs overcome mathematics anxiety so that this type of anxiety is not passed on to their students. The EPTs who had high mathematics anxiety in this present study did not totally overcome their mathematics anxiety. There were variations to the extent of mathematics anxiety showed by Ally, Belinda and Nancy. 
Ally showed few signs of mathematics anxiety during her teaching of the subject over the semester. Ally's cooperating teacher indicated early in the semester that this was the first year she would be teaching mathematics in over a decade and commented that she had more mathematics anxiety than Ally. Mathematics was the first subject that Ally took over and she developed confidence in teaching the subject. Her confidence level was probably also affected because the students were reviewing content for most of the lesson. She did not worry about teaching content that the students were not familiar with. When asked about her confidence level, she compared it to her cooperating teacher's and decided that she would do well since she had less mathematics anxiety than her cooperating teacher. This is important for cooperating teachers to note; they should be aware that their attitudes affect the EPTs in their classroom.

Another EPT with the highest mathematics anxiety, Belinda, indicated having high levels of mathematics anxiety for most lessons and this was evident during the teaching of her observed lessons. There was only one lesson where she showed confidence during teaching and she also commented that both she and her students were confident with the content of the lesson.

Finally, Nancy, the last EPT with high mathematics anxiety showed signs of anxiety during the teaching of mathematics during every observed lesson. She used rapid speech, laughed nervously at times, and had a flushed face at times. Nancy taught kindergarten which provides the opportunity to teach content at the lowest grade level to students. Although she had the opportunity to teach content from the lowest grade level, she still made errors in the content for the students. Nancy understood the topics, but had a very challenging time explaining the content to her students. She did not challenge 
students' thinking; instead, she simply told the students what answers to put in their textbook. Overall, mathematics anxiety manifested itself in EPTs with high mathematics anxiety mostly when they or their students were not confident with the content of the lessons.

As expected, EPTs with low mathematics anxiety showed very few signs of mathematics anxiety. However, all of them indicated having some anxiety when they did not sufficiently plan for some aspect of a lesson. Also, some signs of anxiety were observed when these EPTs with low mathematics anxiety felt that their students struggled excessively with the content of the lessons. Anxiety only manifested itself during one of Val's observed lessons; she began to sweat intensely. Val became anxious when she realized there was a mistake on a test that she had created, and the students would not be able to get the problem correct because she had not taught them to answer the type of question that she put on the quiz. Val cared about student understanding and realized immediately that her error could cause much confusion. Yoli reported some anxiety when students made errors, or when students were having difficulty with content. Yoli's anxiety was not really math anxiety as it was more related to her performance; her anxiety manifested itself when she indicated a lack of preparedness. This anxiety could be explained by the deficit-model of test anxiety which discusses that poor performance occurs when someone is unprepared for a task (Tobias, 1985). Yoli was the participant who took the least time to prepare for lessons, and she indicated that she did not review all the problems before teaching them. Yoli was also given all her CT's previous lesson plans to use, so she did not have to create every mathematics lesson. I believe that Yoli's anxiety manifested itself because of her lack of preparedness and the fact that she did not 
create the lesson plans; instead she used those of her cooperating teacher. Yoli did not take ownership nor did she think about the lesson plan in detail. Gigi showed no outward signs of mathematics anxiety; she only indicated anxiety about students not understanding the content.

\section{Content Knowledge}

The content knowledge of the EPTs in this study was not measured using an instrument. The analysis of their content knowledge was based on what participants reported during interviews and what was observed by the researcher during the observed lessons throughout the semester. Table 2 displays a summary of content knowledge of both the EPTs with both high and low levels of mathematics anxiety.

Table 2

Summary of the Content Knowledge of All Participants.

\begin{tabular}{|c|c|c|}
\hline $\begin{array}{l}\text { Mathematics } \\
\text { Anxiety } \\
\text { Level }\end{array}$ & $\begin{array}{l}\text { Student } \\
\text { Teacher }\end{array}$ & Content Knowledge \\
\hline \multirow[t]{3}{*}{ High Anxiety } & Ally & $\begin{array}{l}\text { Overall moderate knowledge of the content } \\
\text { Some weakness in promoting conceptual understanding. }\end{array}$ \\
\hline & Belinda & $\begin{array}{l}\text { Had difficulty with some aspect of the content for each lesson. Had } \\
\text { difficulty with promoting conceptual understanding. }\end{array}$ \\
\hline & Nancy & $\begin{array}{l}\text { Overall moderate knowledge of elementary school content, and had } \\
\text { some weakness in conceptual understanding. Had difficulty } \\
\text { explaining content to students. Was not successful in promoting } \\
\text { conceptual understanding. }\end{array}$ \\
\hline \multirow[t]{3}{*}{ Low Anxiety } & Gigi & $\begin{array}{l}\text { Understood the content and clearly promoted conceptual } \\
\text { understanding in students. }\end{array}$ \\
\hline & Val & $\begin{array}{l}\text { Understood the content and clearly promoted conceptual } \\
\text { understanding in students. }\end{array}$ \\
\hline & Yoli & $\begin{array}{l}\text { Understood the content but had some challenges promoting conceptual } \\
\text { understanding. She was more successful at promoting procedural } \\
\text { understanding. }\end{array}$ \\
\hline
\end{tabular}

The case study findings revealed that there was a difference in the observed content knowledge of the participants with high and low mathematics anxiety in this 
study. The EPTs with low mathematics anxiety were more knowledgeable of their content than the EPTs with high mathematics anxiety. Based on lessons observed, the EPTs with high mathematics anxiety made more mistakes with content and struggled more with expressing conceptual explanations of the content in their observed lessons than the participants with low mathematics anxiety. These findings regarding content knowledge and mathematics anxiety are consistent with prior research as reported by Hembree (1990) revealing that mathematics anxiety has a significant inverse relationship with mathematics performance. The EPTs in this study were required by state policy to complete at least two undergraduate mathematics courses (not including developmental mathematics classes). None completed mathematics courses that would help them develop mathematics problem solving, representations, and conceptual knowledge that they could draw on in teaching elementary school mathematics. According to the Mathematical Education of Teachers II (Conference Board of the Mathematical Sciences, 2012) based on the work of mathematicians, mathematics educators, state education supervisors, and other important stakeholders, an elementary teacher's content knowledge is important, and all elementary teachers should be educated in the specific content needed to teach the elementary grades and make the connections of that content to the content in pre-kindergarten and in the middle grades.

It is also important to note that the EPTs with high mathematics anxiety avoided some of the mathematics content that they were either uncomfortable with, or that they did not know the answers to. Trice and Ogden (1987) found that elementary teachers with high mathematics anxiety often avoided the subject, or spent less time teaching mathematics. While the EPTs in this study could not avoid the subject, they did at times 
avoid mathematical content with which they were uncomfortable by skipping particular problems or sections during a lesson or suggesting that their cooperating teacher would explain certain content.

\section{Pedagogical Content Knowledge}

The pedagogical content knowledge of the participants in this study was analyzed using the five big ideas presented by Graeber (1999) as qualities that all mathematics teachers should possess. This section discusses how the participants of this study demonstrated PCK in each of these big ideas. Overall, the EPTs with low mathematics anxiety evidenced stronger and more extensive PCK than the EPTs who had high mathematics anxiety. A table summarizing the pedagogical content knowledge of all participants in this study can be found in Appendix L.

Interestingly, all EPTs in this study showed weakness with the fourth big idea, certain instructional characteristics appear to promote retention. The EPTs who had low levels of mathematics anxiety were better at all other aspects of PCK including planning and enacting lessons that checked for students' understanding throughout the lessons, noting that students learn in various ways, understanding that previous knowledge of students should be understood since some previous ideas could contribute to misconceptions, and using manipulatives somewhat effectively as an alternative representation to mathematics ideas. Nancy showed the most weakness in PCK of the three EPTs with high mathematics anxiety and Yoli showed the most weakness in PCK of the three EPTs with low mathematics anxiety. Yoli was the EPT who took the least time to prepare for her lessons and she was observed to be least prepared while enacting her lessons. She commented that she did not take much time to plan lessons and she 
rarely worked out problems prior to teaching the lesson. This lack of sufficient preparedness contributed to the fact that she showed the most weakness in PCK.

Graeber's (1999) first big idea is understanding students' current understanding is important. The EPTs with high mathematics anxiety knew the importance of knowing what their students understood, but used traditional methods to assess their students' understanding e.g., typical worksheets and exercises at the end of the textbook sections. They rarely assessed students' previous knowledge and rarely supported students' reasoning during the observed mathematics lessons. There was only one of the EPTs with high mathematics anxiety, Belinda, who made an effort to ask students to explain their thinking during the observed lessons; however, she used this information in limited ways to inform her teaching. The EPTs with low mathematics anxiety showed more evidence of the importance of understanding students' understanding. They all used traditional methods of assessment, but Gigi and Val used additional forms of questioning that probed students' reasoning during the lesson. Yoli, who did not take a lot of time to prepare for her lessons, was the only EPT with low mathematics anxiety who rarely probed her students' understanding. Additionally, Gigi stood out in her ability for challenging her students' thinking as well as encouraging students to question the content and one another.

Graber's (1999) second big idea highlights the importance of recognizing that students knowing in one way do not necessarily know in others. All of the EPTs with both high and low levels of mathematics anxiety were able to promote procedural knowledge among their students; however, only EPTs with low mathematics anxiety, were able to provide some conceptual understanding for their students. Val and Gigi 
were able to promote some conceptual understanding for their students; however, Yoli, who prepared very little for her lessons, did not promote much conceptual understanding for her students. The cases of Val and Gigi are in line with the work of Widmer and Chavez (2001) who found that EPTs who stressed understanding in mathematics showed less mathematics anxiety than those who stressed computation.

Overall, the EPTs with low mathematics anxiety showed more evidence of Graeber's (1999) third big idea than the EPTs with high mathematics anxiety. Graeber's (1999) third big idea focuses on intuitive knowledge as both an asset and a liability; it focuses on how well mathematics teachers recognize preconceptions and misconceptions in their students. The EPTs with high mathematics anxiety showed some awareness of possible misconceptions in their post-lesson interviews, but did not take measures to prepare for addressing these misconceptions during their lessons. In fact, the EPTs with high mathematics anxiety may have even contributed to possible misconceptions during their teaching of mathematics. For the most part, the EPTs with low mathematics anxiety demonstrated awareness of possible misconceptions, and addressed them at times during the lessons. Gigi and Val went a step further to immediately address misunderstandings in their lessons before these could lead to misconceptions. On the other hand, Yoli showed awareness of misconceptions in post lesson interviews; however, she did not typically prepare for or address misconceptions during her lesson.

All of the elementary preservice teachers in this study showed weakness in Graeber's (1999) fourth big idea which states that all mathematics teachers should use instructional characteristics that promote retention. Direct instruction was used in all of the observed lessons for all of the participants of this study. These EPTs were expected 
to write lesson plans in an "I do, We do, You do" format. In conversations that were not recorded, some of the EPTs in this study explained to the researcher that they interpreted that they had to use direct instruction to model this lesson format. They did not know how to use constructivist methods that were taught to them during their mathematics methods course in the format of the lesson plans that they had to create. Belinda and Nancy, both with high mathematics anxiety, used some instructional strategies in their lessons that may promote retention, but they tended not to use them effectively. Ally used only direct instruction in the observed lessons, and did not add varied instructional strategies. Gigi and Val who both have low mathematics anxiety did not use many strategies that would promote retention, however, during the post lessons interviews, they tended to reflect on improving their lessons by using various strategies that promote retention. Additionally, when they used varied instructional strategies during the lessons they used them more effectively than the EPTs with high mathematics anxiety. On the other hand, Yoli, an EPT with low mathematics anxiety focused on using only direct instruction without much thought to using varied instructional strategies to promote retention.

Graeber's (1999) last big idea discusses the importance of alternative representations and the recognition and analysis of alternative methods. Within this idea lies the use of manipulatives, accepting and discussing alternative solutions to problems, and examining different ideas to similar mathematics problems. Interestingly, all of the EPTs in this study except Yoli, an EPT with low mathematics anxiety, accepted alternative solutions to problems. Of all the EPTs in this study who accepted alternative solutions to problems all of them except for Nancy discussed these solutions with their 
students. All of the EPTs in this study used manipulatives in at least two of the five observed lessons as alternative representations for mathematical ideas. Belinda who had the highest level of mathematics anxiety made the most use of manipulatives to represent ideas and she tried to connect ideas to real life in every observed lesson; however, she did not always use them effectively. When she was asked about her use of manipulatives, she explained that she took into account the way she learned mathematics and wanted to provide experiences that would help her students learn in the most effective way.

As evidenced in the comparison of EPTs with high and low mathematics anxiety, the EPTs with low mathematics anxiety had stronger PCK than the others. This is important to note when considering student learning. As Hill et al. (2005) revealed, elementary school teacher's mathematical knowledge for teaching affects the mathematics achievement of their students. With respect to the present study, mathematical knowledge for teaching (MKT) is aligned with PCK in that MKT represents the mathematical knowledge used for effectively teaching including explaining concepts and terms to students and providing examples of concepts, algorithms and proofs, interpreting students' solutions and statements, using representations accurately, and judging and correcting the mathematics material available for teaching. Given the relationships between teachers' MKT and their students' achievement, it could be inferred that the achievement of the students of EPTs with low mathematics anxiety and stronger PCK may be greater than the achievement of the students of EPTs with high mathematics anxiety and weaker PCK. 


\section{Implications for Practice}

The cases in this study contribute to the literature by providing a deeper understanding of the manifestation of mathematics anxiety in EPTs' teaching of mathematics. This section discusses the implications for practice regarding policy implementation, program coursework for elementary education majors, student teaching requirements, and considerations for hiring and the induction years.

\section{Policy Implications}

The findings of this study can help to inform policy makers at the state level reconsider the minimum requirements of elementary education programs. All the EPTs in this study successfully completed state mandated exams for certification; however, some EPTs still showed weakness in content knowledge. Currently, EPTs in elementary programs are required to take mathematics content courses, but none of those mathematics courses are required to focus on the specific content needed to teach the elementary grades. The findings of this multiple case study corroborates the suggestion of the Mathematics Education of Teachers II (Conference Board of the Mathematical Sciences, 2012) to require a content specific mathematics course for elementary education majors in addition to the mathematics methods for elementary education course requirement.

\section{Program Coursework}

At the time of this study, the elementary education program at the southeastern university only required students, including EPTs, to take two general introductory mathematics classes to fulfill their mathematics content requirement. The two classes that EPTs take vary and in some instances a computer science course could be substituted 
for a mathematic content course. A content course designed specifically for EPTs could be beneficial to ensure that they increase and deepen mathematics knowledge and understanding of the content needed for teaching at the elementary school level. This is also in line with the recommendation of the Mathematical Education of Teachers II (Conference Board of the Mathematical Sciences, 2012) that suggests that elementary teachers be trained directly in the mathematics content of grades K-5 with connections to mathematics content of pre-kindergarten and of the middle grades. A content course created specifically for EPTs would help all EPTs, but would especially help the EPTs with high mathematics anxiety to alleviate some of the anxiety linked to lack of content knowledge.

In addition to two content courses, EPTs from this study were only required to take one mathematics methods course in which EPTs were introduced to methods used to teach mathematics at all grade levels of elementary school. Since this study ended, the elementary education program began to require two mathematics methods courses. This should help EPTs think about using a variety of methods to ensure understanding when teaching future students. Mathematics education courses employing manipulatives and approaches to problem solving help to reduce mathematics anxiety (Harper \& Daane, 1998). Mathematics educators can plan experiences in methods classes to help reduce mathematics anxiety and help EPTs teach mathematics more successfully to their students. The mathematics methods courses could also include an emphasis on all of Graeber's (1999) big ideas in the teaching of mathematics.

In this multiple case study, it was evident that the textbook was the primary resource used by EPTs in their planning and enactment of lessons. Methods courses 
could focus on promoting a deeper understanding of valuable textbook use. In mathematics methods courses, mathematics educators could help foster a better understanding of how to effectively use a textbook and help EPTs explore the valuable resources that accompany textbooks.

During methods classes, case studies from this investigation could be used to help EPTs think more deeply about their own mathematics anxiety and their teaching of mathematics to better understand and reflect on the manifestation of mathematics anxiety in their teaching and consider ways to alleviate it, as needed. Students pursuing elementary education degrees who read these case studies (or abridged versions of the studies) can identify with the participants' stories and can learn from their experiences during student teaching. They may see aspects of themselves and their teaching in the cases of the students. They can use these case studies to identify areas of possible weakness that they may have and seek help to improve their teaching before beginning their student teaching experience or during their semester of student teaching.

Finally, in mathematics methods courses, mathematics educators can help EPTs to write inquiry based lessons that fit the format of the lesson plans used during student teaching to better support the use of more inquiry-based mathematics lessons. During the student teaching of this multiple case study, student teachers were only required to write one detailed mathematics lesson plan for student teaching, and the other lessons could be in the format of preference of their CTs. Some of the lesson plan formats used by CTs did not require EPTs to have to truly think about their lessons during planning. 


\section{Student Teaching}

Current student teaching policies can be revisited to enhance the experience of EPTs with high mathematics anxiety. Firstly, all EPTs who have high mathematics anxiety should be given an opportunity to teach mathematics during student teaching to ensure that they know what skill set is necessary to teach mathematics. Currently, not all EPTs with high mathematics anxiety are required to teach mathematics in some states. EPTs are placed with CTs, and shadow the CTs in their role. Some CTs are departmentalized, so EPTs teach only the subjects that their CTs teach. When selecting participants for this current study, some EPTs with high mathematics anxiety were not included because they were not required to teach mathematics. If an EPT with high mathematics anxiety does not get an opportunity to teach mathematics until the first year of teaching, the individual can possibly be unsuccessful. Teaching mathematics during student teaching when an EPT has support is critical to help EPTs overcome their fear of teaching mathematics and to help them learn methods that will ensure their success in their future teaching of mathematics. In addition to having to teach mathematics, EPTs with high mathematics anxiety should be required to take over mathematics classes first during student teaching so that they can focus attention only on teaching mathematics. Requiring that mathematics is the first subject to be taught will allow EPTs with high mathematics anxiety more time to focus on their teaching of mathematics with the necessary support needed to be successful.

Studies have shown that CTs play an important role in EPTs learning within student teaching (Beck \& Kosnik, 2002; Koerner, Rust, \& Baumgartner, 2002). The EPTs in this study relied heavily on their CT for help with planning their lessons and they took 
recommendations that the $\mathrm{CT}$ made seriously. CTs can benefit from reading these case studies by helping them notice the importance of their role and the influence that they have with EPTs in their classrooms. These case studies can also help CTs understand that their attitude toward mathematics impacts the student teachers in their classroom. CTs of EPTs with high mathematics anxiety need to have a strong understanding of mathematics content. CTs also need to have a strong understanding of PCK in mathematics. EPTs often mimic their CTs in their role as a student teacher. CTs need to be trained in PCK for mathematics and in strategies to help EPTs with mathematics anxiety.

A professional development program in mathematics education should be required for CTs prior to taking student teachers or when they are working with a student teacher who will be teaching mathematics so they can put mentoring ideas into practice while developing them. This professional development can help CTs learn to mentor and conduct post-lesson discussions that engage their student teachers in reflecting more deeply on mathematics lessons by the CTs use of questioning and related types of communication involving PCK and CK related to the lesson observed, as suggested in Fernandez and Erbilgin (2009). This professional development should also focus on the importance of allowing student teachers to plan their own lessons. Although it is beneficial for CTs to share their lesson plans with student teachers, if the student teachers use the exact lesson plans of their CT, they will not be forced to develop the skills that come with thinking through the planning of a lesson and additionally, they may not be fully prepared to teach the lessons that they are directly adopting. 
In addition to a professional development in mathematics education for CTs, a professional development in mathematics education should be enforced for university supervisors as well. In this professional development experience, university supervisors could review the case studies presented in this multiple case study. These case studies can help university supervisors recognize symptoms of students who may have mathematics anxiety and reflect on ways to help these particular students during student teaching. The case studies can also help university supervisors identify additional resources and mentors for students if their own strength is not in the field of mathematics education. Also, university supervisors can be educated in the PCK of mathematics as outlined by Graeber (1999) to ensure that the mathematics lessons that they observe show areas of strength in PCK and have aspects of the five big ideas for teachers of mathematics. Mathematics educators can be invited to professional development sessions for university supervisors to discuss PCK required for mathematics teaching and illustrate good inquiry based mathematics lessons. Further, the mathematics educators can help structure or align these inquiry lessons with mathematics lesson requirements of a particular district such as into the "I do, We do, You do" lesson format that is what was expected of these student teachers. The EPTs of this study had a hard time creating inquiry based mathematics lessons that fit the mandated "I do, We do, You do" lesson format.

University supervisors could also be trained in supervision strategies used during the post-observation conferences with student teachers. University supervisors could ask questions about PCK in the observed mathematics lessons and they can engage the EPTs in reflecting on and provide feedback on how to successfully address issues relating to 
PCK in the observed lesson as recommended by Fernandez and Erbilgin (2009). These discussions could motivate EPTs with high mathematics anxiety to seek new ways to improve their lessons. All of the EPTs in this study shared that the conversations with the researcher about their mathematics lessons during post-lesson interviews were valuable and helped them to reflect on their lessons and think about new strategies to try for their next mathematics lesson.

\section{Hiring and Induction Year}

Administrators of elementary schools can benefit from reading this multiple case study prior to hiring new teachers, and when helping these teachers in their induction year. Elementary school administrators can gain a better understanding of the experience that EPTs with high mathematics anxiety have during student teaching. With this knowledge administrators can draft valuable questions to pose for these EPTs as they interview them to become first year teachers. They can also capitalize on the knowledge that some EPTs may either be excited about teaching mathematics or may not want to teach mathematics at all in making their decisions about instructional assignments. These first year teachers may be more successful in a departmentalized setting that suits their preferences; this type of placement would be beneficial to the first year teachers and their students. Additionally, district and school administrators can help support EPTs interested in teaching mathematics their first year with opportunities for professional development, including graduate mathematics education coursework, to help them develop their understanding of approaches to teaching mathematics aligned with recent research and recommendations for effective student learning. 


\section{Recommendations for Future Research}

The findings of this multiple case study allow for future research. To gain a better understanding of the experience that EPTs have with mathematics anxiety, a future longitudinal study may be considered following EPTs from their experiences in their mathematics content or methods classes to their experience during student teaching and observing their experience into their first year of teaching. This might lead to a better understanding of how students with mathematics anxiety cope throughout their early experiences with teaching mathematics.

Content knowledge was only observed in this present study, but during a future study content knowledge of EPTs with high and low anxiety could be assessed using instruments that are developed to specifically test content knowledge in the areas that students are actually teaching. Information gleaned from this could further shed light onto similarities or differences between EPTs with high and low levels of mathematics anxiety.

Interventions to reduce mathematics anxiety can be developed and studied as part of mathematics courses specifically for elementary education majors or in methods of teaching mathematics courses. These interventions can draw on the ideas of behavioral methods such as systematic desensitization, and cognitive-behavioral methods, such as cognitive modifications emphasizing confidence building, found to be successful for reducing mathematics anxiety in a meta-analysis of research on mathematics anxiety conducted by Hembree (1990).

This findings of this study show similarities and differences between EPTs with high and low mathematics anxiety, and future case studies could follow only EPTs with 
high levels of mathematics anxiety. This present case study focused on six participants, but future studies could focus on few participants to gain a more in-depth understanding of their cases.

Finally, future research could be conducted with EPTs who have high mathematics anxiety to test measures that may improve the teaching of these EPTs during student teaching. Such a study could test whether pedagogical content knowledge could be improved by giving these EPTs with high mathematics anxiety additional resources and support.

\section{Limitations of the Study}

Demographics of participants might be one limitation of this study. All the participants were Hispanic females. There were a small number of males in the initial sample size, and one male was invited to participate as an EPT with low mathematics anxiety; however, his cooperating teacher did not wish to participate in the study. As a result there were no males represented in the final six participants.

Another limitation included the privacy of the interviews and observations that were conducted with the EPTs in this study. There was not complete privacy for all interviews conducted. For some interviews cooperating teachers were present in the room. During some interviews students were present working in other areas of the classroom where the interviews were being conducted. Also, some interviews were conducted in public areas of the school such as courtyards and hallways where other teachers and students were passing by. Finally, both Belinda's university supervisor and the researcher observed three of Belinda's lessons. She chose for this to happen simultaneously, and although she promised that she was comfortable with the both the 
researcher and her university supervisor in the room, this could have added extra pressure to her observed lessons.

\section{Conclusions}

The purpose of this study was to explore the teaching experiences of EPTs with both high and low levels of mathematics anxiety in their lesson planning, and enacting of lessons through the lenses of mathematics anxiety, content knowledge of mathematics, and pedagogical content knowledge in mathematics. There was a difference in mathematics anxiety, content knowledge and pedagogical content knowledge of the participants with high mathematics anxiety and the participants with low mathematics anxiety. As expected, the EPTs with high mathematics anxiety, showed more signs of mathematics anxiety than their counterparts with low mathematics anxiety. The EPTs with low mathematics anxiety were observed to understand the content and impart that understanding to their students more clearly than their counterparts with high mathematics anxiety. Finally, the EPTs with low mathematics anxiety had a better grasp of pedagogical content knowledge than their counterparts with high mathematics anxiety. 


\section{References}

Alexander, L., \& Martray, C. (1989). The development of an abbreviated version of the Mathematics Anxiety Rating Scale. Measurement and Evaluation in Counseling and Development, 22, 143-150.

Bandura, A. (1977). Self-efficacy: Toward a unifying theory of behavioral change. Psychological Review, 88(4), 191-215.

Beck, C., \& Kosnik, C. (2002). Components of a good practicum placement: Student teacher perceptions. Teacher Education Quarterly, 29 (2), 81-98.

Betz, N. (1978). Prevalence, distribution, and correlates of math anxiety in college students. Journal of Counseling Psychology, 25, 441-448.

Bibby, T. (2002). Shame: An emotional response to doing mathematics as an adult and a teacher. British Educational Research Journal 28(5), 705-721.

Bogdan, R. C., \& Biklen, S. K. (2007). Qualitative research for education: An introduction to Theories and Methods. New York, NY: Pearson Education.

Brady, P., \& Bowd, A. (2005). Mathematics anxiety, prior experience and confidence to teach mathematics among pre-service education students. Teachers and Teaching: Theory and Practice 11(1), 37-46.

Brush, L. (1981). Some thoughts for teachers on mathematics anxiety. Arithmetic Teacher, 29(4), 37-39.

Bursal, M., Paznokas, L. (2006). Mathematics anxiety and preservice elementary teaches' confidence to teach mathematics and science. School Science and Mathematics 106 (4)173-180.

Bush, W. S. (1989). Mathematics anxiety in upper elementary school teachers. School Science and Mathematics, 89, 499-509.

Conference Board of the Mathematical Sciences (2012). The Mathematical Education of Teachers II. Providence RI and Washington DC: American Mathematical Society and Mathematical Association of America.

Creswell, J. W. (2007). Qualitative inquiry and research design: Choosing among five traditions $\left(2^{\text {nd }}\right.$ ed.).Thousand Oaks, CA: Sage.

Daane, C. J. (2001). A teacher education in-service program that made a difference. Education 106(1), 12-14. 
Daane, C.J., Giesen, J., \& Sloan, T. (2002). Mathematics anxiety and learning styles: What is the relationship in elementary preservice teachers? School Science and Mathematics 102(2) $84-87$.

Dew, K.M.H., Galassi, J.P., \& Galassi, M.D. (1983). Mathematics anxiety: Some basic issues. Journal of Counselling Psychology, 30 (3), 443-446.

Fernandez, M. L., \& Erbilgin, E. (2009). Examining the supervision of mathematics student teachers through analysis of conference communications. Educational Studies in Mathematics, 72 (1), 93-110.

Flyvbjerg B. (2011). Case Study. In Denzin, N. K. and Lincoln, Y. S. (Eds.), The Sage handbook of qualitative research $\left(3^{\text {rd }}\right.$ ed.) Thousand Oaks, CA.: Sage

Graeber, A.O. (1999). Forms of knowing mathematics: What preservice teachers should learn. Educational Studies in Mathematics, 38(1), 189-208.

Gresham, G. (2007). A study of mathematics anxiety in pre-service teachers. Early Childhood Education Journal 35(2), 181-188.

Guba, E. (1981). Criteria for Assessing the Trustworthiness of Naturalistic Inquiries. ERIC/ECTJ Annual Review Paper 29(2), 75-91.

Harper, N. W., \& Daane, C. J. (1998).Causes and reduction of math anxiety in preservice elementary teachers. Action in Teacher Education 19(4), 29-38.

Hembree, R. (1990). The nature, effects, and relief of mathematics anxiety. Journal for Research in Mathematics Education, 21(1), 33-46.

Hill, H., Rowan, B, \& Ball, D. (2005) Effects of teachers' mathematical knowledge for teaching on student achievement. American Education Research Journal, 42(2), 371-406.

Hopko, D. R., Mahadevan, R., Bare, R.L., \& Hunt, M.K. (2003). The abbreviated math anxiety scale (AMAS): Construction, validity, and reliability. Assessment 10(2), $178-182$.

Jackson, C. D. \& Leffingwell, R. J. (1999). The role of instructors in creating math anxiety in students from kindergarten through college. Mathematics Teacher 92(7), 583-586.

Koerner, M., Rust, F. O., \& Baumgartner, F. (2002). Exploring roles in student teaching placements. Teacher Education Quarterly, 29 (2), 35-58. 
Ma, X. (1999). A meta-analysis of the relationship between anxiety toward mathematics and achievement in mathematics. Journal for Research in Mathematics Education, 30 (5), 520-540.

Malinsky, M., Ross, A., Pannells, T., \& McJunkin, M. (2006). Math anxiety in preservice elementary school teachers. Education 127(2), 274-280.

Merriam, S. B. (2002a). Introduction to Qualitative Research. In S. B. Merriam \& Associates (Eds.), Qualitative research in practice: Examples for discussion and analysis. San Francisco, CA: Jossey-Bass

Merriam, S. B. (2002b). Assessing and Evaluating Qualitative Research. In S. B. Merriam

\& Associates (Eds.), Qualitative research in practice: Examples for discussion and analysis. San Francisco, CA: Jossey-Bass

National Council of Teachers of Mathematics (2000). Principles and Standards for School

Mathematics. Reston, VA: National Council of Teachers of Mathematics

National Governors Association Center for Best Practices (NGA Center) \& The Council of Chief State School Officers, (2011). Common Core State Standards Initiative: Preparing America's students for college and career. Retrieved from: http://www.corestandards.org/the-standards/mathematics

Nicol, C. C. \& Crespo, S. M. (2006). Learning to teach with mathematics textbooks: How preservice teachers interpret and use curriculum materials. Educational Studies in Mathematics 62, 331-355.

Peshkin, A. (1988). In search of subjectivity - One's own. Educational Researcher 17(7), 17-21.

Plake, B. S, \& Parker, C. S. (1982). The development and validation of a revised version of the mathematics anxiety rating scale. Educational and Psychological Measurement42, 551-557.

Richardson, F. C. \& Suinn, R. M. (1972).The mathematics anxiety rating scale: Psychometric data. Journal of Counseling Psychology 19, 551-554.

Rubin, H. J. \& Rubin, I. S. (2005).Qualitative interviewing: The art of hearing data (2nd ed.). Thousand Oaks, CA: Sage.

Sarason, S. B., \& Mandler, G. (1952). Some correlates of test anxiety. Journal of Consulting and Clinical Psychology, 47, 810-817. 
Shulman, L.S. (1986). Those who understand knowledge growth in teaching. Educational Researcher, 15(2), 4-14.

Stober, J. \& Pekrun, R. (2004). Advances in test anxiety research (Editorial). Anxiety, Stress, \& Coping, 17(3), 205-211.

Suinn, R., Edie, C., Nicoletti, J., \& Spinelli, P. (1972).The MARS, a measurement of Mathematics anxiety: Psychometric data. Journal of Clinical Psychology, 28, 373-375.

Swars, S.L. (2005). Examining perceptions of mathematics teaching effectiveness among elementary preservice teachers with differing levels of mathematics teacher efficacy. Journal of Instructional Psychology 32(2), 139-147.

Swars, S. L., Daane, C. J. \& Giesen, J. (2006). Mathematics anxiety and mathematics efficacy: What is the relationship in elementary preservice teachers? School Science and Mathematics, 106(7), 306-315.

Tobias, Sigmund. (1985). Test anxiety: Interference, defective skills, and cognitive capacity. Educational Psychologist, 20, 135-142.

Tobias, Sheila. (1993). Overcoming math anxiety: Revised and Expanded. New York: W.W. Norton \& Company.

Trice, A.D., \& Ogden, E. D., (1987). Correlates of mathematics anxiety in first-year elementary school teachers. Education Research Quarterly, 11 (3), 2-4.

Trujillo, K. M., \& Hadfield, O. D. (1999). Tracing the roots of mathematics anxiety through in-depth interviews with preservice elementary teachers. College Student Journal 33(2), 219-233.

Unglaub, K. W. (1995). Mathematics anxiety in preservice elementary school teachers. ProQuest Dissertations and Theses, n/a. Retrieved from http://search.proquest.com/docview/304256002?accountid=10901

Uusimaki, L., \& Nason, R. (2004). Causes underlying pre-service teachers' negative beliefs and anxieties about mathematics. Psychology of Mathematics Education 4, 369-376.

Vinson, B. M. (2001). A comparison of preservice teachers' mathematics anxiety before and after a methods class emphasizing manipulatives. Early Childhood Education Journal, 29(2), 89-94.

Widmer, C.C., \& Chavez, A. (2001).Math anxiety and elementary school teachers. 
Education 102(3), 272-276.

Wood, E. F. (1988). Math anxiety and elementary teachers: What does research tell us? For the Learning of Mathematics, 8(1), 8-13.

Yin, R. K. (2003). Case study research: Design and methods ( $3^{\text {rd }}$ ed.). Thousand Oaks, CA: Sage. 


\section{APPENDICES}

\section{Appendix A}

\section{AMAS Survey \\ Abbreviated Math Anxiety Scale (AMAS)}

For each item, circle only one response that best represents how you feel in such a situation. Circle one of the values between 1 (low anxiety) to 5 (high anxiety).

1. Having to use the tables in the back of a math book.

$\begin{array}{llllll}1 & 2 & 3 & 4 & 5\end{array}$

2. Thinking about an upcoming math test one day before.

$\begin{array}{lllll}1 & 2 & 3 & 4 & 5\end{array}$

3. Watching a teacher work an algebraic equation on the blackboard.

$\begin{array}{lllll}1 & 2 & 3 & 4 & 5\end{array}$

4. Taking an examination in a math course.
1
2
3
$4 \quad 5$

5. Being given a homework assignment of many difficult problems that is due the next class meeting.
1
2
3
4
5

6. Listening to a lecture in math class.
1
2
3
45

7. Listening to another student explain a math formula.

$\begin{array}{lllll}1 & 2 & 3 & 4 & 5\end{array}$

8. Being given a "pop" quiz in math class.

$\begin{array}{lllll}1 & 2 & 3 & 4 & 5\end{array}$

9. Starting a new chapter in a math book.
1
2
3
4
5

Taken from: Hopko, D. R., Mahadevan, R., Bare, R.L., \& Hunt, M.K. (2003). The abbreviated math anxiety scale (AMAS): Construction, validity, and reliability. Assessment, 10(2), $178-182$. 


\section{Appendix B}

\section{Interview Questions}

\section{Mathematics Anxiety Interview Questions: Interview Questions: (INITIAL STUDENT TEACHING INTERVIEW)}

- You are here because you took the AMAS. How did you feel taking that survey? (Show the survey to the student)

- Have you heard of Mathematics Anxiety?

- If so, can you tell me what it is in your own words?

- How do you feel toward mathematics?

- What do you think the purpose of mathematics is?

- How do you use mathematics in your daily life? Formal? Informal?

- What was your earliest memory of an experience learning mathematics?

- As a young child, what events at home helped you to shape your mathematics identity?

- As a young child, what events at school helped you to shape your mathematics identity?

- What was your first bad experience/good experience with mathematics?

- What was your first bad experience/good experience with mathematics in school?

- What are some other bad experiences/good experiences that you have had with mathematics?

- How was mathematics taught to you in school? (groups, lecture, worksheets)

- What happened when you took tests in mathematics? How was it structured? How did you feel?

- Can you think of any friends or family members that have influenced your thinking of mathematics?

- Has your culture influenced your mathematics identity?

- Have you had any good experiences/bad experiences with mathematics more recently? Was there any time that you have enjoyed/not enjoyed mathematics?

- Do you have a favorite teacher in mathematics? Do you have a teacher that you dislike most in mathematics? Why?

- What do you fear the most when it comes to mathematics?

- What is your current experience like with mathematics?

(If the participant has mathematics anxiety the following questions will be asked)

- Do you have anxiety in any other classes?

- Why do you think you have anxiety in mathematics?

- Do you think there is any way you could eliminate or overcome mathematics anxiety? (Be specific)

- How could your teachers (especially those preparing you to teach mathematics) have helped you to overcome mathematics anxiety? 
(The rest of the questions will be asked to all participants)

- Do you think your future students will have these same feelings that you have described toward mathematics?

- Do you think it is important to teach mathematics to your students? Why/Why not?

- Are you looking forward to teaching mathematics this semester? Why? /Why not?

- How do you think you will teach mathematics this semester?

- Do you plan on using anything that you have learned during course work to help you teach mathematics? What do you plan on using?

- Are there any other comments you would like to make on mathematics anxiety?

- Are there any other questions that I should have asked you about mathematics anxiety?

What did you gain from the MAE 4310? What strategies did you gain? What did you take away for that class? How will you use this in your student teaching?

\section{Interview Questions (POST OBSERVATION INTERVIEW)}

- Tell me about the mathematics lesson that you just taught.

- What is your overall feeling of the success of the lesson?

- How did you feel while you were teaching the lesson?

- Was there any part of the lesson that made you the most anxious?

- Was there any part of the lesson that made you the least anxious?

- What did you do to prepare for the lesson?

- What resources did you use in planning for the lesson?

- What did you like most about your lesson?

- What did you like least about your lesson?

- What do you think you would have done differently if you had to teach the lesson again?

- What else could you have done to better prepare yourself to teach the lesson?

- Is there anything else that you would like to share about your mathematics lesson?

\section{Interview Questions: (FINAL STUDENT TEACHING INTERVIEW)}

- How do you feel about your teaching of mathematics this semester?

- Where there any challenges to teaching mathematics?

- What did you enjoy the most about teaching mathematics this semester?

- What did you enjoy the least about teaching mathematics this semester?

- What was your favorite mathematics lesson this semester?

- What was your least favorite mathematics lesson this semester?

- How did you generally plan for your mathematics lessons? 
- Are there any resources that you found to be helpful other than the textbook being used? What are they?

- What have you learned about teaching mathematics to elementary students this semester?

(If a student has mathematics anxiety, these questions will be asked)

- Do you think you were always anxious about teaching mathematics?

- Were you as anxious about teaching other subjects this semester? If so, which ones and why? If not, why not?

- Do you think that your anxiousness toward mathematics anxiety has decreased or increased? Explain. Why do you think this happened?

(All participants will be asked the remaining questions)

- Are you looking forward to teaching mathematics in your future classrooms?

- Do you think you will do a good job at teaching mathematics?

- What strategies will you use in the future as a mathematics teacher?

- Is there anything else that you would like to share with me about teaching mathematics this semester? 


\section{Appendix C}

\section{Pre-Lesson Survey}

Please respond to the following questions as honestly as possible.

1. What is your main expectation for what your students will learn through this lesson?

2. What resources did you use to plan the lesson? (Textbook, cooperating teacher, resource book, internet resource) Please explain how you used these resources.

3. Is there anything that you would like to include in the lesson but you are not able to do so? Please explain why.

4. Describe the feelings you had while planning this lesson.

5. What are your feelings now as you get ready to teach this lesson?

6. How comfortable are you with mathematics content of this lesson?
12
3
4
5
Not comfortable
very comfortable

7. How comfortable do you feel with the mathematics lesson you are about to teach?

$\begin{array}{lrrcc}2 & 3 & 4 & 5 \\ \text { Not comfortable } & & & \text { very comfortable }\end{array}$




\section{Appendix D}

\section{List of Signs of Mathematics Anxiety used during Observations}

\begin{tabular}{|l|l|}
\hline Observed Signs & Tally of Observed Signs \\
\hline Flushed Face & \\
\hline Sweating & \\
\hline Rapid Speech & \\
\hline Avoidance of Content of Lesson & \\
\hline Heaving Breathing & \\
\hline Fidgeting & \\
\hline
\end{tabular}




\section{Appendix E}

\section{Data Tracking System}

\begin{tabular}{|c|c|c|c|c|c|c|c|}
\hline $\begin{array}{l}\text { Participa } \\
\mathrm{nt}\end{array}$ & $\begin{array}{l}\text { Inter- } \\
\text { view } 1\end{array}$ & $\begin{array}{l}\text { Inter- } \\
\text { view } 2\end{array}$ & $\begin{array}{l}\text { Inter- } \\
\text { view } 3\end{array}$ & $\begin{array}{l}\text { Inter- } \\
\text { view } 4\end{array}$ & $\begin{array}{l}\text { Inter- } \\
\text { view } 5\end{array}$ & $\begin{array}{l}\text { Inter- } \\
\text { view } 6\end{array}$ & $\begin{array}{l}\text { Inter- } \\
\text { view } 7\end{array}$ \\
\hline $\begin{array}{l}1 \\
\text { Ally }\end{array}$ & $\mathrm{X}$ & $\mathrm{X}$ & $\mathrm{X}$ & $\mathrm{X}$ & $\mathrm{X}$ & $\mathrm{X}$ & $\mathrm{X}$ \\
\hline $\begin{array}{l}2 \\
\text { Belinda }\end{array}$ & $X$ & $X$ & $X$ & $X$ & $X$ & $\mathrm{X}$ & $\mathrm{X}$ \\
\hline $\begin{array}{l}3 \\
\text { Nancy }\end{array}$ & $X$ & $X$ & $X$ & $X$ & $X$ & $X$ & $X$ \\
\hline $\begin{array}{l}4 \\
\text { Gigi }\end{array}$ & $X$ & $X$ & $X$ & $X$ & $X$ & $\mathrm{X}$ & $X$ \\
\hline $\begin{array}{l}5 \\
\text { Val }\end{array}$ & $X$ & $X$ & $X$ & $X$ & $X$ & $\mathrm{X}$ & $X$ \\
\hline $\begin{array}{l}6 \\
\text { Yoli }\end{array}$ & & $X$ & $X$ & $\mathrm{X}$ & $X$ & $X$ & $X$ \\
\hline
\end{tabular}

\begin{tabular}{|l|l|l|l|l|l|}
\hline Participant & $\begin{array}{l}\text { Pre-Lesson } \\
\text { Survey 1 }\end{array}$ & $\begin{array}{l}\text { Pre-Lesson } \\
\text { Survey 2 }\end{array}$ & $\begin{array}{l}\text { Pre-Lesson } \\
\text { Survey 3 }\end{array}$ & $\begin{array}{l}\text { Pre-Lesson } \\
\text { Survey 4 }\end{array}$ & $\begin{array}{l}\text { Pre-Lesson } \\
\text { Survey 5 }\end{array}$ \\
\hline $\begin{array}{l}\text { Ally } \\
2 \\
\text { Belinda }\end{array}$ & $\mathrm{X}$ & $\mathrm{X}$ & $\mathrm{X}$ & $\mathrm{X}$ & $\mathrm{X}$ \\
\hline $\begin{array}{l}3 \\
\text { Nancy }\end{array}$ & $\mathrm{X}$ & $\mathrm{X}$ & $\mathrm{X}$ & $\mathrm{X}$ & $\mathrm{X}$ \\
\hline $\begin{array}{l}4 \\
\text { Gigi }\end{array}$ & $\mathrm{X}$ & $\mathrm{X}$ & $\mathrm{X}$ & $\mathrm{X}$ & $\mathrm{X}$ \\
\hline $\begin{array}{l}5 \\
\text { Val }\end{array}$ & $\mathrm{X}$ & $\mathrm{X}$ & $\mathrm{X}$ & $\mathrm{X}$ & $\mathrm{X}$ \\
\hline $\begin{array}{l}6 \\
\text { Yoli }\end{array}$ & $\mathrm{X}$ & $\mathrm{X}$ & $\mathrm{X}$ & $\mathrm{X}$ & $\mathrm{X}$ \\
\hline
\end{tabular}




\begin{tabular}{|l|l|l|l|l|l|}
\hline Participant & $\begin{array}{l}\text { Lesson Plan } \\
1\end{array}$ & $\begin{array}{l}\text { Lesson Plan } \\
2\end{array}$ & $\begin{array}{l}\text { Lesson Plan } \\
3\end{array}$ & $\begin{array}{l}\text { Lesson Plan } \\
4\end{array}$ & $\begin{array}{l}\text { Lesson Plan } \\
5\end{array}$ \\
\hline $\begin{array}{l}1 \\
\text { Ally }\end{array}$ & & & & & \\
\hline $\begin{array}{l}2 \\
\text { Belinda }\end{array}$ & $\mathrm{X}$ & & & & \\
\hline $\begin{array}{l}3 \\
\text { Nancy }\end{array}$ & & $\mathrm{X}$ & & $\mathrm{X}$ & \\
\hline $\begin{array}{l}4 \\
\text { Gigi }\end{array}$ & $\mathrm{X}$ & $\mathrm{X}$ & & $\mathrm{X}$ & $\mathrm{X}$ \\
\hline $\begin{array}{l}5 \\
\text { Val }\end{array}$ & & $\mathrm{X}$ & $\mathrm{X}$ & & \\
\hline $\begin{array}{l}6 \\
\text { Yoli }\end{array}$ & $\mathrm{X}$ & & $\mathrm{X}$ & & \\
\hline
\end{tabular}

\begin{tabular}{|l|l|l|l|l|l|}
\hline Participant & $\begin{array}{l}\text { Field } \\
\text { Observation } \\
1\end{array}$ & $\begin{array}{l}\text { Field } \\
\text { Observation } \\
2\end{array}$ & $\begin{array}{l}\text { Field } \\
\text { Observation } \\
3\end{array}$ & $\begin{array}{l}\text { Field } \\
\text { Observation } \\
4\end{array}$ & $\begin{array}{l}\text { Field } \\
\text { Observation } \\
5\end{array}$ \\
\hline $\begin{array}{l}1 \\
\text { Ally }\end{array}$ & $\mathrm{X}$ & $\mathrm{X}$ & $\mathrm{X}$ & $\mathrm{X}$ & $\mathrm{X}$ \\
\hline $\begin{array}{l}2 \\
\text { Belinda }\end{array}$ & $\mathrm{X}$ & $\mathrm{X}$ & $\mathrm{X}$ & $\mathrm{X}$ & $\mathrm{X}$ \\
\hline $\begin{array}{l}3 \\
\text { Nancy }\end{array}$ & $\mathrm{X}$ & $\mathrm{X}$ & $\mathrm{X}$ & $\mathrm{X}$ & $\mathrm{X}$ \\
\hline $\begin{array}{l}4 \\
\text { Gigi }\end{array}$ & $\mathrm{X}$ & $\mathrm{X}$ & $\mathrm{X}$ & $\mathrm{X}$ & $\mathrm{X}$ \\
\hline $\begin{array}{l}5 \\
\text { Val }\end{array}$ & $\mathrm{X}$ & $\mathrm{X}$ & $\mathrm{X}$ & $\mathrm{X}$ & $\mathrm{X}$ \\
\hline $\begin{array}{l}6 \\
\text { Yoli }\end{array}$ & $\mathrm{X}$ & $\mathrm{X}$ & $\mathrm{X}$ & $\mathrm{X}$ & $\mathrm{X}$ \\
\hline
\end{tabular}




\begin{tabular}{|l|l|l|l|}
\hline Participant & Journal Entry & Artifact & Artifact \\
\hline 1 & $\mathrm{X}$ & & \\
Ally & & & \\
Belinda & $\mathrm{X}$ & Fraction Chart & \\
\hline 3 & $\mathrm{X}$ & & \\
Nancy & & & \\
\hline 4 & $\mathrm{X}$ & & \\
Gigi & & & \\
\hline 5 & $\mathrm{X}$ & Money Poster & \\
Val & & & \\
\hline 6 & $\mathrm{X}$ & & \\
Yoli & & & \\
\hline
\end{tabular}




\section{Appendix F}

\section{Tables Summarizing Nancy’s Case}

Description of Nancy's Five Observed Lessons and Summary of her Planning of those Lessons
Description of Lesson
Lesson Planning

\begin{tabular}{|c|c|}
\hline Lesson 1: & $20 \min$ \\
\hline Before and After & Resources used: Teacher Edition of Textbook and CT \\
\hline Lesson 2: & $30 \mathrm{~min}$ \\
\hline More Time vs. Less Time Part 1 & Resources used: Textbook and CT \\
\hline Lesson 3: & $20 \mathrm{~min}$ \\
\hline More Time vs Less Time Part 2 & Resources used: Textbook and CT \\
\hline Lesson 4: & $30 \mathrm{~min}$ \\
\hline Equal Parts & Resources used: CT only \\
\hline Lesson 5: & $25-30 \mathrm{~min}$ \\
\hline Skip Counting $(2 s, 5 s, 10 s)$ & Resources used: Practice SAT student workbook and CT \\
\hline
\end{tabular}

Summary of Nancy's Mathematics Anxiety over Five Observed Lessons

Description of Lesson Mathematics Anxiety

Lesson 1:

Before and After

Lesson 2:

More Time vs. Less Time Part 1

Lesson 3:

More Time vs Less Time Part 2

Lesson 4:

Equal Parts

Lesson 5:

Skip Counting $(2 \mathrm{~s}, 5 \mathrm{~s}, 10 \mathrm{~s})$
Showed signs of anxiety in her rapid speech.

Showed signs of anxiety in her rapid speech.

Showed signs of anxiety in her nervous laughs and flushed face during the lesson.

Showed signs of anxiety in her flushed face, rapid speech and stuttering.

Showed signs of anxiety in her rapid speech, nervous laugh, and flushed face during her lesson. 
Lesson 1:

Before and After

Lesson 2:

More Time vs. Less Time Part 1

Lesson 3:

More Time vs Less Time Part 2

Lesson 4:

Equal Parts

Lesson 5:

Skip Counting $(2 \mathrm{~s}, 5 \mathrm{~s}, 10 \mathrm{~s})$
Did not use a point of reference to explain 'before' and 'after'. Discussed events that occur in the afternoon that could occur in either the morning of the afternoon. Did not use a reference point to compare 'more time' and 'less time'. She accepted isolated examples to explore the concept.

Difficulty with having the students conceptualize the concept. After students discovered an answer, she told the students that their answer was wrong, and the outcome was not supposed to happen. Had difficulty explaining the before and after aspect of numbers on a number line.

Understood the content, but had difficulty showing the value of skip counting to students. 


\begin{tabular}{|c|c|c|c|c|c|}
\hline $\begin{array}{l}\text { Description of } \\
\text { Lesson }\end{array}$ & $\begin{array}{l}\text { Understanding } \\
\text { student's } \\
\text { current } \\
\text { understanding }\end{array}$ & $\begin{array}{l}\text { Students } \\
\text { knowing in one } \\
\text { way do not } \\
\text { necessarily } \\
\text { know in the } \\
\text { other(s) }\end{array}$ & $\begin{array}{l}\text { Intuitive } \\
\text { knowledge is } \\
\text { both an asset } \\
\text { and a liability }\end{array}$ & $\begin{array}{c}\text { Certain } \\
\text { instructional } \\
\text { characteristics } \\
\text { appear to } \\
\text { promote } \\
\text { retention }\end{array}$ & $\begin{array}{l}\text { Alternative } \\
\text { representations } \\
\text { and the } \\
\text { recognition and } \\
\text { analysis of } \\
\text { alternative } \\
\text { methods are } \\
\text { important }\end{array}$ \\
\hline
\end{tabular}

\begin{tabular}{|c|c|c|c|c|c|}
\hline $\begin{array}{l}\text { Lesson 1: } \\
\text { Before and } \\
\text { After }\end{array}$ & $\begin{array}{l}\text { Teacher told } \\
\text { students } \\
\text { answers to fill } \\
\text { in the } \\
\text { workbook. }\end{array}$ & $\begin{array}{l}\text { Not Observed. } \\
\text { Teacher } \\
\text { directed } \\
\text { instruction was } \\
\text { used with } \\
\text { examples from } \\
\text { the text. }\end{array}$ & $\begin{array}{l}\text { Not Observed. } \\
\text { Possible } \\
\text { misconception } \\
\text { created. }\end{array}$ & $\begin{array}{l}\text { Not Observed - } \\
\text { direct } \\
\text { instruction used }\end{array}$ & $\begin{array}{l}\text { Used number } \\
\text { line located on } \\
\text { the top of the } \\
\text { board in the } \\
\text { classroom, but } \\
\text { the students } \\
\text { were not given } \\
\text { their own, so } \\
\text { this proved } \\
\text { somewhat } \\
\text { ineffective. } \\
\text { Used pictures } \\
\text { from the lesson } \\
\text { in the textbook. }\end{array}$ \\
\hline $\begin{array}{l}\text { Lesson 2: } \\
\text { More Time vs. } \\
\text { Less Time Part } \\
1\end{array}$ & $\begin{array}{l}\text { Allowed choral } \\
\text { answering. } \\
\text { Checked for } \\
\text { understanding } \\
\text { by asking } \\
\text { several students } \\
\text { for the answer } \\
\text { until the right } \\
\text { answer was } \\
\text { given. }\end{array}$ & $\begin{array}{l}\text { Not Observed. } \\
\text { Teacher } \\
\text { directed } \\
\text { instruction was } \\
\text { used with } \\
\text { examples from } \\
\text { the text. }\end{array}$ & Not Observed. & $\begin{array}{l}\text { Not Observed- } \\
\text { direct } \\
\text { instruction used }\end{array}$ & $\begin{array}{l}\text { Used pictures } \\
\text { from the lesson } \\
\text { in the textbook. }\end{array}$ \\
\hline $\begin{array}{l}\text { Lesson 3: } \\
\text { More Time vs } \\
\text { Less Time Part } \\
2\end{array}$ & $\begin{array}{l}\text { Teacher told } \\
\text { students } \\
\text { answers to fill } \\
\text { in the } \\
\text { workbook. }\end{array}$ & $\begin{array}{l}\text { Not Observed. } \\
\text { Teacher } \\
\text { directed } \\
\text { instruction was } \\
\text { used with } \\
\text { examples from } \\
\text { the text. }\end{array}$ & Not Observed. & $\begin{array}{l}\text { Had students do } \\
\text { some acting out } \\
\text { of scenarios to } \\
\text { explain content. }\end{array}$ & $\begin{array}{l}\text { Used pictures } \\
\text { from the lesson } \\
\text { in the textbook. }\end{array}$ \\
\hline $\begin{array}{l}\text { Lesson 4: } \\
\text { Equal Parts }\end{array}$ & $\begin{array}{l}\text { Teacher told } \\
\text { students } \\
\text { answers to fill } \\
\text { in the } \\
\text { workbook. }\end{array}$ & $\begin{array}{l}\text { Reflected on } \\
\text { possibly using a } \\
\text { scale to help } \\
\text { the students } \\
\text { understand. } \\
\text { Not Observed. } \\
\text { Teacher } \\
\text { directed } \\
\text { instruction was } \\
\text { used with } \\
\text { examples from } \\
\text { the text. }\end{array}$ & Not Observed. & $\begin{array}{l}\text { Not observed - } \\
\text { direct } \\
\text { instruction used }\end{array}$ & $\begin{array}{l}\text { Used the } \\
\text { number line } \\
\text { located on the } \\
\text { top of the board } \\
\text { in the } \\
\text { classroom, but } \\
\text { was not } \\
\text { effective } \\
\text { because } \\
\text { students could } \\
\text { not follow } \\
\text { along. } \\
\text { Used Unifix } \\
\text { cubes to } \\
\text { introduce the } \\
\text { concept. } \\
\text { Used pictures } \\
\text { from the lesson } \\
\text { in the textbook. }\end{array}$ \\
\hline
\end{tabular}




\begin{tabular}{|c|c|c|c|c|c|}
\hline $\begin{array}{l}\text { Lesson 5: } \\
\text { Skip Counting } \\
(2 \mathrm{~s}, 5 \mathrm{~s}, 10 \mathrm{~s})\end{array}$ & $\begin{array}{l}\text { Teacher told } \\
\text { students } \\
\text { answers to fill } \\
\text { in the } \\
\text { workbook. }\end{array}$ & $\begin{array}{l}\text { Not Observed. } \\
\text { Teacher } \\
\text { directed } \\
\text { instruction was } \\
\text { used with } \\
\text { examples from } \\
\text { the text. }\end{array}$ & Not Observed. & $\begin{array}{l}\text { Used songs } \\
\text { Tried to } \\
\text { incorporate } \\
\text { group work, but } \\
\text { students } \\
\text { worked along } \\
\text { for the most } \\
\text { part }\end{array}$ & $\begin{array}{l}\text { Used Unifix } \\
\text { cubes to } \\
\text { introduce the } \\
\text { concept. These } \\
\text { were used } \\
\text { ineffectively. } \\
\text { Used pictures } \\
\text { from the lesson } \\
\text { in the textbook. }\end{array}$ \\
\hline
\end{tabular}




\section{Appendix G}

\section{Tables Summarizing Ally's Case}

Description of Ally's Five Observed Lessons and Summary of her Planning of those Lessons
Description of Lesson
Lesson Planning

\begin{tabular}{ll}
\hline Lesson 1: & $40-60$ min \\
Telling Time to the quarter, & $\begin{array}{l}\text { Resources used: } \\
\text { Textbook, Brain Pop, and CT } \\
\text { half and whole hour. }\end{array}$ \\
$\begin{array}{l}\text { Lesson 2: } \\
\text { Classifying Properties of }\end{array}$ & $\begin{array}{l}\text { Resources used: Test Practice Workbooks, CT and } \\
\text { Smart Board }\end{array}$ \\
Polygons & $30-45$ min \\
Lesson 3: & Resources used: Test Practice Book, Smart Board \\
Perimeter & Exchange, and CT \\
& $20-30$ min \\
Lesson 4: & Resources used: Test Practice Books and CT \\
Reading Pictographs & \\
& $20-30$ min \\
Lesson 5: & Resources used: Test Practice Books, Brain Pop Video \\
Multiplication as Repeated & and CT \\
Addition &
\end{tabular}

Summary of Ally's Mathematics Anxiety over Five Observed Lessons

Description of Lesson

Mathematics Anxiety

\begin{tabular}{ll}
$\begin{array}{l}\text { Lesson 1: } \\
\text { Telling Time to the quarter, } \\
\text { half and whole hour. }\end{array}$ & $\begin{array}{l}\text { Overly Confident- Least anxiety, but still some anxiety } \\
\text { when students showed a lack of understanding }\end{array}$ \\
$\begin{array}{l}\text { Lesson 2: } \\
\text { Classifying Properties of }\end{array}$ & Overly Confident- No anxiety \\
Polygons & \\
$\begin{array}{l}\text { Lesson 3: } \\
\text { Perimeter }\end{array}$ & $\begin{array}{l}\text { Very little anxiety Overly Confident (She was more } \\
\text { confident than CT) -Only anxiety when students } \\
\text { showed lack of understanding on challenging problem. }\end{array}$ \\
$\begin{array}{l}\text { Lesson 4: } \\
\text { Reading Pictographs }\end{array}$ & No anxiety \\
$\begin{array}{l}\text { Lesson 5: } \\
\text { Multiplication as Repeated } \\
\text { Addition }\end{array}$ & $\begin{array}{l}\text { Some anxiety because she did not solve problems before } \\
\text { the lesson and made errors. }\end{array}$ \\
\hline
\end{tabular}


Description of Lesson Description of Content Knowledge

\begin{tabular}{ll}
$\begin{array}{l}\text { Lesson 1: } \\
\text { Telling Time to the quarter, } \\
\text { half and whole hour. }\end{array}$ & $\begin{array}{l}\text { Knowledgeable of content, but she did not present all } \\
\text { content clearly }\end{array}$ \\
$\begin{array}{l}\text { Lesson 2: } \\
\text { Classifying Properties of } \\
\text { Polygons }\end{array}$ & $\begin{array}{l}\text { Knowledgeable of content and provided clear } \\
\text { explanations to students }\end{array}$ \\
$\begin{array}{l}\text { Lesson 3: } \\
\text { Perimeter }\end{array}$ & $\begin{array}{l}\text { Some knowledge of content, but did not provide } \\
\text { justification of answers for students, she made an error, } \\
\text { and she did not emphasize the use of Units in answers. }\end{array}$ \\
$\begin{array}{l}\text { Lesson 4: } \\
\text { Reading Pictographs }\end{array}$ & $\begin{array}{l}\text { Strong knowledge of content, but struggled to explain the } \\
\text { concept of "at least" to the students. }\end{array}$ \\
$\begin{array}{l}\text { Lesson 5: } \\
\text { Multiplication as Repeated } \\
\text { Addition }\end{array}$ & $\begin{array}{l}\text { Good knowledge of content, and was able to successfully } \\
\text { explain the content to students. }\end{array}$ \\
\hline
\end{tabular}




\begin{tabular}{|c|c|c|c|c|c|}
\hline $\begin{array}{l}\text { Description of } \\
\text { Lesson }\end{array}$ & $\begin{array}{l}\text { Understanding } \\
\text { student's current } \\
\text { understanding }\end{array}$ & $\begin{array}{l}\text { Students } \\
\text { knowing in one } \\
\text { way do not } \\
\text { necessarily know } \\
\text { in the other(s) }\end{array}$ & $\begin{array}{c}\text { Intuitive } \\
\text { knowledge is } \\
\text { both an asset and } \\
\text { a liability }\end{array}$ & $\begin{array}{c}\text { Certain } \\
\text { instructional } \\
\text { characteristics } \\
\text { appear to } \\
\text { promote } \\
\text { retention }\end{array}$ & $\begin{array}{l}\text { Alternative } \\
\text { representations } \\
\text { and the } \\
\text { recognition and } \\
\text { analysis of } \\
\text { alternative } \\
\text { methods are } \\
\text { important }\end{array}$ \\
\hline $\begin{array}{l}\text { Lesson 1: } \\
\text { Telling Time to } \\
\text { the quarter, half } \\
\text { and whole hour. }\end{array}$ & $\begin{array}{l}\text { Checked for } \\
\text { understanding by } \\
\text { questioning the } \\
\text { group }\end{array}$ & $\begin{array}{l}\text { Evidence of } \\
\text { Procedural } \\
\text { Understanding }\end{array}$ & $\begin{array}{l}\text { Realized that } \\
\text { students had } \\
\text { possible } \\
\text { misconceptions } \\
\text { with the topic }\end{array}$ & $\begin{array}{l}\text { Direct } \\
\text { Instruction } \\
\text { Teacher-Led } \\
\text { Instruction } \\
\text { Whole Class } \\
\text { Drill } \\
\text { Individual Drill }\end{array}$ & $\begin{array}{l}\text { Direct Modeling } \\
\text { with Individual } \\
\text { Clocks, but did } \\
\text { not use clocks to } \\
\text { effectively } \\
\text { promote } \\
\text { understanding. } \\
\text { Accepted } \\
\text { different } \\
\text { techniques }\end{array}$ \\
\hline $\begin{array}{l}\text { Lesson 2: } \\
\text { Classifying } \\
\text { Properties of } \\
\text { Polygons }\end{array}$ & $\begin{array}{l}\text { Used assessment } \\
\text { to check for } \\
\text { understanding }\end{array}$ & Not Observed & Not Observed & $\begin{array}{l}\text { Direct } \\
\text { Instruction } \\
\text { Students showed } \\
\text { work on } \\
\text { interactive } \\
\text { Smart Board } \\
\text { lesson } \\
\text { Discussed } \\
\text { student work } \\
\text { with class. }\end{array}$ & $\begin{array}{l}\text { Polygons } \\
\text { projected on } \\
\text { Smart Board } \\
\text { Individual } \\
\text { Pattern Blocks } \\
\text { used but did not } \\
\text { help students } \\
\text { promote } \\
\text { understanding. }\end{array}$ \\
\hline $\begin{array}{l}\text { Lesson 3: } \\
\text { Perimeter }\end{array}$ & Not Observed & Not Observed & Not Observed & $\begin{array}{l}\text { Direct } \\
\text { Instruction } \\
\text { Students showed } \\
\text { work on } \\
\text { interactive Smart } \\
\text { Board lesson } \\
\text { Discussed } \\
\text { student work } \\
\text { with class. } \\
\text { Allowed students } \\
\text { to individually } \\
\text { measure objects }\end{array}$ & $\begin{array}{l}\text { Individual } \\
\text { Student Rulers } \\
\text { used but } \\
\text { measuring was } \\
\text { not discussed. } \\
\text { Ruler Projected } \\
\text { onto the Smart } \\
\text { Board }\end{array}$ \\
\hline $\begin{array}{l}\text { Lesson 4: } \\
\text { Reading } \\
\text { Pictographs }\end{array}$ & $\begin{array}{l}\text { Encouraged } \\
\text { students to } \\
\text { recheck their } \\
\text { work to ensure } \\
\text { understanding. }\end{array}$ & Not Observed & $\begin{array}{l}\text { Described a } \\
\text { students' } \\
\text { misconceptions } \\
\text { as careless } \\
\text { errors. }\end{array}$ & $\begin{array}{l}\text { Direct } \\
\text { Instruction and } \\
\text { Individual Work }\end{array}$ & Not Observed \\
\hline $\begin{array}{l}\text { Lesson 5: } \\
\text { Multiplication as } \\
\text { Repeated } \\
\text { Addition }\end{array}$ & Not Observed & $\begin{array}{l}\text { Presented } \\
\text { procedures to the } \\
\text { students and } \\
\text { allowed them to } \\
\text { choose. }\end{array}$ & $\begin{array}{l}\text { Contributed to } \\
\text { create a } \\
\text { misconception } \\
\text { that was never } \\
\text { resolved. }\end{array}$ & $\begin{array}{l}\text { Direct } \\
\text { Instruction } \\
\text { Students showed } \\
\text { work on } \\
\text { interactive Smart } \\
\text { Board lesson } \\
\text { Discussed } \\
\text { student work } \\
\text { with class. } \\
\text { Sang Songs } \\
\text { Brain Pop Video }\end{array}$ & $\begin{array}{l}\text { Accepted } \\
\text { multiple } \\
\text { strategies to } \\
\text { solve problems }\end{array}$ \\
\hline
\end{tabular}




\section{Appendix $\mathbf{H}$}

\section{Tables Summarizing Belinda’s Case}

Description of Belinda's Five Observed Lessons and Summary of her Planning of those Lessons
Description of Lesson
Planning Time/Resources Used

\begin{tabular}{|c|c|}
\hline $\begin{array}{l}\text { Lesson 1: } \\
\text { Understanding Fractions: Whole, } \\
\text { Half, Thirds, and Fourths }\end{array}$ & $\begin{array}{l}120 \text { min } \\
\text { Resources used: Textbook and Student Practice Book }\end{array}$ \\
\hline $\begin{array}{l}\text { Lesson 2: } \\
\text { Angles }\end{array}$ & $\begin{array}{l}180 \text { min } \\
\text { Resources used: Textbook, First Grade Literature Book, } \\
\text { CT }\end{array}$ \\
\hline $\begin{array}{l}\text { Lesson 3: } \\
\text { Money: Equal Amounts }\end{array}$ & $\begin{array}{l}180 \text { min } \\
\text { Resources used: Textbook (Teacher's Edition), Literature } \\
\text { Book, CT }\end{array}$ \\
\hline $\begin{array}{l}\text { Lesson 4: } \\
\text { Money: Amounts Greater Than } \\
\$ 1\end{array}$ & $\begin{array}{l}240 \text { min } \\
\text { Resources used: Textbook, Student Practice Book, } \\
\text { Internet, CT }\end{array}$ \\
\hline $\begin{array}{l}\text { Lesson 5: } \\
\text { SAT Review Lesson }\end{array}$ & $\begin{array}{l}60 \mathrm{~min} \\
\text { Resources used: SAT Practice Book }\end{array}$ \\
\hline
\end{tabular}


Description of Lesson Mathematics Anxiety

Lesson 1: $\quad$ Indicated nervousness prior to lesson; obvious

Understanding Fractions: Whole, perspiration

Half, Thirds, and Fourths $\quad$ Flustered face

During lesson both confident and nervous

Lesson 2:

Indicated nervousness

Angles

Flustered, red cheeks, obvious perspiration

Removed Jacket due to sweating

Lesson 3:

Indicated nervousness

Money: Equal Amounts

Lesson 4:

Money: Amounts Greater Than

$\$ 1$

Lesson 5:

SAT Review Lesson
Confident, not nervous because both she and the students were comfortable in the content.

Appeared nervous, face turned red, obvious perspiration, and skipped two problems. She did not discuss the answer of those problems with the students because she was not comfortable with the content. 
Description of Lesson Description of Content Knowledge

\begin{tabular}{ll}
$\begin{array}{l}\text { Lesson 1: } \\
\text { Understanding Fractions: Whole, } \\
\text { Half, Thirds, and Fourths }\end{array}$ & $\begin{array}{l}\text { Showed inconsistency in partitioning shapes; } \\
\text { counted by ones when she intended to count by } \\
\text { fives. } \\
\text { Angles }\end{array}$ \\
$\begin{array}{l}\text { Lesson 3: } \\
\text { Money: Equal Amounts }\end{array}$ & $\begin{array}{l}\text { Kefinition of an angle was not clear; does not } \\
\text { connect the idea of polygons and circles. } \\
\text { difference in size and value of penny and dime. }\end{array}$ \\
$\begin{array}{l}\text { Lesson 4: } \\
\text { Money: Amounts Greater Than \$1 }\end{array}$ & $\begin{array}{l}\text { Knowledgeable of content; misused the word "coin" } \\
\text { when the word "penny" was intended. }\end{array}$ \\
$\begin{array}{l}\text { Lesson 5: } \\
\text { SAT Review Lesson }\end{array}$ & $\begin{array}{l}\text { Lesson covered multiple topics; had difficulty with } \\
\text { some topics and decided to allow the CT to explain } \\
\text { at a later time. }\end{array}$ \\
\hline
\end{tabular}




\begin{tabular}{|c|c|c|c|c|c|}
\hline $\begin{array}{l}\text { Description of } \\
\text { Lesson }\end{array}$ & $\begin{array}{l}\text { Understanding } \\
\text { student's } \\
\text { current } \\
\text { understanding }\end{array}$ & $\begin{array}{c}\text { Students } \\
\text { knowing in } \\
\text { one way do } \\
\text { not necessarily } \\
\text { know in the } \\
\text { other(s) }\end{array}$ & $\begin{array}{c}\text { Intuitive } \\
\text { knowledge is } \\
\text { both an asset } \\
\text { and a liability }\end{array}$ & $\begin{array}{c}\text { Certain } \\
\text { instructional } \\
\text { characteristics } \\
\text { appear to } \\
\text { promote } \\
\text { retention }\end{array}$ & $\begin{array}{l}\text { Alternative } \\
\text { representations } \\
\text { and the } \\
\text { recognition } \\
\text { and analysis of } \\
\text { alternative } \\
\text { methods are } \\
\text { important }\end{array}$ \\
\hline $\begin{array}{l}\text { Lesson 1: } \\
\text { Understanding } \\
\text { Fractions: } \\
\text { Whole, Half, } \\
\text { Thirds, and } \\
\text { Fourths }\end{array}$ & $\begin{array}{l}\text { Asked students } \\
\text { to explain } \\
\text { ideas. } \\
\text { Asked students } \\
\text { to verbally } \\
\text { explain ideas } \\
\text { to check for } \\
\text { understanding. } \\
\text { Used } \\
\text { worksheet as } \\
\text { assessment. }\end{array}$ & $\begin{array}{l}\text { No evidence of } \\
\text { conceptual } \\
\text { understanding } \\
\text { observed. }\end{array}$ & Not observed & $\begin{array}{l}\text { Used a } \\
\text { chocolate to } \\
\text { illustrate } \\
\text { fractional } \\
\text { ideas. }\end{array}$ & $\begin{array}{l}\text { 2-dimentional } \\
\text { shapes cut into } \\
\text { fractional parts } \\
\text { used to help } \\
\text { students } \\
\text { visualize } \\
\text { fractions. }\end{array}$ \\
\hline $\begin{array}{l}\text { Lesson 2: } \\
\text { Angles }\end{array}$ & $\begin{array}{l}\text { Asked students } \\
\text { to verbally } \\
\text { explain ideas } \\
\text { to check for } \\
\text { understanding. } \\
\text { Used } \\
\text { worksheet as } \\
\text { assessment. }\end{array}$ & $\begin{array}{l}\text { No evidence of } \\
\text { conceptual } \\
\text { understanding } \\
\text { observed. }\end{array}$ & $\begin{array}{l}\text { Indicated the } \\
\text { possibility of } \\
\text { misconception } \\
\text { s, but did not } \\
\text { address it with } \\
\text { students. }\end{array}$ & $\begin{array}{l}\text { Used real life } \\
\text { classroom } \\
\text { objects to } \\
\text { clarify content. } \\
\text { Used a } \\
\text { literature book. }\end{array}$ & $\begin{array}{l}\text { Pipe Cleaners } \\
\text { as } \\
\text { manipulatives } \\
\text { to illustrate } \\
\text { angles. } \\
\text { Used 3- } \\
\text { dimensional } \\
\text { shapes to } \\
\text { illustrate } \\
\text { angles. This } \\
\text { helped } \\
\text { students to } \\
\text { visualize the } \\
\text { properties of } \\
\text { an angle. }\end{array}$ \\
\hline $\begin{array}{l}\text { Lesson 3: } \\
\text { Money: Equal } \\
\text { Amounts }\end{array}$ & $\begin{array}{l}\text { Allowed } \\
\text { students to } \\
\text { explain } \\
\text { answers to } \\
\text { each other. } \\
\text { Used } \\
\text { worksheet as } \\
\text { assessment. }\end{array}$ & $\begin{array}{l}\text { No evidence of } \\
\text { conceptual } \\
\text { understanding } \\
\text { observed. }\end{array}$ & Not observed & $\begin{array}{l}\text { Used a } \\
\text { literature book. }\end{array}$ & $\begin{array}{l}\text { Fake money } \\
\text { for students to } \\
\text { manipulate. } \\
\text { The money } \\
\text { helped } \\
\text { students count } \\
\text { amounts. }\end{array}$ \\
\hline $\begin{array}{l}\text { Lesson 4: } \\
\text { Money: } \\
\text { Amounts } \\
\text { Greater Than } \\
\text { \$1 }\end{array}$ & $\begin{array}{l}\text { Asked students } \\
\text { to verbally } \\
\text { explain ideas } \\
\text { to check for } \\
\text { understanding. }\end{array}$ & $\begin{array}{l}\text { No evidence of } \\
\text { conceptual } \\
\text { understanding } \\
\text { observed. }\end{array}$ & Not observed & $\begin{array}{l}\text { Introduced the } \\
\text { lesson with a } \\
\text { meaningful } \\
\text { mathematics } \\
\text { task. }\end{array}$ & $\begin{array}{l}\text { Fake money } \\
\text { for students to } \\
\text { manipulate. } \\
\text { She allowed } \\
\text { the students to } \\
\text { use these to } \\
\text { count. }\end{array}$ \\
\hline
\end{tabular}




\begin{tabular}{|c|c|c|c|c|c|}
\hline $\begin{array}{l}\text { Lesson 5: } \\
\text { SAT Review } \\
\text { Lesson }\end{array}$ & $\begin{array}{l}\text { Asked students } \\
\text { to verbally } \\
\text { explain ideas } \\
\text { to check for } \\
\text { understanding. } \\
\text { When students } \\
\text { had difficulty } \\
\text { understanding, } \\
\text { she used } \\
\text { alternative } \\
\text { methods to } \\
\text { explain. }\end{array}$ & $\begin{array}{l}\text { No evidence of } \\
\text { conceptual } \\
\text { understanding } \\
\text { observed. }\end{array}$ & $\begin{array}{l}\text { Not observed, } \\
\text { but discussed } \\
\text { her own } \\
\text { misconception } \\
\text { s in interview } \\
\text { following } \\
\text { lesson. }\end{array}$ & Not observed. & Not observed. \\
\hline
\end{tabular}




\section{Appendix I}

\section{Tables Summarizing Val's Case}

Description of Val's Five Observed Lessons and Summary of her Planning of those Lessons
Description of Lesson
Lesson Planning

\begin{tabular}{|c|c|}
\hline Lesson 1: & $20 \min$ \\
\hline Properties of 3D Shapes & $\begin{array}{l}\text { Resources used: Planned with Grade level teachers, Encore } \\
\text { website for the Brain Pop Video }\end{array}$ \\
\hline Lesson 2: & $20 \min$ \\
\hline Pennies, Nickels, and Dimes & Resources used: Textbook, Practice booklet, and CT \\
\hline Lesson 3: & $15 \mathrm{~min}$ \\
\hline $\begin{array}{l}\text { Money: Counting } \\
\text { Collections }\end{array}$ & Resources used: Textbook, CT, and worksheet. \\
\hline Lesson 4: & $15-20 \mathrm{~min}$ \\
\hline $\begin{array}{l}\text { Money: Combination of } \\
\text { Coins }\end{array}$ & Resources used: Textbook, worksheet, workbook, and CT \\
\hline Lesson 5: & $15 \mathrm{~min}$ \\
\hline Money: Bills $(\$ 1, \$ 5, \$ 10)$ & $\begin{array}{l}\text { Resources used: Teacher Ed. Textbook, CT, and online } \\
\text { search for assessment }\end{array}$ \\
\hline
\end{tabular}

Summary of Val's Mathematics Anxiety over Five Observed Lessons

Description of Lesson Mathematics Anxiety

Lesson 1:

Properties of 3D Shapes

Lesson 2:

Pennies, Nickels, and Dimes

Lesson 3:

Money: Counting

Collections

Lesson 4:

Money: Combination of

Coins

Lesson 5:

Money: Bills $(\$ 1, \$ 5, \$ 10)$
Some anxiety resulting from a lack of practice with the content.

No anxiety reported or observed

No anxiety reported or observed

No anxiety reported or observed

Some anxiety observed by perspiration on her forehead at the end of the lesson when two errors were discovered on the assessment that she created. 
Description of Lesson Description of Content Knowledge

Lesson 1:

Properties of 3D Shapes

Lesson 2:

Pennies, Nickels, and Dimes

Lesson 3:

Money: Counting

Collections

Lesson 4:

Money: Combination of

Coins

Lesson 5:

Money: Bills $(\$ 1, \$ 5, \$ 10)$
Understood the content and enjoyed teaching it.

Indicated that she forgot to review the properties of shapes with students and mentioned that she would do so in the subsequent lessons.

Understood content and explained it well. Upon reflection she thought of having students discuss the differences in the faces of the coins to prevent confusion.

Understood the content, but found the content too easy for students. Upon reflection would have prepared more challenging content. Created an extension to challenge students who were finished early.

Understood the content. She allowed students to explore different possibilities and accepted different answers. She also encouraged students to explain their thinking and helped them to correct their own errors. Was not prepared for all the possible solutions to one problem so had to figure it out with the students.

Understood the content and explained it well. 


\begin{tabular}{|c|c|c|c|c|c|}
\hline $\begin{array}{l}\text { Description of } \\
\text { Lesson }\end{array}$ & $\begin{array}{l}\text { Understanding } \\
\text { student's } \\
\text { current } \\
\text { understanding }\end{array}$ & $\begin{array}{l}\text { Students } \\
\text { knowing in one } \\
\text { way do not } \\
\text { necessarily } \\
\text { know in the } \\
\text { other(s) }\end{array}$ & $\begin{array}{l}\text { Intuitive } \\
\text { knowledge is } \\
\text { both an asset } \\
\text { and a liability }\end{array}$ & $\begin{array}{l}\text { Certain } \\
\text { instructional } \\
\text { characteristics } \\
\text { appear to } \\
\text { promote } \\
\text { retention }\end{array}$ & $\begin{array}{l}\text { Alternative } \\
\text { representations } \\
\text { and the } \\
\text { recognition and } \\
\text { analysis of } \\
\text { alternative } \\
\text { methods are } \\
\text { important }\end{array}$ \\
\hline $\begin{array}{l}\text { Lesson 1: } \\
\text { Properties of } \\
\text { 3D Shapes }\end{array}$ & $\begin{array}{l}\text { Believed } \\
\text { manipulatives } \\
\text { helped to } \\
\text { promote } \\
\text { understanding. } \\
\text { Enjoyed } \\
\text { challenging her } \\
\text { students. } \\
\text { Assessed } \\
\text { student } \\
\text { knowledge with } \\
\text { a quiz. }\end{array}$ & $\begin{array}{l}\text { Connected } \\
\text { concept to } \\
\text { objects in the } \\
\text { classroom. } \\
\text { Upon reflection } \\
\text { she wanted to } \\
\text { use more } \\
\text { connections. } \\
\text { Believed } \\
\text { conceptual } \\
\text { understanding } \\
\text { was important. }\end{array}$ & Not Observed & $\begin{array}{l}\text { Allowed } \\
\text { students to } \\
\text { make } \\
\text { connections to } \\
\text { real life. }\end{array}$ & $\begin{array}{l}\text { Used clear 3-D } \\
\text { geometric } \\
\text { shapes. } \\
\text { Used real-life } \\
\text { objects as } \\
\text { example of 3-D } \\
\text { geometric } \\
\text { shapes. These } \\
\text { helped students } \\
\text { visualize } \\
\text { shapes. } \\
\text { Showed an } \\
\text { online, 'brain } \\
\text { pop' video. } \\
\text { She wanted to } \\
\text { use real life } \\
\text { objects but was } \\
\text { not able to } \\
\text { purchase the } \\
\text { items that she } \\
\text { wanted to use. }\end{array}$ \\
\hline $\begin{array}{l}\text { Lesson 2: } \\
\text { Pennies, } \\
\text { Nickels, and } \\
\text { Dimes }\end{array}$ & $\begin{array}{l}\text { Measured } \\
\text { student } \\
\text { understanding } \\
\text { based on } \\
\text { participation. } \\
\text { Called on a } \\
\text { variety of } \\
\text { students to } \\
\text { participate to } \\
\text { evaluate } \\
\text { understanding } \\
\text { and did not rely } \\
\text { on volunteers. } \\
\text { Circulated room } \\
\text { to check on } \\
\text { student } \\
\text { understanding. }\end{array}$ & $\begin{array}{l}\text { Student solved } \\
\text { problems by } \\
\text { following } \\
\text { procedures. }\end{array}$ & $\begin{array}{l}\text { Cognizant of } \\
\text { ways previous } \\
\text { knowledge } \\
\text { impacts the } \\
\text { introduction of } \\
\text { new content. }\end{array}$ & $\begin{array}{l}\text { Allowed } \\
\text { students to } \\
\text { solve problems } \\
\text { using } \\
\text { manipulatives } \\
\text { as an } \\
\text { assessment } \\
\text { strategy. }\end{array}$ & $\begin{array}{l}\text { Used fake coins } \\
\text { available for } \\
\text { each student. } \\
\text { The coins aided } \\
\text { students in their } \\
\text { understanding } \\
\text { of the content. } \\
\text { Used an } \\
\text { overhead } \\
\text { projector to } \\
\text { display the } \\
\text { coins. } \\
\text { Used pictures } \\
\text { of coins. Upon } \\
\text { reflection she } \\
\text { thought of } \\
\text { showing coins } \\
\text { on the Smart } \\
\text { Board to } \\
\text { enhance } \\
\text { understanding. }\end{array}$ \\
\hline
\end{tabular}




\begin{tabular}{|c|c|c|c|c|c|}
\hline $\begin{array}{l}\text { Lesson 3: } \\
\text { Money: } \\
\text { Counting } \\
\text { Collections }\end{array}$ & $\begin{array}{l}\text { Used informal } \\
\text { assessment and } \\
\text { a worksheet. } \\
\text { Believed that } \\
\text { students } \\
\text { understood the } \\
\text { content so well } \\
\text { that they } \\
\text { worked ahead } \\
\text { and "tuned her } \\
\text { out". } \\
\text { Preferred to } \\
\text { challenge } \\
\text { students. }\end{array}$ & $\begin{array}{l}\text { Student solved } \\
\text { problems by } \\
\text { following } \\
\text { procedures. }\end{array}$ & $\begin{array}{l}\text { Not directly } \\
\text { observed. }\end{array}$ & $\begin{array}{l}\text { Thought of } \\
\text { using group } \\
\text { work during the } \\
\text { lesson, but } \\
\text { decided that she } \\
\text { wanted students } \\
\text { to practice the } \\
\text { skill } \\
\text { individually. }\end{array}$ & $\begin{array}{l}\text { Used fake coins } \\
\text { available to all } \\
\text { students. The } \\
\text { coins helped } \\
\text { students as they } \\
\text { learned to } \\
\text { count. } \\
\text { Wanted to use } \\
\text { Think Central } \\
\text { to project the } \\
\text { textbook, but } \\
\text { had technical } \\
\text { difficulties. } \\
\text { Drew coins to } \\
\text { correctly } \\
\text { represent } \\
\text { proportion. }\end{array}$ \\
\hline $\begin{array}{l}\text { Lesson 4: } \\
\text { Money: } \\
\text { Combination of } \\
\text { Coins }\end{array}$ & $\begin{array}{l}\text { Provided one- } \\
\text { on-one } \\
\text { instruction to a } \\
\text { struggling } \\
\text { student. } \\
\text { Used a quiz as } \\
\text { an assessment } \\
\text { and gave } \\
\text { immediate } \\
\text { feedback as she } \\
\text { walked around } \\
\text { to check the } \\
\text { answers to the } \\
\text { quiz. }\end{array}$ & $\begin{array}{l}\text { Began class } \\
\text { with a problem } \\
\text { that would } \\
\text { result in } \\
\text { multiple } \\
\text { solutions. } \\
\text { Connected } \\
\text { concept to real } \\
\text { life. }\end{array}$ & $\begin{array}{l}\text { Allowed } \\
\text { students to } \\
\text { realize and } \\
\text { correct their } \\
\text { own errors. } \\
\text { Introduced half- } \\
\text { dollar amount } \\
\text { even though } \\
\text { students were } \\
\text { not familiar } \\
\text { with it. }\end{array}$ & $\begin{array}{l}\text { Made only one } \\
\text { connection of } \\
\text { the concept to } \\
\text { the practicality } \\
\text { of real-life. } \\
\text { Upon } \\
\text { reflection, she } \\
\text { thought she } \\
\text { should have } \\
\text { incorporated } \\
\text { group work to } \\
\text { enhance the } \\
\text { lesson. }\end{array}$ & $\begin{array}{l}\text { Used fake coins } \\
\text { available to all } \\
\text { students. The } \\
\text { coins were used } \\
\text { effectively. } \\
\text { Displayed coins } \\
\text { on an overhead } \\
\text { projector. }\end{array}$ \\
\hline $\begin{array}{l}\text { Lesson 5: } \\
\text { Money: Bills } \\
(\$ 1, \$ 5, \$ 10)\end{array}$ & $\begin{array}{l}\text { Used a quiz as } \\
\text { assessment of } \\
\text { the lesson; } \\
\text { however, she } \\
\text { indicated that } \\
\text { an item on the } \\
\text { quiz caused } \\
\text { confusion since } \\
\text { she did not } \\
\text { review the } \\
\text { content for that } \\
\text { item. She } \\
\text { individually } \\
\text { helped students } \\
\text { on that item and } \\
\text { decided not to } \\
\text { count that item } \\
\text { as a part of the } \\
\text { grade. }\end{array}$ & $\begin{array}{l}\text { Student solved } \\
\text { problems by } \\
\text { following } \\
\text { procedures. }\end{array}$ & $\begin{array}{l}\text { On the quiz, she } \\
\text { assessed a } \\
\text { concept that } \\
\text { was not } \\
\text { emphasized } \\
\text { during the } \\
\text { lesson, and she } \\
\text { was } \\
\text { immediately } \\
\text { aware of her } \\
\text { error as } \\
\text { students were } \\
\text { working. }\end{array}$ & $\begin{array}{l}\text { Offered } \\
\text { students a } \\
\text { procedure to } \\
\text { follow to solve } \\
\text { problems. } \\
\text { Upon reflection } \\
\text { she thought } \\
\text { group work and } \\
\text { problem solving } \\
\text { could have } \\
\text { enhanced the } \\
\text { lesson. }\end{array}$ & $\begin{array}{l}\text { Displayed } \\
\text { posters of dollar } \\
\text { bills, and upon } \\
\text { reflection } \\
\text { would have } \\
\text { wanted to make } \\
\text { fake dollar bills } \\
\text { accessible to } \\
\text { students to } \\
\text { manipulate. }\end{array}$ \\
\hline
\end{tabular}




\section{Appendix $\mathbf{J}$}

\section{Tables Summarizing Gigi’s Case}

Description of Gigi's Five Observed Lessons and Summary of her Planning of those Lessons

Description of Lesson $\quad$ Lesson Planning

\begin{tabular}{|c|c|}
\hline Lesson 1: & $15-20 \min$ \\
\hline Using the Area Formula & Resources used: Textbook and CT \\
\hline Lesson 2: & $15-20 \mathrm{~min}$ \\
\hline Area of Irregular Shapes & Resources used: Textbook, electronic textbook, and CT \\
\hline Lesson 3: & $10-15 \min$ \\
\hline Rotation: & Resources used: Textbook, CT for an idea, and looked for a \\
\hline Clockwise/Counterclockwise & video but could not find one. \\
\hline Lesson 4: & $10 \mathrm{~min}$ \\
\hline Geometric Patterns & Resources used: Textbook \\
\hline Lesson 5: & $30 \mathrm{~min}$ \\
\hline Tessellations & $\begin{array}{l}\text { Resources used: Textbook, Internet research, briefly told } \\
\text { CT the intended lesson plan. }\end{array}$ \\
\hline
\end{tabular}

\section{Summary of Gigi's Mathematics Anxiety over Five Observed Lessons}

Description of Lesson Mathematics Anxiety

$\begin{array}{ll}\begin{array}{l}\text { Lesson 1: } \\ \text { Using the Area Formula }\end{array} & \begin{array}{l}\text { Some anxiety toward the teaching of mathematics when } \\ \text { students asked about the change in units from feet to feet } \\ \text { squared. } \\ \text { Some anxiety toward the teaching of mathematics when }\end{array} \\ \begin{array}{l}\text { Area of Irregular Shapes } \\ \text { students had difficulty with content. }\end{array} \\ \begin{array}{l}\text { Lesson 3: } \\ \text { Rotation: } \\ \begin{array}{l}\text { Clockwise/Counterclockwise } \\ \text { Gesson 4: }\end{array}\end{array} & \text { No anxiety reported or observed } \\ \begin{array}{l}\text { Lesson 5: } \\ \text { Tessellations }\end{array} & \text { No anxiety reported or observed }\end{array}$


Description of Lesson

Lesson 1:
Using the Area Formula
Lesson 2:
Area of Irregular Shapes
Lesson 3:
Rotation:
Clockwise/Counterclockwise
Lesson 4:
Geometric Patterns

Lesson 5:

Tessellations
Description of Content Knowledge

Understood content and clearly presented the content to students.

Was able to explain the idea of change in units when a student posed this challenging question.

Understood the content and presented it clearly using mathematical language.

Understood the content and presented it clearly to students using the clock as previous knowledge to connect to the content of the lesson.

Understood contend and presented it clearly. Required students to use their previous knowledge to create new shapes.

Understood content and clearly presented content. Used real-life examples to connect ideas of the lesson. 


\begin{tabular}{|c|c|c|c|c|c|}
\hline $\begin{array}{l}\text { Description of } \\
\text { Lesson }\end{array}$ & $\begin{array}{l}\text { Understanding } \\
\text { student's current } \\
\text { understanding }\end{array}$ & $\begin{array}{l}\text { Students } \\
\text { knowing in one } \\
\text { way do not } \\
\text { necessarily know } \\
\text { in the other(s) }\end{array}$ & $\begin{array}{l}\text { Intuitive } \\
\text { knowledge is } \\
\text { both an asset and } \\
\text { a liability }\end{array}$ & $\begin{array}{l}\text { Certain } \\
\text { instructional } \\
\text { characteristics } \\
\text { appear to } \\
\text { promote } \\
\text { retention }\end{array}$ & $\begin{array}{l}\text { Alternative } \\
\text { representations } \\
\text { and the } \\
\text { recognition and } \\
\text { analysis of } \\
\text { alternative } \\
\text { methods are } \\
\text { important }\end{array}$ \\
\hline $\begin{array}{l}\text { Lesson 1: } \\
\text { Using the Area } \\
\text { Formula }\end{array}$ & $\begin{array}{l}\text { Adjusted } \\
\text { content to } \\
\text { enhance student } \\
\text { understanding. } \\
\text { Circulated } \\
\text { classroom to } \\
\text { check for } \\
\text { understanding } \\
\text { while students } \\
\text { worked on } \\
\text { problems. }\end{array}$ & $\begin{array}{l}\text { Helped students } \\
\text { visualize the } \\
\text { content by using } \\
\text { a real-life } \\
\text { example. } \\
\text { Reflected on the } \\
\text { use of the } \\
\text { textbook and } \\
\text { concluded that } \\
\text { the use of other } \\
\text { examples may } \\
\text { have helped } \\
\text { students } \\
\text { understand } \\
\text { content more } \\
\text { clearly. }\end{array}$ & $\begin{array}{l}\text { Identified } \\
\text { possible } \\
\text { misconception } \\
\text { before the } \\
\text { lesson and } \\
\text { attempted to } \\
\text { correct it with } \\
\text { her own } \\
\text { examples. }\end{array}$ & $\begin{array}{l}\text { Allowed } \\
\text { students to } \\
\text { solve open- } \\
\text { ended word } \\
\text { problems and } \\
\text { explain their } \\
\text { ideas. } \\
\text { Upon reflection } \\
\text { thought of using } \\
\text { real-life } \\
\text { examples to } \\
\text { enhance } \\
\text { understanding. }\end{array}$ & $\begin{array}{l}\text { Teacher used } \\
\text { grid paper but } \\
\text { the students did } \\
\text { not. } \\
\text { She did try to } \\
\text { help students } \\
\text { understand } \\
\text { using the } \\
\text { manipulative, It } \\
\text { would have } \\
\text { been effective if } \\
\text { all students } \\
\text { were } \\
\text { committed. }\end{array}$ \\
\hline $\begin{array}{l}\text { Lesson 2: } \\
\text { Area of } \\
\text { Irregular Shapes }\end{array}$ & $\begin{array}{l}\text { Allowed } \\
\text { students to work } \\
\text { problems on the } \\
\text { board to check } \\
\text { for } \\
\text { understanding. } \\
\text { Circulated } \\
\text { classroom while } \\
\text { students worked } \\
\text { independently. }\end{array}$ & $\begin{array}{l}\text { Used grid paper } \\
\text { to show } \\
\text { examples to the } \\
\text { class, but did } \\
\text { not allow } \\
\text { students to work } \\
\text { with grid paper. } \\
\text { Focused on } \\
\text { having students } \\
\text { use procedures } \\
\text { to solve } \\
\text { problems. }\end{array}$ & $\begin{array}{l}\text { Identified two } \\
\text { areas of concern } \\
\text { that might cause } \\
\text { students to } \\
\text { incorrectly } \\
\text { solve problems } \\
\text { and addressed } \\
\text { those areas with } \\
\text { students to help } \\
\text { them correctly } \\
\text { calculate areas } \\
\text { of irregular } \\
\text { shapes. }\end{array}$ & $\begin{array}{l}\text { Allowed } \\
\text { students to } \\
\text { individually } \\
\text { solve problems. } \\
\text { Upon reflection } \\
\text { she thought of } \\
\text { using a real life } \\
\text { example as a } \\
\text { visual to aid in } \\
\text { understanding. }\end{array}$ & $\begin{array}{l}\text { Used the } \\
\text { electronic } \\
\text { version of the } \\
\text { textbook. } \\
\text { Drew on the } \\
\text { projected image } \\
\text { for the students. }\end{array}$ \\
\hline $\begin{array}{l}\text { Lesson 3: } \\
\text { Rotation: } \\
\text { Clockwise/Cou } \\
\text { nterclockwise }\end{array}$ & $\begin{array}{l}\text { Encouraged and } \\
\text { enjoyed } \\
\text { answering } \\
\text { questions posed } \\
\text { by students to } \\
\text { enhance their } \\
\text { understanding. }\end{array}$ & $\begin{array}{l}\text { Used a spinner } \\
\text { to help students } \\
\text { visualize the } \\
\text { four quadrants } \\
\text { when discussing } \\
\text { the content. } \\
\text { Gave open- } \\
\text { ended questions } \\
\text { and allowed } \\
\text { students to } \\
\text { investigate. }\end{array}$ & $\begin{array}{l}\text { Took additional } \\
\text { time in the } \\
\text { lesson to clarify } \\
\text { a topic for } \\
\text { students to } \\
\text { prevent any } \\
\text { misunderstandin } \\
\text { g and to ensure } \\
\text { that all students } \\
\text { could visualize } \\
\text { the concept. }\end{array}$ & $\begin{array}{l}\text { Enjoyed } \\
\text { discussion, } \\
\text { justification and } \\
\text { reflection on } \\
\text { content. } \\
\text { Saw the need to } \\
\text { activate prior } \\
\text { knowledge to } \\
\text { connect to new } \\
\text { ideas in the } \\
\text { lesson. }\end{array}$ & $\begin{array}{l}\text { Spinner with } \\
\text { four quadrants } \\
\text { available for } \\
\text { each student. } \\
\text { This } \\
\text { manipulative } \\
\text { was used } \\
\text { effectively. }\end{array}$ \\
\hline
\end{tabular}




\begin{tabular}{|c|c|c|c|c|c|}
\hline $\begin{array}{l}\text { Lesson 4: } \\
\text { Geometric } \\
\text { Patterns }\end{array}$ & $\begin{array}{l}\text { Circulated the } \\
\text { room as } \\
\text { students worked } \\
\text { on problems. } \\
\text { Asked students } \\
\text { to explain their } \\
\text { thinking to } \\
\text { check for } \\
\text { understanding. }\end{array}$ & $\begin{array}{l}\text { Allowed } \\
\text { students to work } \\
\text { on open-ended } \\
\text { task and had } \\
\text { students create } \\
\text { knew patterns } \\
\text { using their } \\
\text { previous } \\
\text { knowledge. } \\
\text { Asked students } \\
\text { to explain their } \\
\text { work. }\end{array}$ & $\begin{array}{l}\text { Made } \\
\text { clarifications to } \\
\text { students before } \\
\text { allowing them } \\
\text { to solve } \\
\text { problems to } \\
\text { avoid } \\
\text { misunderstandin } \\
\text { g. } \\
\text { Upon reflection, } \\
\text { decided it } \\
\text { would have } \\
\text { been best to } \\
\text { create own } \\
\text { examples in } \\
\text { addition to } \\
\text { those in } \\
\text { textbook to help } \\
\text { students } \\
\text { understand } \\
\text { concept. }\end{array}$ & None observed. & $\begin{array}{l}\text { Teacher used an } \\
\text { orange right } \\
\text { triangle to } \\
\text { illustrate an } \\
\text { example. Not } \\
\text { available for all } \\
\text { students. It was } \\
\text { not effective to } \\
\text { only have } \\
\text { students } \\
\text { observe. } \\
\text { Upon reflection, } \\
\text { she would have } \\
\text { used a grid with } \\
\text { students. } \\
\text { Students } \\
\text { worked in } \\
\text { groups. }\end{array}$ \\
\hline $\begin{array}{l}\text { Lesson 5: } \\
\text { Tessellations }\end{array}$ & $\begin{array}{l}\text { Felt students } \\
\text { understood } \\
\text { content, but } \\
\text { indicated she } \\
\text { needed to } \\
\text { reteach with } \\
\text { new methods } \\
\text { after assessing } \\
\text { the questions as } \\
\text { students worked } \\
\text { on individual } \\
\text { problems. }\end{array}$ & $\begin{array}{l}\text { Allowed } \\
\text { students to } \\
\text { visualize the } \\
\text { content by } \\
\text { having them } \\
\text { manipulate } \\
\text { shapes to create } \\
\text { tessellations, } \\
\text { but never } \\
\text { allowed } \\
\text { students to see } \\
\text { non-examples } \\
\text { of shapes that } \\
\text { are not able to } \\
\text { tessellate. She } \\
\text { reflected on this } \\
\text { problem and } \\
\text { thought of } \\
\text { possible } \\
\text { solutions. }\end{array}$ & $\begin{array}{l}\text { Upon reflection } \\
\text { noticed that a } \\
\text { possible } \\
\text { misconception } \\
\text { might have } \\
\text { occurred } \\
\text { because of the } \\
\text { manipulatives } \\
\text { that she chose } \\
\text { to use. Decided } \\
\text { to address this } \\
\text { idea in the } \\
\text { subsequent } \\
\text { lesson. }\end{array}$ & $\begin{array}{l}\text { Upon reflection } \\
\text { she would have } \\
\text { made changes } \\
\text { to increase } \\
\text { student } \\
\text { retention. }\end{array}$ & $\begin{array}{l}\text { Introduced the } \\
\text { lesson with real- } \\
\text { life examples. } \\
\text { Used pattern } \\
\text { blocks } \\
\text { accessible to all } \\
\text { students. The } \\
\text { pattern blocks } \\
\text { were used to } \\
\text { promote } \\
\text { understanding. }\end{array}$ \\
\hline
\end{tabular}




\section{Appendix K}

\section{Tables Summarizing Yoli’s Case}

Description of Yoli's Five Observed Lessons and Summary of her Planning of those Lessons

Description of Lesson Lesson Planning

\begin{tabular}{|c|c|}
\hline $\begin{array}{l}\text { Lesson 1: } \\
\text { Using two Geometric } \\
\text { Shapes to form a New } \\
\text { Geometric Shape }\end{array}$ & $\begin{array}{l}30 \text { minutes } \\
\text { Textbook, Cooperating Teacher's lesson plans, the } \\
\text { guide and Online edition of textbook on Think Cer }\end{array}$ \\
\hline $\begin{array}{l}\text { Lesson 2: } \\
\text { Drawing shapes over lines } \\
\text { of Symmetry }\end{array}$ & $\begin{array}{l}\text { 20-30 minutes } \\
\text { Cooperating Teacher lesson plan } \\
\text { Textbook. }\end{array}$ \\
\hline $\begin{array}{l}\text { Lesson 3: } \\
\text { Telling Time }\end{array}$ & $\begin{array}{l}120 \text { minutes } \\
\text { Cooperating teacher lesson plans } \\
\text { Cooperating teacher suggestions } \\
\text { Teacher Guide of textbook } \\
\text { Online Edition of the Textbook on think Central } \\
30-45 \text { minutes } \\
\text { Cooperating Teacher's Lesson Plan } \\
\text { Teacher's Edition of textbook } \\
\text { Online resources of textbook on Think Central }\end{array}$ \\
\hline $\begin{array}{l}\text { Lesson 5: } \\
\text { Elapsed Time }\end{array}$ & $\begin{array}{l}30 \text { minutes } \\
\text { Cooperating Teacher's Lesson Plan } \\
\text { Teacher Guide of textbook } \\
\text { Online Edition of the Textbook on Think Central }\end{array}$ \\
\hline
\end{tabular}


Description of Lesson Mathematics Anxiety

\begin{tabular}{|c|c|}
\hline $\begin{array}{l}\text { Lesson 1: } \\
\text { Using two Geometric } \\
\text { Shapes to form a New } \\
\text { Geometric Shape }\end{array}$ & No reported or observed mathematics anxiety. \\
\hline Lesson 2: & No reported or observed mathematics anxiety. \\
\hline $\begin{array}{l}\text { Drawing shapes over lines } \\
\text { of Symmetry }\end{array}$ & $\begin{array}{l}\text { Indicated some anxiety toward teaching when students did } \\
\text { not understand content. }\end{array}$ \\
\hline $\begin{array}{l}\text { Lesson 3: } \\
\text { Telling Time }\end{array}$ & No reported or observed mathematics anxiety. \\
\hline $\begin{array}{l}\text { Lesson 4: } \\
\text { AM vs PM }\end{array}$ & No reported or observed mathematics anxiety. \\
\hline $\begin{array}{l}\text { Lesson 5: } \\
\text { Elapsed Time }\end{array}$ & No reported or observed mathematics anxiety. \\
\hline
\end{tabular}

Summary of Yoli's Content Knowledge over Five Observed Lessons

Description of Lesson Description of Content Knowledge

\begin{tabular}{ll}
\hline $\begin{array}{l}\text { Lesson 1: Using two } \\
\text { Geometric Shapes to form a } \\
\text { New Geometric Shape }\end{array}$ & $\begin{array}{l}\text { Comfortable with content. Presented content, but did not } \\
\text { deeply analyze content with students. } \\
\text { She was willing to skip content in the lesson. }\end{array}$ \\
$\begin{array}{l}\text { Lesson 2: } \\
\text { Drawing shapes over lines } \\
\text { of Symmetry }\end{array}$ & $\begin{array}{l}\text { Considered content easy. There was an error in her } \\
\text { understanding of the content and she presented this error: } \\
\text { All triangles have three lines of symmetry. } \\
\text { Discussed symmetry with only rectangular objects, but } \\
\text { asked students to show symmetry in other objects as well. } \\
\text { Comfortable with the content. } \\
\text { Only revealed correct answers to students without } \\
\text { discussing understanding of content. }\end{array}$ \\
Lesson 3: Telling Time & $\begin{array}{l}\text { Confident with knowledge of the content. She thought the } \\
\text { content was easy. Had some issues with explaining the } \\
\text { difference between 12am and 12pm to the students. }\end{array}$ \\
Lesson 4:AM vs PM & $\begin{array}{l}\text { Understood the content, but faced challenges presenting } \\
\text { content to students. Made a few mistakes when solving } \\
\text { problems with students, but became aware of and corrected } \\
\text { her errors. }\end{array}$
\end{tabular}




\begin{tabular}{cccccc} 
Summary of Yoli's Pedagogical Content Knowledge over Five Observed Lessons \\
\hline $\begin{array}{c}\text { Description of } \\
\text { Lesson }\end{array}$ & $\begin{array}{c}\text { Understanding } \\
\text { student's current } \\
\text { understanding }\end{array}$ & $\begin{array}{c}\text { Students } \\
\text { knowing in one } \\
\text { way do not } \\
\text { necessarily know } \\
\text { in the other(s) }\end{array}$ & $\begin{array}{c}\text { Intuitive } \\
\text { knowledge is } \\
\text { both an asset and } \\
\text { a liability }\end{array}$ & $\begin{array}{c}\text { Certain } \\
\text { instructional } \\
\text { characteristics } \\
\text { appear to } \\
\text { promote } \\
\text { retention }\end{array}$ & $\begin{array}{c}\text { Alternative } \\
\text { representations } \\
\text { and the } \\
\text { recognition and } \\
\text { analysis of } \\
\text { alternative } \\
\text { methods are } \\
\text { important }\end{array}$
\end{tabular}

\begin{tabular}{|c|c|c|c|c|c|}
\hline $\begin{array}{l}\text { Lesson 1: } \\
\text { Using two } \\
\text { Geometric } \\
\text { Shapes to form a } \\
\text { New Geometric } \\
\text { Shape }\end{array}$ & $\begin{array}{l}\text { Did not ask for } \\
\text { justification of } \\
\text { problems to } \\
\text { show student } \\
\text { understanding. } \\
\text { Was aware of the } \\
\text { importance of } \\
\text { student } \\
\text { understanding. }\end{array}$ & $\begin{array}{l}\text { Not observed. } \\
\text { Used traditional } \\
\text { methods of } \\
\text { teaching which } \\
\text { emphasized } \\
\text { procedures. }\end{array}$ & $\begin{array}{l}\text { Identified } \\
\text { possible } \\
\text { misconception of } \\
\text { students, they } \\
\text { thought a } \\
\text { heptagon had } \\
\text { only one shape. } \\
\text { She tried to } \\
\text { correct this } \\
\text { misconception } \\
\text { during the } \\
\text { lesson. }\end{array}$ & $\begin{array}{l}\text { Used traditional } \\
\text { methods to } \\
\text { promote } \\
\text { retention. } \\
\text { Allowed students } \\
\text { to work in pairs } \\
\text { in order to share } \\
\text { manipulatives. }\end{array}$ & $\begin{array}{l}\text { Geometric } \\
\text { Shapes } \\
\text { (Tangrams) that } \\
\text { students shared } \\
\text { in pairs. } \\
\text { Did not plan on } \\
\text { using these until } \\
\text { CT told her they } \\
\text { were available } \\
\text { during the } \\
\text { lesson. } \\
\text { Did not fully } \\
\text { think of how the } \\
\text { manipulatives } \\
\text { could be used to } \\
\text { promote } \\
\text { understanding. }\end{array}$ \\
\hline $\begin{array}{l}\text { Lesson } 2 \text { : } \\
\text { Drawing shapes } \\
\text { over lines of } \\
\text { Symmetry }\end{array}$ & $\begin{array}{l}\text { Disappointed in } \\
\text { the level of } \\
\text { student } \\
\text { understanding. } \\
\text { Encouraged } \\
\text { students to figure } \\
\text { out answers on } \\
\text { their own and } \\
\text { correct their own } \\
\text { errors. }\end{array}$ & $\begin{array}{l}\text { Not observed. } \\
\text { Used traditional } \\
\text { methods of } \\
\text { teaching which } \\
\text { emphasized } \\
\text { procedures. }\end{array}$ & Not observed. & $\begin{array}{l}\text { Used traditional } \\
\text { methods. } \\
\text { Allowed students } \\
\text { to work } \\
\text { independently. } \\
\text { Allowed some } \\
\text { students to } \\
\text { interact with the } \\
\text { Smart Board and } \\
\text { share their ideas. }\end{array}$ & $\begin{array}{l}\text { Tried to use } \\
\text { Smart Board, but } \\
\text { it was not } \\
\text { calibrated. } \\
\text { Upon reflection, } \\
\text { thought a } \\
\text { tangible } \\
\text { manipulative } \\
\text { would have been } \\
\text { useful. }\end{array}$ \\
\hline
\end{tabular}




\begin{tabular}{|c|c|c|c|c|c|}
\hline $\begin{array}{l}\text { Lesson 4: } \\
\text { AM vs PM }\end{array}$ & $\begin{array}{l}\text { Enjoyed when } \\
\text { students were } \\
\text { enthusiastic } \\
\text { about } \\
\text { understanding. } \\
\text { Identified areas } \\
\text { of difficulty for } \\
\text { students to } \\
\text { understand. }\end{array}$ & $\begin{array}{l}\text { Not observed. } \\
\text { Used traditional } \\
\text { methods of } \\
\text { teaching which } \\
\text { emphasized } \\
\text { procedures. }\end{array}$ & $\begin{array}{l}\text { Offered different } \\
\text { explanations of } \\
\text { the same concept } \\
\text { which confused } \\
\text { students. Tried to } \\
\text { correct this to } \\
\text { avoid a } \\
\text { misconception } \\
\text { but was not } \\
\text { successful during } \\
\text { the lesson. }\end{array}$ & $\begin{array}{l}\text { Used traditional } \\
\text { methods of } \\
\text { teaching. } \\
\text { Called on } \\
\text { individual } \\
\text { students to say } \\
\text { answers. }\end{array}$ & $\begin{array}{l}\text { Equipped with } \\
\text { individual clocks } \\
\text { but a majority of } \\
\text { the students did } \\
\text { not use them. } \\
\text { Students were } \\
\text { not required to } \\
\text { explain their } \\
\text { understanding } \\
\text { with the clocks. } \\
\text { The clocks were } \\
\text { not used } \\
\text { effectively. } \\
\text { Drew a Clock on } \\
\text { the Board to } \\
\text { illustrate the } \\
\text { concept of a } \\
\text { quarter hour. }\end{array}$ \\
\hline $\begin{array}{l}\text { Lesson 5: } \\
\text { Elapsed Time }\end{array}$ & $\begin{array}{l}\text { Was aware of } \\
\text { students' lack of } \\
\text { understanding of } \\
\text { the content. }\end{array}$ & $\begin{array}{l}\text { Not observed. } \\
\text { Used traditional } \\
\text { methods of } \\
\text { teaching which } \\
\text { emphasized } \\
\text { procedures. }\end{array}$ & $\begin{array}{l}\text { Wrote } 5: 15 \text { to } \\
\text { symbolize } 5 \\
\text { hours and } 15 \\
\text { minutes. Did not } \\
\text { know that this } \\
\text { might confuse } \\
\text { students and did } \\
\text { not address this } \\
\text { during the } \\
\text { lesson. }\end{array}$ & $\begin{array}{l}\text { Allowed students } \\
\text { to share some } \\
\text { ideas on } \\
\text { solutions to a } \\
\text { problem, but } \\
\text { emphasized the } \\
\text { use of a } \\
\text { procedure to } \\
\text { solve problems. }\end{array}$ & $\begin{array}{l}\text { Equipped with } \\
\text { Individual } \\
\text { Clocks } \\
\text { Upon reflection } \\
\text { thought students } \\
\text { should have used } \\
\text { two clocks at a } \\
\text { time. She said } \\
\text { she would have } \\
\text { displayed two } \\
\text { clocks on the } \\
\text { board to } \\
\text { illustrate the } \\
\text { idea. } \\
\text { The single clock } \\
\text { was not used } \\
\text { effectively to } \\
\text { promote } \\
\text { understanding of } \\
\text { the content. }\end{array}$ \\
\hline
\end{tabular}




\section{Appendix L}

\section{Table Summarizing the Pedagogical Content Knowledge of All Participants in the Study}

\begin{tabular}{|c|c|c|c|c|c|c|}
\hline $\begin{array}{l}\text { Mathematics } \\
\text { Anxiety Level }\end{array}$ & Student Teacher & $\begin{array}{l}\text { Big Idea } 1 \\
\text { Understanding } \\
\text { students' current } \\
\text { understanding is } \\
\text { important }\end{array}$ & $\begin{array}{l}\text { Big Idea } 2 \\
\text { Students } \\
\text { knowing in one } \\
\text { way do not } \\
\text { necessarily } \\
\text { know in other(s) }\end{array}$ & $\begin{array}{l}\text { Big Idea } 3 \\
\text { Intuitive } \\
\text { knowledge is } \\
\text { both an asset } \\
\text { and a liability }\end{array}$ & $\begin{array}{l}\text { Big Idea } 4 \\
\text { Certain } \\
\text { instructional } \\
\text { characteristics } \\
\text { appear to } \\
\text { promote } \\
\text { retention }\end{array}$ & $\begin{array}{l}\text { Big Idea } 5 \\
\text { Alternative } \\
\text { representations } \\
\text { and the } \\
\text { recognition and } \\
\text { analysis of } \\
\text { alternative } \\
\text { methods are } \\
\text { important }\end{array}$ \\
\hline \multirow[t]{2}{*}{ High Anxiety } & Ally & $\begin{array}{l}\text { Assessed } \\
\text { students' } \\
\text { thinking in } \\
\text { traditional ways. } \\
\text { Rarely } \\
\text { supported } \\
\text { students' } \\
\text { reasoning. }\end{array}$ & $\begin{array}{l}\text { Showed some } \\
\text { evidence of } \\
\text { providing } \\
\text { procedural } \\
\text { understanding } \\
\text { for students. } \\
\text { Showed no } \\
\text { evidence of } \\
\text { providing } \\
\text { conceptual } \\
\text { understanding } \\
\text { for students. }\end{array}$ & $\begin{array}{l}\text { Was } \\
\text { occasionally } \\
\text { aware of student } \\
\text { misconceptions } \\
\text { but thought it } \\
\text { was a careless } \\
\text { error. On one } \\
\text { occasion may } \\
\text { have contributed } \\
\text { to cause a } \\
\text { possible } \\
\text { misconception } \\
\text { for students. }\end{array}$ & $\begin{array}{l}\text { Used mostly } \\
\text { direct } \\
\text { instruction to } \\
\text { teach lessons. } \\
\text { Used very few } \\
\text { strategies to } \\
\text { promote } \\
\text { retention. }\end{array}$ & $\begin{array}{l}\text { Used } \\
\text { manipulative in } \\
3 \text { of } 5 \text { observed } \\
\text { lessons, but } \\
\text { manipulatives } \\
\text { were not used } \\
\text { effectively. Did } \\
\text { accept and } \\
\text { discuss some } \\
\text { alternative } \\
\text { solutions to } \\
\text { problems. Did } \\
\text { not examine } \\
\text { different ideas } \\
\text { to similar } \\
\text { mathematical } \\
\text { experiences. }\end{array}$ \\
\hline & Belinda & $\begin{array}{l}\text { Used traditional } \\
\text { methods of } \\
\text { assessment and } \\
\text { supported } \\
\text { students' } \\
\text { reasoning by } \\
\text { asking them to } \\
\text { explain their } \\
\text { ideas both to } \\
\text { each other and } \\
\text { to the whole } \\
\text { class. }\end{array}$ & $\begin{array}{l}\text { Showed some } \\
\text { evidence of } \\
\text { providing } \\
\text { procedural } \\
\text { understanding } \\
\text { for students. } \\
\text { Showed no } \\
\text { evidence of } \\
\text { providing } \\
\text { conceptual } \\
\text { understanding } \\
\text { for students. }\end{array}$ & $\begin{array}{l}\text { Was once aware } \\
\text { of possible } \\
\text { students' } \\
\text { misconceptions } \\
\text { but did not } \\
\text { address them. } \\
\text { Was also aware } \\
\text { of her own } \\
\text { misconception } \\
\text { in an } \\
\text { observation } \\
\text { interview. } \\
\text { May have } \\
\text { contributed to } \\
\text { misconceptions. }\end{array}$ & $\begin{array}{l}\text { Used direct } \\
\text { instruction to } \\
\text { teach lessons. } \\
\text { Also used some } \\
\text { strategies to } \\
\text { promote } \\
\text { retention such } \\
\text { as making } \\
\text { connections to } \\
\text { real life, and } \\
\text { connecting } \\
\text { mathematics to } \\
\text { literature. }\end{array}$ & $\begin{array}{l}\text { Used } \\
\text { manipulative in } \\
4 \text { of } 5 \text { observed } \\
\text { lessons, but did } \\
\text { not use } \\
\text { manipulative } \\
\text { effectively in all } \\
\text { lessons. Did } \\
\text { accept some } \\
\text { alternative } \\
\text { solutions to } \\
\text { problems. Did } \\
\text { not examine } \\
\text { different ideas } \\
\text { to similar } \\
\text { mathematical } \\
\text { experiences. }\end{array}$ \\
\hline
\end{tabular}




\begin{tabular}{|c|c|c|c|c|c|c|}
\hline & Nancy & $\begin{array}{l}\text { Rarely assessed } \\
\text { students' } \\
\text { understanding. } \\
\text { She told } \\
\text { students the } \\
\text { right answer to } \\
\text { fill in their } \\
\text { workbook. } \\
\text { Rarely } \\
\text { supported } \\
\text { students' } \\
\text { reasoning. }\end{array}$ & $\begin{array}{l}\text { Showed some } \\
\text { evidence of } \\
\text { providing } \\
\text { procedural } \\
\text { understanding } \\
\text { for students; } \\
\text { used teacher- } \\
\text { directed } \\
\text { instruction. } \\
\text { Showed no } \\
\text { evidence of } \\
\text { providing } \\
\text { conceptual } \\
\text { understanding } \\
\text { for students. }\end{array}$ & $\begin{array}{l}\text { Was not aware } \\
\text { of students' } \\
\text { misconceptions } \\
\text { nor of their } \\
\text { preconceptions. } \\
\text { On one occasion } \\
\text { may have } \\
\text { contributed to } \\
\text { cause a possible } \\
\text { misconception } \\
\text { for students. }\end{array}$ & $\begin{array}{l}\text { Used mostly } \\
\text { direct } \\
\text { instruction to } \\
\text { teach lessons. } \\
\text { Used few } \\
\text { strategies to } \\
\text { promote } \\
\text { retention such } \\
\text { as acting out } \\
\text { scenarios, using } \\
\text { songs, and tried } \\
\text { group work. }\end{array}$ & $\begin{array}{l}\text { Used } \\
\text { manipulative in } \\
2 \text { of } 5 \text { observed } \\
\text { lessons. The } \\
\text { manipulatives } \\
\text { did not help } \\
\text { students develop } \\
\text { their own } \\
\text { understanding. } \\
\text { Did accept but } \\
\text { did not discuss } \\
\text { alternative } \\
\text { solutions to } \\
\text { problems. Did } \\
\text { not examine } \\
\text { different ideas } \\
\text { to similar } \\
\text { mathematical } \\
\text { experiences. }\end{array}$ \\
\hline \multirow[t]{2}{*}{ Low Anxiety } & Gigi & $\begin{array}{l}\text { Encouraged } \\
\text { students to ask } \\
\text { question and to } \\
\text { challenge their } \\
\text { understanding. } \\
\text { Used both } \\
\text { traditional and } \\
\text { non-traditional } \\
\text { methods to } \\
\text { assess } \\
\text { understanding } \\
\text { as well as } \\
\text { supported } \\
\text { students' } \\
\text { reasoning by } \\
\text { having them } \\
\text { explain their } \\
\text { thinking. }\end{array}$ & $\begin{array}{l}\text { Showed some } \\
\text { evidence of } \\
\text { providing both } \\
\text { procedural and } \\
\text { conceptual } \\
\text { understanding } \\
\text { for her students. }\end{array}$ & $\begin{array}{l}\text { Identified } \\
\text { possible } \\
\text { misconceptions } \\
\text { and addressed } \\
\text { misunderstandin } \\
\text { gs immediately } \\
\text { to prevent } \\
\text { further } \\
\text { misconceptions. }\end{array}$ & $\begin{array}{l}\text { Used mostly } \\
\text { direct } \\
\text { instruction to } \\
\text { teach lessons. } \\
\text { Used some } \\
\text { strategies to } \\
\text { promote } \\
\text { retention such } \\
\text { as making } \\
\text { connections to } \\
\text { real life, but } \\
\text { upon reflection } \\
\text { of lessons saw } \\
\text { the need to } \\
\text { diversify her } \\
\text { instruction. }\end{array}$ & $\begin{array}{l}\text { Used } \\
\text { manipulative in } \\
3 \text { of } 5 \text { observed } \\
\text { lessons. Most } \\
\text { manipulatives } \\
\text { were used to } \\
\text { effectively } \\
\text { promote } \\
\text { understanding. } \\
\text { Did accept and } \\
\text { discuss } \\
\text { alternative } \\
\text { solutions to } \\
\text { problems. Did } \\
\text { not examine } \\
\text { different ideas } \\
\text { to similar } \\
\text { mathematical } \\
\text { experiences. }\end{array}$ \\
\hline & Val & $\begin{array}{l}\text { Used traditional } \\
\text { methods of } \\
\text { assessment. } \\
\text { Enjoyed } \\
\text { challenging } \\
\text { students' } \\
\text { thinking. } \\
\text { Somewhat } \\
\text { supported } \\
\text { students' } \\
\text { reasoning. }\end{array}$ & $\begin{array}{l}\text { Showed some } \\
\text { evidence of } \\
\text { providing } \\
\text { procedural } \\
\text { understanding for } \\
\text { students. } \\
\text { Showed some } \\
\text { evidence of } \\
\text { providing } \\
\text { conceptual } \\
\text { understanding for } \\
\text { students. }\end{array}$ & $\begin{array}{l}\text { Was aware of } \\
\text { previous } \\
\text { knowledge and } \\
\text { its impact on } \\
\text { learning. } \\
\text { Was aware of } \\
\text { the possibility } \\
\text { of } \\
\text { misconceptions } \\
\text { and addressed } \\
\text { misunderstandi } \\
\text { ngs } \\
\text { immediately to } \\
\text { prevent further } \\
\text { misconceptions. }\end{array}$ & $\begin{array}{l}\text { Used mostly } \\
\text { direct instruction } \\
\text { to teach lessons. } \\
\text { Used very few } \\
\text { strategies to } \\
\text { promote } \\
\text { retention such as } \\
\text { making } \\
\text { connections to } \\
\text { real life, but } \\
\text { upon reflection } \\
\text { thought of using } \\
\text { group work to } \\
\text { enhance lessons. }\end{array}$ & $\begin{array}{l}\text { Used } \\
\text { manipulative in } \\
4 \text { of } 5 \text { observed } \\
\text { lessons. Most } \\
\text { of the } \\
\text { manipulatives } \\
\text { were used } \\
\text { effectively to } \\
\text { help students } \\
\text { understand the } \\
\text { topic. Did } \\
\text { accept and } \\
\text { discuss some } \\
\text { alternative } \\
\text { solutions to } \\
\text { problems. Did } \\
\text { not examine } \\
\text { different ideas } \\
\text { to similar } \\
\text { mathematical } \\
\text { experiences. }\end{array}$ \\
\hline
\end{tabular}




\begin{tabular}{|c|c|c|c|c|c|}
\hline Yoli & $\begin{array}{l}\text { Used traditional } \\
\text { methods of } \\
\text { assessment. } \\
\text { Rarely asked } \\
\text { students to } \\
\text { explain their } \\
\text { thinking. Rarely } \\
\text { supported } \\
\text { students' } \\
\text { reasoning. }\end{array}$ & $\begin{array}{l}\text { Showed evidence } \\
\text { of providing } \\
\text { procedural } \\
\text { understanding for } \\
\text { students. } \\
\text { Showed no } \\
\text { evidence of } \\
\text { providing } \\
\text { conceptual } \\
\text { understanding for } \\
\text { students. }\end{array}$ & $\begin{array}{l}\text { Was not aware } \\
\text { of students' } \\
\text { misconception } \\
\text { s nor of their } \\
\text { preconception } \\
\text { s. On one } \\
\text { occasion may } \\
\text { have } \\
\text { contributed to } \\
\text { cause a } \\
\text { possible } \\
\text { misconception } \\
\text { for students. }\end{array}$ & $\begin{array}{l}\text { Used mostly } \\
\text { direct instruction } \\
\text { to teach lessons. } \\
\text { Used very few } \\
\text { strategies to } \\
\text { promote } \\
\text { retention such as } \\
\text { work in pairs and } \\
\text { interacting with } \\
\text { technology. }\end{array}$ & $\begin{array}{l}\text { Provided } \\
\text { manipulatives } \\
\text { for students in } 4 \\
\text { of } 5 \text { observed } \\
\text { lessons. Not all } \\
\text { manipulatives } \\
\text { were used } \\
\text { effectively. Did } \\
\text { not accept } \\
\text { alternative } \\
\text { solutions to } \\
\text { problems. Did } \\
\text { not examine } \\
\text { different ideas } \\
\text { to similar } \\
\text { mathematical } \\
\text { experiences. }\end{array}$ \\
\hline
\end{tabular}


VITA

\section{LESLIE NISBET}

Born, Belize City, Belize

1995-1997

AA, General Studies

St. John's Junior College

Belize City, Belize

1997-1999

B.Ed., Education

Spalding University

Louisville, Kentucky

1999-2003

Mathematics and Social Studies Teacher

Belize Elementary School

Belize City, Belize

2000-2003

M.Ed., Educational Leadership

University of North Florida

Jacksonville, Florida

2004-2007

Lecturer/Academic Chairperson in the Teacher Education Department

St. John's College Junior College

Belize City, Belize

2008-2015

Doctoral Candidate

Florida International University

Miami, Florida

2009-2014

Graduate Assistant

Florida International University

Miami, Florida

2014-2015

Clinical Assistant Professor

Florida International University

Miami, Florida

\section{PUBLICATIONS AND PRESENTATIONS}

Fernandez, M. L., Rincon, D., Bowe, G., Molina R., and Nisbet, L. (2010). Investigating AP Dialogues. Algebra Project Meeting, Miami, FL.

Molina, R., Nisbet, L., and Fernandez, M.L. (2010). Examining the Effect of 
Microteaching Lesson Study Participation on Preservice Teacher Content and Pedagogical Content Knowledge, Florida Council of Teachers of Mathematics (FCTM) Annual Meeting (refereed).

Molina, R., Nisbet, L., and Fernandez, M. L. (2010). Preservice Teachers' Problem Solving Strategies and Math Anxiety in Relation to Contextual vs. Non-Contextual Problems, Annual National Council of Teachers of Mathematics (MCTM) Regional Meeting, New Orleans, LA.

Nisbet, L., and Fernandez, M. L. (2010). Comparing the Effects of Context Based vs. Non-Context Based Problems in a Mathematics Methods Course on Pre-Service Teacher Math Anxiety, Florida Educational Research Association (FERA) Annual Meeting, Orlando, FL.

Soltan Zadeh, M, Nisbet, L, Moores-Abdool, W., Unzueta, C., and White-Lindsey, C. (2010). Student Socialization and Collaboration: Exploring a Community of Emerging Scholars. In T. Rocco (Ed.) Proceedings of the $9^{\text {th }}$ Annual College of Education and Graduate Student Network Research Conference. Miami, FL (peer review).

Molina, R., Fernandez, M.L. \& Nisbet, L. (2011). Analyzing Elementary Preservice Teachers' Development of Content and Pedagogical Content Knowledge in Mathematics through Microteaching Lesson Study. In T. Rocco (Ed.) Proceedings of the $10^{\text {th }}$ Annual College of Education and Graduate Student Network Research Conference. Miami, FL. (peer review).

Molina, R., Nisbet, L., and Fernandez, M. L., (2011). Examining the Effectiveness of Microteaching Lesson Study with Elementary Preservice Teachers, Annual Meeting of the Association of Mathematics Teacher Educators (AMTE), Irvine, CA.

Nisbet, L., Molina, R., and Fernandez, M. L., (2011). Preservice Teachers Problem Solving Strategies and Math Anxiety in Relation to Contextual vs. Non-Contextual Problems, Annual Meeting of the Association of Mathematics Teacher Educators (AMTE), Irvine, CA.

Fernandez, M. L., and Nisbet, L., (2012). Mathematical Problem Solving, Mathematics Anxiety, and Preservice Elementary School Teachers in a Mathematics Methods Course, Annual Meeting of the American Educational Research Association (AERA), Vancouver, British Columbia, Canada.

Fernandez, M.L., Molina, R., Joseph, E.F., and Nisbet, L. (2012). "Microteaching Lesson Study (MLS) for Promoting Habits of Mind in Courses for Learning to Teach Mathematics". Chapter 11 in Dottin, E., 'Structuring Learning Environments in Teacher Education to Elicit Dispositions as Habits of Mind: Strategies and Approaches Used and Lessons Learned'. University Press of America, Lanham, Maryland. 